\title{
Seismic Attributes to Constrain the Distribution of Rakopi Formation Coals in the Southwest Offshore Taranaki Basin, New Zealand
}

\section{Harry Greenfield}

TE WHARE WĀNANGA O TE ÜPOKO O TE IKA A MĀUI

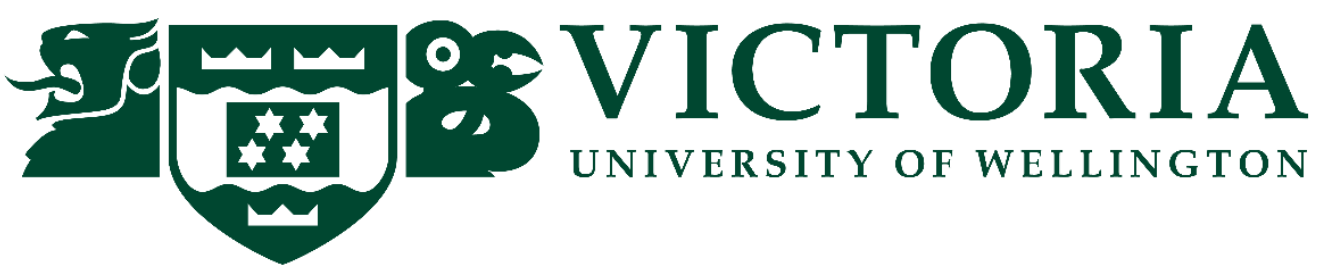

A thesis submitted to Victoria University of Wellington

In partial fulfilment of requirements for the degree of

Master of Science in Petroleum Geoscience

School of Geography, Environment, and Earth Sciences

May 2016 


\section{Abstract}

The Rakopi Formation, in the Taranaki Basin of New Zealand, is a Late Cretaceous (Haumurian) sequence of coal measures interbedded with siltstone and sparse sandstone. It is the lowest widespread stratigraphic unit in the Taranaki Basin, and has a syn-rift deposition which is concentrated in isolated grabens and sub-basins. It was deposited during the extensional tectonic regime linked to the breakup of Gondwana.

The Rakopi is one of the major hydrocarbon source rocks in the Taranaki Basin; New Zealand's only currently-producing basin. However, there are very few well penetrations of the Cretaceous interval within the basin, and this fact - coupled with the non-continuous deposition - means that the Rakopi's distribution is poorly constrained further away from wells.

In petroleum systems models, the entire Rakopi Formation interval is commonly represented entirely as source rock facies. By observing the limited well penetrations available, it is known that this is not the case. As such, it is likely that the total hydrocarbons generated within the basin are overestimated when modelled. Improved constraint of the distribution of the coal within the Rakopi Formation will improve the accuracy of these models.

This study presents the results of the extraction and analysis of a suite of seismic attributes from 3D seismic reflection surveys in the southwest offshore Taranaki Basin, for the purpose of constraining the distribution of coal within the Rakopi Formation. The attribute outputs were temporally averaged, with the resulting frequency distributions analysed for significant patterns or variations between the coaly- versus non-coaly vertical intervals of the formation.

Within the Maari 3D seismic reflection volume, six attributes were identified which correlated with the presence of coals observed in the Maui-4 well. These attributes were temporally averaged within the Rakopi Formation interval in both the Maari 3D and Pipeline 3D volumes, with the areas of high average values identified as being more likely to contain coal.

Using this attribute analysis method, the distribution of coal within the Rakopi Formation has been better constrained. Attribute analysis is easily transferable, and has the potential to be utilised elsewhere for the identification of hydrocarbon source rocks. 


\section{Acknowledgements}

During the process of undertaking this project, and writing this thesis, there have been a few people who have lent their time and expertise, to whom I am grateful.

First of all, I would like to thank Suzanne Bull for providing me with patient direction amidst my enthusiastic-but-aimless initial foray into the realm of project management. She kept me on track, in terms of timekeeping, but also by providing realistic goals, expectations, and guidelines, while still giving me free rein to explore the project as I saw fit.

Secondly, I would like to thank Huw Horgan, for being the sober and calm voice of reason to counterpoint my sometimes manic and helter-skelter approach to academic study. He has provided invaluable input in the form of steering my work towards the academic, helping me to understand the details of certain seismic attributes, and keeping me focused on the initial aims of the project.

Thirdly, I would like to thank Euan Smith, who freely invested his own time to writing Matlab code for the analysis of the seismic attributes in Chapter 6, as well as providing follow-up consultations to help me smooth over any inconsistencies. Without Euan my results would not have been as convincing.

Finally, I would like to thank my peers Tom Ayling and Cam Watson, for keeping me sane, for proofreading my work, and for reminding me that a Master's thesis is not supposed to be easy. 


\section{Table of Contents}

Table of Figures ................................................................................8 8

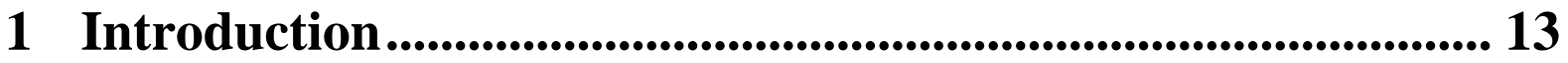

$\begin{array}{lll}1.1 & \text { Seismic Attributes } & 14\end{array}$

$\begin{array}{lll}1.2 & \text { Study Area } & 17\end{array}$

$\begin{array}{lll}1.3 & \text { Project Aims and Outline } & 17\end{array}$

2 Background Geology .................................................... 18

$\begin{array}{lll}2.1 & \text { Taranaki Basin Tectonic Setting } & 18\end{array}$

2.2 Tectonic and Sedimentary History 18

$\begin{array}{lll}2.3 & \text { Petroleum System } & 24\end{array}$

$\begin{array}{lll}2.4 & \text { Pakawau Group } & 24\end{array}$

2.4.1 Rakopi Formation 24

$\begin{array}{lll}\text { 2.4.2 North Cape Formation } & 27\end{array}$

$\begin{array}{lll}\text { 2.4.3 Coaly Facies } & 27\end{array}$

2.4.4 Cretaceous Coals in New Zealand 28

$\begin{array}{lll}2.5 & \text { Summary } & 28\end{array}$

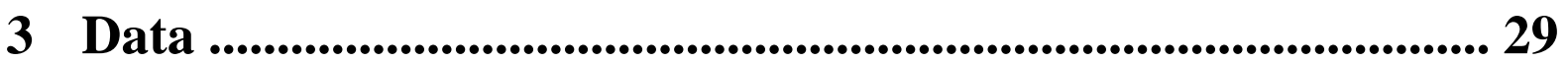

\begin{tabular}{ll}
3.1 & Introduction \\
\hline
\end{tabular}

3.2 Seismic Reflection Data 31

3.3 Well Data 32

$\begin{array}{lll}3.3 .1 & \text { Maui-4 } & 33\end{array}$

$\begin{array}{lll}3.3 .2 & \text { Pukeko-1 } & 33\end{array}$

4 Seismic Interpretation ....................................................... 34

$\begin{array}{lll}4.1 & \text { Introduction } & 34\end{array}$

4.2 Software and Hardware Setup 34 
4.2.1 Seisware $^{\mathrm{TM}}$ Setup $\quad 34$

$\begin{array}{lll}4.3 & \text { Methods } & 36\end{array}$

4.4 Maari 3D Seismic Reflection Volume 38

4.4.1 Gridding Horizons in Seisware ${ }^{\mathrm{TM}} \quad 38$

4.5 Interpreted Horizons 39

$\begin{array}{lll}\text { 4.5.1 Top Basement } & 39\end{array}$

4.5.2 Top Rakopi Formation $\quad 40$

4.5.3 Rakopi Subdivision $\quad 42$

4.5.4 Top Farewell Formation 43

$\begin{array}{lll}\text { 4.5.5 Top Mangahewa Formation } & 43\end{array}$

5 Seismic Attribute Extraction ........................................................ 44

5.1 Seismic Attributes $\quad 44$

5.1.1 Seismic Amplitude $\quad 44$

5.1.2 Type 1: Thickness Dependent Amplitude Maps 47

5.1.3 Type 2: Isochron Dependent Amplitude Maps 47

5.1.4 Type 3: Other Amplitude Maps $\quad 47$

5.2 Rock Solid Attributes $\quad 48$

6 Analysis of Seismic Attributes ............................................ 51

6.1 Introduction $\quad 51$

$\begin{array}{lll}\text { 6.2 Methods } & 51\end{array}$

6.2.1 Rakopi Subdivision Rock Solid Attributes $\quad 51$

6.2.2 RSA Value Distributions in Rakopi Subdivision 51

$\begin{array}{lll}6.3 & \text { Control Tests } & 62\end{array}$

6.3.1 Scale Tests $\quad 62$

6.3.2 Mangahewa Control Group $\quad 62$

$\begin{array}{lll}\text { 6.3.3 Control Test Results } & 65\end{array}$

6.4 Final RSA Suite Descriptions $\quad 82$ 
6.4.1 Trace Envelope $\quad 82$

6.4.2 Wavelet Envelope $\quad 82$

6.4.3 Q by Frequency Shift 82

6.4.4 Time Derivative of Wavelet Envelope $\quad 82$

6.4.5 Imaginary Part of Complex Trace 83

6.4.6 Relative Acoustic Impedance 83

7 Discussion and Conclusions ................................................................ 84

$\begin{array}{lll}7.1 & \text { Introduction } & 84\end{array}$

$\begin{array}{lll}7.2 & \text { Summary of Results } & 84\end{array}$

7.2.1 Coal Predicting Rock Solid Attributes 84

$\begin{array}{lll}7.3 & \text { Discussion } & 84\end{array}$

7.3.1 Trace Envelope, Wavelet Envelope, Time Derivative of Wavelet Envelope $\quad 85$

$\begin{array}{ll}\text { 7.3.2 Q by Frequency Shift } & 85\end{array}$

7.3.3 Relative Acoustic Impedance \& Imaginary Part of Complex Trace 85

7.4 Inferred Coal Distributions by RSA Amplitude Map Analysis 85

$\begin{array}{lll}7.5 & \text { Applications } & 96\end{array}$

7.5.1 Limitations and Uncertainty 96

7.5.2 Applications to Other Data 96

7.5.3 Ratios of RSA Values between Coaly and Non-Coaly Intervals 97

$\begin{array}{lll}7.6 & \text { Outlook } & 98\end{array}$

7.7 Implications for Petroleum Systems Models 99

$\begin{array}{lll}7.8 & \text { Conclusions } & 100\end{array}$

$\begin{array}{lll}7.8 .1 & \text { Summary } & 100\end{array}$

$\begin{array}{lll}\text { 7.8.2 Project Achievements } & 100\end{array}$

$\begin{array}{lll}\text { 7.8.3 Recommendation } & 100\end{array}$

$\begin{array}{lll}\text { 7.8.4 Applications } & 101\end{array}$

8 References ............................................................................................ 102 


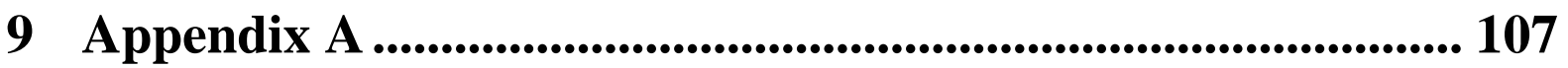

$\begin{array}{lll}9.1 & \text { Amplitude Attributes } & 107\end{array}$

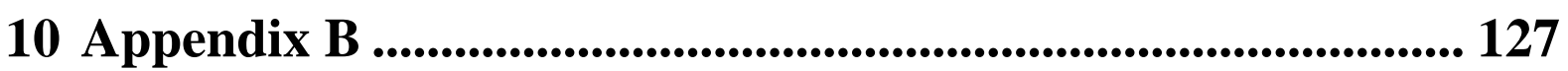

$\begin{array}{lll}\text { 10.1 Rakopi Formation RSA Amplitude Maps } & 127\end{array}$

11 Appendix C .................................................................. 161

11.1 RSA Averages and Frequency Counts within the Rakopi

$\begin{array}{ll}\text { Subdivision } & 161\end{array}$

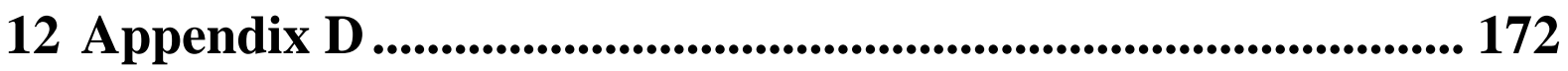

12.1 RSA Control Tests Statistical Analysis 172 


\section{Table of Figures}

Figure 1.1 Taranaki Basin Geological and Geographical Setting ................................................... 15

Figure 1.2 Taranaki Basin Tectonic Setting and Study Area......................................................... 16

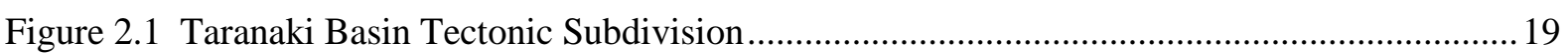

Figure 0.2 Generalised Taranaki Basin Stratigraphic Column....................................................... 20

Figure 0.3 New Zealand's Cretaceous-Miocene Tectonic Development............................................ 22

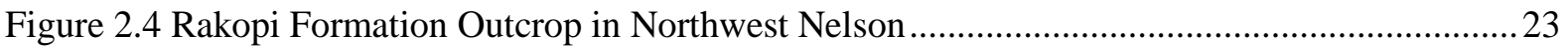

Figure 2.5 Rakopi Formation Distribution in the Study Area...........................................................25

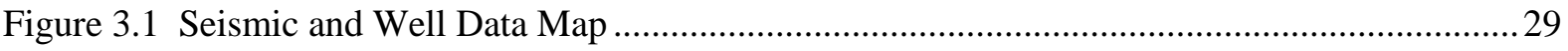

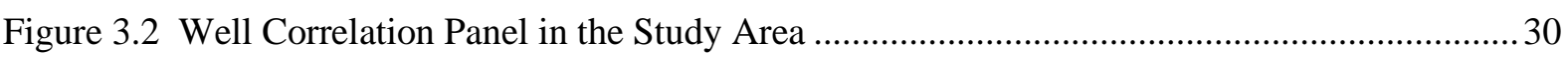

Figure 3.3 Pipeline 3D Seismic Volume Representative 2D Line \#2169 ........................................... 33

Figure 4.1 2D Seismic Line through Maui-4 Well with Interpreted Horizons ..................................... 35

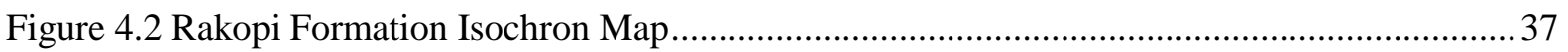

Figure 4.3 Typical Seismic Reflection Pattern Configurations and Interpretations ............................39

Figure 4.4 Cretaceous Coaly Facies away from Well Penetration...................................................... 40

Figure 4.5 Rakopi Subdivision Map, Representative 2D Seismic Line, and Well Lithology ............. 41

Figure 5.1 Representative Amplitude Attribute Types and Rakopi Formation Isochron Map .............46

Figure 5.2 Example of Rock Solid Attribute Averaging within the Rakopi Formation .......................50

Figure 6.1 Category 1 Rock Solid Attribute Temporal Averages and Frequency Distributions - Trace

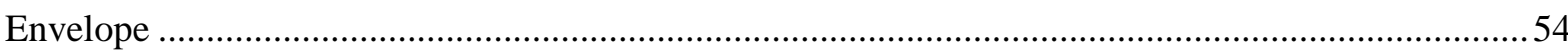

Figure 6.2 Category 1 Rock Solid Attribute Temporal Averages and Frequency Distributions -

Wavelet Envelope

Figure 6.3 Category 1 Rock Solid Attribute Temporal Averages and Frequency Distributions - Time

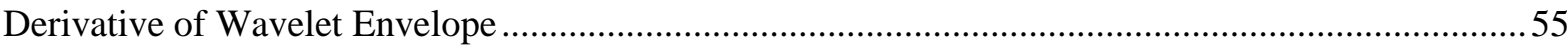

Figure 6.4 Category 1 Rock Solid Attribute Temporal Averages and Frequency Distributions - Q by

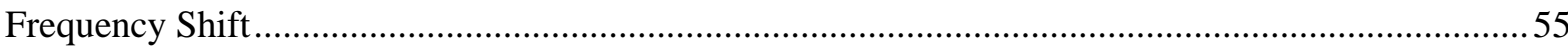

Figure 6.5 Category 2 Rock Solid Attribute Temporal Averages and Frequency Distributions -

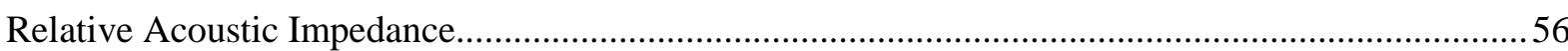

Figure 6.6 Category 2 Rock Solid Attribute Temporal Averages and Frequency Distributions Imaginary Part of Complex Trace...

Figure 6.7 Category 2 Rock Solid Attribute Temporal Averages and Frequency Distributions - Band

Limited Relative Acoustic Impedance.

Figure 6.8 Category 2 Rock Solid Attribute Temporal Averages and Frequency Distributions -

Spectral Balance 57 
Figure 6.9 Category 2 Rock Solid Attribute Temporal Averages and Frequency Distributions -

Spectral Bandwidth

Figure 6.10 Category 2 Rock Solid Attribute Temporal Averages and Frequency Distributions - Time

Derivative of Envelope 58

Figure 6.11 Category 3 Rock Solid Attribute Temporal Averages and Frequency Distributions -

Wavelet Dominant Frequency 59

Figure 6.12 Category 3 Rock Solid Attribute Temporal Averages and Frequency Distributions -

Maximum Subband Envelope Frequency. .59

Figure 6.13 Category 3 Rock Solid Attribute Temporal Averages and Frequency Distributions - Q by Spectral Ratio.

Figure 6.14 Category 3 Rock Solid Attribute Temporal Averages and Frequency Distributions -

Mean Frequency of Spectra

Figure 6.15 Category 4 Rock Solid Attribute Temporal Averages and Frequency Distributions -

Semblance 61

Figure 6.16 Map of Control Test Extents within the Maari 3D Volume 63

Figure 6.17 Mangahewa Control Test Map, Representative Seismic Line, and Well Lithology .64

Figure 6.18 Category 1 RSA Frequency Distributions and Model Distribution Fits - Trace Envelope

Figure 6.19 Category 1 RSA Frequency Distributions and Model Distribution Fits - Wavelet

Envelope .68

Figure 6.20 Category 1 RSA Frequency Distributions and Model Distribution Fits - Time Derivative of Wavelet Envelope .69

Figure 6.21 Category 1 RSA Frequency Distributions and Model Distribution Fits - Q by Frequency Shift. .70

Figure 6.22 Category 2 RSA Frequency Distributions and Model Distribution Fits - Relative Acoustic Impedance. .71

Figure 6.23 Category 2 RSA Frequency Distributions and Model Distribution Fits - Imaginary Part of Complex Trace

Figure 6.24 Category 2 RSA Frequency Distributions and Model Distribution Fits - Band Limited Relative Acoustic Impedance.

Figure 6.25 Category 2 RSA Frequency Distributions and Model Distribution Fits - Spectral Bandwidth

Figure 6.26 Category 2 RSA Frequency Distributions and Model Distribution Fits - Spectral Balance

Figure 6.27 Category 2 RSA Frequency Distributions and Model Distribution Fits - Time Derivative of Envelope .76 
Figure 6.28 Category 3 RSA Frequency Distributions and Model Distribution Fits - Wavelet

Dominant Frequency

Figure 6.29 Category 3 RSA Frequency Distributions and Model Distribution Fits - Frequency of

Maximum Subband Envelope

Figure 6.30 Category 3 RSA Frequency Distributions and Model Distribution Fits - Q by Spectral

Ratio

Figure 6.31 Category 3 RSA Frequency Distributions and Model Distribution Fits - Mean Frequency of Spectra .80

Figure 6.32 Category 4 RSA Frequency Distributions and Model Distribution Fits - Semblance ..... 81

Figure 7.1 Rakopi Formation Inferred Coal Distributions - Trace Envelope …................................... 86

Figure 7.2 Rakopi Formation Inferred Coal Distributions - Wavelet Envelope ................................. 87

Figure 7.3 Rakopi Formation Inferred Coal Distributions - Time Derivative of Wavelet Envelope... 88

Figure 7.4 Rakopi Formation Inferred Coal Distributions - Q by Frequency Shift .............................. 89

Figure 7.5 Rakopi Formation Inferred Coal Distributions - Relative Acoustic Impedance................. 90

Figure 7.6 Rakopi Formation Inferred Coal Distributions - Imaginary Part of Complex Trace.......... 91

Figure 7.7 Inferred Coal Distributions - All Category 1 RSAs ......................................................... 93

Figure 7.8 Inferred Coal Distributions - All Category 2 RSAs........................................................... 94

Figure 7.9 Inferred Coal Distribution - Combined Category 1 \& 2 RSAs............................................95

Figure 9.1 Type 1 Amplitude Attribute Maps - Peak Count ............................................................. 108

Figure 9.2 Type 1 Amplitude Attribute Maps - Average Thickness of Peak .................................... 109

Figure 9.3 Type 1 Amplitude Attribute Maps - Amplitude Thickness of Trough ............................. 110

Figure 9.4 Type 1 Amplitude Attribute Maps - Area Under Peak .................................................... 111

Figure 9.5 Type 1 Amplitude Attribute Maps - Area Under Trough................................................ 112

Figure 9.6 Type 1 Amplitude Attribute Maps - Average Value ........................................................ 113

Figure 9.7 Type 1 Amplitude Attribute Maps - Peak Count .................................................................. 114

Figure 9.8 Type 1 Amplitude Attribute Maps - Sum of Absolute Amplitudes.................................. 115

Figure 9.9 Type 1 Amplitude Attribute Maps - Trough Count ....................................................... 116

Figure 9.10 Type 1 Amplitude Attribute Maps - Zero Crossing Count .............................................117

Figure 9.11 Type 2 Amplitude Attribute Maps - Average Absolute ................................................ 118

Figure 9.12 Type 2 Amplitude Attribute Maps - Average Energy Value ............................................. 119

Figure 9.13 Type 2 Amplitude Attribute Maps - Maximum Value ................................................. 120

Figure 9.14 Type 2 Amplitude Attribute Maps - Max Negative Value .............................................121

Figure 9.15 Type 2 Amplitude Attribute Maps - Max Positive Value................................................... 122

Figure 9.16 Type 2 Amplitude Attribute Maps - Minimum Value..................................................... 123

Figure 9.17 Type 2 Amplitude Attribute Maps - RMS Value ......................................................... 124

Figure 9.18 Type 3 Amplitude Attribute Maps - Sum of Amplitudes .............................................. 125

Figure 9.19 Type 3 Amplitude Attribute Maps - Zero Crossing Frequency ...................................... 126 
Figure 10.1 Rakopi Formation RSA Data - Trace Envelope ….................................................... 128

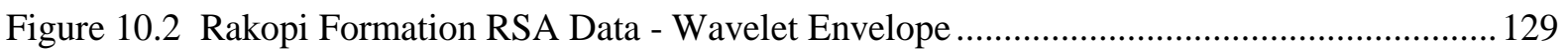

Figure 10.3 Rakopi Formation RSA Data - Time Derivative of Wavelet Envelope ......................... 130

Figure 10.4 Rakopi Formation RSA Data - Q by Frequency Shift .................................................. 131

Figure 10.5 Rakopi Formation RSA Data - Relative Acoustic Impedance ...................................... 132

Figure 10.6 Rakopi Formation RSA Data - Imaginary Part of Complex Trace................................. 133

Figure 10.7 Rakopi Formation RSA Data - Band Limited Relative Acoustic Impedance ................ 134

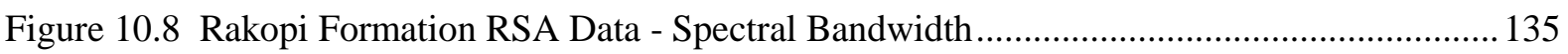

Figure 10.9 Rakopi Formation RSA Data - Spectral Balance ……................................................. 136

Figure 10.10 Rakopi Formation RSA Data - Time Derivative of Envelope..................................... 137

Figure 10.11 Rakopi Formation RSA Data - Wavelet Dominant Frequency ……............................ 138

Figure 10.12 Rakopi Formation RSA Data - Maximum Subband Envelope Frequency ................... 139

Figure 10.13 Rakopi Formation RSA Data - Mean Frequency of Spectra ...................................... 140

Figure 10.14 Rakopi Formation RSA Data - Semblance ............................................................. 141

Figure 10.15 Rakopi Formation RSA Data - Real Part of Complex Trace...................................... 142

Figure 10.16 Rakopi Formation RSA Data - Instantaneous Phase ................................................. 143

Figure 10.17 Rakopi Formation RSA Data - Instantaneous Frequency............................................ 144

Figure 10.18 Rakopi Formation RSA Data - Dominant Frequency .................................................. 145

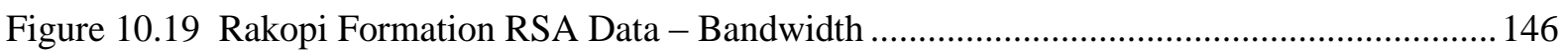

Figure 10.20 Rakopi Formation RSA Data - Instantaneous Q Factor ............................................. 147

Figure 10.21 Rakopi Formation RSA Data - Normalised Amplitude.............................................. 148

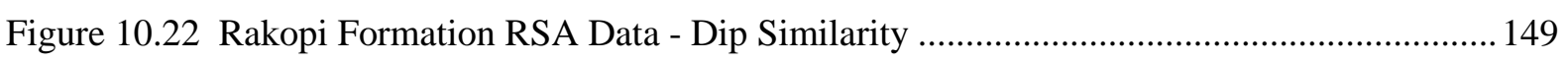

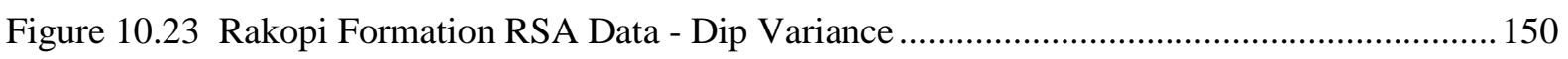

Figure 10.24 Rakopi Formation RSA Data - Similarity .............................................................. 151

Figure 10.25 Rakopi Formation RSA Data - Similarity Variance ................................................... 152

Figure 10.26 Rakopi Formation RSA Data - Smoothed Dip Similarity ……..................................... 153

Figure 10.27 Rakopi Formation RSA Data - Dip Azimuth ............................................................... 154

Figure 10.28 Rakopi Formation RSA Data - Mean Curvature ....................................................... 155

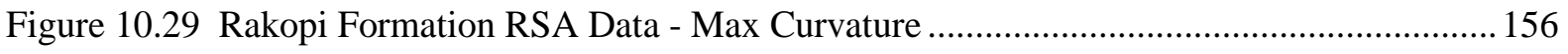

Figure 10.30 Rakopi Formation RSA Data - Minimum Curvature ................................................ 157

Figure 10.31 Rakopi Formation RSA Data - Most Negative Curvature .......................................... 158

Figure 10.32 Rakopi Formation RSA Data - Most Positive Curvature ............................................ 159

Figure 10.33 Rakopi Formation RSA Data - Maximum Subband of Envelope ................................ 160

Figure 11.1 RSA Averages and Frequency Distributions in the Rakopi Subdivision - Real Part of Complex Trace.

Figure 11.2 RSA Averages and Frequency Distributions in the Rakopi Subdivision - Instantaneous

Phase 162 
Figure 11.3 RSA Averages and Frequency Distributions in the Rakopi Subdivision - Instantaneous Frequency

Figure 11.4 RSA Averages and Frequency Distributions in the Rakopi Subdivision - Dominant

Frequency

Figure 11.5 RSA Averages and Frequency Distributions in the Rakopi Subdivision - Bandwidth... 164

Figure 11.6 RSA Averages and Frequency Distributions in the Rakopi Subdivision - Instantaneous Q

Factor .

Figure 11.7 RSA Averages and Frequency Distributions in the Rakopi Subdivision - Normalised

Amplitude

Figure 11.8 RSA Averages and Frequency Distributions in the Rakopi Subdivision - Dip Similarity

Figure 11.9 RSA Averages and Frequency Distributions in the Rakopi Subdivision - Dip Variance

Figure 11.10 RSA Averages and Frequency Distributions in the Rakopi Subdivision - Similarity .. 166

Figure 11.11 RSA Averages and Frequency Distributions in the Rakopi Subdivision - Similarity

Variance

Figure 11.12 RSA Averages and Frequency Distributions in the Rakopi Subdivision - Smoothed Dip of Maximum Similarity.

Figure 11.13 RSA Averages and Frequency Distributions in the Rakopi Subdivision - Dip Azimuth

Figure 11.14 RSA Averages and Frequency Distributions in the Rakopi Subdivision - Mean

Curvature

Figure 11.15 RSA Averages and Frequency Distributions in the Rakopi Subdivision - Maximum

Curvature

Figure 11.16 RSA Averages and Frequency Distributions in the Rakopi Subdivision - Minimum

Curvature

Figure 11.17 RSA Averages and Frequency Distributions in the Rakopi Subdivision - Most Negative

Curvature

Figure 11.18 RSA Averages and Frequency Distributions in the Rakopi Subdivision - Most Positive

Curvature

Figure 11.19 RSA Averages and Frequency Distributions in the Rakopi Subdivision - Maximum

Subband of Envelope.

Figure 12.1 RSA Control Tests Frequency Distributions - Real Part of Complex Trace ................... 173

Figure 12.2 RSA Control Tests Frequency Distributions - Instantaneous Phase................................ 174

Figure 12.3 RSA Control Tests Frequency Distributions - Instantaneous Frequency ....................... 175

Figure 12.4 RSA Control Tests Frequency Distributions - Dominant Frequency ............................. 176

Figure 12.5 RSA Control Tests Frequency Distributions - Bandwidth ............................................ 177 
Figure 12.6 RSA Control Tests Frequency Distributions - Instantaneous Q Factor 178

Figure 12.7 RSA Control Tests Frequency Distributions - Normalised Amplitude 179

Figure 12.8 RSA Control Tests Frequency Distributions - Dip Similarity 180

Figure 12.9 RSA Control Tests Frequency Distributions - Dip Variance 181

Figure 12.10 RSA Control Tests Frequency Distributions - Similarity 182

Figure 12.11 RSA Control Tests Frequency Distributions - Similarity Variance 183

Figure 12.12 RSA Control Tests Frequency Distributions - Smoothed Dip of Maximum Similarity

Figure 12.13 RSA Control Tests Frequency Distributions - Dip Azimuth 185

Figure 12.14 RSA Control Tests Frequency Distributions - Mean Curvature 186

Figure 12.15 RSA Control Tests Frequency Distributions - Maximum Curvature 187

Figure 12.16 RSA Control Tests Frequency Distributions - Minimum Curvature 188

Figure 12.17 RSA Control Tests Frequency Distributions - Most Negative Curvature 189

Figure 12.18 RSA Control Tests Frequency Distributions - Most Positive Curvature. 190

Figure 12.19 RSA Control Tests Frequency Distributions - Maximum Subband of Envelope 191

\section{List of Tables}

Table 3.1 Selected 3D Seismic Reflection Volumes' Acquisition Parameters.......................31

Table 3.2 Cretaceous-Penetrating Wells in Study Area.........................................32

Table 5.1 List of Seisware ${ }^{\mathrm{TM}}$ Rock Solid Attributes used in this Project........................... 49

Table 7.1 Rakopi Formation Inferred Coal Distribution Percentages......................... 92

Table 7.2 Ratios of RSA Values in Coaly/Non-Coaly Intervals.................................. 98 


\section{Introduction}

In the Taranaki Basin, coaly rocks of Cretaceous age are of interest to the oil and gas industry, as they often contain the requisite organic carbon content to produce hydrocarbons, as well as being buried deeply enough to be thermally mature.

The Pakawau Group is a Late Cretaceous sedimentary sequence in the Taranaki Basin which contains coal measures (Browne et al. 2008). It consists of two formations: the upper, shallow marine North Cape Formation, and the lower, more coal-rich terrestrial Rakopi Formation (Wizevich et al. 1992; Wizevich 1994). The coaly facies of the Rakopi Formation are one of the major hydrocarbon source rocks in the Taranaki Basin, which is currently the only hydrocarbon-producing basin in New Zealand (King \& Thrasher 1996).

The Rakopi Formation has been the subject of numerous previous studies (Armstrong et al. 1996; Browne et al. 2008; King et al. 1999; King \& Thrasher 1996; Sherwood et al. 1992; Sykes et al. 2004; Sykes et al. 2014; Thrasher 1992; Uruski 2008, and Wizevich et al. 1992). These studies designate the Rakopi Formation as a predominantly terrestrial coal measure formation, with some marine influence in the upper strata. It is credited as being one of the predominant source rocks in the Taranaki Basin (Browne et al. 2008; Uruski 2008), with hydrocarbon generation beginning in the Paleocene-Eocene (Armstrong et al. 1996).

In petroleum systems models which aim to predict (both known, and as-yet-undiscovered) hydrocarbon accumulations, the Rakopi Formation is commonly represented as consisting entirely of source rock facies. However, the spatial variability of the source rock potential of the Rakopi Formation in the subsurface is not well understood (Kroeger et al., 2016). The lithological variation of the formation has been acknowledged from both well and outcrop studies (e.g. Browne et al., 2008), meaning that the total source rock contained within the Rakopi Formation, and therefore the Taranaki Basin as a whole, is currently overestimated. Improved mapping of the Rakopi Formation, especially the coal-rich portions of the formation, would provide more accurate assessments of the total volume of hydrocarbons generated within the basin.

\subsection{Seismic Attributes}

"Seismic Attributes are all the information obtained from seismic data, either by direct measurements or by logical or experience based reasoning." - Taner 2003.

Seismic attributes are measures of seismic data which enable it to be visually enhanced, or enable features to be quantified for the purpose of interpretation. Desirable attributes are those which are 


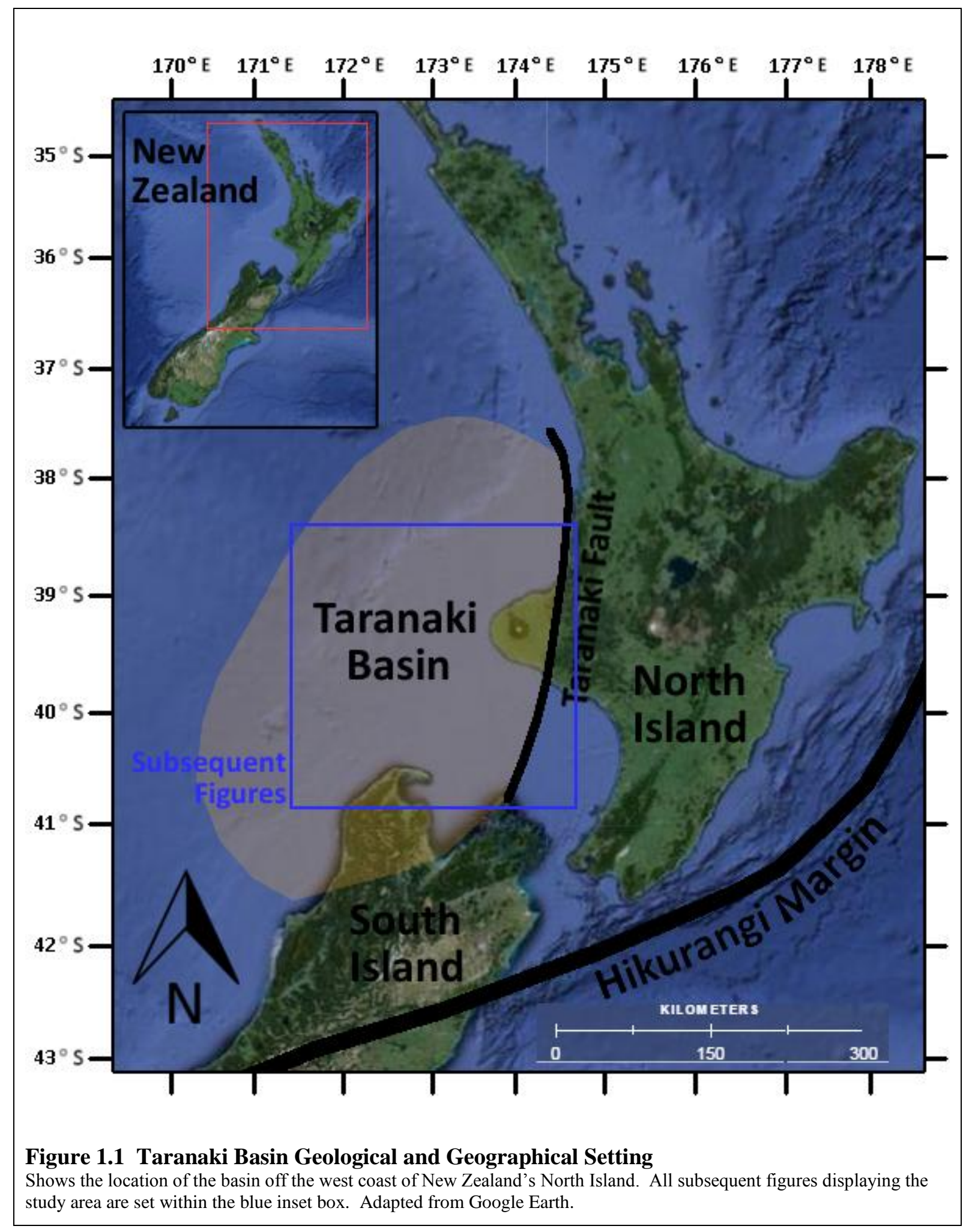




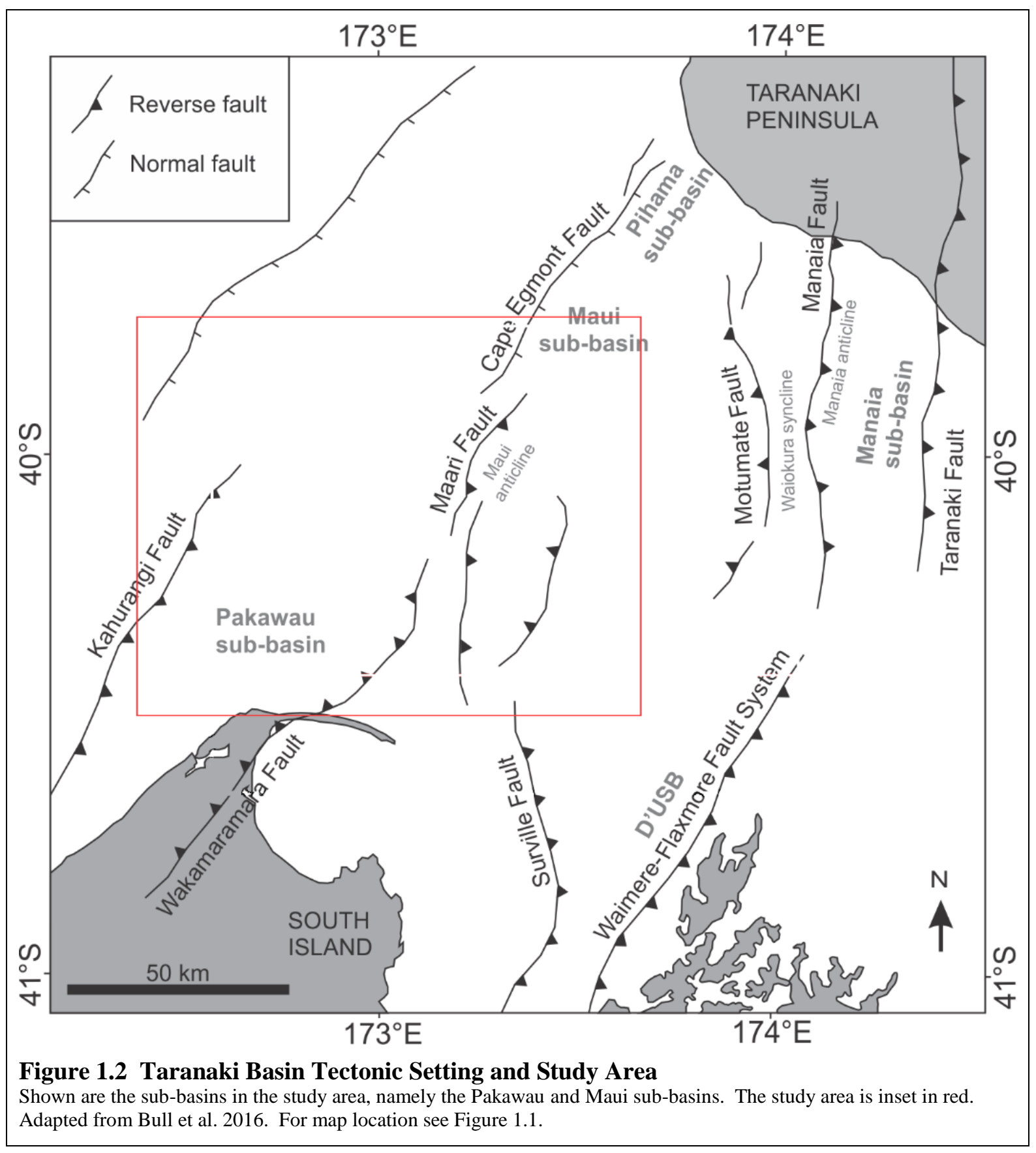

sensitive to a geologic feature or lithologic property, and enable definition of a structural or depositional environment (Chopra \& Marfurt 2007).

This thesis ties together attributes from the selected 2D and 3D seismic reflection data with exploration wells - together with results from previous studies based on outcrop information - to investigate a new way to constrain the extent of coaly facies within the Cretaceous interval of the offshore southwest Taranaki Basin. By extracting selected attributes from the seismic data, this study seeks to determine whether the coaly facies of the Rakopi Formation can be identified and constrained away from well penetrations. The results generated here have the potential to be applied elsewhere, 
so that further coaly facies can be identified in other areas and stratigraphic intervals in the basin, and potentially elsewhere in the world.

\subsection{Study Area}

The Taranaki Basin is a mostly offshore sedimentary basin, located off the west coast of the North Island of New Zealand (Figure 1.1). It covers an area of approximately $100,000 \mathrm{~km}^{2}$, ranging from the top of the South Island in northwest Nelson, and extending approximately $200 \mathrm{~km}$ off the west coast from Taranaki (King \& Thrasher 1996). This research project is focused on the southwest offshore region of the Taranaki Basin, in the Pakawau and Maari sub-basins (Figure 1.2), due to the availability of 3D seismic reflection data which can be tied to exploration wells.

The Cretaceous Rakopi and North Cape formations are present throughout this area, although their distributions are not continuous, and there are limited well penetrations (Figures $2.5 \& 3.2$ ).

\subsection{Project Aims and Outline}

This aim of this project is to determine whether seismic attributes can be used to identify and constrain the coaly rocks from within the Cretaceous interval of the Taranaki Basin - in particular the Rakopi Formation - in areas removed from well penetrations.

This is to be done with the following steps:

- Conducting well-ties to link the seismic reflection data to the lithology

- Interpretation of 2D and 3D seismic reflection data to identify the top of the Rakopi, North Cape, and Farewell formations, along with Top Basement, which defines the base of the Cretaceous succession, and the top of the Eocene Mangahewa Formation

- Interpretation of top, base, and intra-formational Cretaceous horizons

- Characterisation of seismic facies

- Identification of meaningful seismic attributes, and their extraction from the data

- Analysis of interpreted seismic intervals and extracted attributes, with correlation to well data

- Identification of an attribute or combination of attributes which predict the occurrence of coaly facies away from well locations

- Use of the identified attributes to constrain the likely distribution of coals within the study area

The study area contains limited well penetrations of the Cretaceous interval; however, the Rakopi Formation is penetrated by the Maui-4 well, which is located within the Maari 3D seismic volume (Figure 2.5). The Maui-4 and Pukeko-1 wells will be correlated between by using the selected 2D and 3D seismic reflection data to carry out a local interpretation of the relevant Cretaceous and Paleocene strata for this project. 


\section{Background Geology}

\subsection{Taranaki Basin Tectonic Setting}

The Taranaki Basin sits atop the Australian Plate, approximately $300-450 \mathrm{~km}$ to the west of its convergent boundary with the Pacific Plate (Figure 2.1) (King \& Thrasher 1996). The subduction zone to the east of the lower North Island is known as the Hikurangi Margin, and extends to the northeast into the Kermadec Trench (Holt \& Stern 1994). The tectonic setting of New Zealand and the Taranaki Basin has altered significantly over the last $100 \mathrm{Ma}$, with separate phases of rifting, passive subsidence, and convergence (King 2000). As a result of this tectonic history, the basin is comprised of several superimposed sub-basins (Figure 2.5), with the different parts of the basin having undergone various types of deformation, resulting in complex faulting patterns, especially in the eastern basin (King \& Thrasher 1996).

The basin is bounded to the east by the Taranaki Fault (Figure 2.1), and consists of 2 major components; the Eastern Mobile Belt and the Western Stable Platform (King \& Thrasher 1996). The basin makes up part of the deformation zone associated with the contemporary Australian-Pacific plate boundary (Muir et al. 2000).

The Eastern Mobile Belt contains superimposed features of both tectonic compression (thrust faults and folding) and extension (normal faults and grabens), and is separated from the more tectonicallydormant Western Stable Platform by the Cape Egmont Fault - a Cretaceous normal fault which was reactivated as a reverse fault during the Miocene (Figures $1.2 \& 2.1$ ) (Nicol et al. 2005).

\subsection{Tectonic and Sedimentary History}

There are 3 main phases of activity which have been recognised in the overall tectonic regime of New Zealand (Gaina et al. 1998, King \& Thrasher 1996, Stern \& Davey 1990):

- Late Cretaceous and Palaeocene extension

- Late Eocene-Oligocene and younger contraction

- Plio-Pleistocene extension

The formation of the Taranaki Basin began with the breakup of Gondwanaland, which provided the oldest phase of extension in the Taranaki Basin, occurring during the late Cretaceous (Haumurian Stage; 83.5-65.5 Ma). The separation of Australia from Zealandia during this period caused the formation of the Tasman Sea (Gaina et al. 1998, Thrasher 1992). During this, the first phase of New Zealand's tectonic history, the sedimentary regime was that of a transgressive systems tract (TST), as 


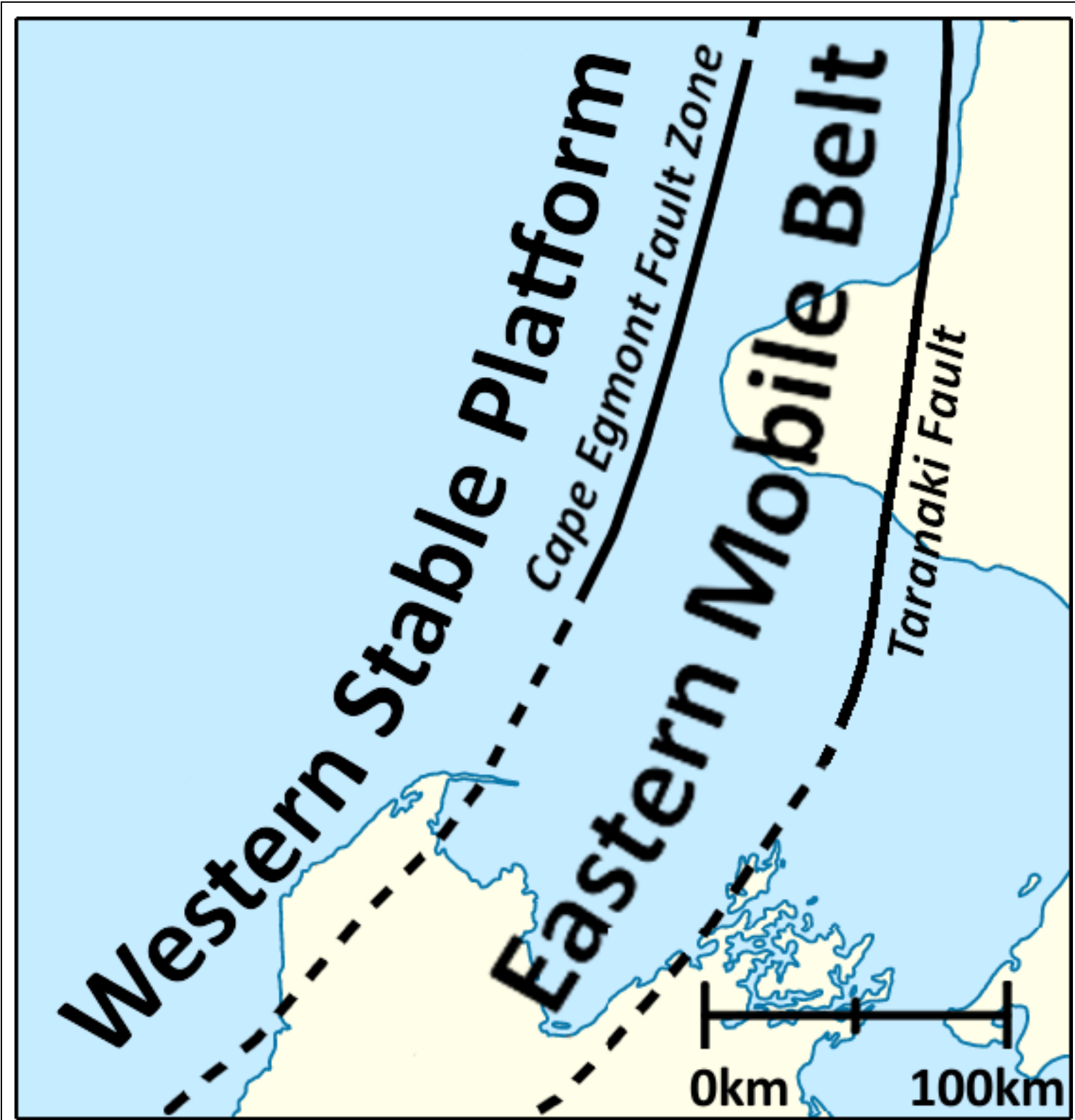

Figure 2.1 Taranaki Basin Tectonic Subdivision

Bounding faults/fault zones are indicated by the solid black lines, and the dashed lines represent the inferred boundaries between the Western Stable Platform and the Eastern Mobile Belt, and the eastern boundary of the basin respectively. Adapted from King \& Thrasher 1996. For map location see Figure 1.1.

part of the overall sedimentary "megasequence" described in detail in King (2000) and King et al. (1999). The general stratigraphic succession of the Taranaki Basin is given by Figure 2.2.

As the proto-New Zealand landmass broke away from Gondwana, it began to drift north, away from the spreading ridge (Gaina et al. 1998). The Late Cretaceous onlap surface represents the start of the deposition of the Pakawau Group in the Taranaki Basin, and corresponds with the beginning of the aforementioned Late Cretaceous TST (King 2000).

As this spreading took place, the subsidence of both the Eastern Mobile Belt and the Western Stable Platform began, with rifting continuing throughout the deposition of the Pakawau Group, which 


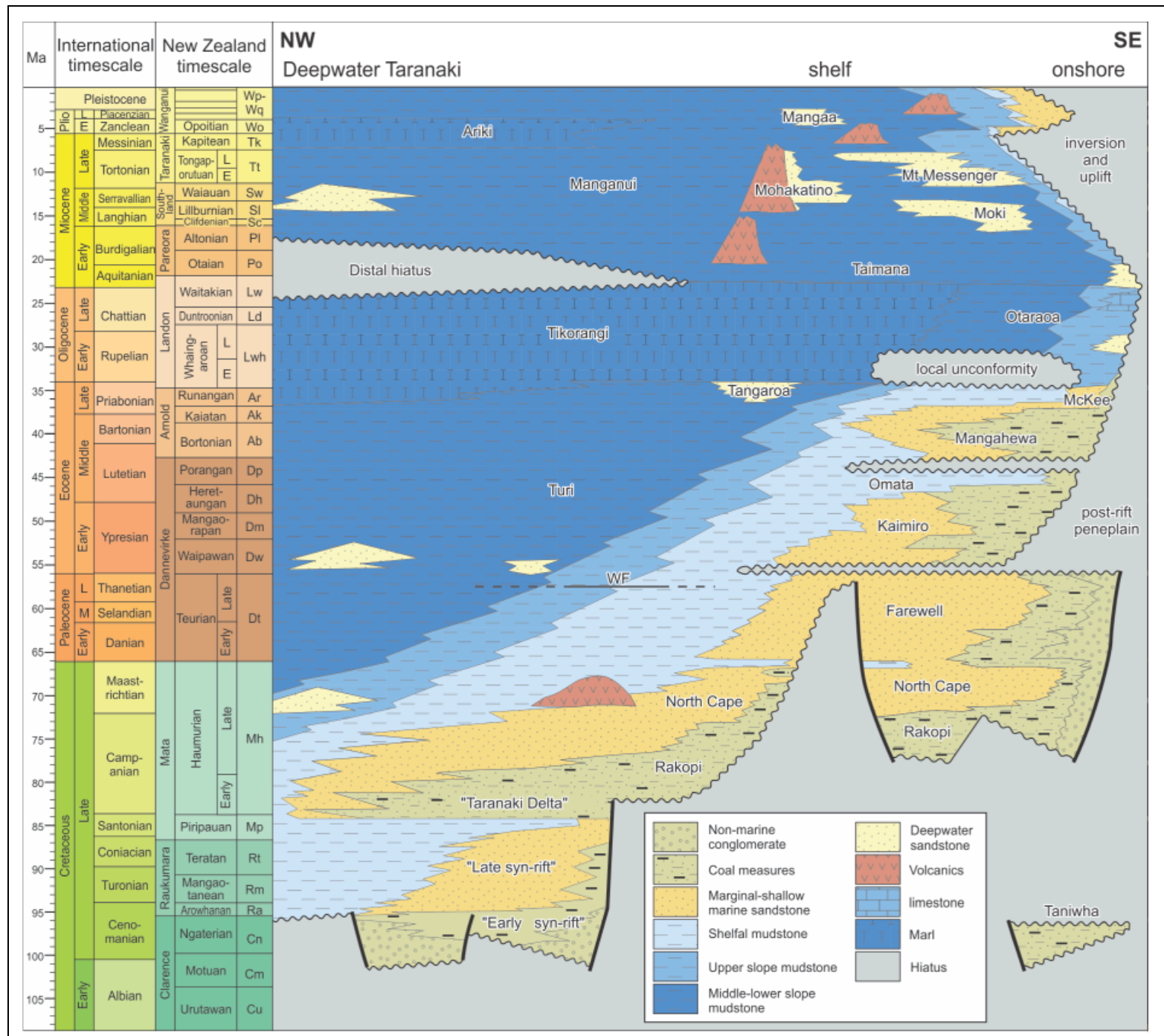

Figure 2.2 Generalised Taranaki Basin Stratigraphic Column

From Bull et al. 2016.

opened up north-south and southwest-northeast striking half-grabens and sub-basins, creating the accommodation space into which these Cretaceous sediments were deposited (King \& Thrasher 1996; King 2000; Thrasher 1992).

At the Cretaceous-Paleocene boundary (K-T boundary; 65.5 Ma), the New Zealand proto-continent was drifting away from the spreading rift to the southwest (Figure 2.3A) (Gaina et al. 1998, King \& Thrasher 1996). At 65.5 Ma, relative sea level was at its lowest point, which meant that the largest New Zealand land area of any time was exposed, the erosion of which provided ample sediment to the surrounding basins (King \& Thrasher 1996). The basin subsequently became a passive margin setting, with slow subsidence, and large-scale sediment accumulation during the late-rift and post-rift transgressive sequence of the Paleocene and Eocene respectively (King et al. 1999).

During the Oligocene Epoch, the basin transitioned to a foreland basin, due to the subduction of the Pacific Plate under the Australian Plate, which caused basin-wide compression and subsequent 
thrusting along the Taranaki Fault (Palmer \& Andrews 1993; King \& Thrasher 1996; Stagpoole \& Nicol 2008; Voggenreiter 1993). This began the overall sedimentary shift into a regressive systems tract (RST), with foredeep and distal sediment-starved shelf and slope sequences giving way to a regressive sequence in the Miocene (King \& Thrasher 1996). The Hikurangi Margin accommodated the subduction, which caused widespread contraction along the eastern boundary of the basin (Reilly et al. 2015). This zone of contraction widened and migrated westward during the Miocene with the migration and enlargement of the subduction zone (King 2000; King \& Thrasher 1996) (Figure 2.3A $\&$ 2.3B). Many of the Taranaki Basin's large extensional faults which were displaced during the Late Cretaceous extension were reactivated as thrust faults during this subsequent deformation to accommodate the contraction (Holt \& Stern 1994; King \& Thrasher 1996; Pilaar \& Wakefield 1978). In the Mid to Late Miocene, rifting began in the northern Taranaki Basin - attributed to slab rollback or slab steepening at the Hikurangi Margin - and migrated through the southern basin, giving way to the overall extensional tectonic regime at around 3-4 Ma (Reilly et al. 2015, from Ballance 1976), and with the sedimentary regime remaining in a regressive systems tract (King \& Thrasher 1996). Subsequently through the Plio-Pleistocene, some new fault traces were created by the extension, but other older faults such as the Cape Egmont Fault - which had undergone Cretaceous normal faulting and been re-activated as a Miocene reverse fault - was reacted once again, this time in a normal sense, to accommodate the ongoing extension (King \& Thrasher 1996; Reilly et al. 2015). 


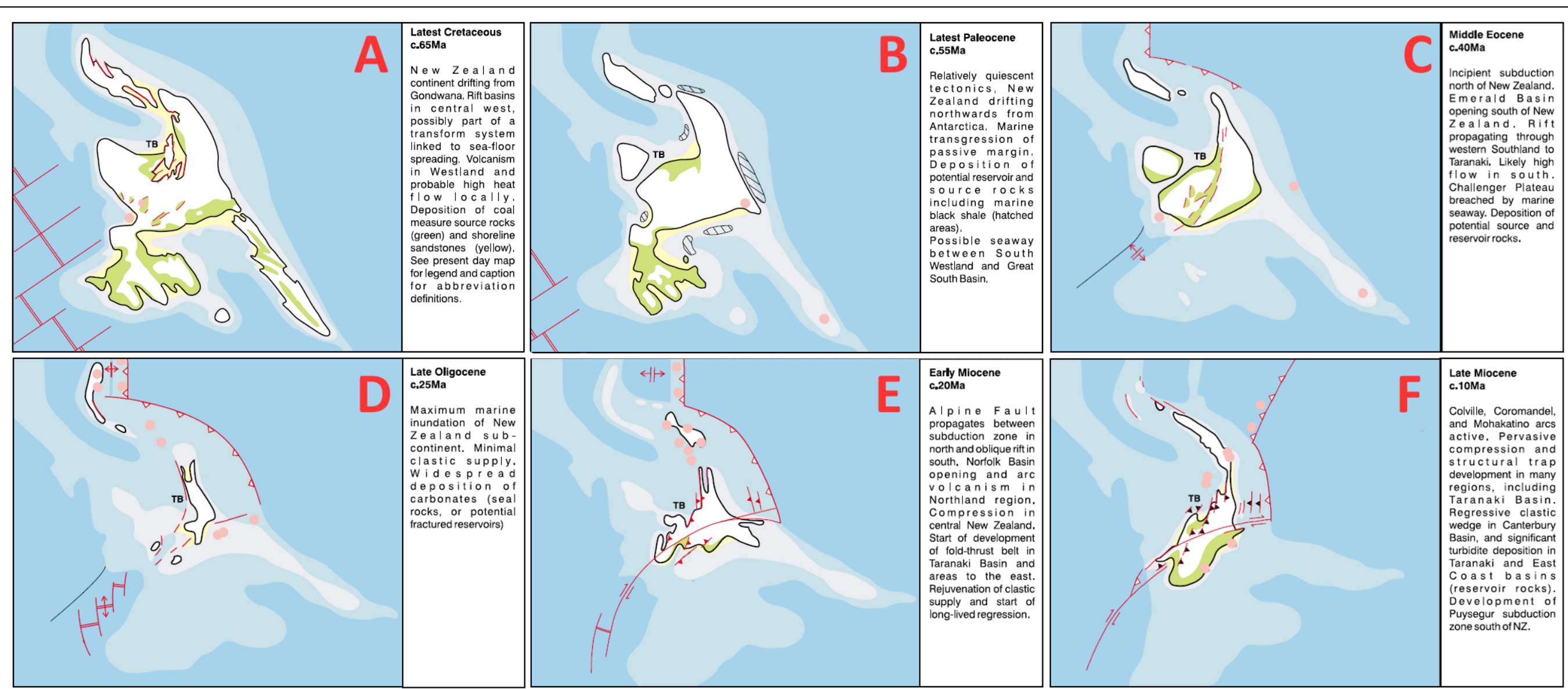

\section{Figure 2.3 New Zealand's Cretaceous-Miocene Tectonic Development}

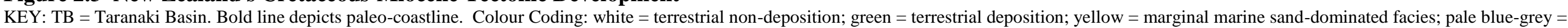

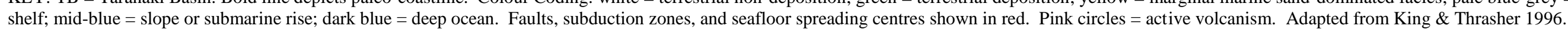



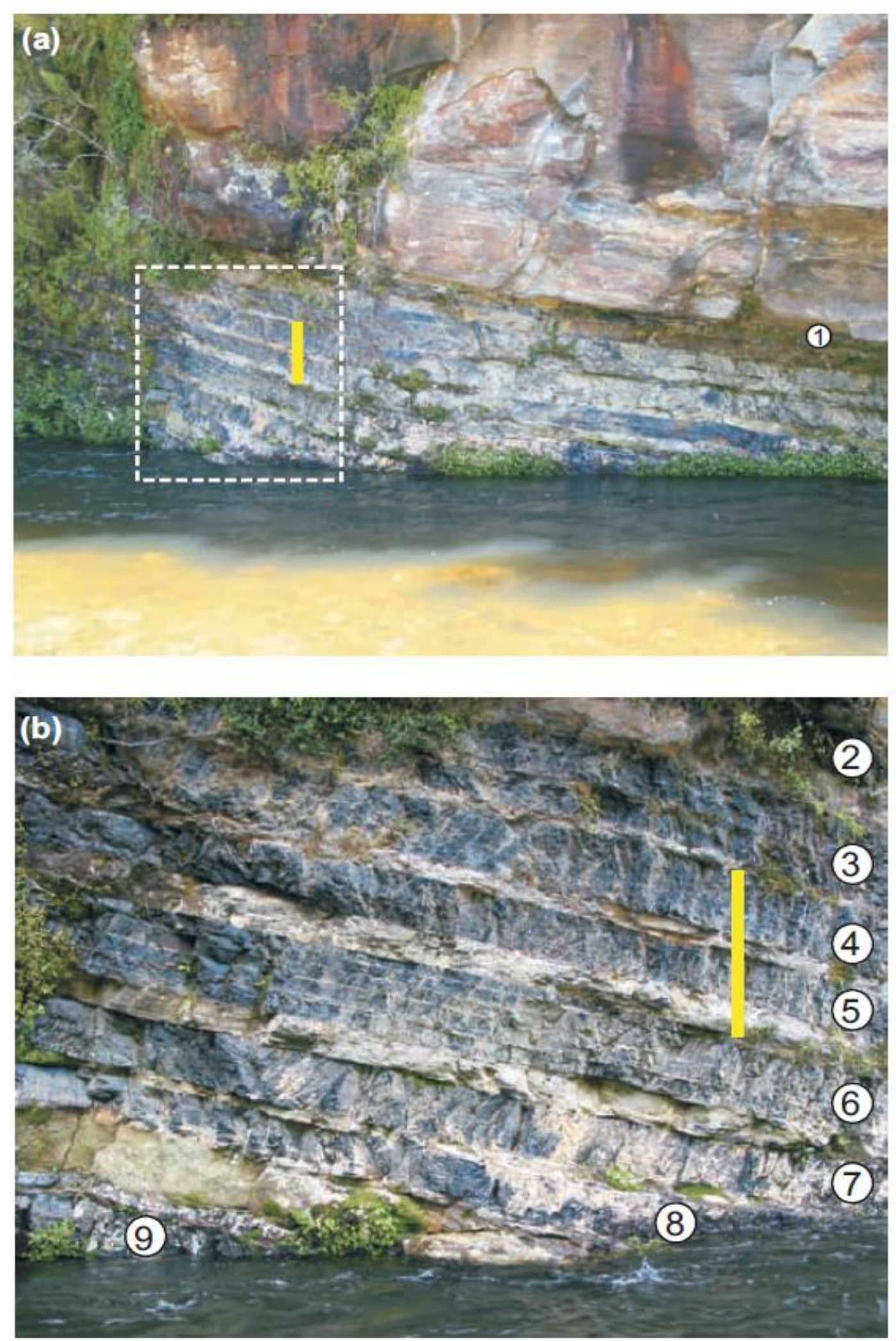

Figure 2.4 Rakopi Formation Outcrop in Northwest Nelson

A) Rakopi outcrop. B) Sampled sequence of 10 coal seams in the upper reaches of the Paturau River, overlain by thick, channel sandstones. The lowest seam is out of view to left. The inset shows (b) a closer up view of the middle 8 seams, highlighting sharp contacts with the intervening carbonaceous (coaly) mudstone-siltstone beds, and mudstone laminae within seam 6. Numbers refer to seam and sample numbers (Table 1). Scale bar in both images is ca. $1 \mathrm{~m}$ long (taken from Sykes et al. 2004). 


\subsection{Petroleum System}

The Taranaki Basin is New Zealand's largest hydrocarbon-producing basin, and (as at the close of 2011) had produced some 418 million barrels of oil and 6190 billion cubic feet of gas, with commercial-scale petroleum having been found at every level between Pliocene-Paleocene (New Zealand Petroleum and Minerals 2016). It produces from around 20 fields, the largest of which is the Maui gas-condensate field, the original gas reserves of which were calculated at 3.4 trillion cubic feet (New Zealand Petroleum and Minerals 2016).

Samples of Cretaceous age coals within the basin have shown that they are thermally mature source rocks (Thompson 1982). The rapid deposition of the Pakawau Group, coupled with the high heat flow resulting from rifting, led to early localised hydrocarbon generation during the Cretaceous (King 2000; Wood et al. 1998).

\subsection{Pakawau Group}

The Pakawau Group includes all of the Late Cretaceous sedimentary deposits in the Taranaki Basin, and is comprised of 2 formations: the lower, coal-bearing Rakopi Formation, and the upper siltstones, sandstones, and conglomerates of the North Cape Formation (Wizevich et al. 1992; Thrasher 1992).

The Pakawau Group is Haumurian in age ( 83.5-65.5 Ma), and is largely thought of as a coal measure sequence. The division of the Pakawau Group into the Rakopi and North Cape formations is defined from lithofacies character in exploration wells, outcrop in northwest Nelson, and seismic reflection mapping offshore (Browne et al. 2008). The boundary between the Rakopi and North Cape formations represents the onset of the oldest regionally defined marine transgression in the Taranaki Basin (King \& Thrasher 1996).

The Pakawau Group is between 500-4200m thick, and was deposited during the rift phase of Tasman seafloor spreading, and is found in interconnected depocentres as well as in isolated sub-basins (Wizevich 1994). The top of the group's seismic reflector generally ties closely in exploration wells with the paleontologically-dated Cretaceous-Tertiary boundary, although in the Pakawau sub-basin the K-T boundary is marked by an unconformity within Paleocene strata (King \& Thrasher 1996).

\subsubsection{Rakopi Formation}

The Rakopi Formation is largely sub-surface, with limited outcrop to the northwest of Nelson (Figure 2.4). As such, the available geological data is largely confined to drill cores, wireline logs, and cuttings. Given the wide variability the formation displays in exploration wells, and the sparse occurrence of Cretaceous well penetrations, it can be difficult to correlate the formation using the connecting seismic data. 


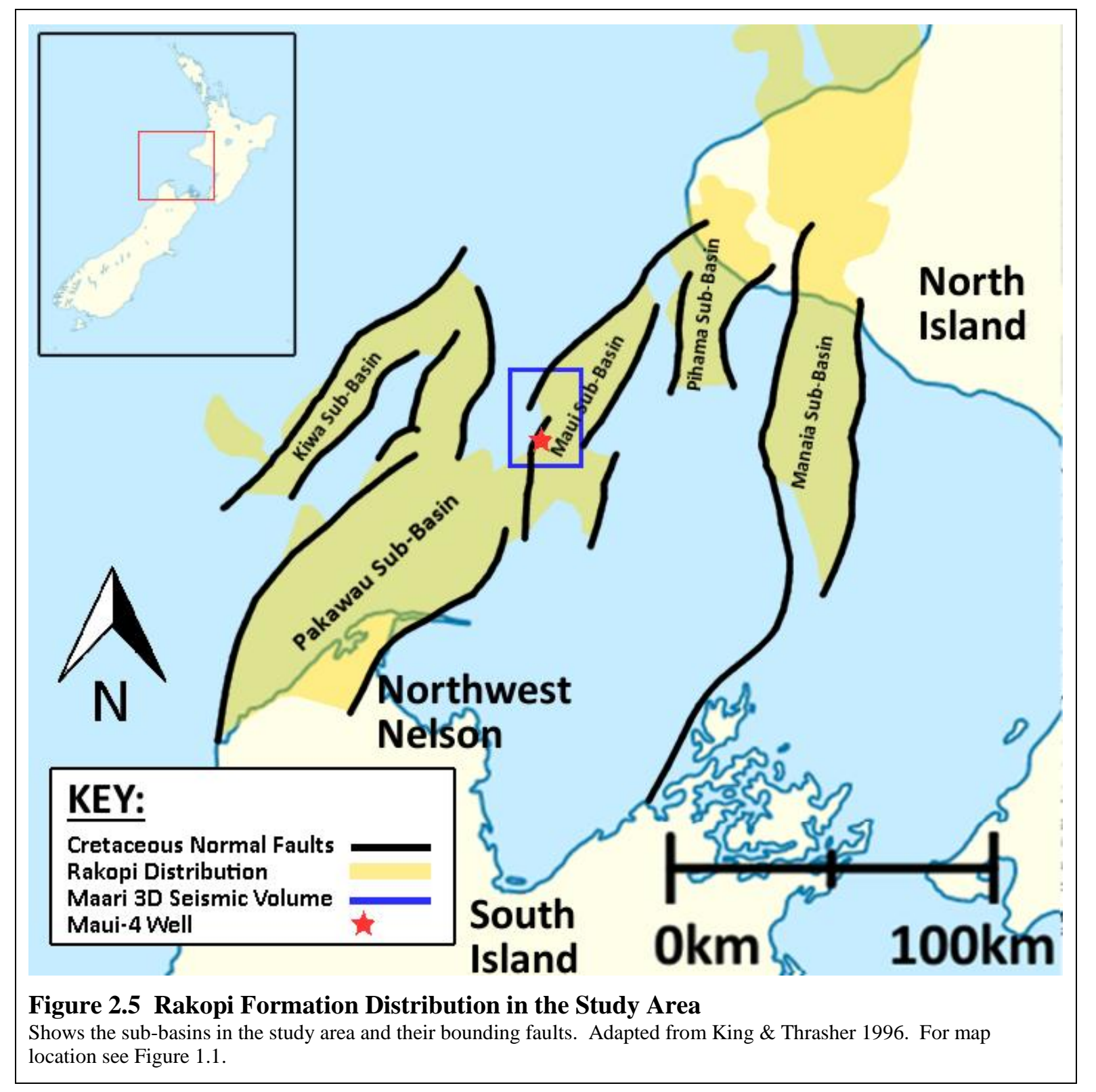

The Rakopi Formation is the earliest-deposited Cretaceous-Cenozoic unit with a widespread distribution in the Taranaki Basin (Uruski 2008), although is not continuous due to its syn-rift deposition (Figure 2.5). It is named after a coal exploration hole drilled in 1915 at Rakopi on Whananui Inlet, and the type section is that of the Cape Farewell-1 exploration well from 11602690m (Figure 3.2) (King \& Thrasher 1996).

The formation's age has been dated based on palynological data from outcrop (Browne et al. 2008; Raine 2004). The upper age of the Rakopi has been constrained by dinoflagellate cyst assemblages which have been identified as having similar composition to those from the base of the overlying North Cape Formation, and thus an early Late Maastrichtian (early Late Haumurian) age has been inferred (Browne et al. 2008). 
The Rakopi Formation is penetrated by only 7 exploration wells within the Taranaki Basin (Cape Farewell-1, Cook-1, Fresne-1, Maui-4, Tahi-1, Takapou-1, and Tane-1) (Figure 3.2), as well as outcropping in northwest Nelson amongst forestry blocks (Figures $2.4 \& 2.5)$ (Browne 2008). In most areas it is generally less than $1000 \mathrm{~m}$ thick, and thins towards the south onto basement, as well as thickening into then-active Late Cretaceous extensional faults, reaching local thicknesses of up to 2500m next to the Taranaki, Rua, and Wakamarama faults (Figure 2.2), as well as reaching a maximum recorded thickness of 3000m (King \& Thrasher 1996).

The formation contains a series of repeated metre- to tens-of-metres-thick fining-upwards cycles, observed in both outcrop and subsurface records. The general pattern of these cycles consists of a planar base, which is succeeded by pebbly sandstone, followed by interbedded sandstone and siltstone, then carbonaceous mudstone, and finally coal at the top of the succession (Browne et al. 2008). The majority of Rakopi Formation coal seams in outcrop and intersected by drill holes are less than 50cm thick, which is well below minimum seismic resolution (Wizevich 1994).

The paraffinic oil potential of the formation is controlled primarily by leaf-derived liptinites, with the preservation of leaf biomass by deposition in thin, planar coal seams producing waxy crude oils (Sykes et al. 2004).

\section{Rakopi Formation Depositional Environment}

The Rakopi Formation was deposited largely as a channel-dominated fluvial coastal plain succession (King \& Thrasher 1996). However, the presence of a marine influence is inferred from the presence of dinoflagellate cysts and glauconite grains in the upper Rakopi Formation (Wizevich 1994). Further palynological sampling of outcrop rocks has confirmed this periodic marine influence (Browne et al. 2008). In addition to outcrop sampling, coal sulphur data acquired in offshore wells provides evidence for more widespread marine influence throughout the formation (Sykes et al. 2004).

The fine-grained sequence of fining-upward channel sandstones, including numerous coal seams, indicates that the Rakopi Formation was deposited in a low-gradient fluvial system. This is inferred as either a meandering (Wizevich 1994), or braided (Browne et al. 2008) stream depositional environment.

The marine influence at the top of the formation is inferred to represent the shift towards a deltaic plain or lagoonal swamp setting during the deposition of the upper coal measures, which is consistent with the overall sedimentary regime shift as part of the transgressive systems tract. Given that marine coaly facies contain greater amounts of organic carbon, this has implications for the source rock potential of the upper Rakopi Formation, which could have greater potential than if it were comprised of purely terrestrial sediments (Browne at al. 2008). A study of coaly Eocene 
source rocks in the Taranaki Basin found that while a greater marine influence only had a very minor effect on the abundance of organic carbon in coaly source rocks, it did increase the Hydrogen Index (HI), and thus the potential for paraffinic oil charge (Sykes et al. 2014).

The intervals of seismic data which correspond to the Rakopi Formation in well-bores display a high amplitude, hummocky, and laterally-discontinuous seismic character (e.g. Figure 4.3). The disconformable contact between the Rakopi Formation and the overlying North Cape Formation is largely uniform in the seismic data throughout the Taranaki Basin (Thrasher 1992).

\subsubsection{North Cape Formation}

The North Cape Formation is the name of the upper unit of the Pakawau Group, and is distinguished from the underlying Rakopi Formation by a more bland seismic reflection character, as well as the greater marine influence on its deposition (King \& Thrasher 1996).

The formation has a maximum thickness of approximately $1800 \mathrm{~m}$, but is generally less than $1000 \mathrm{~m}$ thick in most areas, with an average thickness of approximately 300-400m (Wizevich et al. 1992). It consists of a sequence of siltstones, sandstones, and conglomerates, with minor coal seams. The Puponga and Wainui Members are localised units of coal measures within the North Cape Formation, which are found in the Pakawau sub-basin and the northwest part of the Taranaki Basin respectively (King \& Thrasher 1996).

\section{North Cape Formation Depositional Environment}

The North Cape Formation was deposited in terrestrial, marginal marine, and marine environments, and represents a transgressive sequence of marine, paralic, and coastal plain sediments, which were deposited as a result of regional flooding of the Taranaki Rift in the Late Cretaceous (Thrasher 1992).

\subsubsection{Coaly Facies}

Coals are largely made up of organic matter and carbonaceous sediment, as well as containing various impurities, which are mainly comprised of siliclastic materials such as ash (Boggs 1995)

Coal definition (Boggs, quoting Schopf 1956):

"Coal is a readily combustible rock containing more than $50 \%$ by weight and more than $70 \%$ by volume of carbonaceous material, formed from compaction or induration of variously altered plant remains similar to those of peaty deposits. Differences in the kinds of plant materials (type), in degree of metamorphism (rank), and range of impurities (grade), are characteristic of the varieties of coal." Coaly facies is the name which has been chosen to represent strata which contain significant coal seams. The depositional environment of coaly facies varies from terrestrial (fluvial/lacustrine) to 
marginal marine, although the development of coals requires organic carbon to decay in place, which is less likely to occur with more marine influence, due to sediments being disturbed by tides and currents (Boggs 1995).

Coaly facies which are buried deeply enough to be thermally mature are a common hydrocarbon source rock worldwide, and make up some of the major source rocks in the Taranaki Basin (Uruski 2008).

\subsubsection{Cretaceous Coals in New Zealand}

The Cretaceous coals in New Zealand present a record of the tectonic change which took place during the time period. The relationships between lithofacies, as well as the properties of the coals, represent the many-faceted interplay between modern tectonic influence and paleoenvironmental factors (Sherwood et al. 1992).

The earliest-deposited (Mid-) Cretaceous coal measures in New Zealand are predominantly made up of breccia and conglomerate, as well as containing thin, discontinuous coal seams which are not significant economically. The Latest Cretaceous coal measures (including the Rakopi Formation and its stratigraphic equivalents) were largely deposited in fluvial/lacustrine environments, and are dominated by sandstone, siltstone, and mudstone, as well as discontinuous but thick coal seams. Atop these terrestrial coal measures there exist near-shore, fine-grained coal measures with a marine depositional influence, which reflects the overall marine transgression occurring at the time (Sherwood et al. 1992).

\subsection{Summary}

The Taranaki Basin is New Zealand's only hydrocarbon-producing sedimentary basin, and has a complex tectonic history. The Rakopi Formation was deposited in a fluvial flood plain as a series of coal measures, in mostly isolated sub-basins, during the Late Cretaceous rifting of the Taranaki Basin. The coaly facies within the formation comprise one of the major hydrocarbon source rocks of the basin, the true extent of which is largely unknown due to its discontinuous deposition and lack of well penetrations. 


\section{Data}

\subsection{Introduction}

New Zealand Petroleum and Minerals archives and distributes all well and seismic data acquired under the Crown Minerals Act (1991). This project has used a subset of these data, in order to identify and characterise the coaly facies of the Rakopi Formation, by tying the seismic facies to the physical geology recorded in exploration wells.

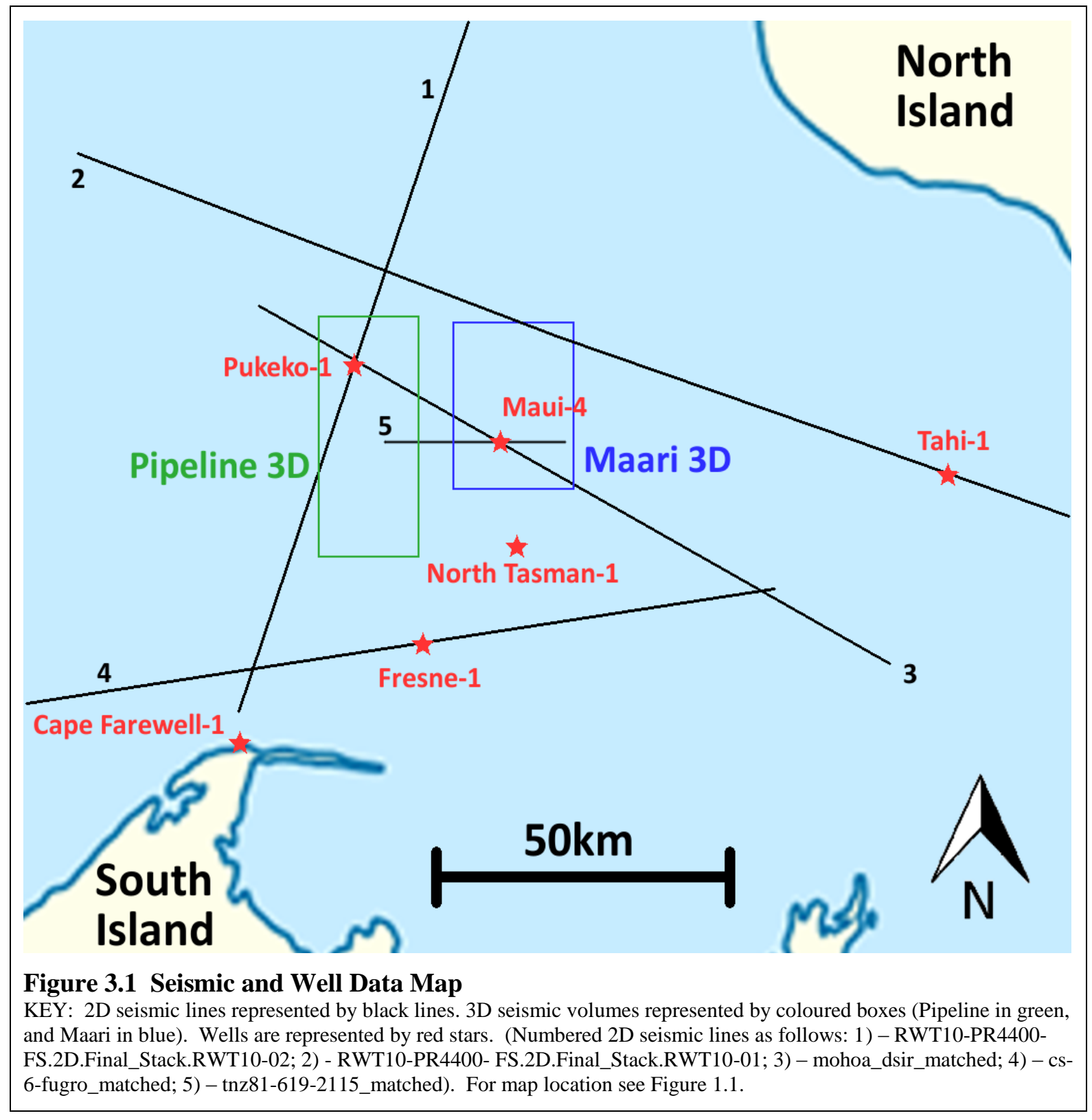




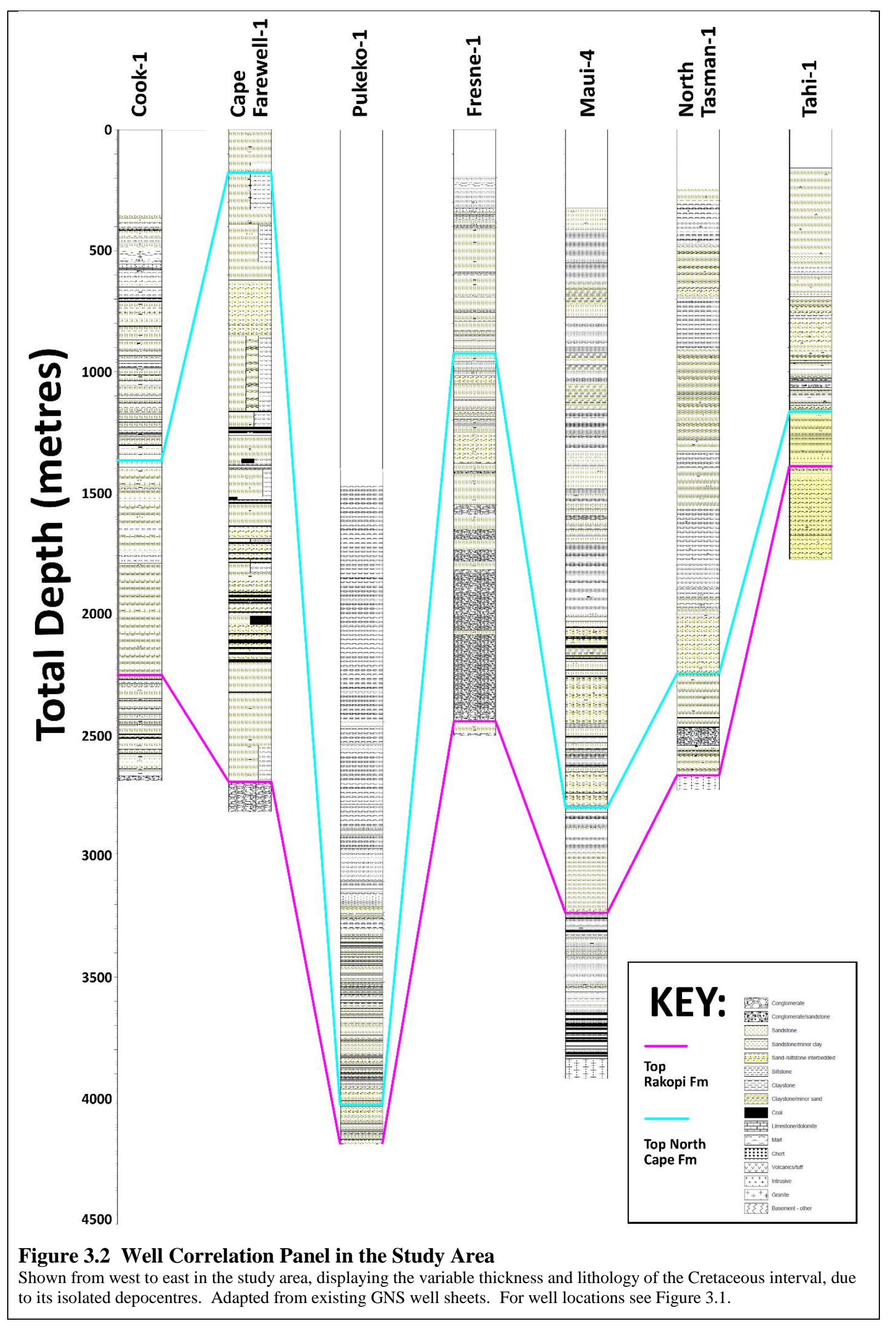


This project utilises two 3D seismic reflection volumes, namely the Maari and Pipeline volumes, located in the southwest offshore Taranaki Basin (Figure 3.1). In addition, a number of 2D seismic lines have been used to correlate between the 3D volumes and outlying wells where possible. Well data has been utilised to tie the seismic data to the physical geology of the basin (Figure 3.2).

\subsection{Seismic Reflection Data}

The seismic data which has been used for this project is a series of post-stack multi-channel seismic reflection data gathered under various exploration licenses within the Taranaki Basin (Figure 3.1). It consists of a total length of approximately $704 \mathrm{~km}$ of 2D seismic lines, in addition to the Maari and Pipeline 3D seismic volumes which cover an area of approximately $935 \mathrm{~km}^{2}$ (Table 3.1).

\begin{tabular}{|l|c|c|}
\cline { 2 - 3 } \multicolumn{1}{c|}{} & Maari 3D & Pipeline 3D \\
\hline Area Covered & $\sim 500 \mathrm{~km}^{2}$ & $435 \mathrm{~km}^{2}$ \\
\hline Survey Dates & 12th March $1999-14$ April 1999 & 19th Feb 2013 - 4th April 2013 \\
\hline Source & $2 \times 2368 \mathrm{in}^{3}$. Bolt Guns & $2 \times 3080 \mathrm{in}^{3}$. Bolt Guns \\
\hline Shot Interval & $18.75 \mathrm{~m}$ & $18.75 \mathrm{~m}$ \\
\hline Fold & 40 & 80 \\
\hline Inline Separation & $25 \mathrm{~m}$ (stack), 12.5m (migration) & $12.5 \mathrm{~m}$ \\
\hline Crossline Separation & $12.5 \mathrm{~m}$ (stack and migration) & $12.5 \mathrm{~m}$ \\
\hline Water Depth & $\sim 100 \mathrm{~m}$ & $100-150 \mathrm{~m}$ \\
\hline Inline Orientation & Approx N/S & $002 / 182$ \\
Streamer Length & $3000 \mathrm{~m}$ & $6000 \mathrm{~m}$ \\
\hline
\end{tabular}

Table 3.1 Selected 3D Seismic Reflection Volumes' Acquisition Parameters 


\subsection{Well Data}

The wells which have been predominantly utilised for this study have been the Maui-4 and Pukeko-1 wells, due to their location within the Maari and Pipeline 3D seismic volumes respectively. A summary of Cretaceous well-penetrations is shown in Table 3.2.

\begin{tabular}{|c|c|c|c|c|c|c|c|}
\hline Well Name & $\begin{array}{c}\text { Cape } \\
\text { Farewell-1 }\end{array}$ & Cook-1 & Fresne-1 & Maui-4 & $\begin{array}{c}\text { North } \\
\text { Tasman-1 }\end{array}$ & Pukeko-1 & Tahi-1 \\
\hline Spud Date & 29-Nov-85 & 10-Aug-70 & 14-Jan-76 & 11-May-70 & 26-Oct-78 & 28-Apr-04 & 1-Feb-84 \\
\hline Depth & $2817 m$ & $2689 m$ & $2503 m$ & $3919.4 \mathrm{~m}$ & $2727 \mathrm{~m}$ & $4190 \mathrm{~m}$ & $1776 \mathrm{~m}$ \\
\hline Objective & $\begin{array}{l}\text { Lower Late } \\
\text { Cretaceous } \\
\text { SST }\end{array}$ & $\begin{array}{l}\text { Kahurangi } \\
\text { Prospects } \\
\text { hydrocarbon } \\
\text { potential }\end{array}$ & $\begin{array}{l}\text { Pakawau } \\
\text { Coal } \\
\text { Measures }\end{array}$ & $\begin{array}{l}\text { Lower } \\
\text { Tertiary } \\
\text { Sands }\end{array}$ & $\begin{array}{l}\text { Pakawau \& } \\
\text { Kapuni } \\
\text { SST } \\
\text { reservoirs }\end{array}$ & $\begin{array}{l}\text { Test Kapuni } \\
\text { Sands }\end{array}$ & $\begin{array}{c}\text { Late } \\
\text { Cretaceous } \\
\text { Pakawau } \\
\text { equivalent }\end{array}$ \\
\hline $\begin{array}{l}\text { Thickness of } \\
\text { Cretaceous }\end{array}$ & $2641 \mathrm{~m}$ & $1504 m$ & $1580 \mathrm{~m}$ & $1042 m$ & $606 \mathrm{~m}$ & $160 \mathrm{~m}$ & $609 m$ \\
\hline $\begin{array}{l}\text { Hydrocarbon } \\
\text { Shows }\end{array}$ & Oil and gas & None & Minor gas & Oil & None & Oil and gas & None \\
\hline $\begin{array}{l}\text { Petroleum } \\
\text { Report }\end{array}$ & 1234 & 513 & 674 & 543 & 736 & 2928 & 1030 \\
\hline Latitude & $40^{\circ} 30^{\prime} 10^{\prime \prime} \mathrm{S}$ & $40^{\circ} 26^{\prime} 29^{\prime \prime} \mathrm{S}$ & $40^{\circ} 21^{\prime} 3.6^{\prime \prime} \mathrm{S}$ & $40^{\circ} 02^{\prime} 24^{\prime \prime} \mathrm{S}$ & $40^{\circ} 12^{\prime} 0^{\prime \prime} \mathrm{S}$ & $39^{\circ} 33^{\prime} 8^{\prime \prime} \mathrm{S}$ & $40^{\circ} 5^{\prime} 6^{\prime \prime} \mathrm{S}$ \\
\hline Longitude & $\begin{array}{c}172^{\circ} 41^{\prime} 55^{\prime \prime} \\
\mathrm{E}\end{array}$ & $\begin{array}{c}172^{\circ} 16^{\prime} 51^{\prime \prime} \\
E\end{array}$ & $\begin{array}{c}173^{\circ} 04^{\prime} 46^{\prime \prime} \\
E\end{array}$ & $\begin{array}{c}173^{\circ} 14^{\prime} 27^{\prime \prime} \\
E\end{array}$ & $\begin{array}{c}173^{\circ} 16^{\prime} 19^{\prime \prime} \\
E\end{array}$ & $\begin{array}{c}172^{\circ} 33^{\prime} 41^{\prime \prime} \\
E\end{array}$ & $174^{\circ} 9^{\prime} 51^{\prime \prime} \mathrm{E}$ \\
\hline Status & $\begin{array}{l}\text { Plugged and } \\
\text { abandoned }\end{array}$ & $\begin{array}{l}\text { Plugged and } \\
\text { abandoned }\end{array}$ & $\begin{array}{l}\text { Plugged and } \\
\text { abandoned }\end{array}$ & $\begin{array}{l}\text { Plugged and } \\
\text { abandoned }\end{array}$ & $\begin{array}{l}\text { Plugged and } \\
\text { abandoned }\end{array}$ & Abandoned & $\begin{array}{l}\text { Plugged and } \\
\text { abandoned }\end{array}$ \\
\hline $\begin{array}{l}\text { Formation } \\
\text { TD'd }\end{array}$ & $\begin{array}{l}\text { Rakopi } \\
\text { Formation }\end{array}$ & $\begin{array}{l}\text { Rakopi } \\
\text { Formation }\end{array}$ & $\begin{array}{l}\text { Rakopi } \\
\text { Formation }\end{array}$ & Basement & Basement & Basement & $\begin{array}{l}\text { Rakopi } \\
\text { Formation }\end{array}$ \\
\hline \multicolumn{8}{|c|}{$\begin{array}{c}\text { Table 3.2 Cretaceous-Penetrating Wells in Study Area } \\
\text { See Figure } 3.1 \text { for well locations. }\end{array}$} \\
\hline
\end{tabular}

Of the many exploration wells that are located within the study area, there are only 7 which penetrate Cretaceous rocks, with 5 of these intersecting the Rakopi Formation (Table 3.2). Additionally, the isolated deposition of the Rakopi Formation and its equivalents means that in general, only wells in close proximity with the 3D seismic volumes can tie the Cretaceous interval directly with the 3D data without significant inference being required. The Maui-4 and Pukeko-1 wells are the wells utilised for this project, due to their location within the Maari and Pipeline 3D seismic volumes respectively. 


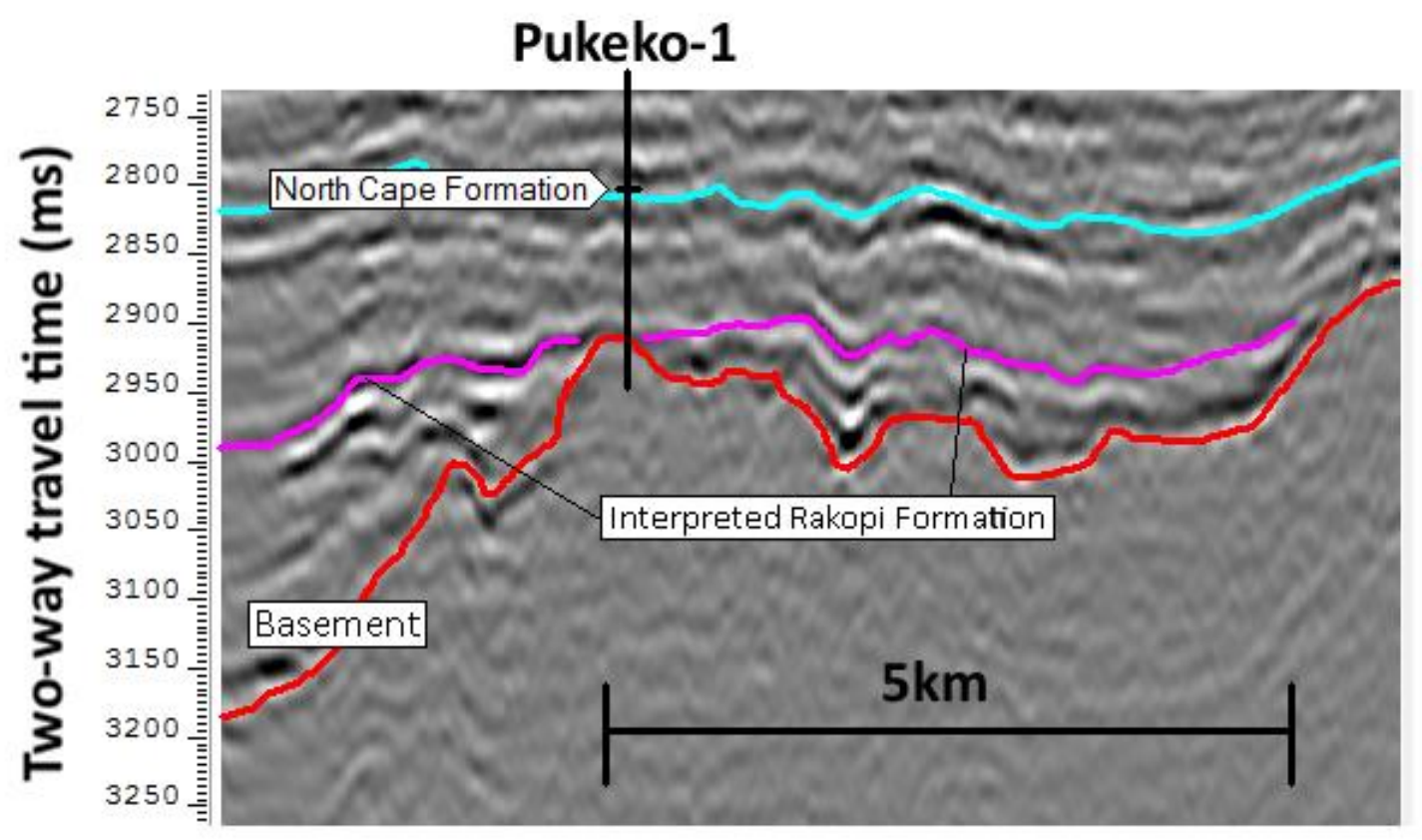

Figure 3.3 Pipeline 3D Seismic Volume Representative 2D Line \#2169

Shown is the Pukeko-1 well, and the interpreted presence of the Rakopi Formation on either side of the basement high into which the well is drilled, on crossline 2169 running west-to-east through the Pipeline 3D seismic volume. For seismic survey location see Figure 3.1.

\subsubsection{Maui-4}

The Maui-4 well is located in the south western quadrant of the Maari 3D seismic volume (Figure 3.1). It was drilled to a depth of $3919.4 \mathrm{~m}$, where it terminates in basement rock. Directly above this, the penetration of the Rakopi Formation includes a significant thickness of coaly facies, and has been subdivided in this project into a further 3 seismic facies packages (see Chapter 5 - Methods), based on seismic character and lithology, for the purpose of attribute extraction and analysis. The Maui-4 well contains the best record of Cretaceous coaly facies which occurs within a 3D seismic volume, and has been used to typecast these facies for attribute extraction.

\subsubsection{Pukeko-1}

The Pukeko-1 well is located in the northwest quadrant of the Pipeline 3D seismic volume (Figure 3.1 ), and was drilled to a total depth of $4190 \mathrm{~m}$, targeting a localised basement high. While it penetrates the Cretaceous interval, Pukeko-1 does not intersect the Rakopi Formation. However, upon analysis of the character of the surrounding strata using the seismic data, it appears that the Rakopi Formation is present in the immediate vicinity, but pinches out onto the Pukeko-1 basement high (Figure 3.3). This assessment is based on comparisons of the seismic character of the Rakopi Formation in the adjacent Maari 3D seismic volume, and on correlations between the 23D surveys carried out using the linking 2D seismic data. 


\section{Seismic Interpretation}

\subsection{Introduction}

Seismic reflection profiling is a method of imaging the structure of the subsurface, by means of recording the travel times of reflected seismic energy pulses from beneath the earth's surface. This produces a representative picture of the stratigraphy, measured in time rather than depth (Kearey \& Brooks 2002). From this, laterally-continuous seismic reflections can be interpreted to represent surfaces of synchronous deposition or unconformities, and correlate to particular chronostratigraphic units (Allaby 2013).

In this chapter, the relevant Cretaceous and Paleogene horizons have been interpreted within the 3D and 2D seismic reflection data, in order to prepare it for the extraction of seismic attributes.

\subsection{Software and Hardware Setup}

The technical work involved in this project has been conducted in Seisware ${ }^{\mathrm{TM}}$, which is a piece of software designed for interpretation of 2D and 3D seismic data, allowing the identification of many tectonic and sedimentary features. Additionally, and critically for this project, it includes the ability to extract seismic attributes from the data, and to display averaged values of these attributes in both representative 2D lines and in pan view on the basemap. The interpretation of the relevant Cretaceous and Paleogene horizons, and extraction of seismic attributes, was carried out with Seisware ${ }^{\mathrm{TM}}$ version 8.0, on a Dell PC running an Intel $3.4 \mathrm{GHz}$ processor, with $24 \mathrm{~Gb}$ RAM, provided by Victoria University of Wellington.

\subsubsection{Seisware ${ }^{\mathrm{TM}}$ Setup}

The following steps were taken to set up the project before any work commenced.

- A project was created in Seisware ${ }^{\mathrm{TM}}$ called HarryGreenfield

- The New Zealand coastline "culture data" was loaded

- Keyword files were obtained to enable 2D and 3D project data to be loaded respectively. The keyword files contained the following information:

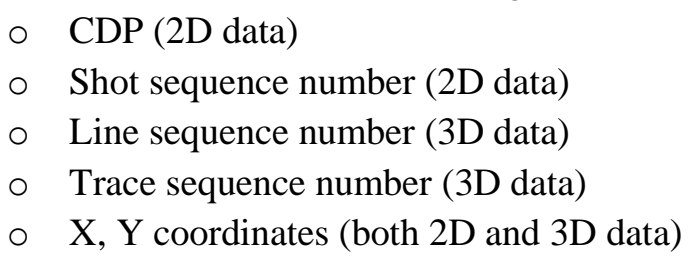

- The 2D and 3D seismic data was then loaded into the project

- The well data was loaded, including:
- X, Y coordinates
- Wireline log data
- Imported stratigraphic formation tops 


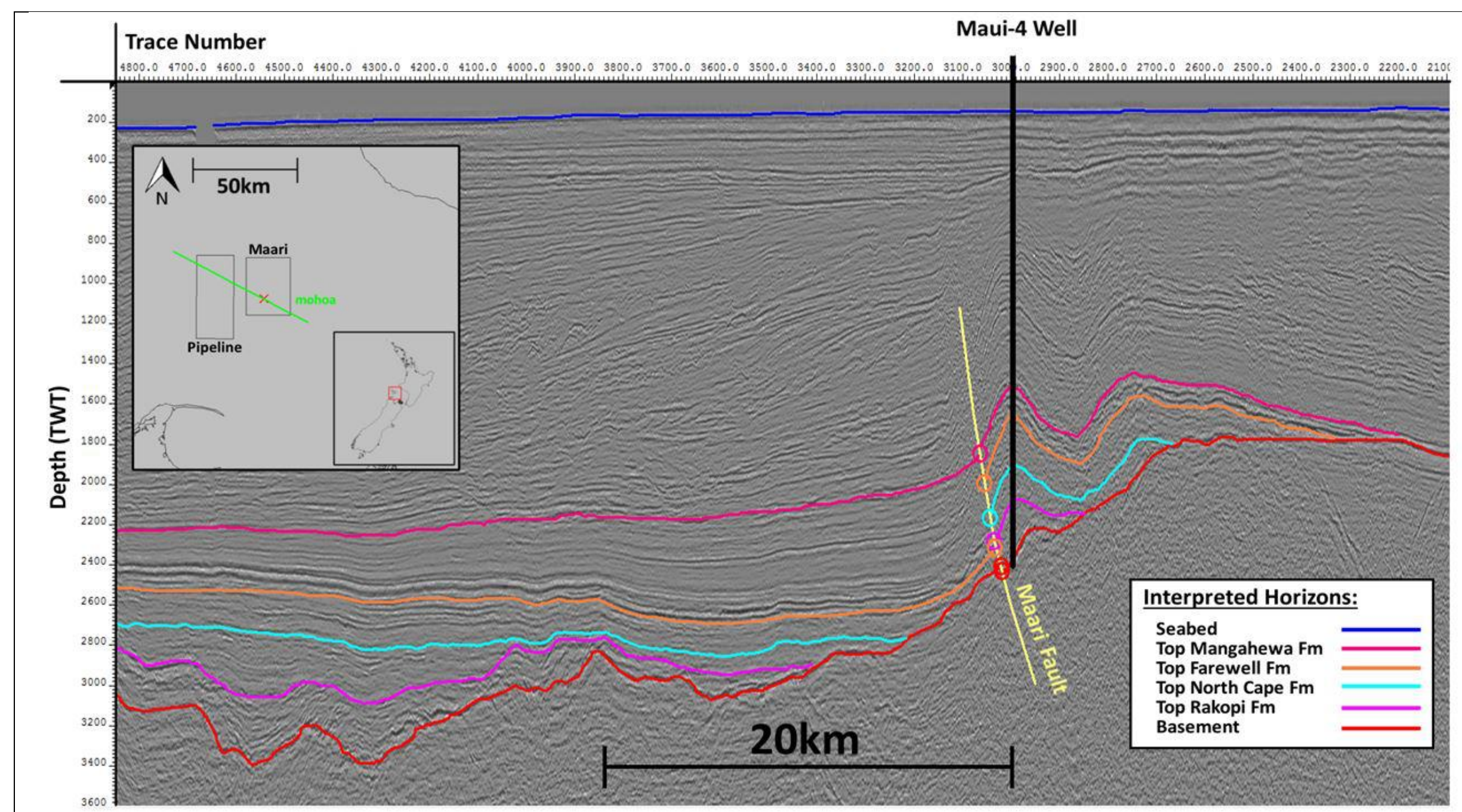

Figure 4.1 2D Seismic Line through Maui-4 Well with Interpreted Horizons

Representative 2D seismic line - Mohoa_dsir_matched. Shows the relevant sedimentary horizons interpreted and utilised in this project, in relation to the Maui-4 well, which has been used as the focal point of seismic attribute extraction in later chapters. Inset is a map of the study area, showing the location of the Mohoa line in green, as well as the nearby $3 \mathrm{D}$ seismic reflection volumes; Maari and Pipeline. For map location see Figure 1.1. 


\subsection{Methods}

The following steps were taken to prepare the data for interpretation, and to carry out the interpretation itself:

- To ensure no time mismatch between any of the seismic surveys, interpretation of the seabed was carried out. The seabed was picked on a high amplitude peak, indicating normal polarity data. This interpretation was used to calibrate the differing 2D lines and 3D surveys. Bulk shifts were conducted of up to approximately $10 \mathrm{~ms}$ where required, to align the data together.

- Following this, the Maui-4 and Pukeko-1 wells were tied to the Maari and Pipeline 3D seismic volumes respectively by generating a velocity curve using the sonic log (from the imported wireline data). The Maui-4 well produced a good tie to the seismic data with prominent reflections corresponding to formation tops in the well

- For the Pukeko-1 well, the velocity curve generated from the sonic log failed to produce a good correlation with the seismic data. To improve the correlation, the Top Basement horizon in the well was matched to the clear (high amplitude, low frequency) basement reflector in the seismic data (confidently interpreted to represent the top of basement rocks), and the well was scaled to fit. Following this, well formation tops for other pertinent horizons (Rakopi, North Cape, Farewell formations) were able to be correlated with prominent reflections which matched those confidently tied to the Maui-4 well. The correlation thus achieved was deemed adequate to proceed with seismic interpretation.

- Within the Maari 3D volume, 4 seismic horizons were interpreted (Top Basement, Top Rakopi, Top North Cape, and Top Farewell formations), and extrapolated outwards from the Maui-4 well to the east of the Maari Fault (Figure 4.1). In addition, 2 intra-formational horizons within the Rakopi Formation were interpreted in an area of approximately $32 \mathrm{~km}^{2}$ directly surrounding the Maui-4 well (Figures 4.5 and 6.16; see Section 5.4 for more detailed explanation).

- Within the Pipeline 3D volume, the Top Basement, Top Rakopi, Top North Cape, and Top Farewell horizons were interpreted; however, given that the Pukeko-1 well does not penetrate the Rakopi Formation or its equivalent, and there is no 2D line which directly connects the Top Rakopi Formation between Maari and Pipeline, inferences were made in order to interpret the Rakopi Formation within Pipeline, based on the seismic character of the Rakopi Formation (Figure 4.4) (Section 4.5).

- In addition to these Cretaceous-Paleocene horizons, the top of the Mangahewa Formation was also picked in the Maari 3D volume, as it contains coaly facies in similar quantities to those of the Rakopi Formation, as displayed in the Maui-4 well (Figure 3.2). This was done in order to carry out direct comparisons of seismic attributes extracted from the Cretaceous coaly facies (Section 6.3.2). 


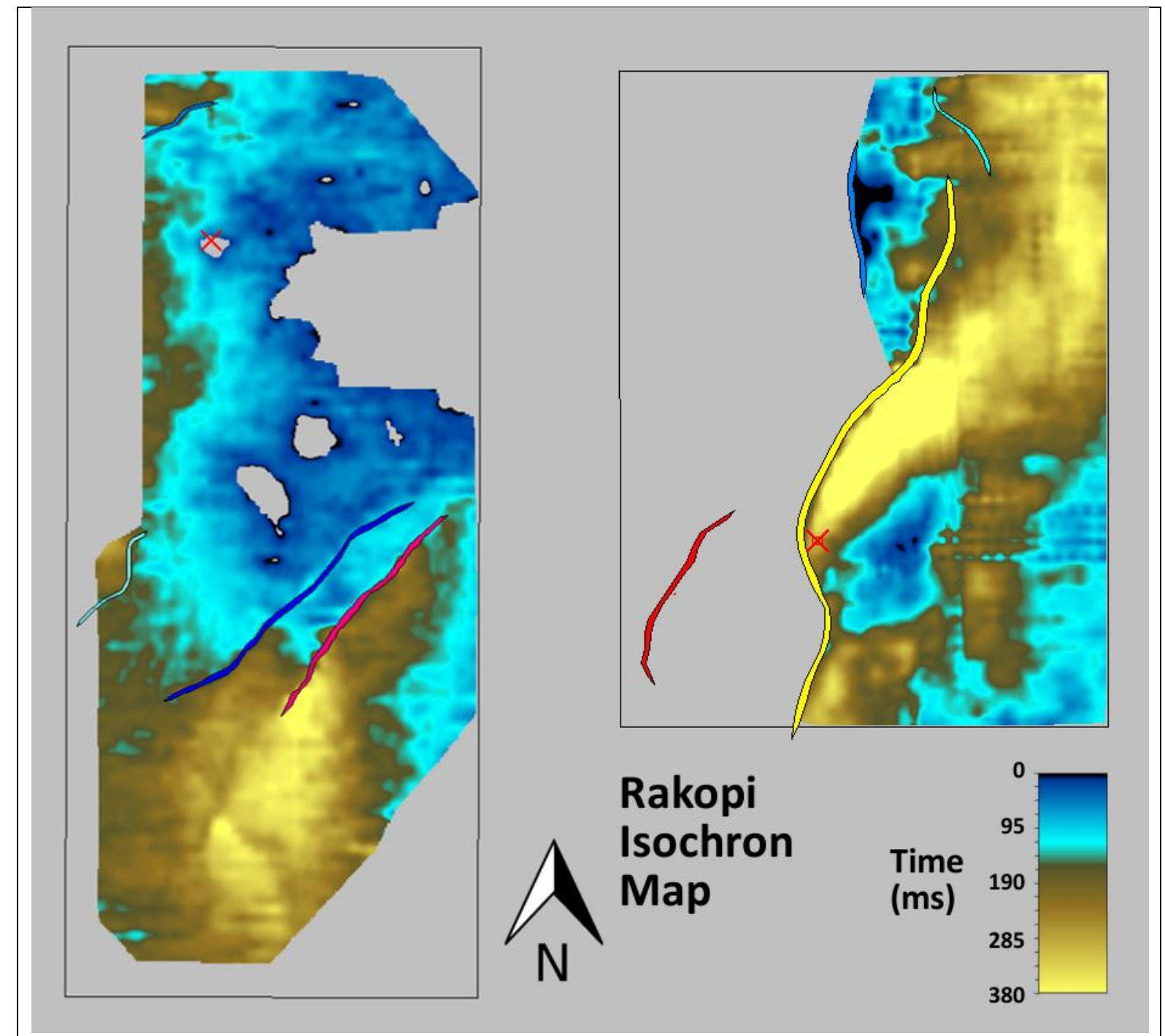

\section{Figure 4.2 Rakopi Formation Isochron Map}

Measuring the distance (in ms TWTT) between the interpreted Top Basement and Top Rakopi formations in the Pipeline (left) and Maari (right) 3D seismic reflection volumes. For map location see Figure 1.1.

- Major basement-cutting faults were interpreted within both the Maari and Pipeline 3D volumes, and were triangulated using Seisware ${ }^{\mathrm{TM}}$, in order to be represented on the basemap (e.g. Figure 5.1).

- Seismic loop ties were attempted by using a combination of 2D seismic lines to connect the 3D data with itself, especially where interpretation was required to cross major faults, which affected the continuity of reflectors (for example, across the Maari Fault; Figure 4.1).

- Isochron maps were generated for each of the interpreted intervals to evaluate thickness (in TWTT) within the 3D volumes (Figure 4.2). 


\subsection{Maari 3D Seismic Reflection Volume}

The Maari 3D volume is tied to the Maui-4 well and images part of the Maui sub-basin, within which the Rakopi Formation is thought to be extensively deposited (King \& Thrasher 1996). As such, the Maari 3D has been used as the focus of this project, as the Maui- 4 well records the most abundant Cretaceous coaly facies of all of the nearby wells (Figure 3.2). The Rakopi Formation interval within the Maari 3D, defined by the Top Basement-Top Rakopi seismic horizons, has been used as the focus point for the extraction of seismic attributes which best represent the coaly facies encountered in the well. However, all attributes have also been extracted from the Pipeline 3D volume as well, for the purpose of comparison and potential identification of coaly source rocks away from the Rakopi Formation well penetrations.

\subsubsection{Gridding Horizons in Seisware ${ }^{\mathrm{TM}}$}

Due to the impracticality of interpreting every line of the 3D data sets, the interpretation was carried out on a grid (one line every 10-30 inlines and crosslines, depending on proximity to the Maui-4 well) within the Maari 3D volume, which was then was interpolated through the rest of the volume. This was carried out using the triangulation algorithm in Seisware ${ }^{\mathrm{TM}}$, which automatically creates direct lines between the points of a horizon which has been manually picked. The reason this method was chosen instead of one which would apply a "smoothing" effect to the horizons is that the smoothing can result in deviation from the values picked, and horizons extending beyond their boundaries. After some experimentation with different gridding methods, triangulation was deemed the best method, as it simply extrapolates between picked points, giving a more true fit to the interpreted horizons. 


\subsection{Interpreted Horizons}

The following horizons have been interpreted within the Maari and Pipeline 3D volumes, as well as on the selected connecting 2D lines (Figure 4.1). Where seismic character is referred to, it is in reference to the characterisations made by Mitchum et al. 1977 (Figure 4.2).

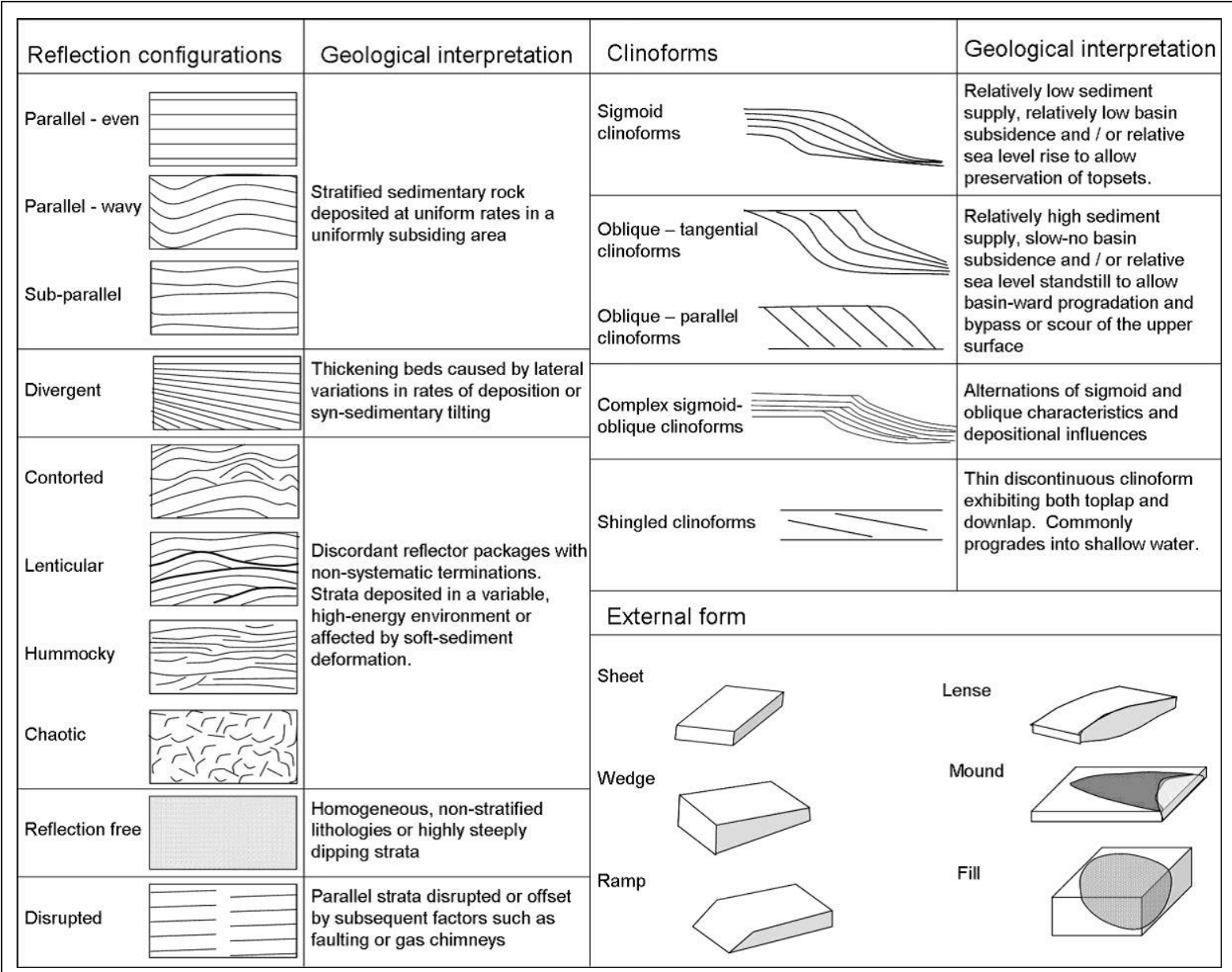

Figure 4.3 Typical Seismic Reflection Pattern Configurations and Interpretations

Modified from Mitchum et al. 1977.

\subsubsection{Top Basement}

The top of basement is defined as "acoustic basement", in that it is defined by its seismic character alone. It is interpreted as the deepest relatively-continuous seismic reflector that can be identified, and is variable in character across the study area. The Top Basement reflector separates reflections above - that are deemed to represent layers of sedimentary stratigraphy - from the discontinuous, chaotic facies below. Top Basement is represented in most areas by a semi-continuous, high amplitude peak. In many areas, the basement is cut by faults of varying size, which introduce further discontinuity and make the reflector difficult to correlate in places. 


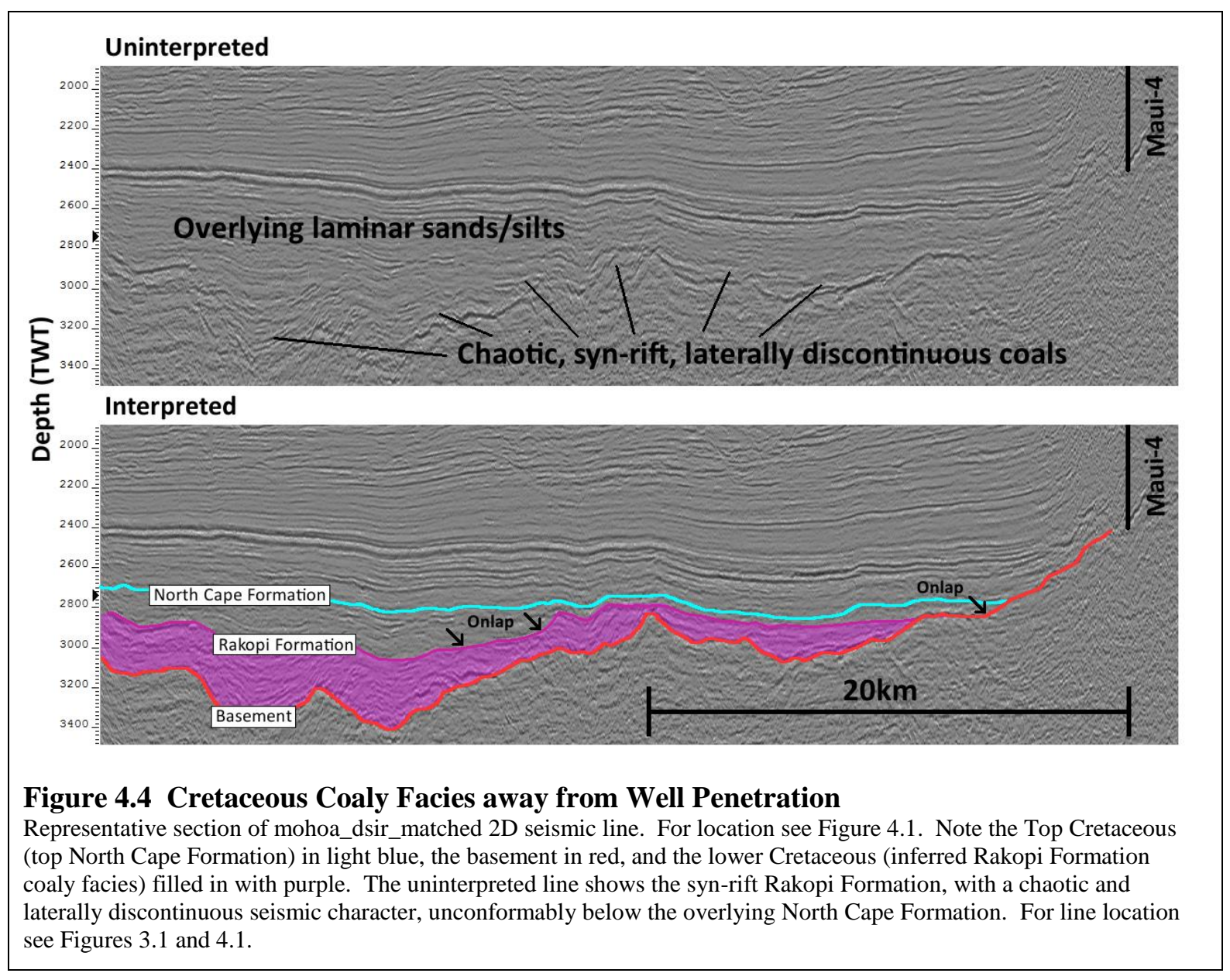

\subsubsection{Top Rakopi Formation}

The Top Rakopi Formation is represented in the seismic section by a hummocky trough amidst several other medium-amplitude peaks and troughs. It is highly laterally-variable, and coupled with poor data quality in some areas, can be difficult to constrain accurately in these places.

Within the Rakopi Formation, the seismic data displays some distinct characteristics. Namely, the division into different seismic facies. In the Maari 3D volume, examining the seismic data around the Maui- 4 well shows that the more high-amplitude parts of the data correspond with the coaly facies (Figure 4.2). Thus, it is possible to infer the presence of these coaly facies in other parts of the 2D and 3D seismic data.

An example of this occurs, in the 2D seismic line mohoa_dsir_matched, wherein there is displayed a clear division in the Cretaceous package in the west part of the line, between relatively bland seismic character and stratified, more laminar, high amplitude packages, which are interpreted as being representative of coaly facies, (Figures $4.1 \& 4.4$ ). 


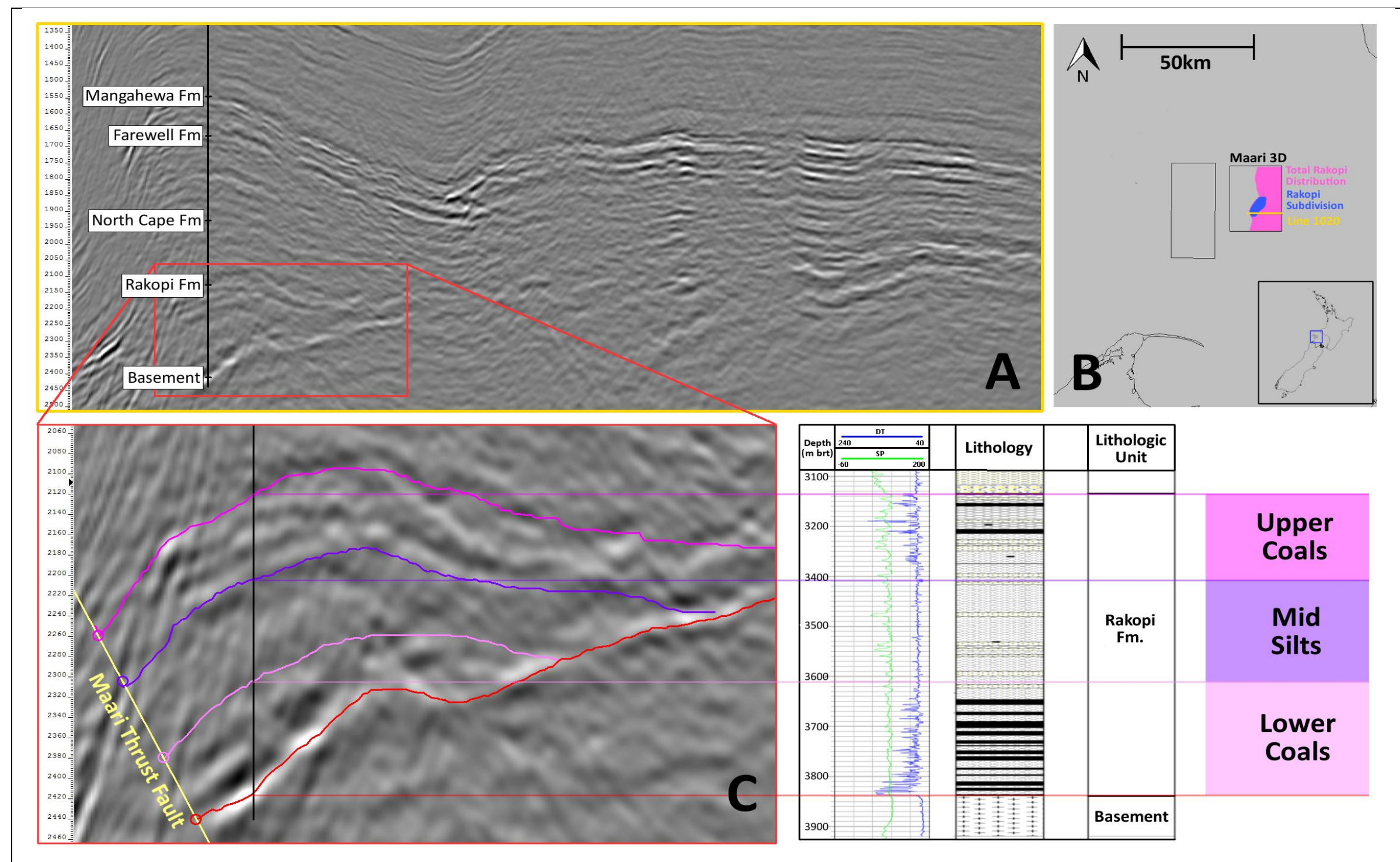

Figure 4.5 Rakopi Subdivision Map, Representative 2D Seismic Line, and Well Lithology

Rakopi Subdivision (the name given to this part of the Rakopi Formation which has been divided into 3 distinct seismic (and lithologic) packages - the Upper Coals, Mid Silts, and Lower Coals. Detailed in Chapter 5.3). For map location see Figure 1.1.

A: Crossline 1020 within the Maari 3D volume. Maui-4 well shown by vertical black line.

B: Map showing location of Maari 3D volume, and the area of Rakopi Formation distribution within the volume, as well as the area within which the Rakopi Subdivision is interpreted.

C: Close up view of the Rakopi Subdivision in the 2D seismic (Maui-4 well as black vertical line), and the correlation to the lithology observed in the Maui-4 well (bottom right). 


\subsubsection{Rakopi Subdivision}

In general, the Rakopi Formation has a high degree of lateral variation. It has a contorted and sometimes chaotic seismic character, as a result of soft-sediment deformation rather than a high energy depositional environment (Browne et al. 2008). Much of the Rakopi Formation is med-high amplitude, with a lack of lateral continuity leading to horizons which are difficult to constrain (Figure $4.5 \mathrm{~A})$.

Within the Maari 3D volume, in the immediate vicinity of the Maui-4 well, the Rakopi Formation has been subdivided into 3 distinct seismic facies packages linked directly to the lithology as observed at the Maui-4 well (Figure 4.5). 2 intra-formational horizons were interpreted in order to subdivide the packages, which have been labelled the Lower Coals, the Mid Silts, and the Upper Coals. The splitting of the Rakopi Formation into these distinct seismic facies packages over approximately $32 \mathrm{~km}^{2}$ (Figure 4.5B) directly around the Maui-4 well is henceforth referred to as the Rakopi Subdivision. It should be noted that the Rakopi Subdivision has only been observed in a limited area of approximately $32 \mathrm{~km}^{2}$ (Figures $4.5 \mathrm{~B} \& 6.2$ ) directly around the Maui-4 well, and that farther afield the seismic facies character becomes too indistinct to interpret with confidence.

\subsubsection{Lower Coals}

The Lower Coals interval contains the highest percentage thickness of coal seams (which make up $43 \%$ net thickness of the interval as measured at the Maui-4 well; Figure 4.5C) of all of the Rakopi Subdivision. As such, it is the best representation of Cretaceous coaly facies in the study area. The remaining lithology is almost all siltstone, with a small amount of isolated sandstone. The seismic character of this facies package is high amplitude, low frequency, and semi-continuous within the small area it is contained.

\subsubsection{Mid Silts}

The Mid Silts contains very little coal, with approximately 12 very thin coal seams being present in the well lithology (Figure 4.5 stratigraphic column). It is comprised mostly of siltstone, with thin sandstone beds sparse throughout. The seismic character of this package is relatively bland when compared to the Lower Coals and Upper Coals, is low to medium amplitude, and highly laterally discontinuous.

\subsubsection{Upper Coals}

The Upper Coals contain far less of a thickness of coal seams than the Lower Coals $(10.6 \%$ net thickness as measured at the Maui-4 well; Figure 4.5C), but is still considered to be coal-rich when compared to the Mid Silts. The lithology (apart from the coals) is largely claystone, with sparse interbedded siltstone and sandstone. The seismic character is comprised of 3-4 medium to high amplitude, semi-continuous, sub-parallel reflectors, with medium to low frequency. 


\subsubsection{Top North Cape Formation}

Compared to the Rakopi Formation, the North Cape Formation is much more laminar, with a largely sub-parallel and hummocky reflection configuration, and an overall moderately-bland seismic character, which onlaps in places onto the unconformable surface of the Top Rakopi Formation (Figure 4.1).

The top of the North Cape Formation has a much lower amplitude and indistinct seismic character than the Rakopi Formation. It is characterised by a low-amplitude trough amidst medium-amplitude troughs and peaks. Due to the limited well-ties, and its bland seismic character, it can be difficult to identify with confidence in areas away from exploration wells.

\subsubsection{Top Farewell Formation}

The Farewell Formation is comprised of sub-parallel, hummocky reflectors which are semicontinuous, and slightly higher in amplitude than the underlying North Cape Formation (Figure 4.1). The top of the Farewell Formation, as seen at the Maui-4 well, is best characterised by the group of 3 4 high amplitude peaks and troughs directly above it, with the formation itself making up the lowest of the series of troughs, above a relatively bland, low amplitude vertical interval of seismic data.

\subsubsection{Top Mangahewa Formation}

The Mangahewa Formation is an Eocene-age formation which is also recognised as being rich in coals, and provides a further source rock interval within the Taranaki Basin (King \& Thrasher 1996). While the Mangahewa Formation is not the focus of this project, it contains a prolific coaly interval that is present throughout the study area and is intersected by the Maui-4 well (Figure 6.17). Therefore it has been identified as a comparable unit to the Rakopi Formation, on which to test the results of seismic attribute analysis (see Chapter 6). A Top Mangahewa Formation horizon has been interpreted in selected seismic lines, and parts of the 3D volumes.

The Mangahewa Formation itself consists of a semi-continuous, parallel series of 5-6 high-amplitude reflectors (Figure 4.1). The top of the formation is characterised by a semi-continuous low frequency, med-high amplitude trough with similar peaks either side of it, lying above a series of high amplitude peaks and troughs. 


\section{Seismic Attribute Extraction}

\subsection{Seismic Attributes}

Seismic attributes allow information to be extracted from the data which is not apparent from viewing a conventional seismic reflection image. This is possible due to the adjustment and simplification of the data which occurs in compiling it for easier stratigraphic interpretation. Any measure of seismic data which visually enhances or quantifies a feature of interpretational interest is a seismic attribute (Chopra \& Marfurt 2007).

Conventional seismic reflection images display the waveforms of each seismic trace as a positive half-cycle in black. This is done to merge the shaded areas between traces into continuous black lines, to allow correlation of features across a section for the purpose of structural interpretation (Kearey et al. 2002).

One negative effect of this process is that the waveform's exact amplitude and shape is lost. Given that the amplitude of a reflected wave corresponds directly to the reflection coefficient at the reflective interface, any variation in amplitude along a reflective surface should correlate with variation in the properties of the respective formations (Kearey et al. 2002). As such, this process results in available information about the properties of the strata above and below a reflective surface being unrepresented in the seismic image. Additional information can be revealed by the extraction of seismic attributes (Chopra \& Marfurt 2007).

There are many seismic attributes, which are not all independent of each other, but are all derivatives of the basic seismic measurements of time, amplitude, frequency, and attenuation (Brown 2004).

\subsubsection{Seismic Amplitude}

Seismic amplitude is just one simple example of an attribute of the seismic wave which can be examined for what it represents in terms of variations in physical geology. These variations can be viewed by imaging the seismic section with the amplitude displayed as a colour scale, to reveal changes in amplitude along a continuous reflector (Kearey et al. 2002).

Amplitude changes along a reflective surface can correlate to changes in rock pore fluid (among other things), and as such can be direct hydrocarbon indicators (DHIs) under ideal circumstances (Brown 2004).

\subsubsection{Amplitude Attributes}

In order to identify a potential attribute or combination which would identify coaly facies, seismic attributes were extracted from the interpreted intervals within both the Maari and Pipeline 3D seismic volumes. Initially, a number of calculations were carried out using Seisware ${ }^{\mathrm{TM}}$, based on variations in 
amplitude, which were then displayed in plan view as amplitude maps (Figure 5.1 and Appendix A). The purpose of this was firstly to compare them with the isochron map of the Rakopi Formation (Figure 5.1D), to see if there was any indication that an attribute was not merely a representation of a variation in thickness. Additionally, amplitude maps allow analysis of the areal distribution of amplitudes, to any potential depositional or lithologic variation.

The operations which were undertaken to facilitate extraction and display of the initial amplitude attributes are as follows:

- An "Elevated Basement" horizon was generated 20ms above the triangulated basement horizon within both of the 3D volumes, to ensure that the high amplitude Basement reflector was excluded as much as possible from any attributes extracted

- A total of 19 amplitude-based calculations (the full list of which is displayed in Appendix A) were made within the Maari and Pipeline 3D volumes, on the interval between the Elevated Basement and Top Rakopi Formation

- $\quad 3$ sets of calculations were made: on the interval as a whole; on the bottom 100ms, and on the bottom $50 \mathrm{~ms}$. The results were very similar between the 3 datasets, and as such the bottom $50 \mathrm{~ms}$ was selected as representative, due to the occurrence of lower-formation coaly facies within the Rakopi Formation being present at the Maui-4 well (Figures $3.2 \& 4.5$ ). While the lower coal succession in the Rakopi Formation is around 100ms thick in most areas, the bottom $50 \mathrm{~ms}$ was selected to ensure that none of the overlying formation was included in the attribute analysis.

- The results of the extraction of these attributes from the bottom 50ms of the Rakopi Formation were exported as horizons for display as amplitude maps (Appendix A).

The initial amplitude attribute calculations were carried out as a first look at the expression of the coals, as coals commonly show a strong amplitude response relative to background rocks (Sahoo et al. 2014). Calculating these initial attributes was less computationally intensive than the more sophisticated Rock Solid Attributes (Section 5.2), so they were extracted as a first look at the Rakopi. Since the resultant amplitude maps have not been used for this project, they have been confined to Appendix A, other than a representative image (Figure 5.1). Upon visual analysis of the spatial distributions of the 19 different amplitude attribute maps, three different types have been identified: 


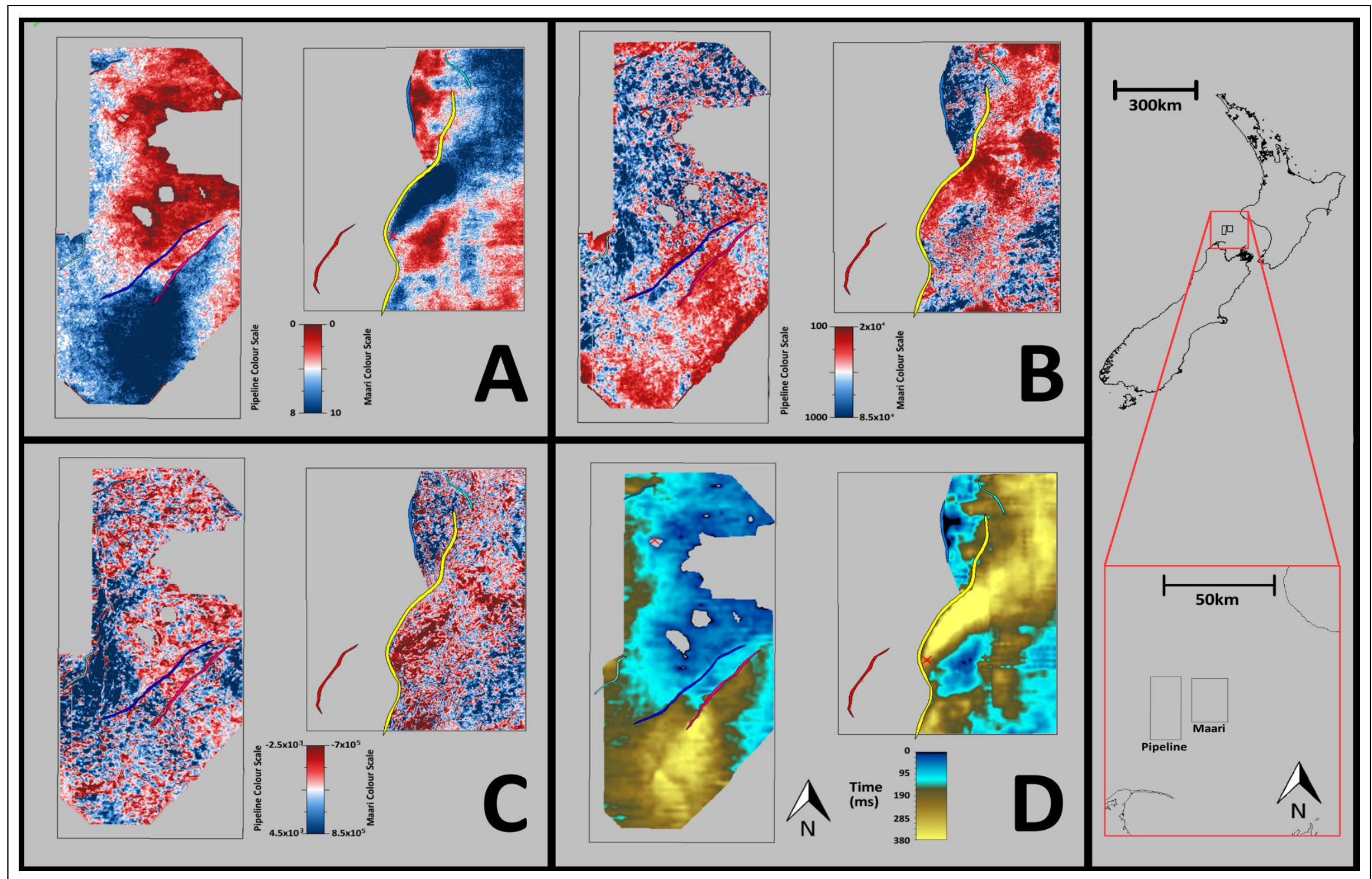

Figure 5.1 Representative Amplitude Attribute Types and Rakopi Formation Isochron Map

Each attribute type discussed in 5.1.2-5.1.4 is represented in A-C respectively, with each section showing the distribution of values within the Rakopi Formation interval of the Pipeline (left) and Maari (right) $3 \mathrm{D}$ seismic volumes, with major basement-cutting faults shown by the coloured lines. The Rakopi Isochron Map is included (D) to show any potential relationship between value distributions and formation seismic volumes, with major basement-cutting faults shown by the coloured lines. The Rakopi Isochron Map is included (D) to show any potential relationship between value distribut
thickness. The 3 representative attributes are: PC - Peak Count; ABS - Average Absolute; SA - Sum of Amplitudes. More information on these attributes is listed in Appendix A. 


\subsubsection{Type 1: Thickness Dependent Amplitude Maps}

The values displayed in these appear to be governed by the thickness of the formation, and as such bear a close resemblance to the Rakopi isochron map (Figure 5.1A \& 5.1D). As such, they are likely responding to the thickness of the formation, rather than any of its lithologic properties, and are not significant to any attribute analysis.

\subsubsection{Type 2: Isochron Dependent Amplitude Maps}

The values displayed in these maps are partially reminiscent of the isochron map, but with differences, and less of a strong correlation (Figure 5.1B). As such, they may be partially influenced by formation thickness, and partially be responding to variations in lithology.

\subsubsection{Type 3: Other Amplitude Maps}

These maps are completely non-conformable with the isochron map (Figure 5.1C). As such, they are likely representing something other than a reflection of the formation thickness. There are only 2 of these amplitude maps of the 19 total amplitude attributes (Sum of Amplitudes (SA), and Zero Crossing Frequency (ZCF); Figures 9.18 \& 9.19 in Appendix A). 


\subsection{Rock Solid Attributes}

Seisware $^{\mathrm{TM}}$ uses a proprietary set of attributes called Rock Solid Attributes (RSAs), produced by and purchased from a company called Rock Solid Images (RSI). A total of 34 different RSAs were extracted from the Maari and Pipeline 3D volumes for this project (Table 5.1).

The steps which were taken to extract and analyse the selected RSAs from the seismic data are as follows:

- Within the Maari 3D volume, attributes were extracted from within the 3 intra-formational packages of the Rakopi Subdivision (Lower Coals, Mid Silts, and Upper Coals).

- $\quad$ The 34 RSAs were averaged through the Rakopi Formation interval as a whole (Figure 5.1), as well as the Lower Coals, Mid Silts, and Upper Coals separately.

- RSAs extracted from the Farewell and Mangahewa formations, and the interval between the Mangahewa Formation and a purpose-generated horizon (Manganui Horizon - this was not interpreted) $150 \mathrm{~ms}$ above it. This was carried out in the $32 \mathrm{~km}^{2}$ area around the Maui- 4 well over which the Rakopi Subdivision extends (see Rakopi Subdivision Polygon; Figure 6.17), for the purpose of comparison of attribute averages of the coaly and non-coaly intervals.

- The resultant attribute averages were output as surfaces on amplitude maps, and the attributeaveraged surfaces were exported from Seisware ${ }^{\mathrm{TM}}$, and processed in the software package MatLab for statistical analysis of the results (Chapter 6.2).

A final selection of the RSA amplitude maps are analysed in Chapter 7. The entire suite of RSA amplitude maps are displayed in Appendix B.

Of the 34 total RSAs extracted, 15 were deemed to be significant, and/or display enough variance between the coaly and non-coaly facies to warrant the results being included in this thesis (based on analysis of outputs detailed in Chapter 6.2) (Figures 6.1-6.15). 


\begin{tabular}{|c|c|}
\hline Attribute Name & Rock Solid Attribute Brief Description \\
\hline Real Part of Complex Trace & Recorded part of seismic trace (amplitude) \\
\hline Imaginary Part of Complex Trace & Real part, phase shifted by 90 degrees \\
\hline Trace Envelope & Total instantaneous energy of the complex trace \\
\hline Time Derivative of Envelope & Rate of change of wavelet envelope over time \\
\hline Instantaneous Phase (Degrees) & Phase of the trace at any given instant \\
\hline Instantaneous Frequency (Hz) & Frequency at any given instant - rate of change of phase over time \\
\hline Dominant Frequency $(\mathrm{Hz})$ & RMS frequency of amplitude spectrum \\
\hline Band Width (Hz) & Difference between upper and lower frequencies in a continuous set \\
\hline Instantaneous Q Factor & Seismic attenuation at any given instant \\
\hline Normalised Amplitude & Cosine of instantaneous phase \\
\hline Relative Acoustic Impedance & Pressure from vibration of seismic layer at a given frequency \\
\hline Wavelet Envelope & Instantaneous attributes at maximum point of envelope \\
\hline $\begin{array}{l}\text { Time Derivative of Wavelet } \\
\text { Envelope }\end{array}$ & Rate of change of envelope over time \\
\hline Wavelet dominant Frequency $(\mathrm{Hz})$ & Frequency for wavelet biased towards the dominant frequency \\
\hline Wavelet Q Factor & Rate of decay of wavelet envelope \\
\hline Dip Similarity & Dip determined from the similarity \\
\hline Dip Variance & $\begin{array}{l}\text { Difference between smoothed dip of maximum similarity and local value of dip of maximum } \\
\text { similarity }\end{array}$ \\
\hline Similarity & Similarity of trace compared to neighbours computed over a moving weighted window \\
\hline Similarity Variance & Difference between smoothed similarity and local value \\
\hline Smoothed Dip Similarity & Maximum similarity's calculated dip smoothed with a low pass filter for long windows \\
\hline Dip Azimuth & Azimuth of crossline axis is added to azimuth of maximum instantaneous dip \\
\hline Mean Curvature & Mean curvature of each trace and surrounding 8 traces \\
\hline Max Curvature & Largest curve at any point \\
\hline Min Curvature & Smallest curve at any point \\
\hline Most Negative Curvature & Largest negative curve at any point \\
\hline Most Positive Curvature & Largest positive curve at any point \\
\hline Spectral Balance Traces & Spectral balancing of the input using the wavelet transform calculated sub bands \\
\hline $\begin{array}{l}\text { Band Limited Relative Acoustic } \\
\text { Impedance }\end{array}$ & A simple band limited inversion using integration and 90 degree phase shift \\
\hline Mean Frequency of Spectra & Mean frequency of the spectra calculated from the wavelet transform sub bands \\
\hline Band Width of Spectra & Bandwidth of the Spectra calculated from the wavelet transform sub bands \\
\hline Max Subband of Envelope & $\begin{array}{l}\text { Amplitude envelope of the peak frequency of the spectrum as calculated from the wavelet } \\
\text { transform sub bands }\end{array}$ \\
\hline $\begin{array}{l}\text { Frequency of Max Subband } \\
\text { Envelope }\end{array}$ & Peak frequency of the spectrum as calculated from the wavelet transform sub band \\
\hline Q by Frequency Shift & Absorption Q estimate using a frequency shift method (see other documentation) \\
\hline Q by Spectral Ratio & Absorption Q estimate using a spectral ratio method (see other documentation) \\
\hline Semblance & Measures the coherency of adjacent traces \\
\hline \multicolumn{2}{|c|}{$\begin{array}{l}\text { Table 5.1 List of Seisware }{ }^{\mathrm{TM}} \text { Rock Solid Attributes used in this Project } \\
\text { Taken from Seisware }{ }^{\mathrm{TM}} \text {. For more information on Rock Solid Attributes, see Taner (2003) and/or the Rock Solid Image } \\
\text { website: http://www.rocksolidimages.com }\end{array}$} \\
\hline
\end{tabular}



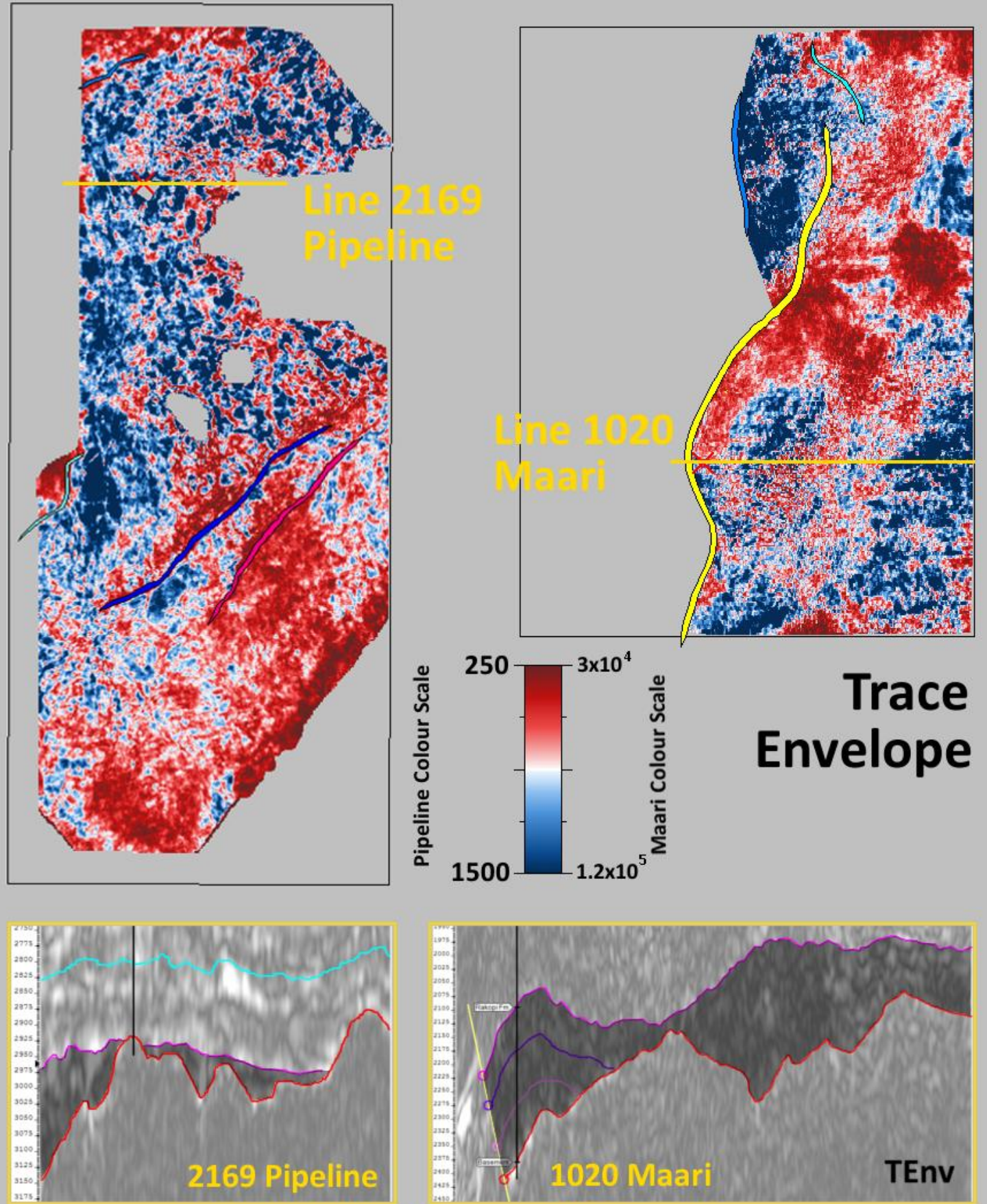

\section{Figure 5.2 Example of Rock Solid Attribute Averaging within the Rakopi Formation}

Shown is the Pipeline (left) and Maari (right) 3D seismic reflection volumes. The representative 2D seismic lines at the bottom of the figure show the Trace Envelope (the attribute which has been chosen as an example) through each 3D volume, and intersect the Pukeko-1 and Maui-4 wells respectively. Major basement-cutting faults are represented by the coloured lines through the 3D volumes.

To produce the attribute amplitude maps displayed, the Trace Envelope values have been temporally averaged (i.e. all of the values in a vertical interval have been averaged to give a single point) within the Rakopi Formation interval (shaded areas on 2D lines), with the resultant horizons shown on the basemaps above, with a red/white/blue, which has been set for each 3D survey separately (as per the numbers on either side of the inset colour scale), to best portray the range of attribute values in each case.

This process has been used to output all subsequent attribute maps in this thesis. For map location see Figure 1.1 


\section{Analysis of Seismic Attributes}

\subsection{Introduction}

The aim of this project was to identify an attribute or combination of attributes which would enable the identification of Cretaceous coaly facies in areas removed from well penetrations. In order to do this, a quantitative method was needed to test whether what was being observed was actually representative of coaly facies.

In this chapter, RSAs extracted from the Rakopi Subdivision and other vertical seismic intervals at the Maui-4 well are analysed in order to identify attributes which are responding to the presence of coal.

\subsection{Methods}

\subsubsection{Rakopi Subdivision Rock Solid Attributes}

In Chapter 4.4, the Rakopi Formation was divided into the Rakopi Subdivision, with extracted RSAs being averaged within each of the resultant temporal intervals. This provided a visual representation of the attribute values as they are distributed throughout the Maari and Pipeline 3D seismic volumes (see Appendix B).

\subsubsection{RSA Value Distributions in Rakopi Subdivision}

In addition to visual analysis of the basemap representations of the extracted RSAs' average values, a method of statistical analysis was used to quantify and summarise their results. The averaged attribute values for each Rakopi Subdivision interval were exported as horizons (X, Y, and attribute value) into the software package Matlab, where frequency plots were analysed to observe any pattern in their distributions (Figures 6.1-6.15). These frequency distributions were also compared to ideal distributions for comparison (e.g. normal distribution, bimodal distribution, etc). The display of attribute outputs both as temporally-averaged amplitude maps, and frequency distributions based on the values observed in the amplitude maps, enabled any patterns or differences in distributions between the different sets of data to be analysed visually. The differences which were being looked for were those which placed the distributions of values from the coal-rich intervals markedly different from those from the non-coaly intervals.

Note that multi-trace attributes such as Semblance, Similarity, Variance, etc, are already a derivative of their surrounding traces (Table 5.1). These attributes are based on statistical comparisons of a given trace to its adjacent traces (Chopra \& Marfurt 2007) and as such any further averaging or analysis of the distribution of attribute values over a larger area will be subject to a "double smoothing" effect, which needs to be considered when viewing their results. 
Of the 34 RSAs extracted, 15 showed significant variation between the coaly versus non-coaly seismic packages. These 15 can be grouped into 4 general attribute categories which are discussed below, with reference to Figures 6.1-6.15. All of the remaining (discarded) RSA frequency distribution graphs are included in Appendix C. The division into these categories was done by visual analysis of the difference between the frequency distributions of RSA values of the coaly- versus noncoaly intervals.

\subsubsection{Category 1: Coal Percentage Order}

These attributes have frequency distributions which appear to be influenced by the increased presence of coals within each interval. The value distributions for each interval are separated, and are in order of most- to least-coaly. These attributes are likely to be scaling with the percentage of coal by volume present, rather than responding to the absolute presence or absence of a certain percentage of coal (see Category 2).

The Coal Percentage Order category includes: Trace Envelope, Wavelet Envelope, Time Derivative of Wavelet Envelope, and Q by Frequency Shift (Figures 6.1-6.4).

\subsubsection{Category 2: Coal Separate}

These attributes display the 2 least-coaly intervals (Upper Coals and Mid Silts) with very similar frequency distributions to each other, and the (most-coaly) Lower Coals interval having a different distribution. Given that the Lower Coals contain significantly greater total percentage of coals than the Upper Coals (Figure 4.3), this indicates that these attributes are likely to be responding to a threshold percentage thickness of coals, below which they are not recognised, in comparison to responding linearly to the percentage of coals as in Category 1.

Note that the Category 2 attribute values which relate to coals are the lowest values, whereas the coalindicating attribute values for Category 1 are the highest values.

The Coal Separate category includes: Relative Acoustic Impedance, Band Limited Impedance, Imaginary Part of Complex Trace, Spectral Bandwidth, Spectral Balance, and Time Derivative of Envelope (Figures 6.5-6.10).

\subsubsection{Category 3: Burial Depth Order}

These attributes show a range of values which varies between each sampled seismic interval; however, the order of values correspond to the order of burial depths of the respective formations (i.e. the most shallow interval plots at one end of the frequency distribution, and the least shallow interval plots at the opposite end). Given this fact, it is possible that these attributes are responding to increased compaction or a further effect of burial depth, rather than the presence of coals or another lithological factor. 
If these RSA attributes are indeed responding to burial depth, they could be a useful porosity indicator, due to the fact that in general, porosity is inversely correlated with burial depth due to compaction (Allen \& Allen 2013).

The Burial Depth category includes: Wavelet Dominant Frequency, Q by Spectral Ratio, Maximum Subband Envelope Frequency, and Mean Frequency of Spectra (Figures 6.11-6.14).

\subsubsection{Category 4: Not Meaningful}

These attributes either show no variation in the frequency distributions between the seismic packages, or show variations, but in a way which runs counter to that which is expected.

Semblance (Figure 6.12) belongs in this category. There were other RSA attribute outputs which displayed strange or noteworthy distributions, but they were deemed not to be significant, due to no observable and significant variation between the coaly and non-coaly intervals sampled (see Appendix C). 


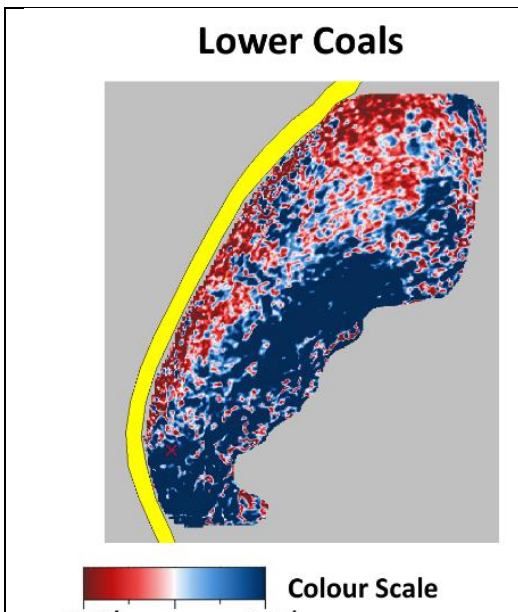

Mid Silts

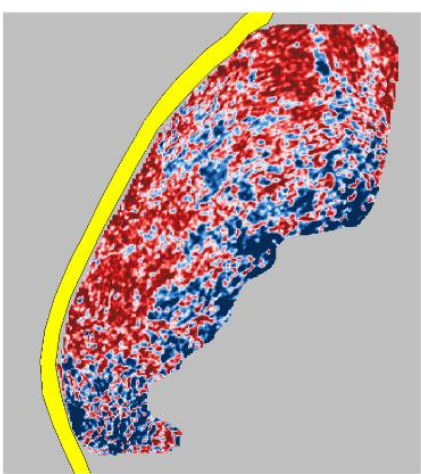

$8 \times 10^{4}$

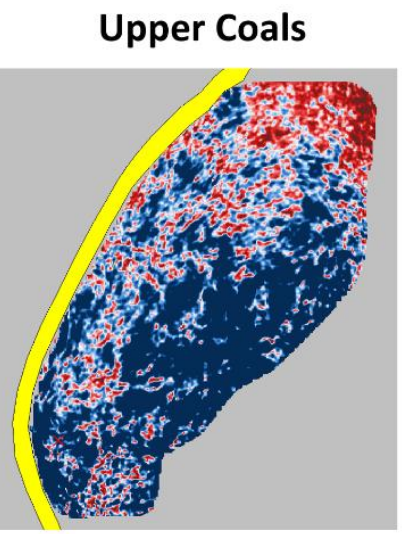

Trace Envelope
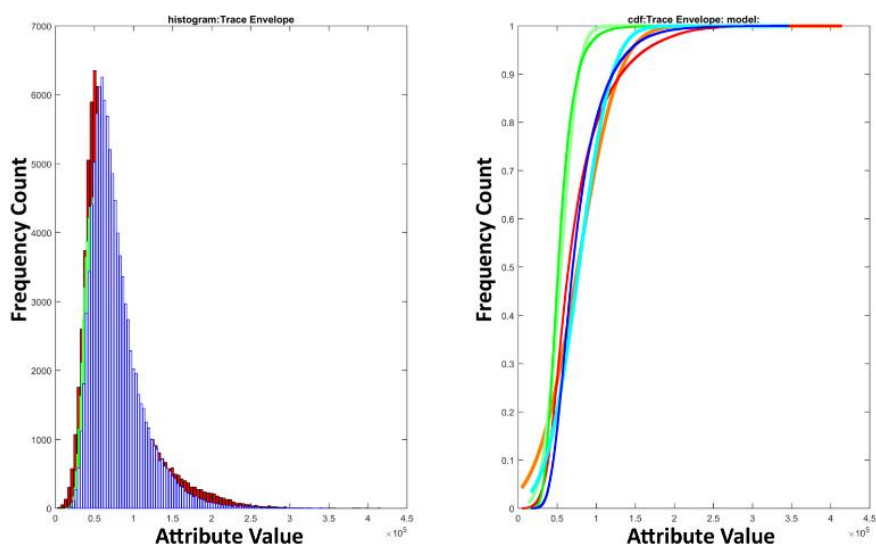

Log Normal Distribution

Figure 6.1 Category 1 Rock Solid Attribute Temporal Averages and Frequency Distributions - Trace Envelope

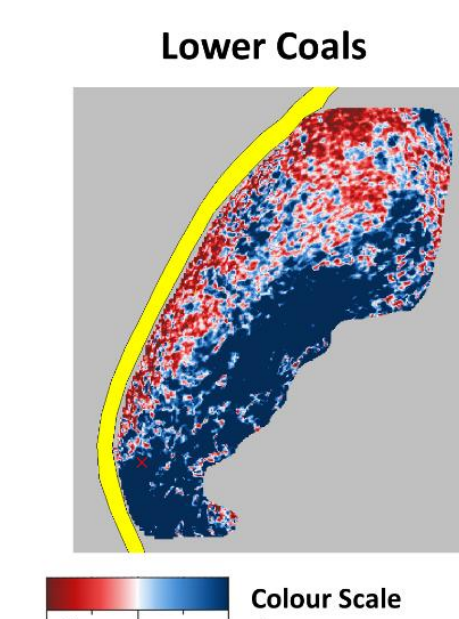

Mid Silts

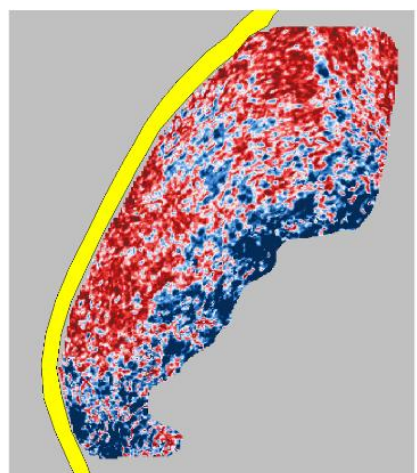

$4 \times 10^{4}$ $1.2 \times 10^{5}$

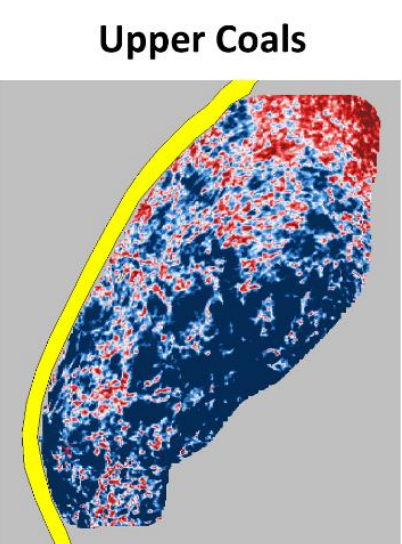

Wavelet Envelope

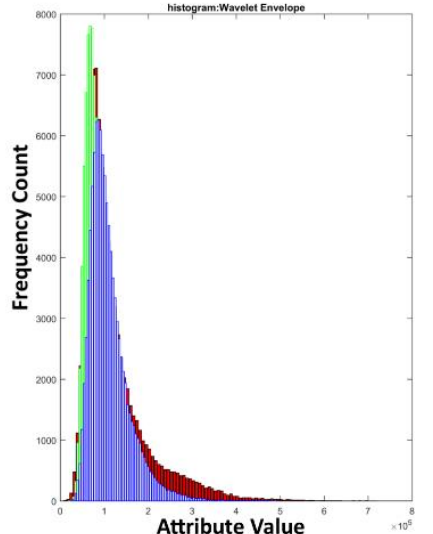

Log Normal Distribution

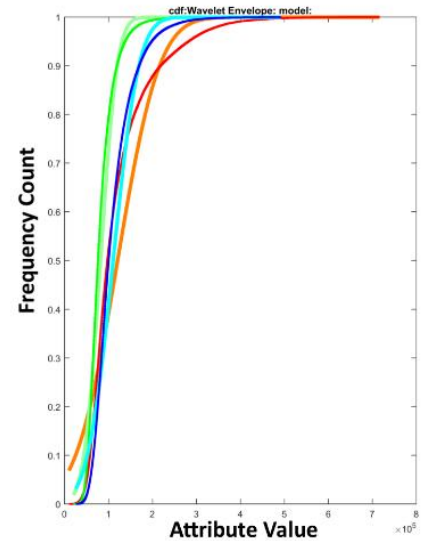

Attribute Value

Figure 6.2 Category 1 Rock Solid Attribute Temporal Averages and Frequency Distributions - Wavelet Envelope

Shown to the left are the temporally-averaged values of this attribute within the 3 vertical intervals of the Rakopi Subdivision (Fig 6.16) displayed as amplitude maps (see Section 4.5.3 and

Figure 4.5). The graphs show the distributions of these values (left graph), and their fit to model distributions (right graph) $($ Lower Coals: red $=$ actual values; orange $=$ model distrbution. Mid Silts: darker green $=$ actual values, lighter green $=$ model distribution. Upper Coals: dark blue $=$ actual values, light blue = model distribution). See Figure 6.16 for Maui- 4 well location. 


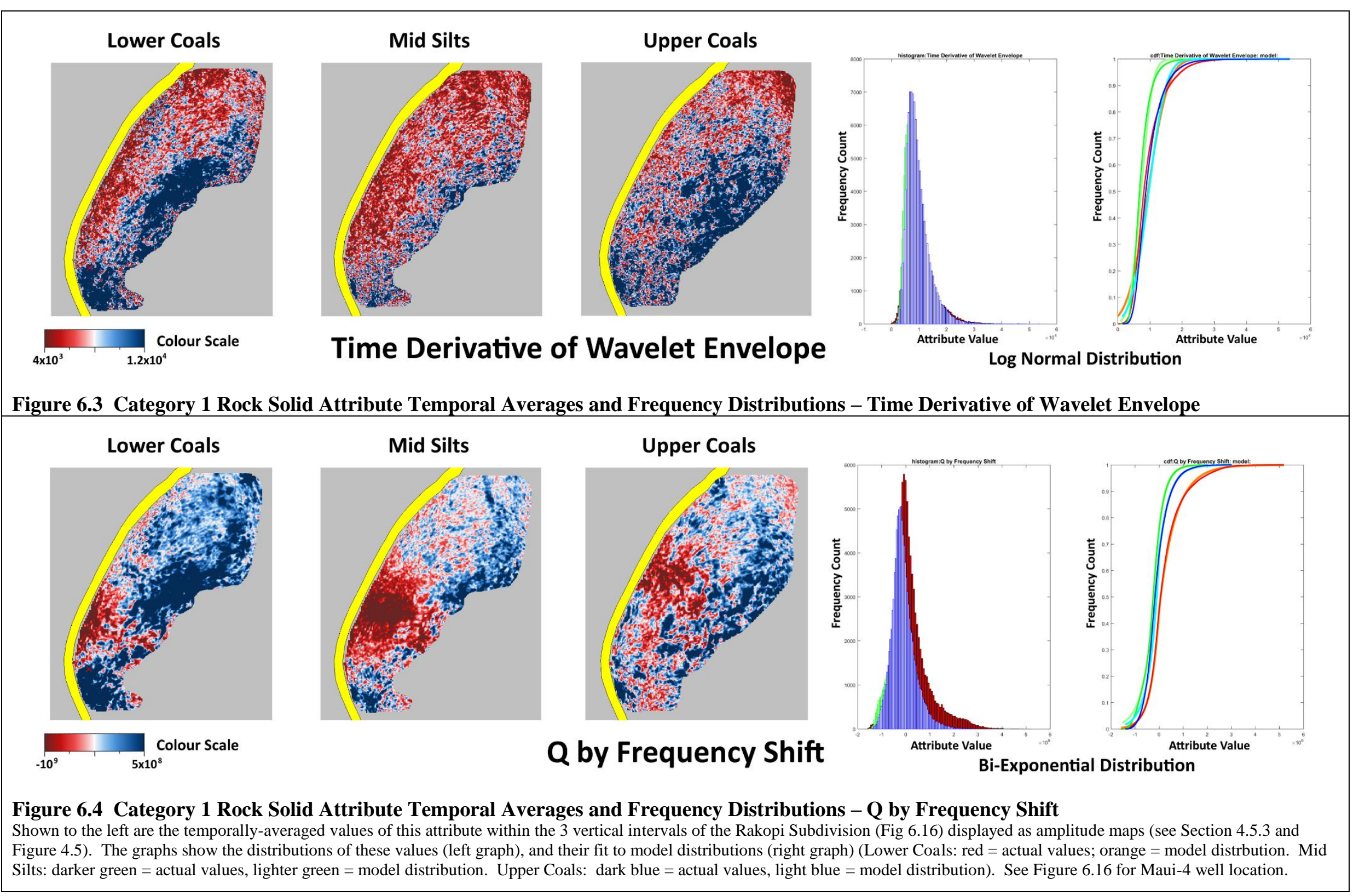




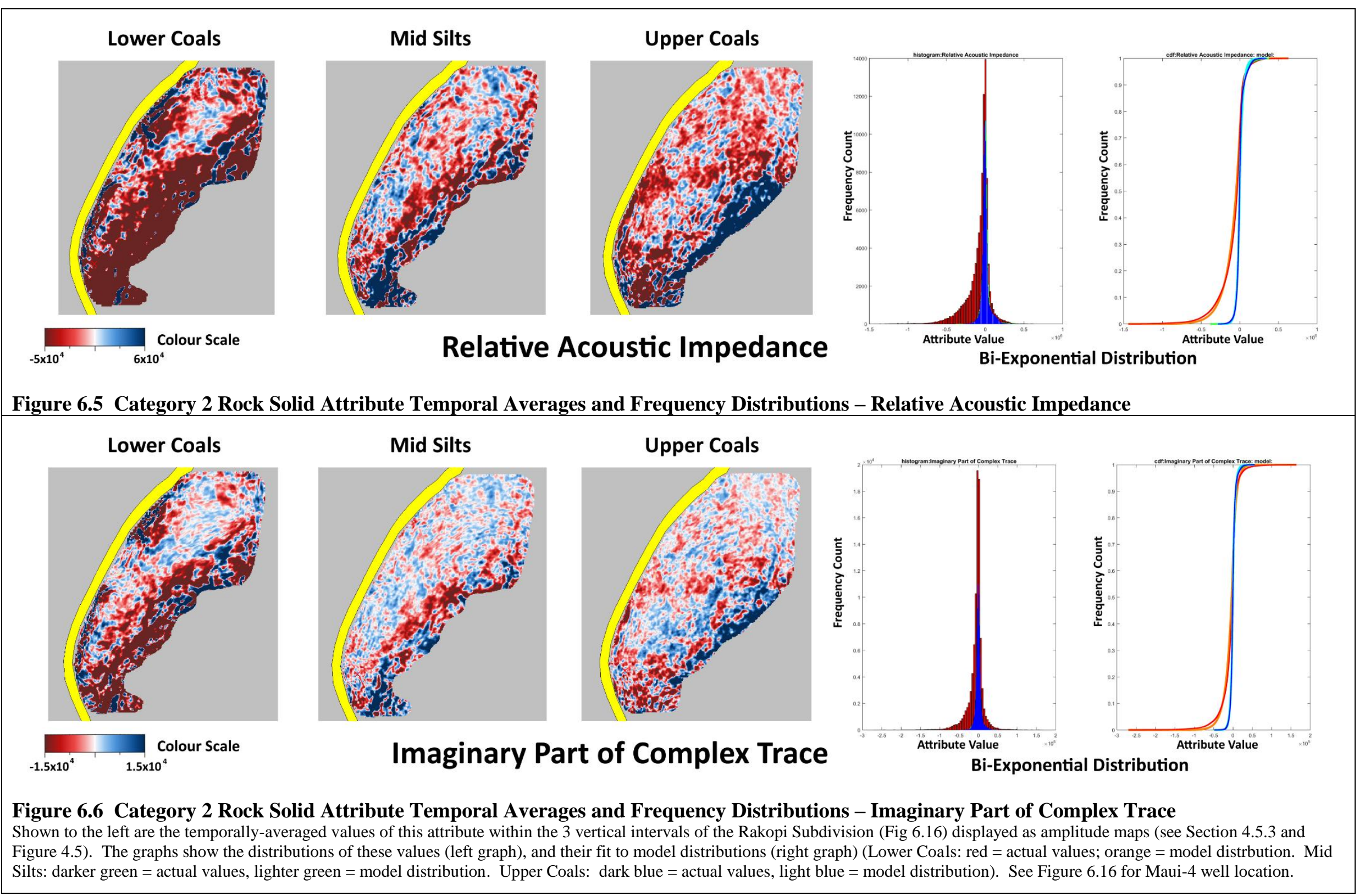




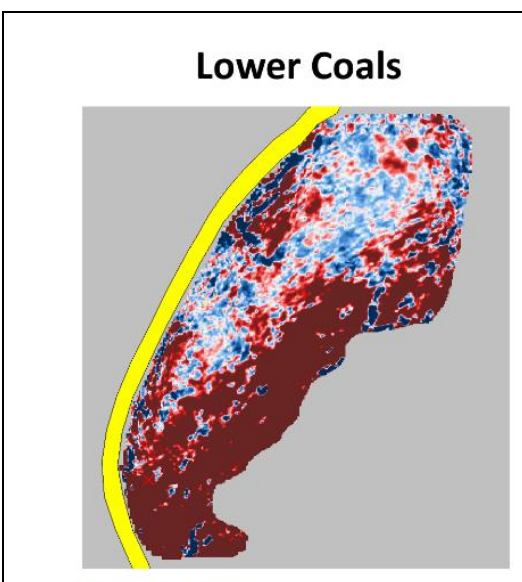

$-2 \times 10^{4}$

Colour Scale $1.6 \times 10^{4}$

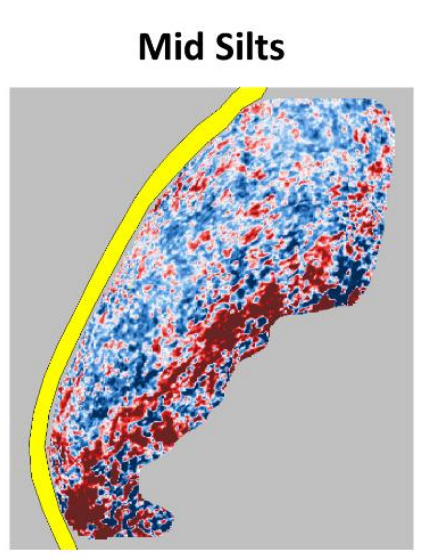

Band Limited Impedance
Upper Coals
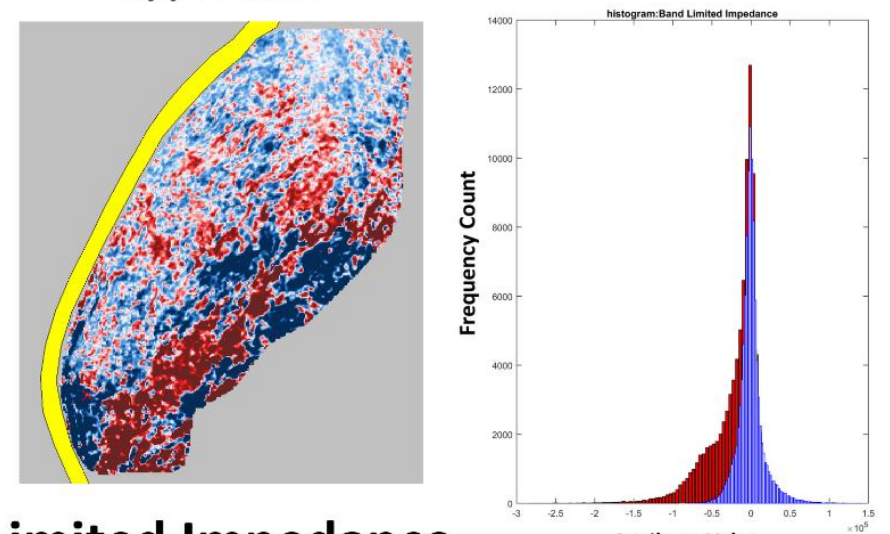

Attribute Value

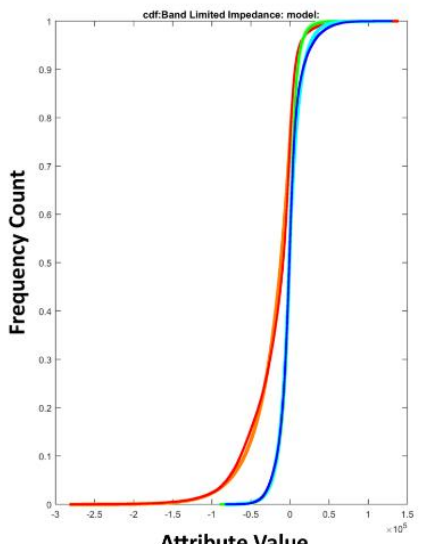

Attribute Valu

Bi-Exponential Distribution

Figure 6.7 Category 2 Rock Solid Attribute Temporal Averages and Frequency Distributions - Band Limited Relative Acoustic Impedance

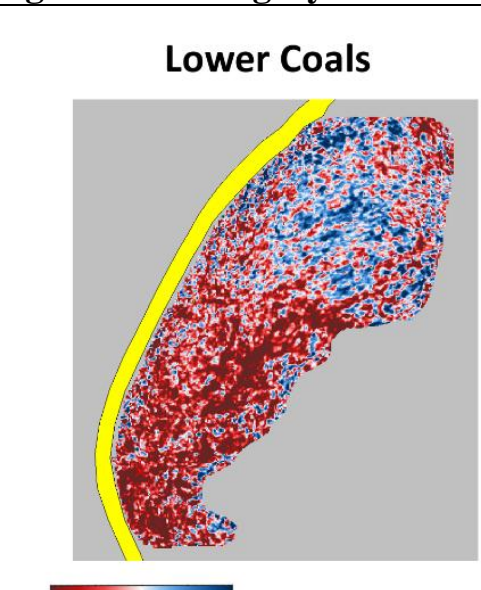

22

32

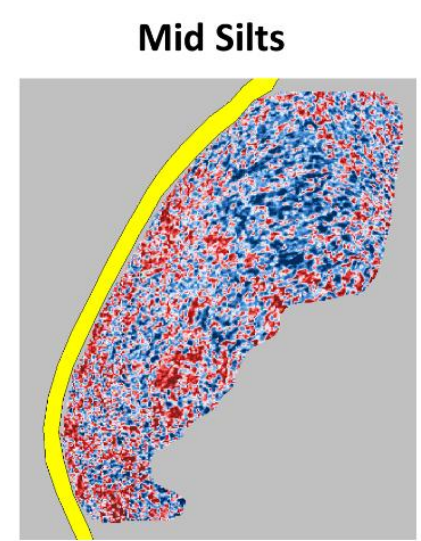

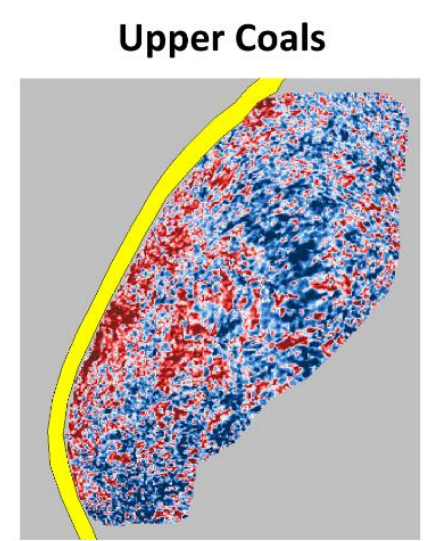

Spectral Bandwidth
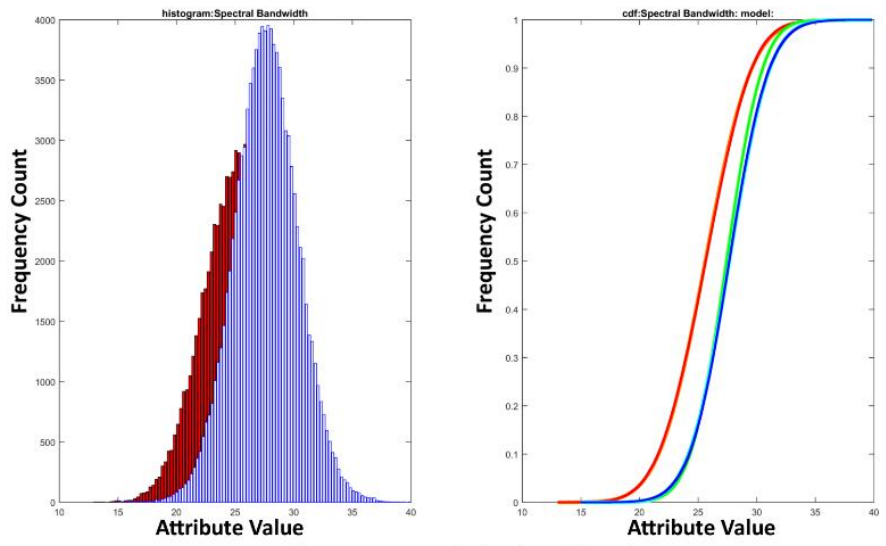

Bi-Exponential Distribution

Figure 6.8 Category 2 Rock Solid Attribute Temporal Averages and Frequency Distributions - Spectral Balance

Shown to the left are the temporally-averaged values of this attribute within the 3 vertical intervals of the Rakopi Subdivision (Fig 6.16) displayed as amplitude maps (see Section 4.5.3 and

Figure 4.5). The graphs show the distributions of these values (left graph), and their fit to model distributions (right graph) $($ Lower Coals: red = actual values; orange $=$ model distrbution. Mid Silts: darker green $=$ actual values, lighter green $=$ model distribution. Upper Coals: dark blue = actual values, light blue = model distribution). See Figure 6.16 for Maui-4 well location. 


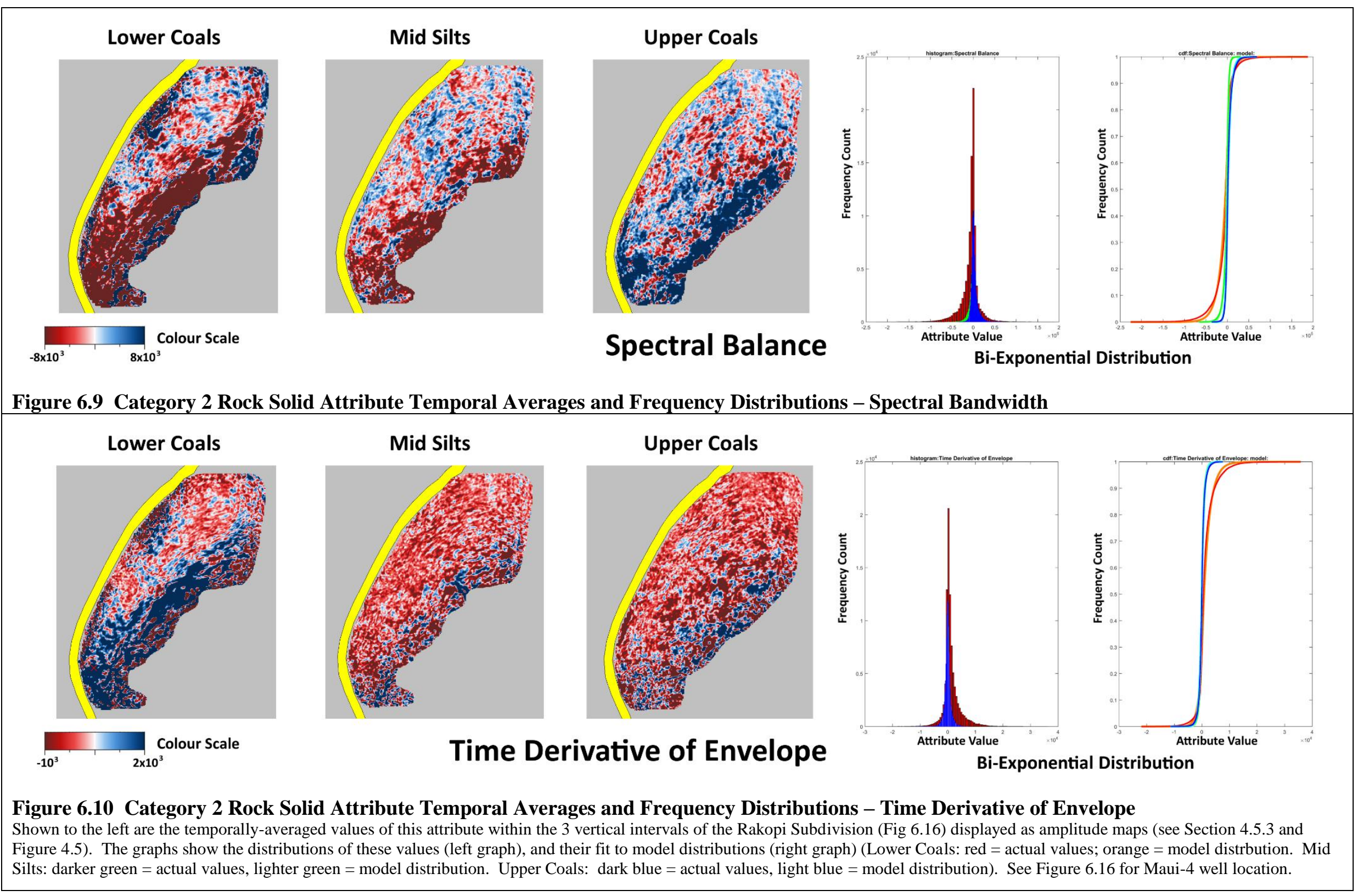




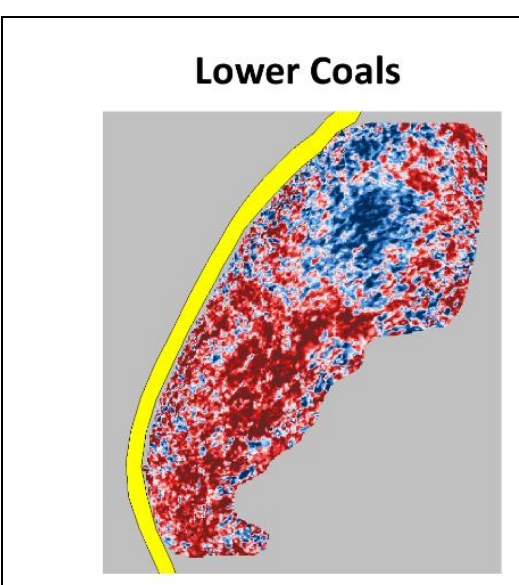

18
Colour Scale
Mid Silts

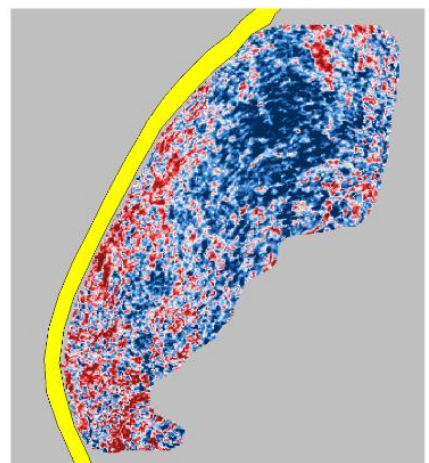

Wavelet Dominant Frequency

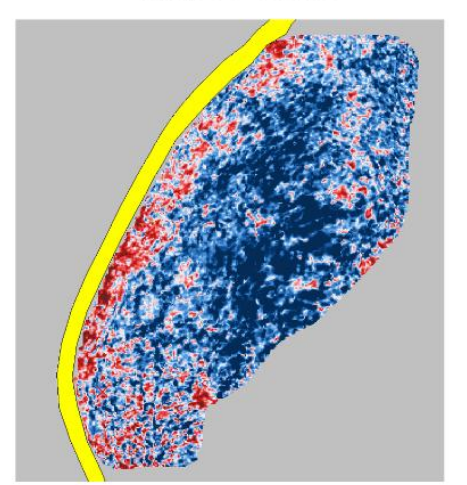

Upper Coals

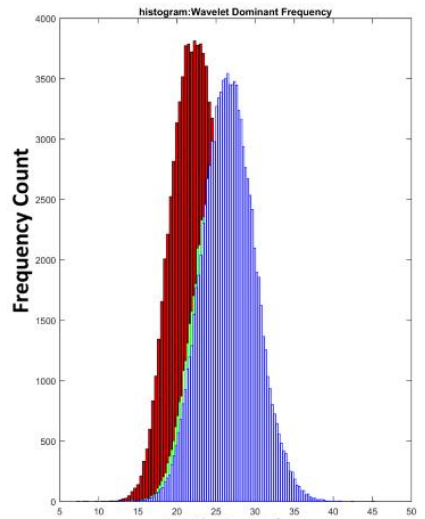

Attribute Value

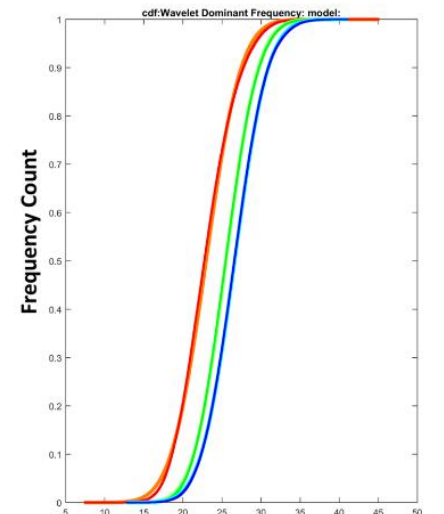

Attribute Value

Log Normal Distribution

Figure 6.11 Category 3 Rock Solid Attribute Temporal Averages and Frequency Distributions - Wavelet Dominant Frequency

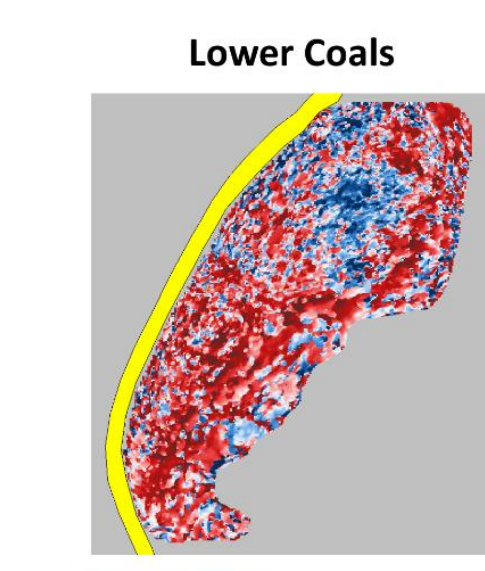

12

36

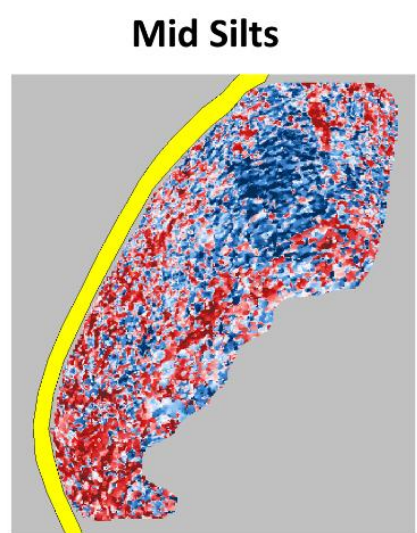

\section{Maximum Subband Envelope Frequency}

Upper Coals
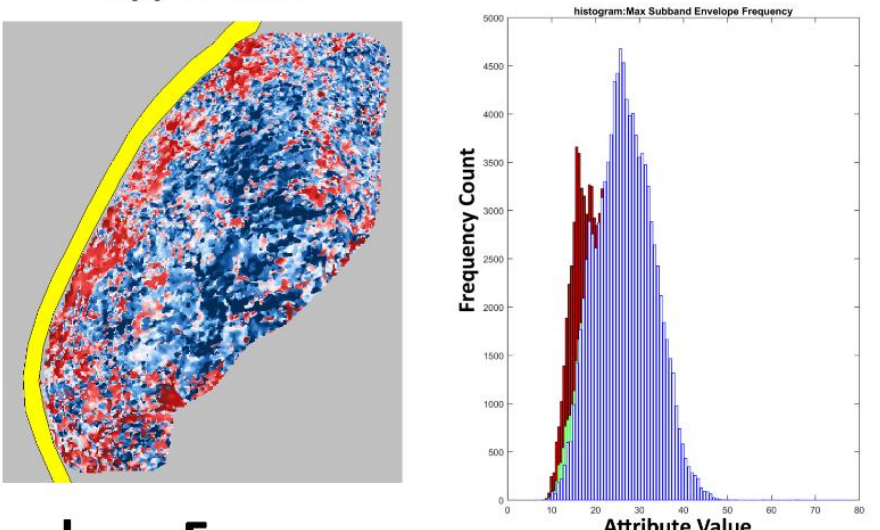

Log Normal Distribution

Figure 6.12 Category 3 Rock Solid Attribute Temporal Averages and Frequency Distributions - Maximum Subband Envelope Frequency

Shown to the left are the temporally-averaged values of this attribute within the 3 vertical intervals of the Rakopi Subdivision (Fig 6.16) displayed as amplitude maps (see Section 4.5.3 and

Figure 4.5). The graphs show the distributions of these values (left graph), and their fit to model distributions (right graph) (Lower Coals: red = actual values; orange = model distrbution. Mid Silts: darker green $=$ actual values, lighter green $=$ model distribution. Upper Coals: dark blue $=$ actual values, light blue $=$ model distribution). See Figure 6.16 for Maui-4 well location. 


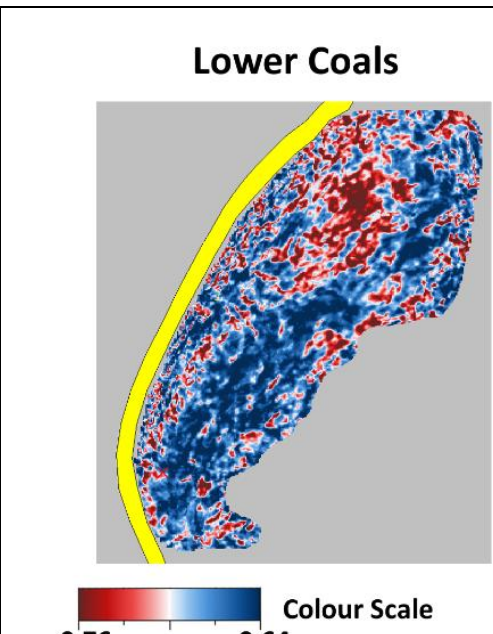

Mid Silts

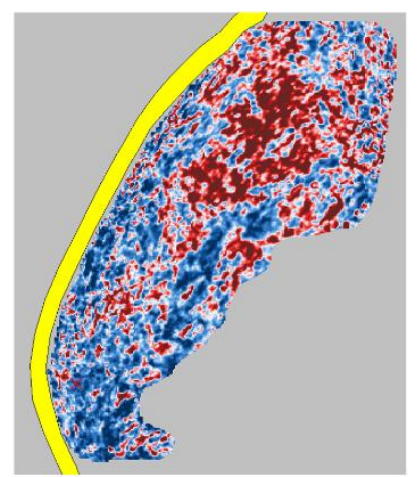

$-0.76$ 0.64

Figure 6.13 Category 3 Rock Solid Attribute Temporal Averages and Frequency Distributions - $Q$ by Spectral Ratio

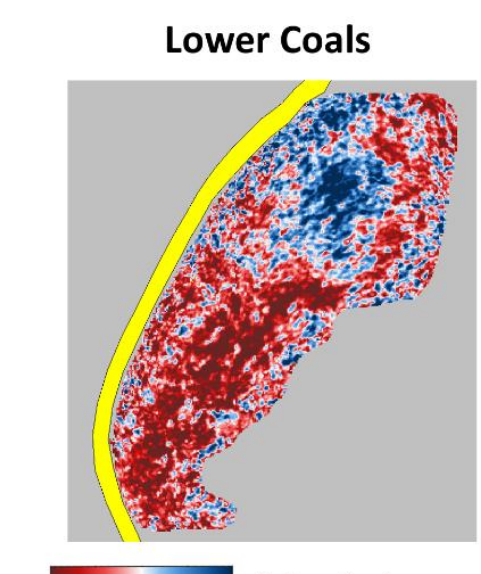

20

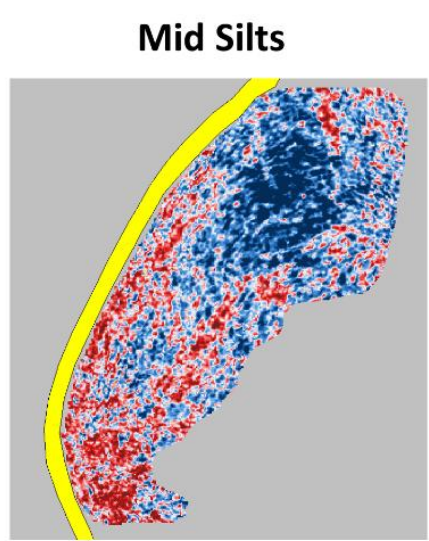

Mean Frequency of Spectra
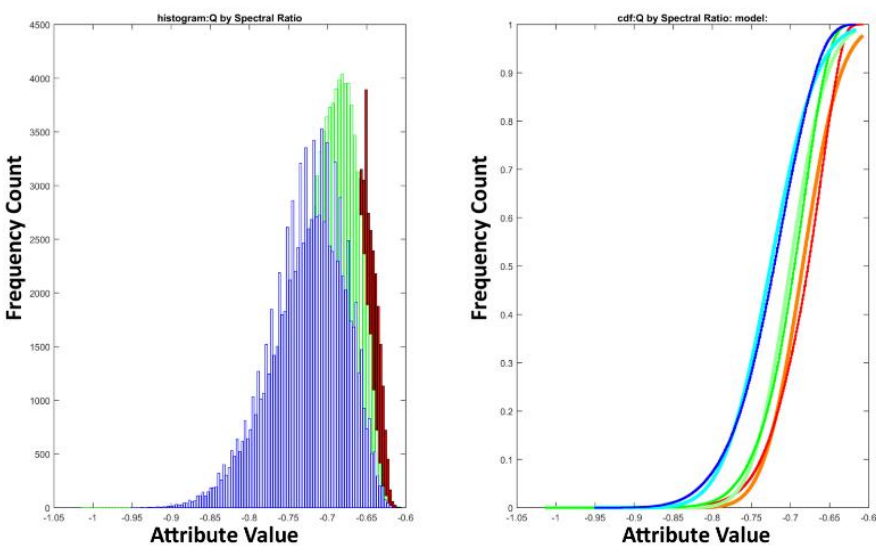

Bi-Exponential Distribution
$Q$ by Spectral Ratio
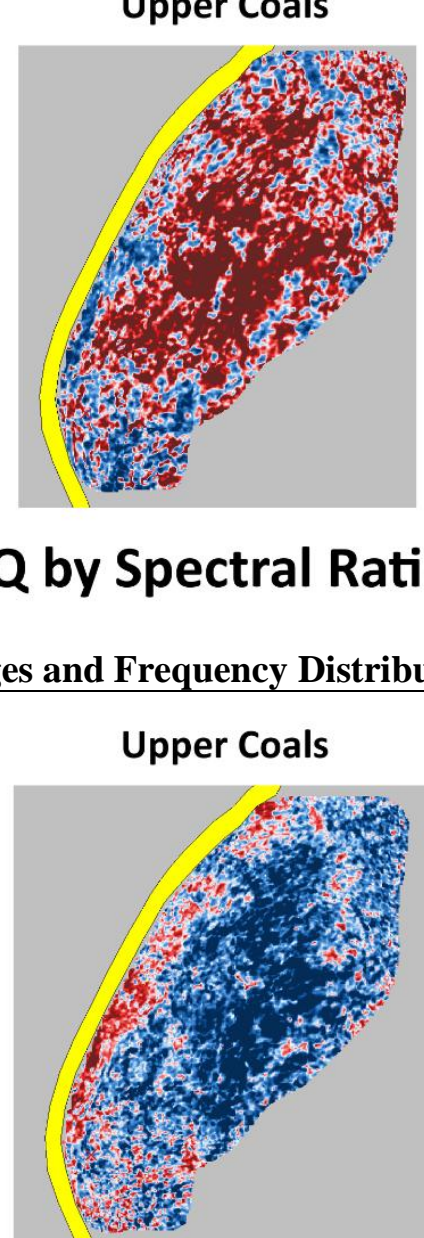

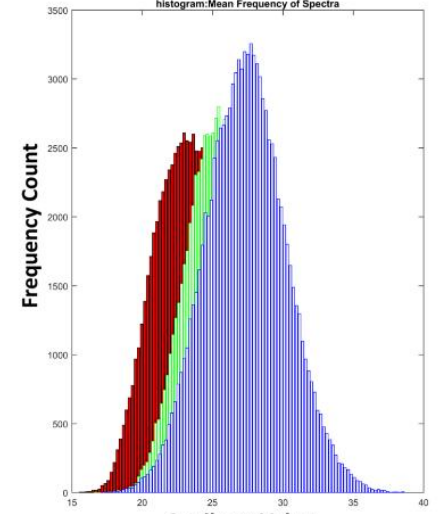

Attribute Value

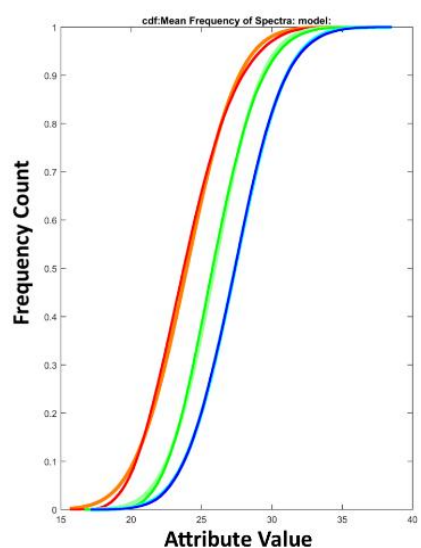

Attribute Value

Log Normal Distribution

Figure 6.14 Category 3 Rock Solid Attribute Temporal Averages and Frequency Distributions - Mean Frequency of Spectra

Shown to the left are the temporally-averaged values of this attribute within the 3 vertical intervals of the Rakopi Subdivision (Fig 6.16) displayed as amplitude maps (see Section 4.5.3 and

Figure 4.5). The graphs show the distributions of these values (left graph), and their fit to model distributions (right graph) (Lower Coals: red = actual values; orange = model distrbution. Mid Silts: darker green $=$ actual values, lighter green $=$ model distribution. Upper Coals: dark blue $=$ actual values, light blue = model distribution). See Figure 6.16 for Maui-4 well location. 


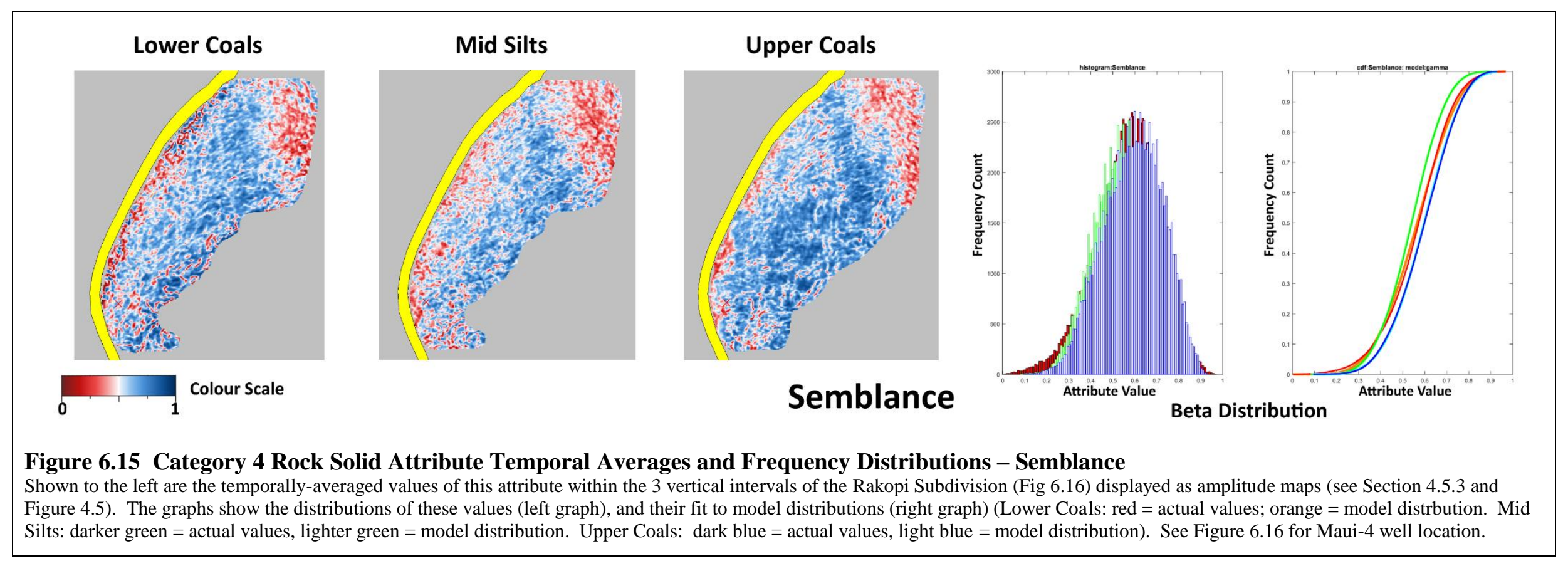




\subsection{Control Tests}

To increase confidence in the likelihood that the 15 chosen RSAs are responding to the presence of coal, as opposed to other factors, 2 types of control tests were carried out based on

a) Scalability of results; and

b) Repeatability of results in another coal-rich interval from the seismic data.

These tests were carried out for the entire suite of RSAs rather than just the selected 15, for reasons of due diligence, in case there were significant differences between the coaly and non-coaly intervals which were not apparent in the analysis thus far.

\subsubsection{Scale Tests}

To test whether the results were consistent at different spatial scales - which would give indications as to the lateral continuity of the formations in question - the RSA extraction and analysis process was repeated in 2 concentrically smaller areas around Maui-4 (Figure 6.16). These covered approximately the following total areas:

- Scale Test $1-2 \mathrm{~km}^{2}$

- $\quad$ Scale Test $2-13.5 \mathrm{~km}^{2}$

For comparison, the Rakopi Subdivision was mapped over an area of approximately $32 \mathrm{~km}^{2}$, and the total area which the Rakopi Formation is interpreted to extend within the Maari 3D survey is approximately $320 \mathrm{~km}^{2}$.

The result of the scale tests was that most of the chosen 15 RSAs were scalable, i.e. the results were the same when the analysis was repeated over areas of differing size (see Section 6.3.3), with a few exceptions. The results of these scale tests increase the confidence in the results of the attribute analysis carried out thus far, due to the fact that the only place where the lithology is known with certainty is at the Maui-4 well. The further from this the interpreted Rakopi Subdivision goes, the less confidence there can be in the subdivision's lateral continuity. As such, Scale Test 2 is the most valuable set of data, as it was conducted in the smallest area around Maui-4 (Figure 6.2) and therefore provides the closest example of the attributes' response to the known lithology.

\subsubsection{Mangahewa Control Group}

The second control test was conducted to explore the ability of the chosen RSAs to identify coaly facies in other coal-rich intervals. This was done by following the process of extracting the same attributes from another known coaly interval penetrated by the Maui-4 well - the Eocene Mangahewa Formation (see Section 4.5.5). Given that this formation is coal-rich, and is overlain by siltstone 


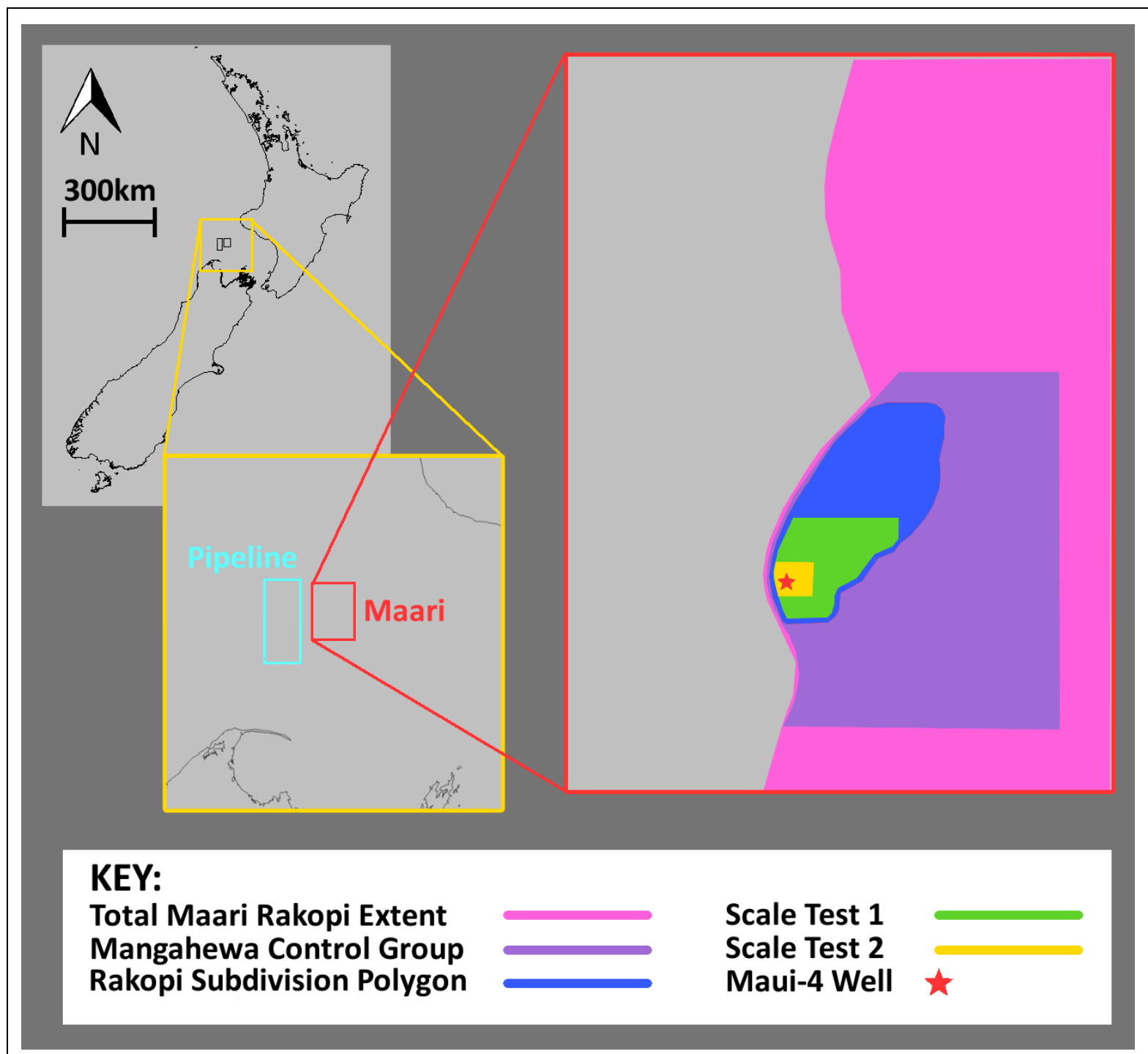

\section{Figure 6.16 Map of Control Test Extents within the Maari 3D Volume}

The Rakopi Subdivision Polygon is the total area in which the Rakopi Subdivision (Lower Coals, Mid Silts, Upper Coals) were interpreted. See Section 5.2 for details and Figure 1.1 for map coordinates.

(Figure 6.17), the comparison between the coals and these silts has been contrasted by extracting the full suite of 34 RSAs from these seismic intervals.

To do this, all of the RSAs, within a selected polygon with an area of approximately $135 \mathrm{~km}^{2}$ within the Maari 3D (Figure 6.1), were averaged in 2 time intervals (Figure 6.3), as follows:

i) Between the top of the Farewell Formation and the top of the Mangahewa Formation

ii) Between the top of the Mangahewa Formation and a horizon generated 150ms above it (the Manganui Horizon. See Section 5.2 \& Figure 6.17C).

The averaged RSA values were then exported as horizons and entered into Matlab for statistical analysis, with the results being plotted next to the existing averaged attribute distributions in the Rakopi Subdivision for comparison (Figures 6.18.6.32). 


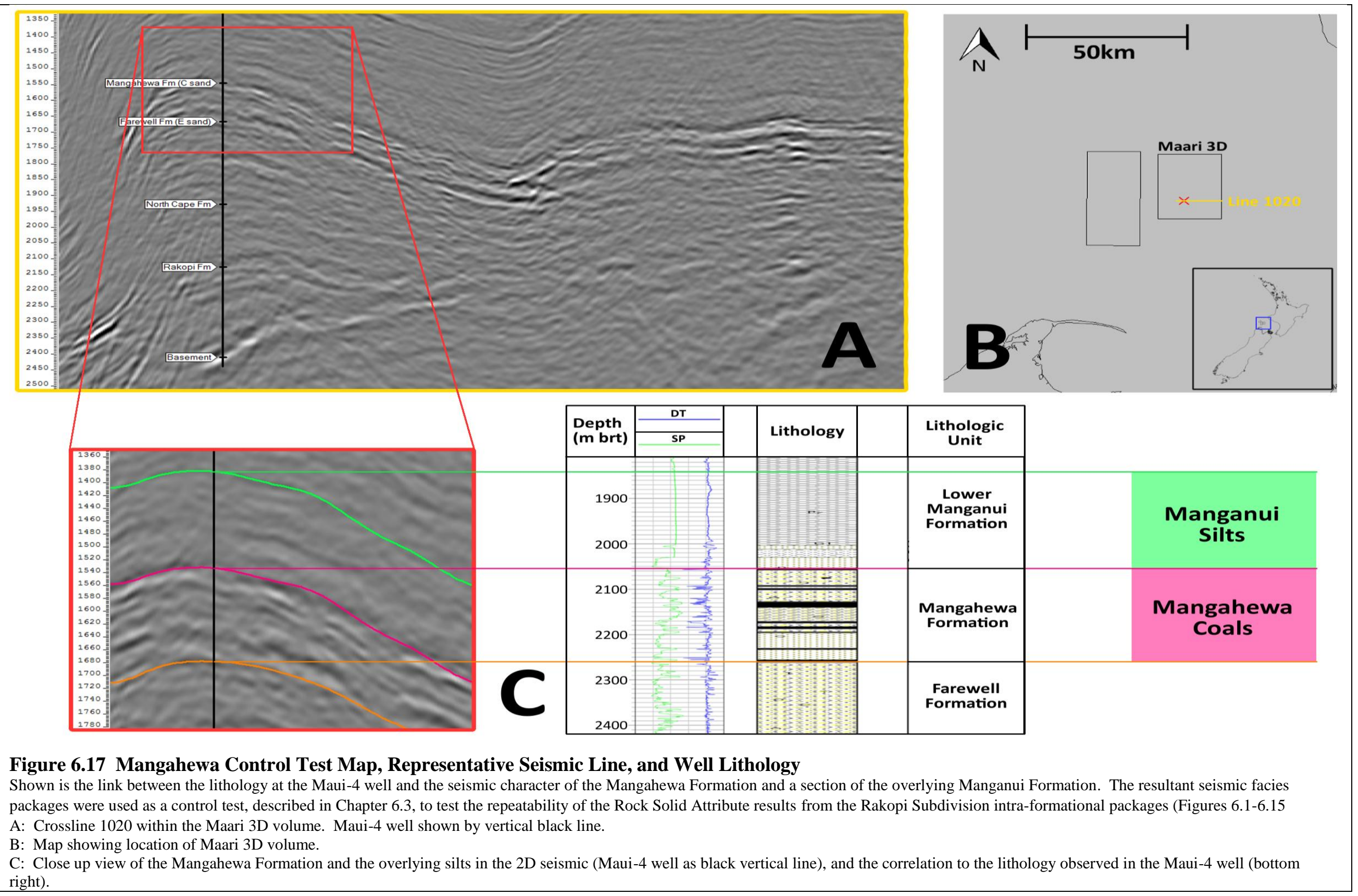

64 | P a g e 


\subsubsection{Control Test Results}

Six of the RSAs extracted from the Mangahewa interval and the Rakopi Subdivision have been identified which could be predicting coaly facies, based on both scalability and repeatability of the results in the control tests.

The following details which of the RSAs remained consistent in the Control Tests, from each of the 4 categories identified earlier in this chapter.

\subsubsection{Category 1: Coal Percentage Order}

Of the 15 RSA attributes which show variation, the 4 attributes in Type 1 (Trace Envelope, Wavelet Envelope, Time Derivative of Wavelet Envelope, and Q by Frequency Shift) all remained consistent over both different scales, as well as the Mangahewa Control Group. They appear to be responding to the presence of coals, with higher values corresponding to greater inferred coal content in all intervals tested (Figures 6.18-6.21)

\subsubsection{Category 2: Coal Separate}

Of the 6 RSAs in Category 2 (Relative Acoustic Impedance, Band Limited Impedance, Time Derivative of Envelope, Imaginary Part of Complex Trace, Spectral Bandwidth, and Spectral Balance), Spectral Bandwidth and Spectral Balance were inconsistent after the control tests. Both RSAs showed difference in the Scale Tests (Figures 6.25 \& 6.26), showing distributions which put them in Category 3 - Burial Depth Order. Additionally, Spectral Balance is inconsistent where applied to the Mangahewa Control Group, showing no significant difference between the coaly and non-coaly intervals. As such, these 2 RSAs have been removed from the potential coal-predicting attributes.

Of the remaining 4 RSAs in Category 2, Relative Acoustic Impedance and Imaginary Part of Complex Trace showed significant variation between the coaly and non-coaly intervals of the Mangahewa Control Group, as well as remaining consistent with scale (Figures $6.22 \& 6.23$ ), and thus are likely the more consistent coal predictors. Time Derivative of Envelope and Band Limited Impedance, while consistent over the Scale Tests, did not show variation between the coaly and non-coaly intervals of the Mangahewa Control Group (Figures 6.24 \& 6.27), and were therefore discarded from the suite of applicable RSA attributes.

\subsubsection{Category 3: Burial Depth Order}

All 4 RSAs identified in Category 3 (Maximum Subband Envelope Frequency, Wavelet Dominant Frequency, Q by Spectral Ratio, Mean Frequency of Spectra) produced frequency relative frequency distributions between the coaly and non-coaly seismic intervals which remained reasonably consistent with scale (Figures 6.28-6.31). However, since the 
variations in distributions are likely explained by the difference in burial depth, they have been omitted from the list of coal-predicting attributes.

\subsubsection{Category 4 - Not Meaningful}

Semblance is the sole Category 4 attribute worth noting, and only so because it displays the opposite of what reasonable intuition may suggest, in that coaly facies are generally not highly laterally continuous, due to their depositional environments (Sherwood et al. 1992). Given that Semblance is a measure of similarity of adjacent traces, it could be expected that the Semblance values would be higher for non-coaly intervals, but in fact the opposite is displayed in the Rakopi Subdivision and in Scale Tests 1 and 2 (Figure 6.32A-6.32C). However, the Mangahewa Control Group produced Semblance values which were significantly higher for the coaly interval than for the non-coaly, which is what is expected in this case (Figure 6.32D).

In addition to these inconsistencies, the Upper Coals display higher overall values of Semblance than the Lower Coals, despite containing less than 50\% of the thickness of coal by volume at the Maui-4 well. As such, in this case, Semblance cannot be used as a predictor of coaly facies. However, it is possible that these results are due to the small sample size.

The final suite of RSAs which are potential coal-predictors is as follows: Trace Envelope; Wavelet Envelope; Time Derivative of Wavelet Envelope; Q by Frequency Shift; Relative Acoustic Impedance, and Imaginary Part of Complex Trace. 


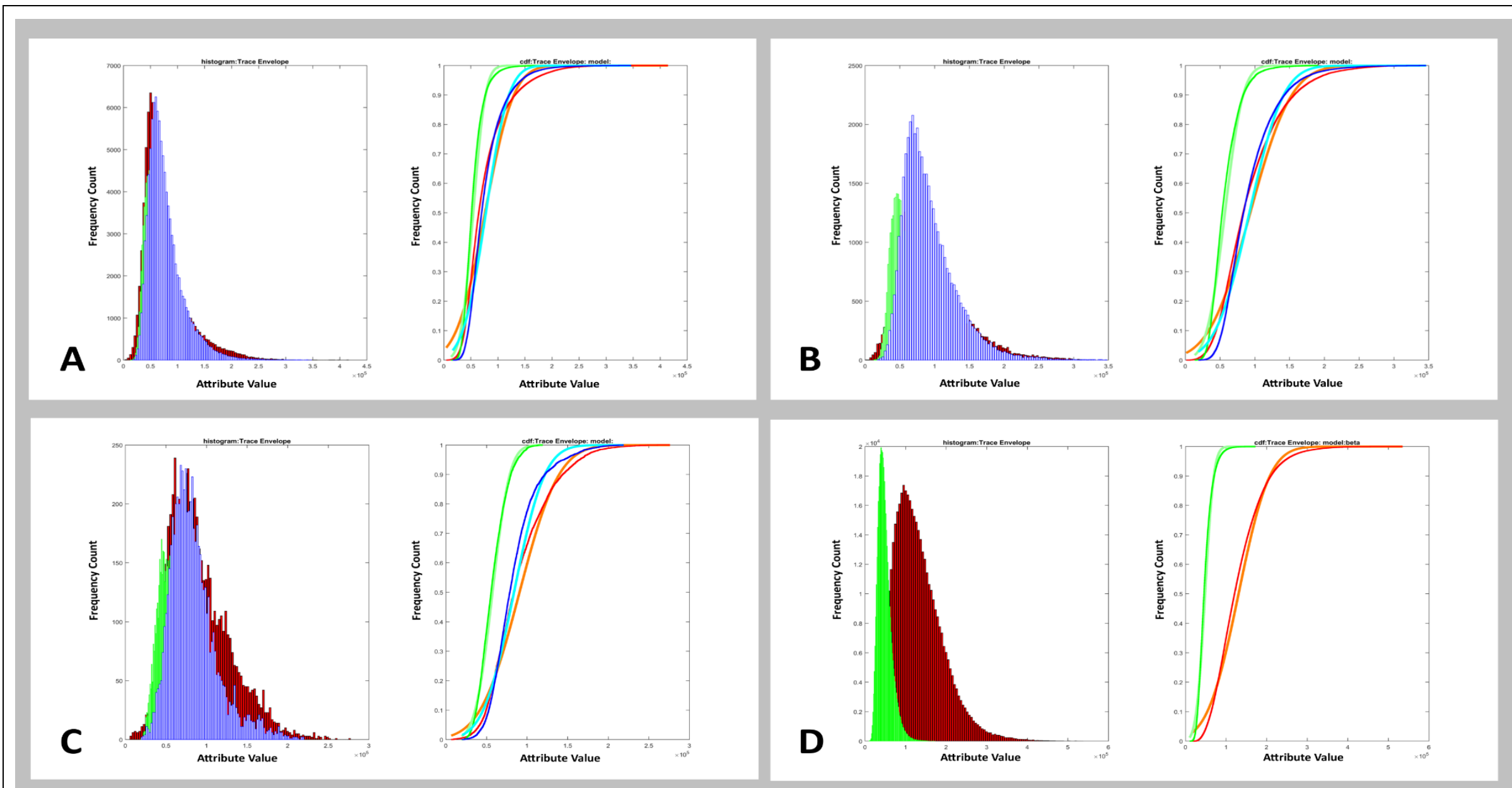

\section{Trace Envelope - Log Normal Distribution}

Figure 6.18 Category 1 RSA Frequency Distributions and Model Distribution Fits - Trace Envelope

Shown in each section A-D are the frequency counts of the attribute values in each respective seismic interval (left graph), and the fit to a model distribution (right graph). Data Set A - Total Rakopi Subdivision (see Section 4.5.3 and Figures 4.4 and 6.16); Data Set B - Scale Test 1; Data Set C - Scale Test 2 (see Section 6.3.1 and Figure 6.16), and Data Set D - Mangahewa

Control Group (see Section 6.3.2 and Figure 6.16). (Lower Coals (A-C)/Mangahewa Coals (D): red = actual values; orange = model distrbution. Mid Silts (A-C)/Manganui Silts (D): darker green $=$ actual values, lighter green $=$ model distribution. Upper Coals: dark blue $=$ actual values, light blue $=$ model distribution $)$. 


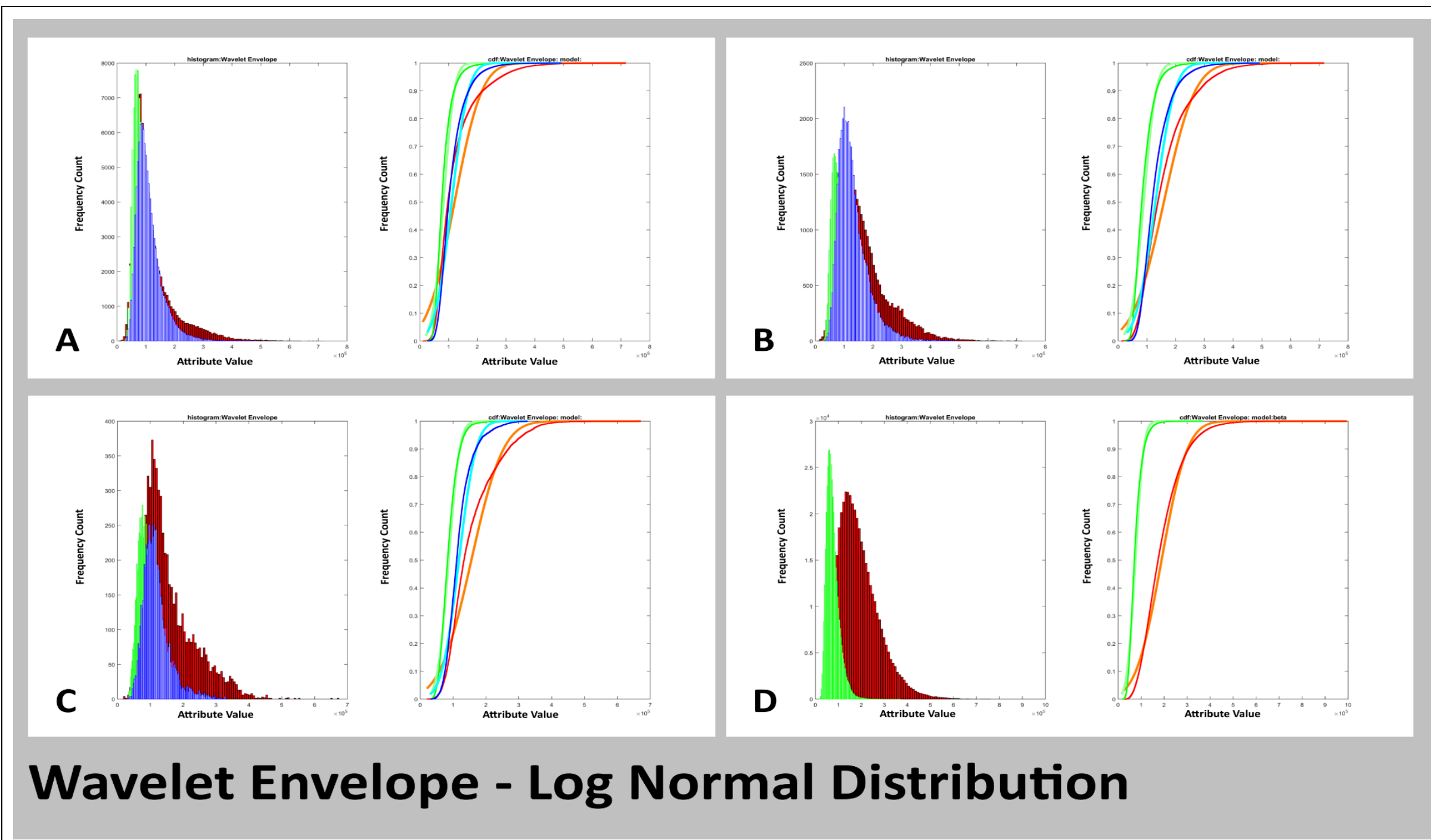

Figure 6.19 Category 1 RSA Frequency Distributions and Model Distribution Fits - Wavelet Envelope

Shown in each section A-D are the frequency counts of the attribute values in each respective seismic interval (left graph), and the fit to a model distribution (right graph). Data Set A - Total Rakopi Subdivision (see Section 4.5.3 and Figures 4.4 and 6.16); Data Set B - Scale Test 1; Data Set C - Scale Test 2 (see Section 6.3.1 and Figure 6.16), and Data Set D - Mangahewa

Control Group (see Section 6.3.2 and Figure 6.16). (Lower Coals (A-C)/Mangahewa Coals (D): red = actual values; orange = model distrbution. Mid Silts (A-C)/Manganui Silts (D): darker green $=$ actual values, lighter green $=$ model distribution. Upper Coals: dark blue $=$ actual values, light blue $=$ model distribution $)$. 


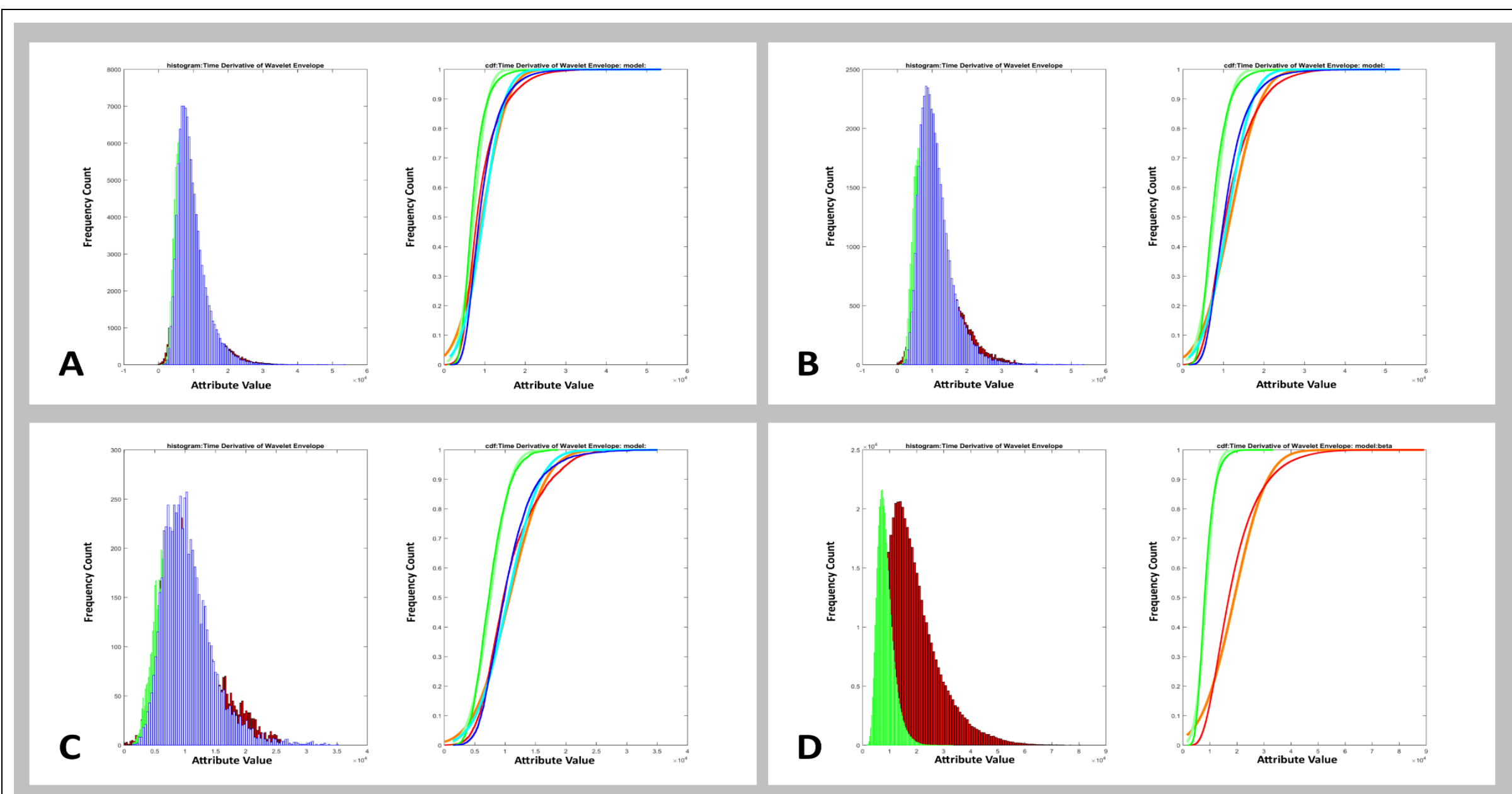

\section{Time Derivative of Wavelet Envelope - Log Normal Distribution}

Figure 6.20 Category 1 RSA Frequency Distributions and Model Distribution Fits - Time Derivative of Wavelet Envelope

Shown in each section A-D are the frequency counts of the attribute values in each respective seismic interval (left graph), and the fit to a model distribution (right graph). Data Set A - Total

Rakopi Subdivision (see Section 4.5.3 and Figures 4.4 and 6.16); Data Set B - Scale Test 1; Data Set C - Scale Test 2 (see Section 6.3.1 and Figure 6.16), and Data Set D - Mangahewa

Control Group (see Section 6.3.2 and Figure 6.16). (Lower Coals (A-C)/Mangahewa Coals (D): red = actual values; orange = model distrbution. Mid Silts (A-C)/Manganui Silts (D): darker green $=$ actual values, lighter green $=$ model distribution. Upper Coals: dark blue $=$ actual values, light blue $=$ model distribution $)$. 


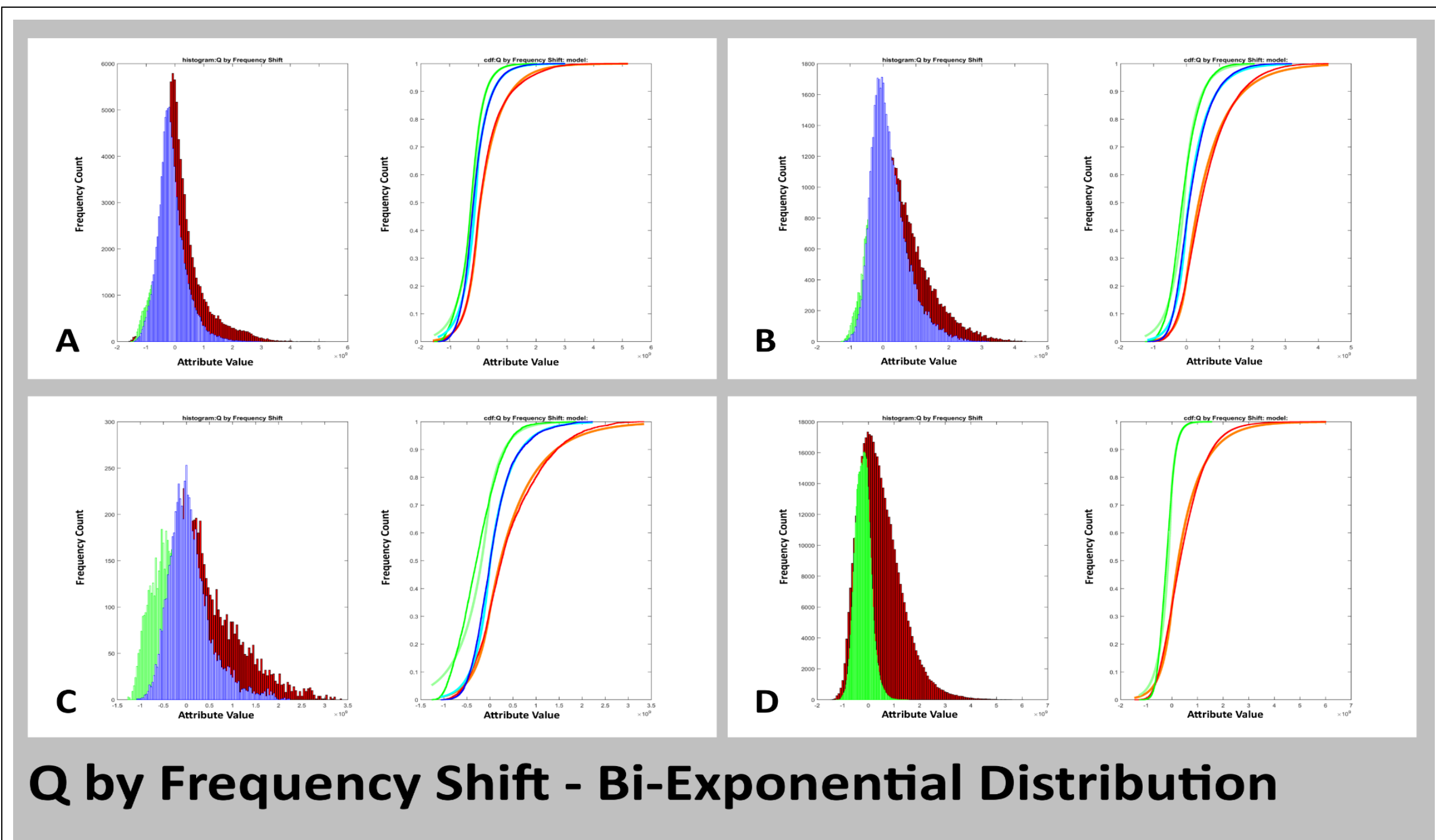

Figure 6.21 Category 1 RSA Frequency Distributions and Model Distribution Fits - $Q$ by Frequency Shift

Shown in each section A-D are the frequency counts of the attribute values in each respective seismic interval (left graph), and the fit to a model distribution (right graph). Data Set A - Total Rakopi Subdivision (see Section 4.5.3 and Figures 4.4 and 6.16); Data Set B - Scale Test 1; Data Set C - Scale Test 2 (see Section 6.3.1 and Figure 6.16), and Data Set D - Mangahewa

Control Group (see Section 6.3.2 and Figure 6.16). (Lower Coals (A-C)/Mangahewa Coals (D): red = actual values; orange = model distrbution. Mid Silts (A-C)/Manganui Silts (D): darker green $=$ actual values, lighter green $=$ model distribution. Upper Coals: dark blue $=$ actual values, light blue $=$ model distribution). 


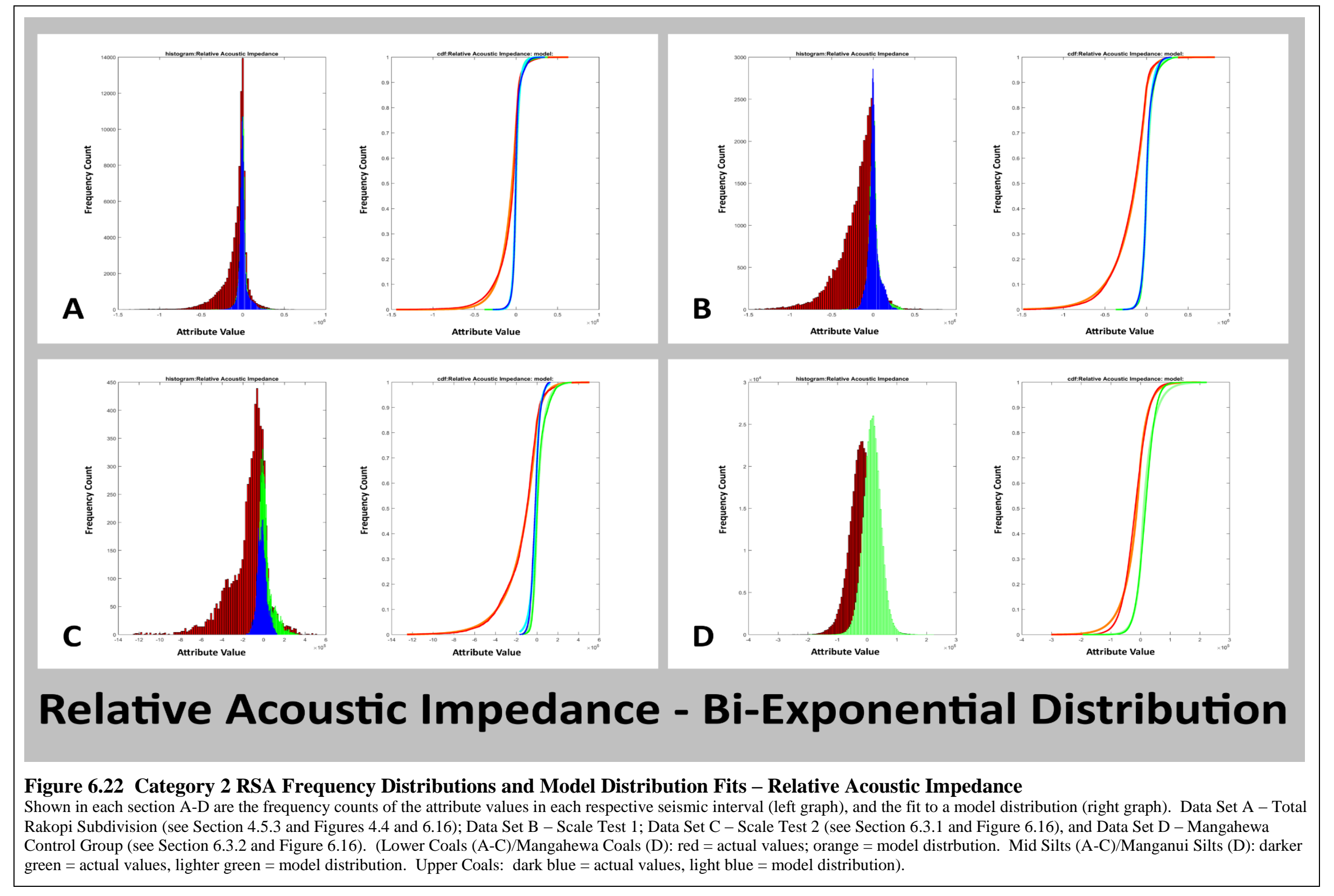




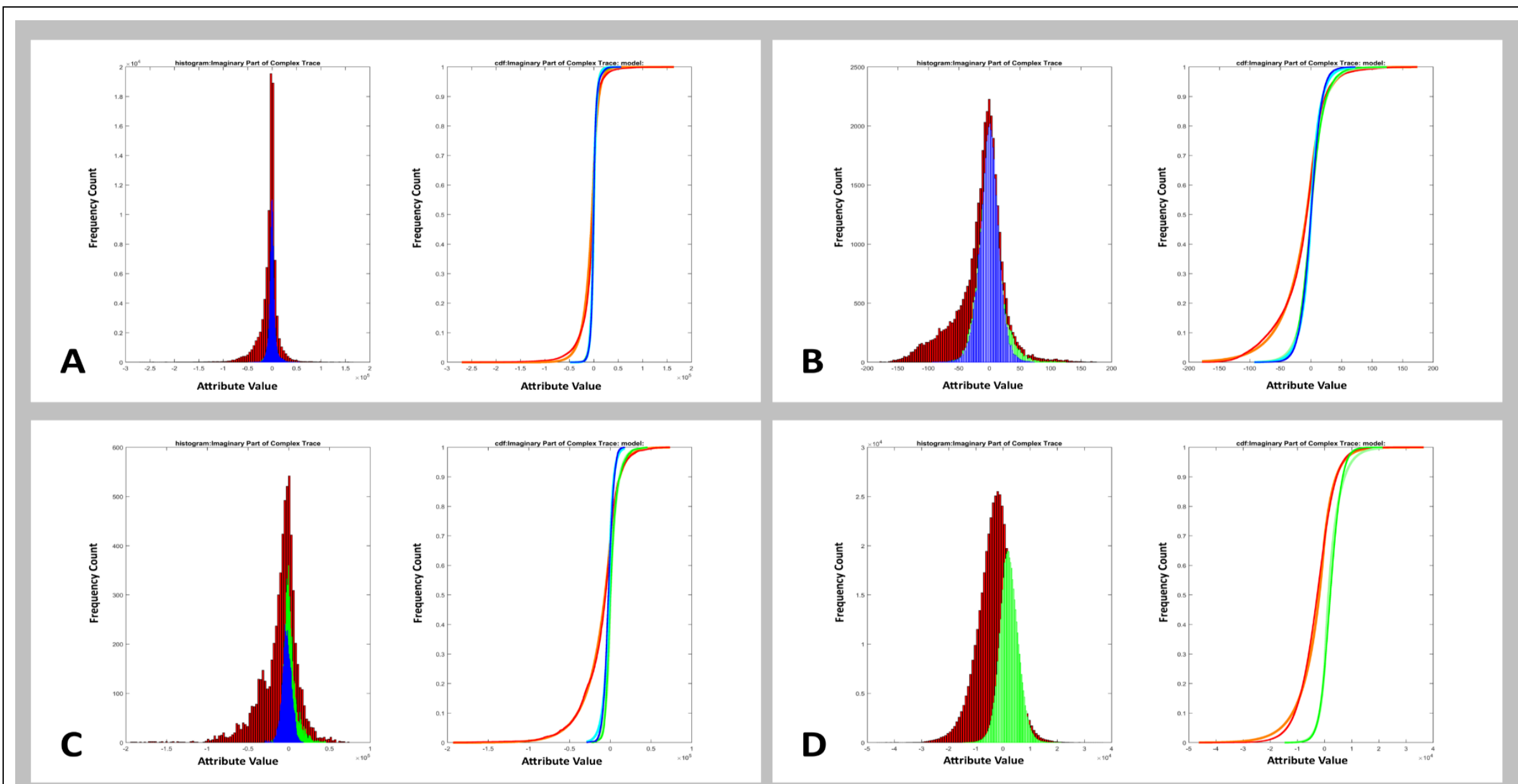

\section{Imaginary Part of Complex Trace - Bi-Exponential Distribution}

Figure 6.23 Category 2 RSA Frequency Distributions and Model Distribution Fits - Imaginary Part of Complex Trace

Shown in each section A-D are the frequency counts of the attribute values in each respective seismic interval (left graph), and the fit to a model distribution (right graph). Data Set A - Total Rakopi Subdivision (see Section 4.5.3 and Figures 4.4 and 6.16); Data Set B - Scale Test 1; Data Set C - Scale Test 2 (see Section 6.3.1 and Figure 6.16), and Data Set D - Mangahewa

Control Group (see Section 6.3.2 and Figure 6.16). (Lower Coals (A-C)/Mangahewa Coals (D): red = actual values; orange = model distrbution. Mid Silts (A-C)/Manganui Silts (D): darker green $=$ actual values, lighter green $=$ model distribution. Upper Coals: dark blue $=$ actual values, light blue $=$ model distribution) . 


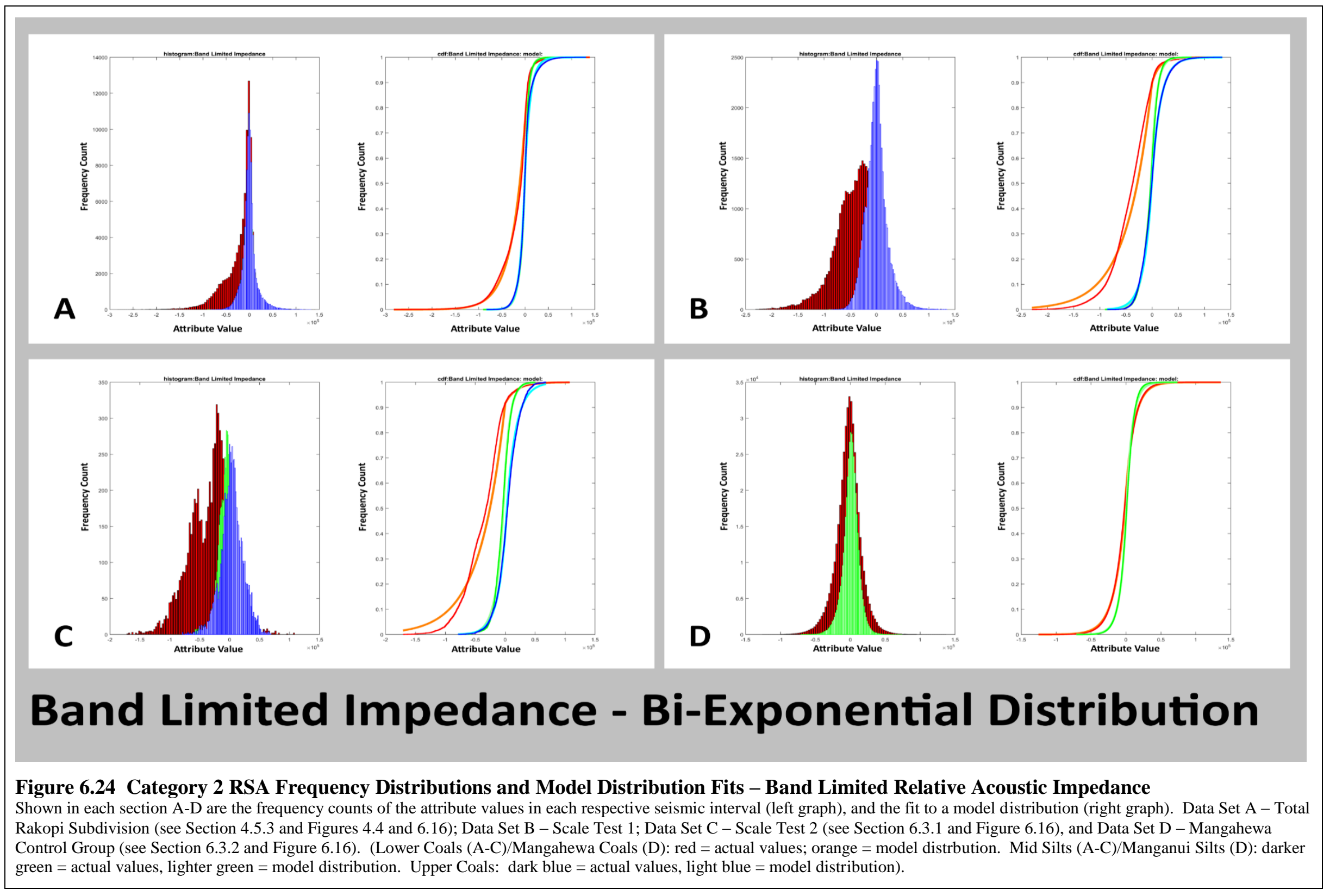




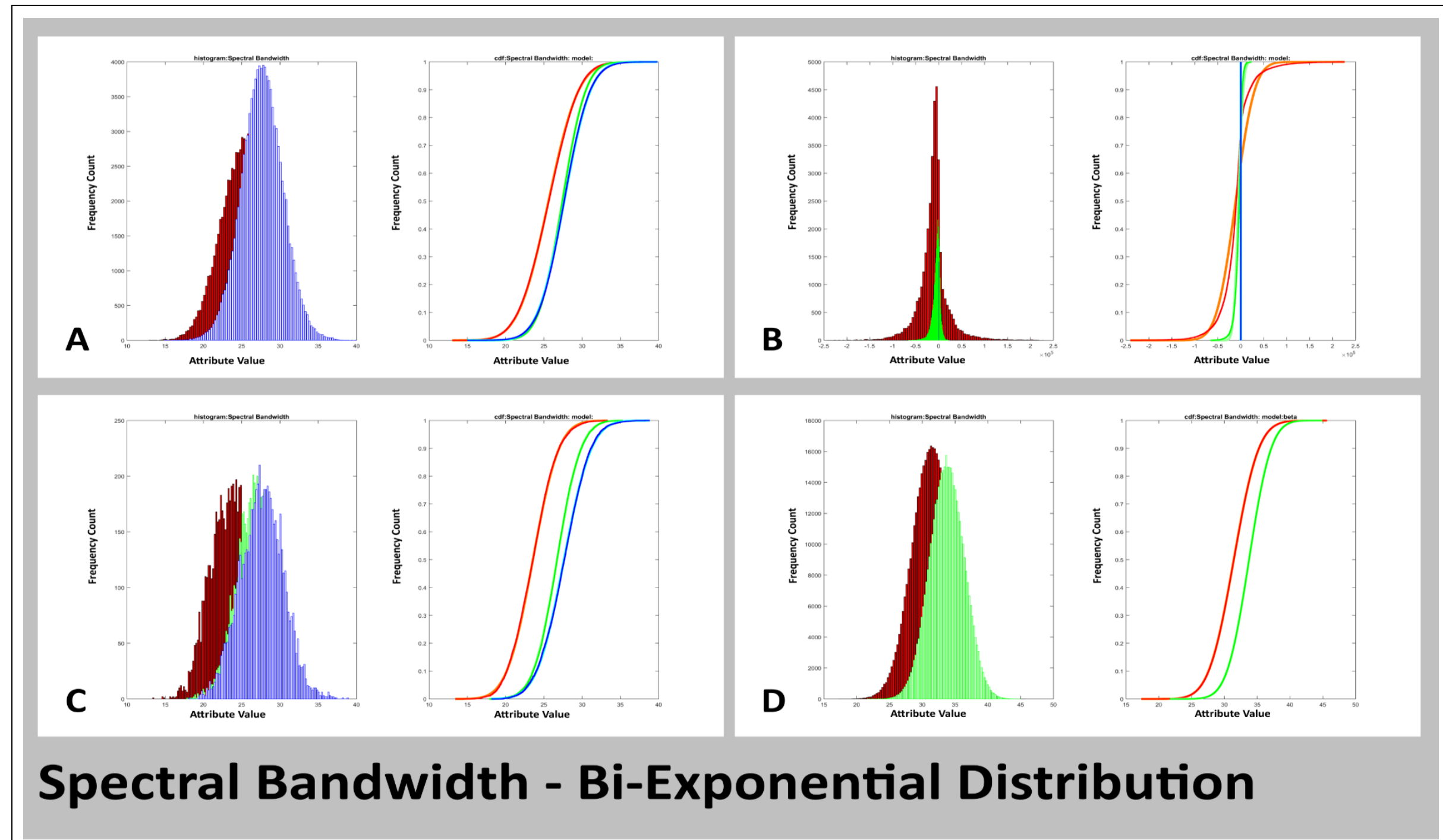

Figure 6.25 Category 2 RSA Frequency Distributions and Model Distribution Fits - Spectral Bandwidth

Shown in each section A-D are the frequency counts of the attribute values in each respective seismic interval (left graph), and the fit to a model distribution (right graph). Data Set A - Total

Rakopi Subdivision (see Section 4.5.3 and Figures 4.4 and 6.16); Data Set B - Scale Test 1; Data Set C - Scale Test 2 (see Section 6.3.1 and Figure 6.16), and Data Set D - Mangahewa

Control Group (see Section 6.3.2 and Figure 6.16). (Lower Coals (A-C)/Mangahewa Coals (D): red = actual values; orange = model distrbution. Mid Silts (A-C)/Manganui Silts (D): darker green $=$ actual values, lighter green $=$ model distribution. Upper Coals: dark blue $=$ actual values, light blue $=$ model distribution . 


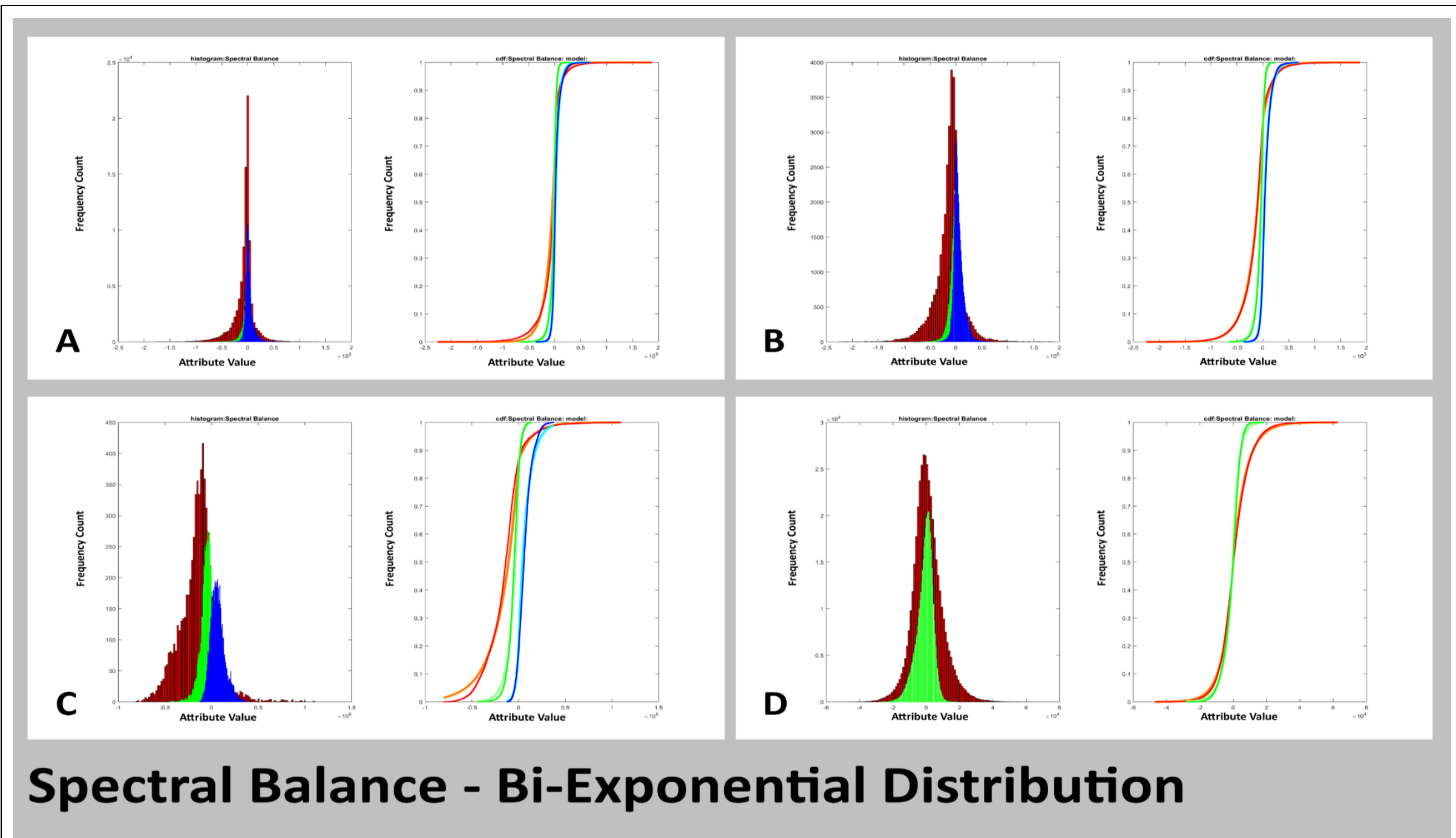

Figure 6.26 Category 2 RSA Frequency Distributions and Model Distribution Fits - Spectral Balance

Shown in each section A-D are the frequency counts of the attribute values in each respective seismic interval (left graph), and the fit to a model distribution (right graph). Data Set A - Total

Rakopi Subdivision (see Section 4.5.3 and Figures 4.4 and 6.16); Data Set B - Scale Test 1; Data Set C - Scale Test 2 (see Section 6.3.1 and Figure 6.16), and Data Set D - Mangahewa

Control Group (see Section 6.3.2 and Figure 6.16). (Lower Coals (A-C)/Mangahewa Coals (D): red = actual values; orange = model distrbution. Mid Silts (A-C)/Manganui Silts (D): darker

green $=$ actual values, lighter green $=$ model distribution. Upper Coals: dark blue $=$ actual values, light blue $=$ model distribution $)$. 


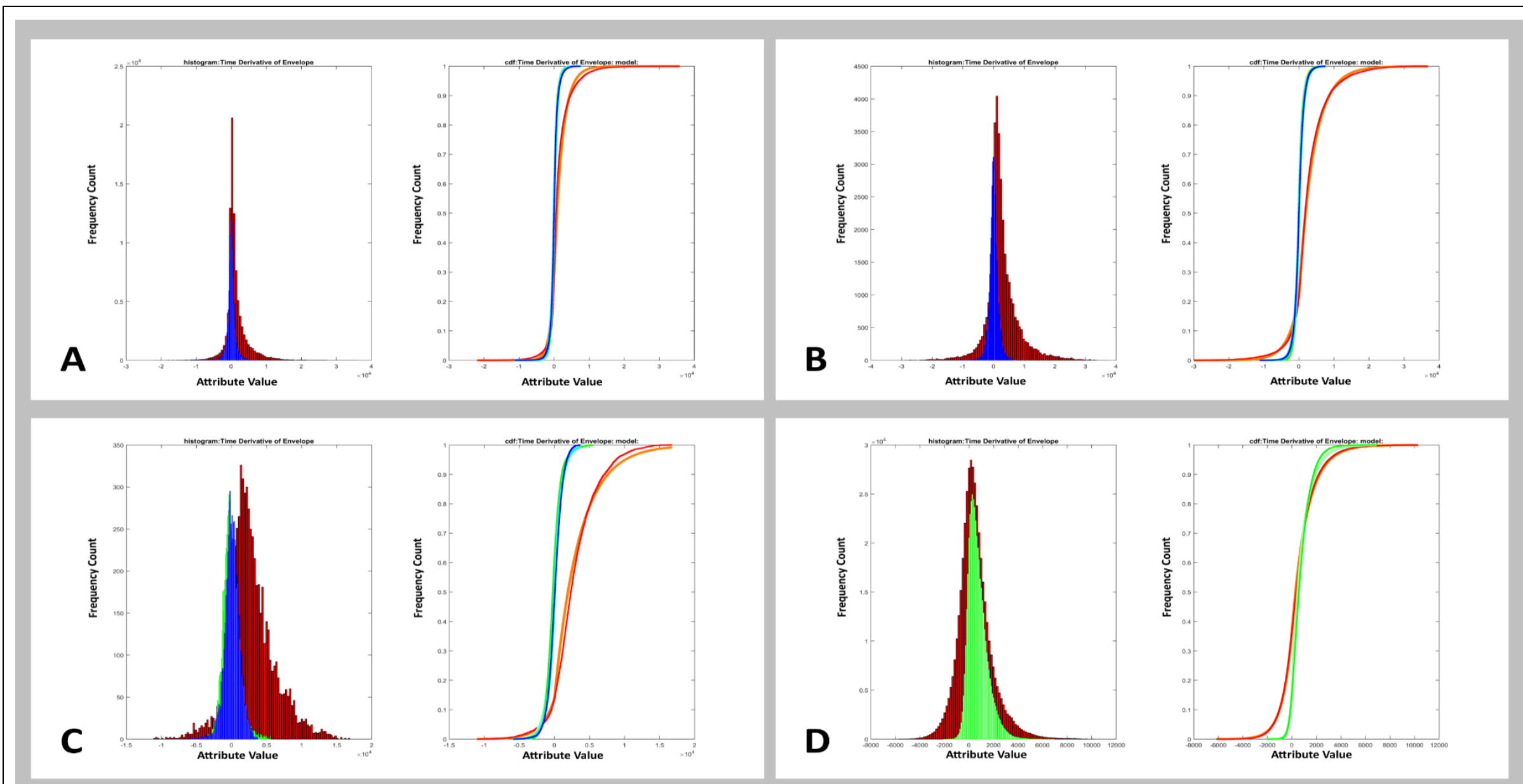

\section{Time Derivative of Envelope - Bi-Exponential Distribution}

Figure 6.27 Category 2 RSA Frequency Distributions and Model Distribution Fits - Time Derivative of Envelope

Shown in each section A-D are the frequency counts of the attribute values in each respective seismic interval (left graph), and the fit to a model distribution (right graph). Data Set A - Total Rakopi Subdivision (see Section 4.5.3 and Figures 4.4 and 6.16); Data Set B - Scale Test 1; Data Set C - Scale Test 2 (see Section 6.3.1 and Figure 6.16), and Data Set D - Mangahewa

Control Group (see Section 6.3.2 and Figure 6.16). (Lower Coals (A-C)/Mangahewa Coals (D): red = actual values; orange = model distrbution. Mid Silts (A-C)/Manganui Silts (D): darker green $=$ actual values, lighter green $=$ model distribution. Upper Coals: dark blue $=$ actual values, light blue $=$ model distribution $)$ 


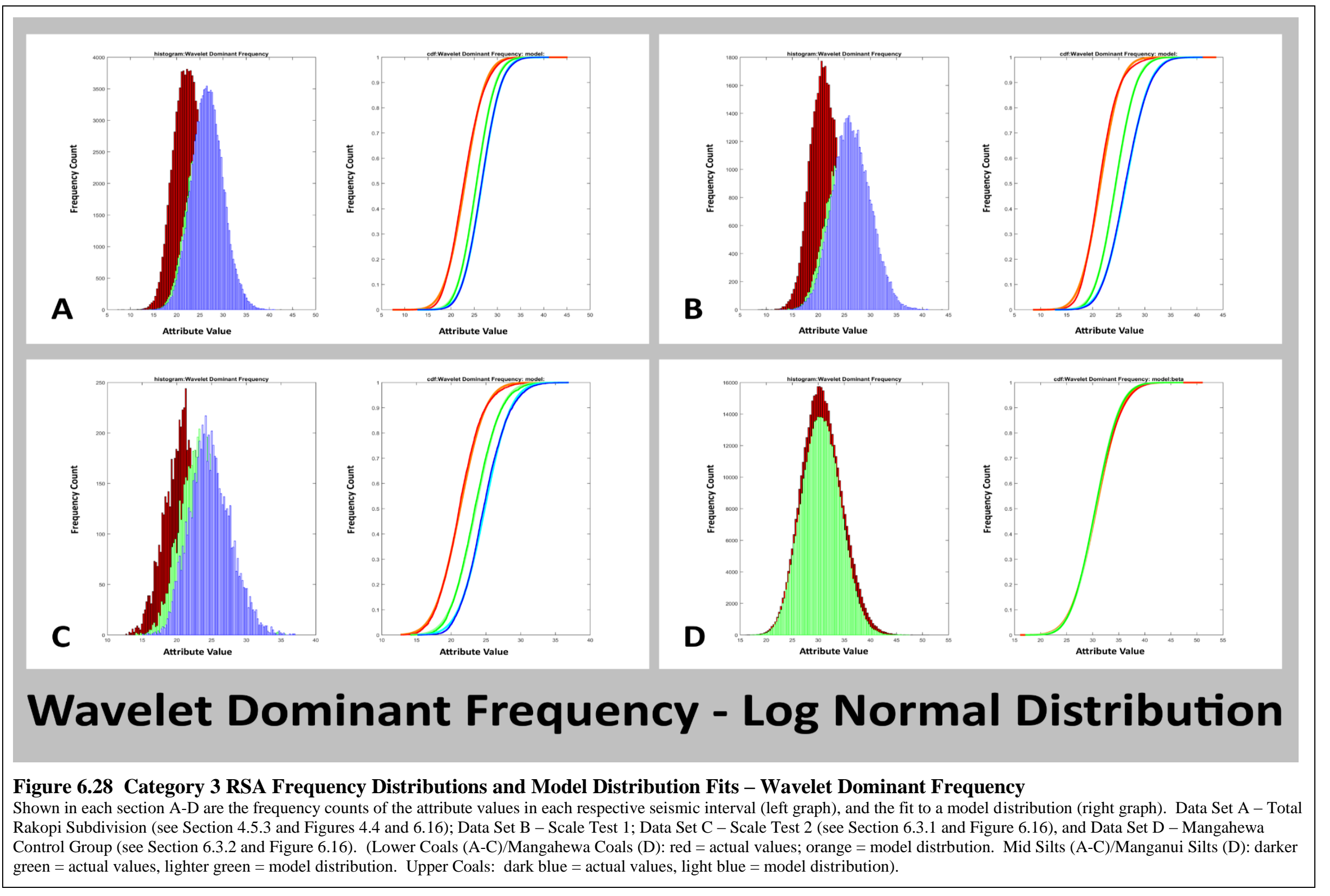




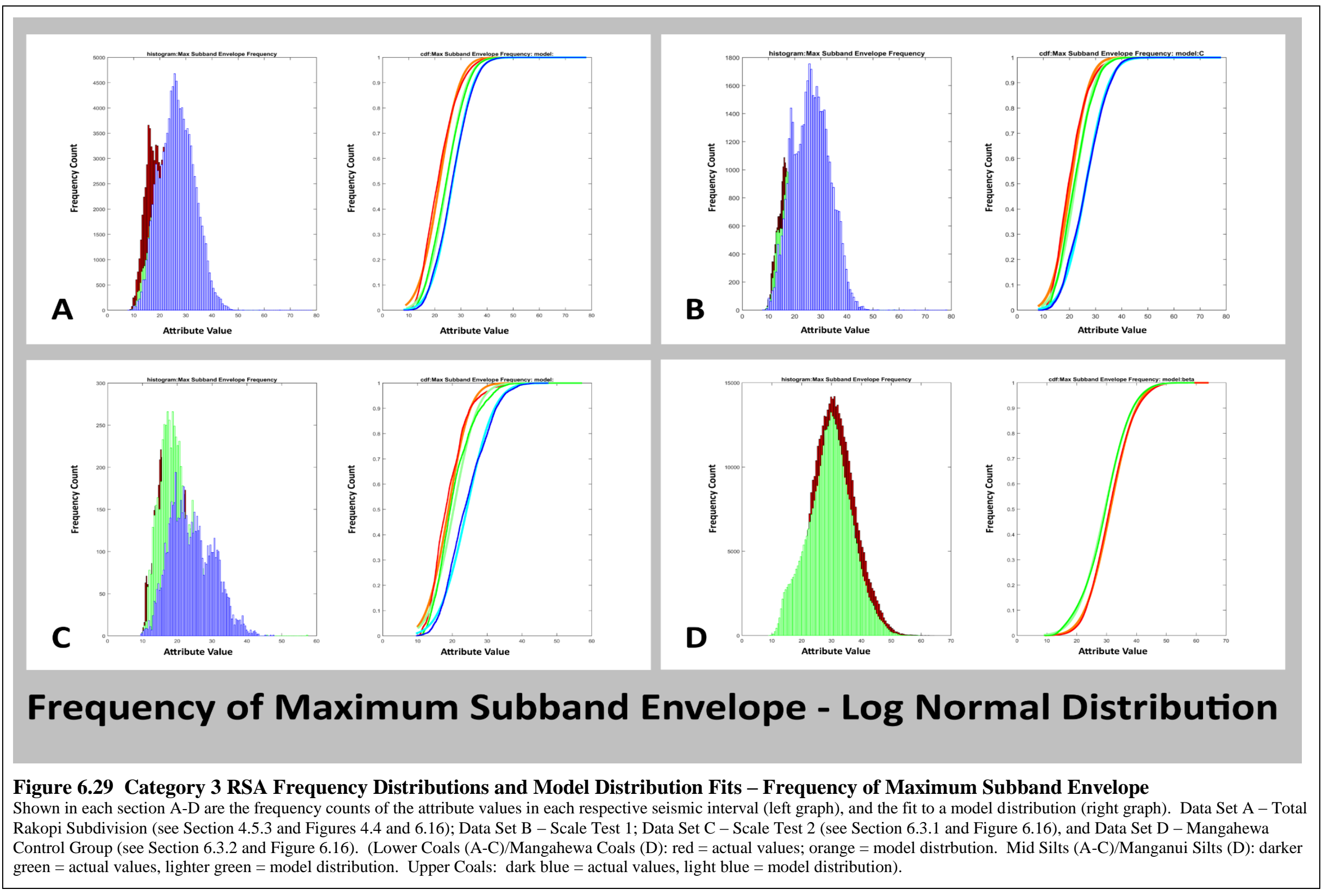



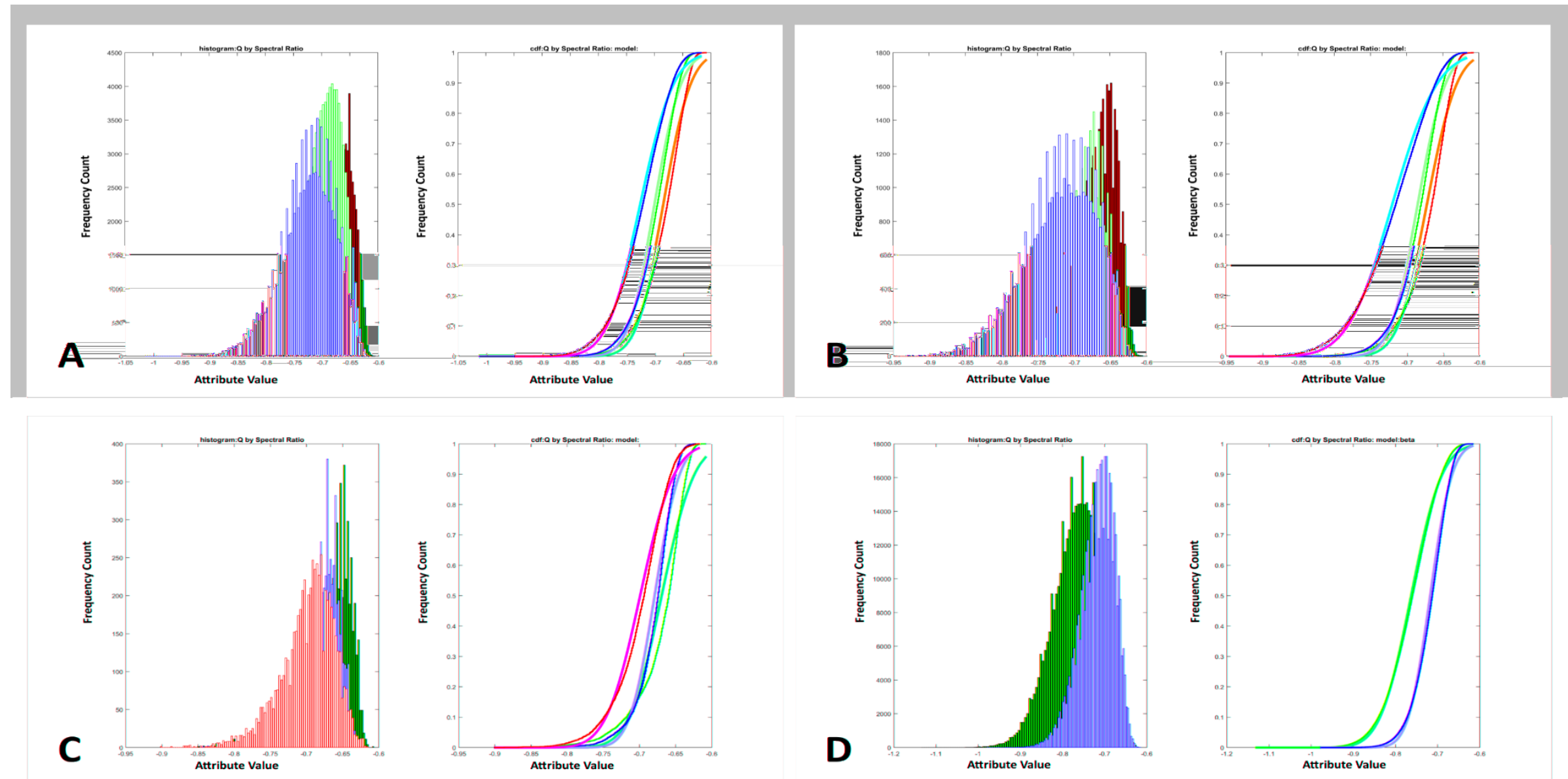

\section{Q by Spectral Ratio - Bi-Exponential Distribution}

Figure 6.30 Category 3 RSA Frequency Distributions and Model Distribution Fits - $Q$ by Spectral Ratio

Shown in each section A-D are the frequency counts of the attribute values in each respective seismic interval (left graph), and the fit to a model distribution (right graph). Data Set A - Total Rakopi Subdivision (see Section 4.5.3 and Figures 4.4 and 6.16); Data Set B - Scale Test 1; Data Set C - Scale Test 2 (see Section 6.3.1 and Figure 6.16), and Data Set D - Mangahewa

Control Group (see Section 6.3.2 and Figure 6.16). (Lower Coals (A-C)/Mangahewa Coals (D): red = actual values; orange = model distrbution. Mid Silts (A-C)/Manganui Silts (D): darker green $=$ actual values, lighter green $=$ model distribution. Upper Coals: dark blue $=$ actual values, light blue $=$ model distribution $)$. 


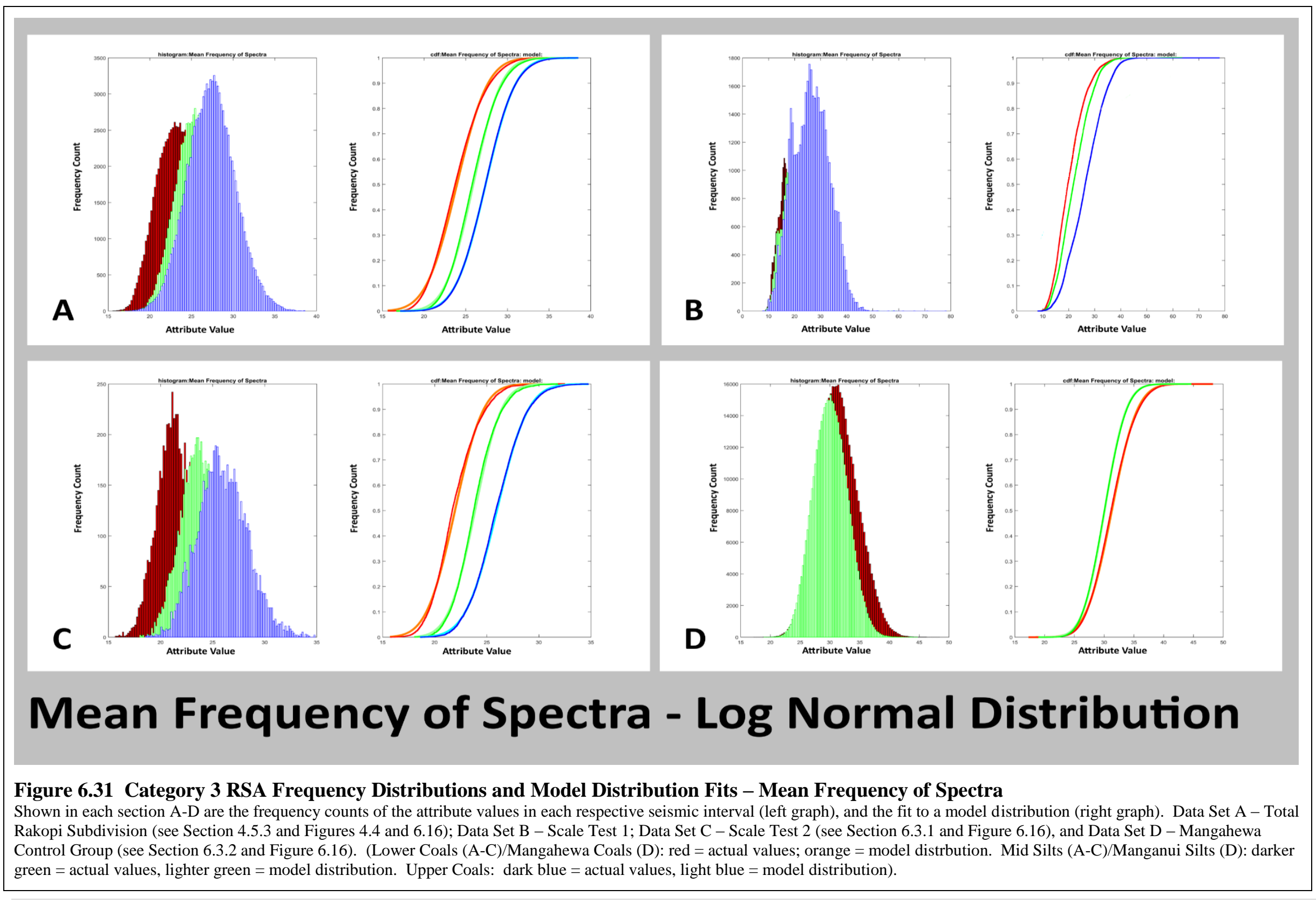




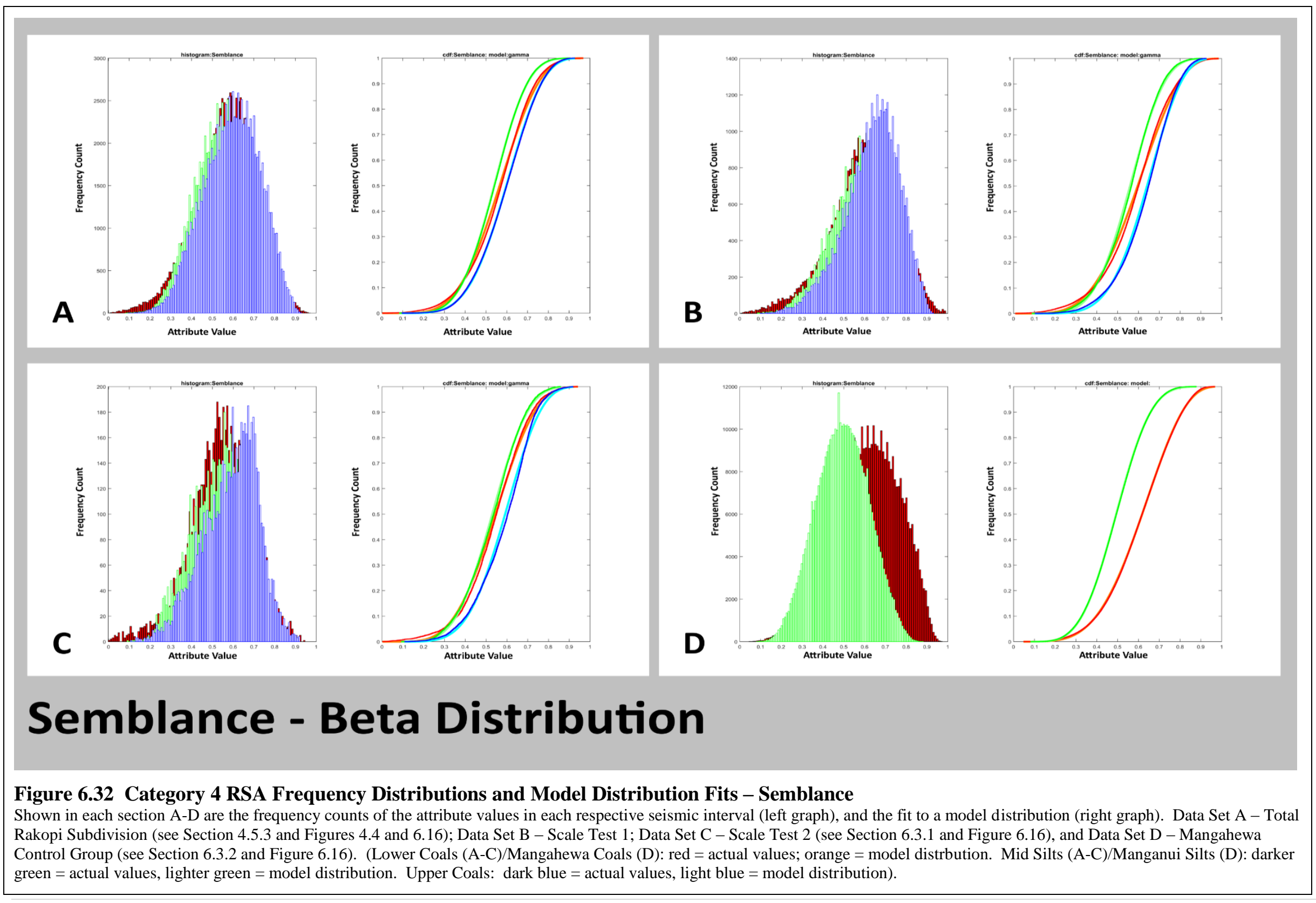




\subsection{Final RSA Suite Descriptions}

Time Derivative of Wavelet Envelope displays frequency distributions almost identical to that of Trace Envelope (Figures 6.21\& 6.17) respectively). As compared to both Time Derivative of Wavelet Envelope and Trace Envelope, Wavelet Envelope also displays very similar frequency distributions of values. The one obvious difference is that in the case of Wavelet Envelope (Figure 6.18), the frequency distributions of the Upper Coals are closer to those of the Mid Silts, whereas for the other 2 attributes (Trace Envelope and Time Derivative of Wavelet Envelope), the Upper Coals frequency distributions are very close to those of the Lower Coals. This could indicate that Wavelet Envelope is more sensitive to specific coal content than the other Category 1 RSAs.I

\subsubsection{Trace Envelope}

Trace Envelope, otherwise known as total instantaneous energy of the complex trace, or instantaneous amplitude, is a physical attribute, and can be used as an indicator of numerous changes in lithological characteristics. It represents mostly the acoustic impedance contrast - and thus reflectivity - and can display lithologic (and hence depositional) changes, faulting, unconformities, thin bed tuning effects, and more (Taner 2003).

\subsubsection{Wavelet Envelope}

Rock Solid Images (2016), who created the RSAs for use by Seisware ${ }^{\mathrm{TM}}$, defines this attribute as: "Instantaneous attributes at the maximum point of the envelope". There is no further specific information provided about this attribute. However, given the description of Trace Envelope above, it is inferred that Wavelet Envelope is referring to the instantaneous amplitude at the peak of the wavelet envelope.

\subsubsection{Q by Frequency Shift}

Q, or Quality Factor, is the inverse of the seismic attenuation. It is calculated by the ratio of the peak energy in a waveform to the energy it loses by dissipation over distance travelled (Allaby 2013). High Q therefore implies low absorption rates of the surrounding rocks.

Seismic attenuation increases with frequency for most natural materials, with the seismic signal's high-frequency components being attenuated more rapidly than low-frequency. Therefore, the signal spectrum centroid downshifts during seismic wave propagation, and this can be observed to reconstruct the attenuation distribution (Quan \& Harris 1997).

\subsubsection{Time Derivative of Wavelet Envelope}

This attribute is given by the rate of change of the wavelet envelope over time (Rock Solid Images 2016). It represents the steepness of the seismic wavelet. 


\subsubsection{Imaginary Part of Complex Trace}

This trace has an identical amplitude spectrum to the real part of the complex trace. Rock Solid Images (2016) defines this as: "The real part of the complex trace (amplitude) phase shifted by 90 degrees".

\subsubsection{Relative Acoustic Impedance}

This attribute is a physical attribute, which reflects a contrast between the physical properties of rocks, which can be correlated to a change in compaction and porosity (Rock Solid Images 2016). 


\section{Discussion and Conclusions}

\subsection{Introduction}

The previous chapters have outlined the process involved in identifying the chosen RSAs, which are displaying significant variations in their value distributions between coaly versus non-coaly intervals. The selected RSAs outlined in chapters 5 and 6 (4 from Category 1, and 2 from Category 2) appear to be correlating to the presence of coaly facies in the study area (Chapter 6.3.3). However, a method does not yet exist for application of this correlation to other seismic reflection data for the purpose of coal prediction.

\subsection{Summary of Results}

Chapter 5 presented the results of extracting a wide range of amplitude-based attributes from the Rakopi Formation interval of both the Maari and Pipeline 3D volumes. The resultant amplitude maps (represented by Figure 5.1) did not show enough to be useful in identification of coals, and as such were largely confined to Appendix A. Additionally, Chapter 5 detailed the extraction of the suite of RSAs in Seisware ${ }^{\mathrm{TM}}$, the results of which were refined in Chapter 6, by spatially averaging the RSA values within the Rakopi Formation interval for display in pan view, and plotting the frequency distributions of these results for visual analysis. Also undertaken were several control tests based on both scalability, and repeatability of results in the coaly facies of the Mangahewa Formation. From these results, a series of attributes were identified which correlate to the increased presence of coaly facies within the selected intervals.

\subsubsection{Coal Predicting Rock Solid Attributes}

There are 6 attributes which appear to predict the increased presence of coals, as follows:

- Trace Envelope

- Wavelet Envelope

- Q by Frequency Shift

- Time Derivative of Wavelet Envelope

- Imaginary Part of Complex Trace

- Relative Acoustic Impedance

\subsection{Discussion}

The 6 selected RSAs all appear to be responding to variations in amplitude. High amplitude parts of seismic reflection data often represent hydrocarbon accumulations (Hart 1999). Given that the seismic velocity and density of coal is typically much less than that of sandstones and siltstones (e.g. 
Hughes \& Kennett 1983; Jackson et al. 2010), it is to be expected that the presence of coal seams in the seismic data would lead to amplitude anomalies. Additionally, the presence of stacked coal seams produces high-amplitude anomalies, due to the short-period multiples caused by many thin beds broadening the below-coal wavelet (Coulombe \& Bird 1996).

\subsubsection{Trace Envelope, Wavelet Envelope, Time Derivative of Wavelet Envelope}

Trace Envelope is a measure of instantaneous amplitude, and it follows that it is correlated with the presence of coals within the Rakopi Formation. Coaly facies are associated with an increase in seismic amplitude (Hughes \& Kennett 1983), and as such, it is to be expected that any attribute which measures an increase in seismic amplitude will predict coaly facies to some degree.

Wavelet Envelope describes another measure of seismic amplitude, and displays similar frequency distributions and corresponding spatial distributions to that of Trace Envelope (Figure 6.19). Time Derivative of Wavelet Envelope represents the rate of change of the wavelet envelope over time, it follows that it should display results similar to that of Wavelet Envelope (Figure 6.20).

\subsubsection{Q by Frequency Shift}

Of the 6 coal-predicting RSAs, perhaps the most significant is Q by Frequency Shift, in that it displays value distributions which appear to scale directly in accordance with the percentage thickness of coals (Figure 6.21), and does so on a more predictable scale than the other Category 1 attributes (Figures 6.18-6.20).

Q is a measurement of seismic attenuation (Section 6.4.3), which is a loss of seismic amplitude over distance travelled. As such, it is also a measure of amplitude.

\subsubsection{Relative Acoustic Impedance \& Imaginary Part of Complex Trace}

Relative Acoustic Impedance is a measure of the change of seismic amplitude between layers, due to a difference between their relative densities, which causes changes in the level of impedance, and therefore affects the amplitude and frequency of seismic wave propagation.

Imaginary Part of Complex Trace is also an attribute which is dependent on seismic amplitude, in that it is a derivative of the real part of the complex trace, which is measured in amplitude (Section 6.4.5).

\subsection{Inferred Coal Distributions by RSA Amplitude Map Analysis}

In order to complete the objective set out by this project, the distribution of the coals within the Rakopi Formation of the study area must be constrained. In order to accomplish this, the averaged attribute maps for each of the 6 selected RSAs have been analysed, with the areas highlighted which are displaying attribute values that have correlated with coaly facies at the Maui-4 well through all control tests (Figures 7.1-7.6). 


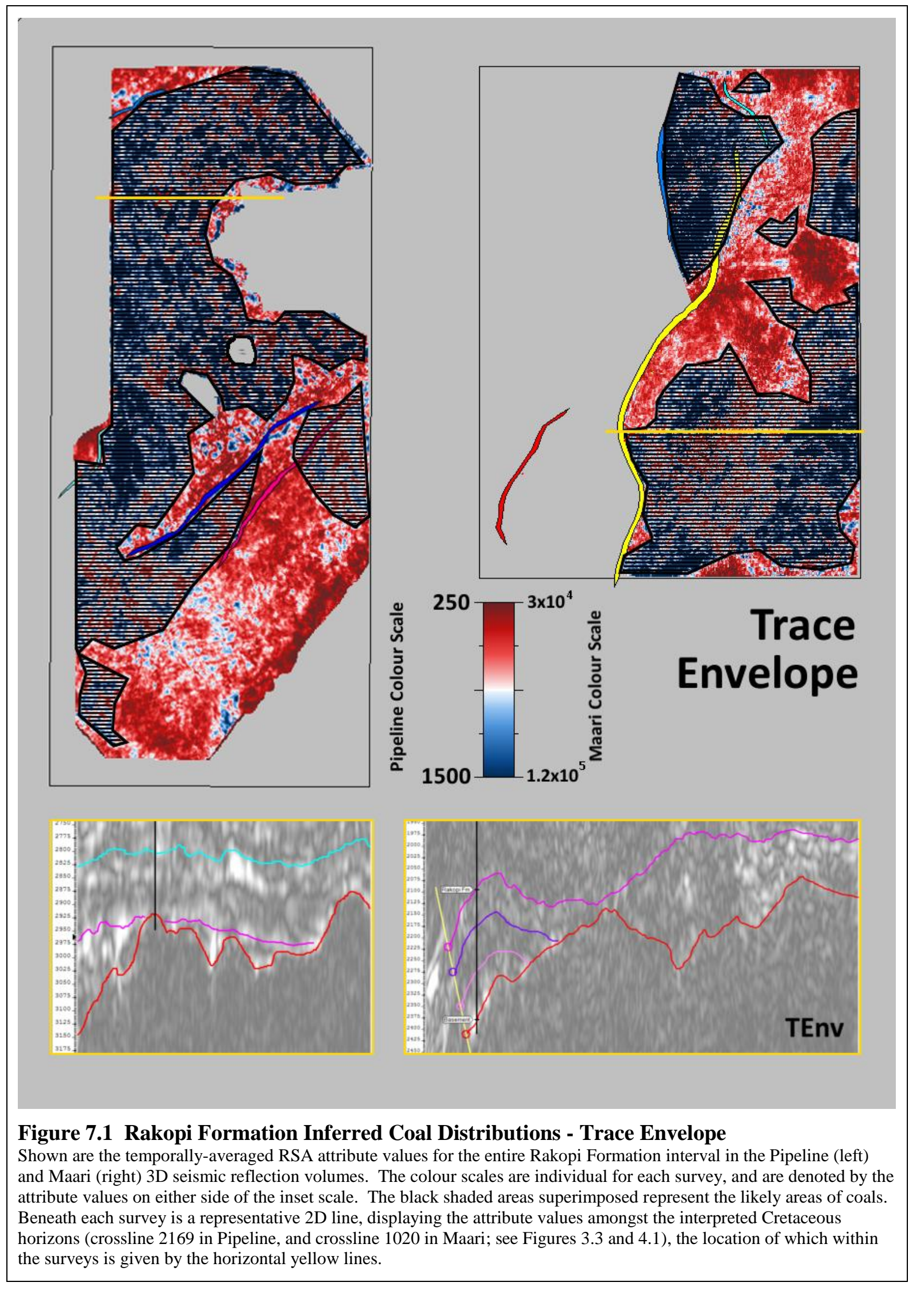



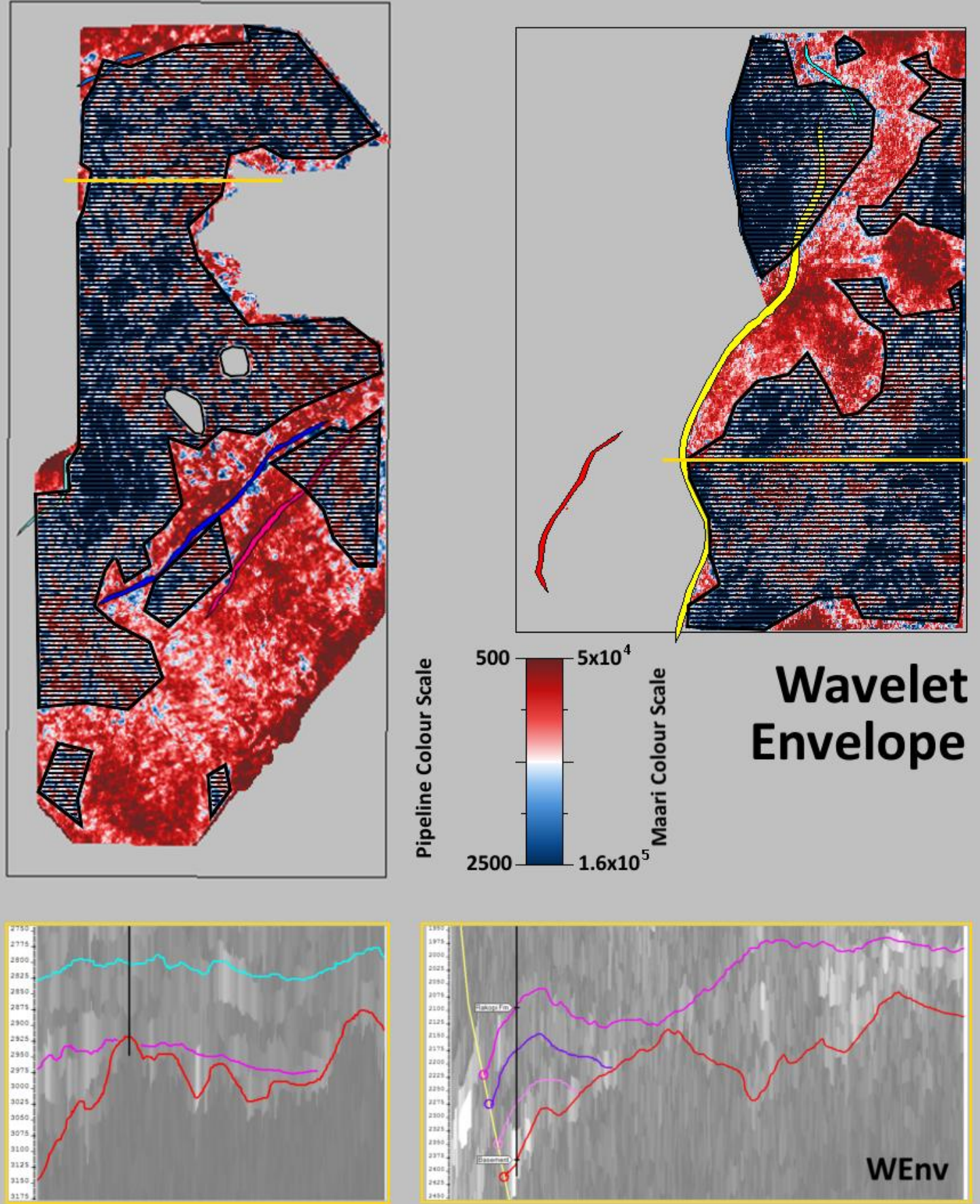

Figure 7.2 Rakopi Formation Inferred Coal Distributions - Wavelet Envelope

Shown are the temporally-averaged RSA attribute values for the entire Rakopi Formation interval in the Pipeline (left) and Maari (right) 3D seismic reflection volumes. The colour scales are individual for each survey, and are denoted by the attribute values on either side of the inset scale. The black shaded areas superimposed represent the likely areas of coals. Beneath each survey is a representative $2 \mathrm{D}$ line, displaying the attribute values amongst the interpreted Cretaceous horizons (crossline 2169 in Pipeline, and crossline 1020 in Maari; see Figures 3.3 and 4.1), the location of which within the surveys is given by the horizontal yellow lines. 

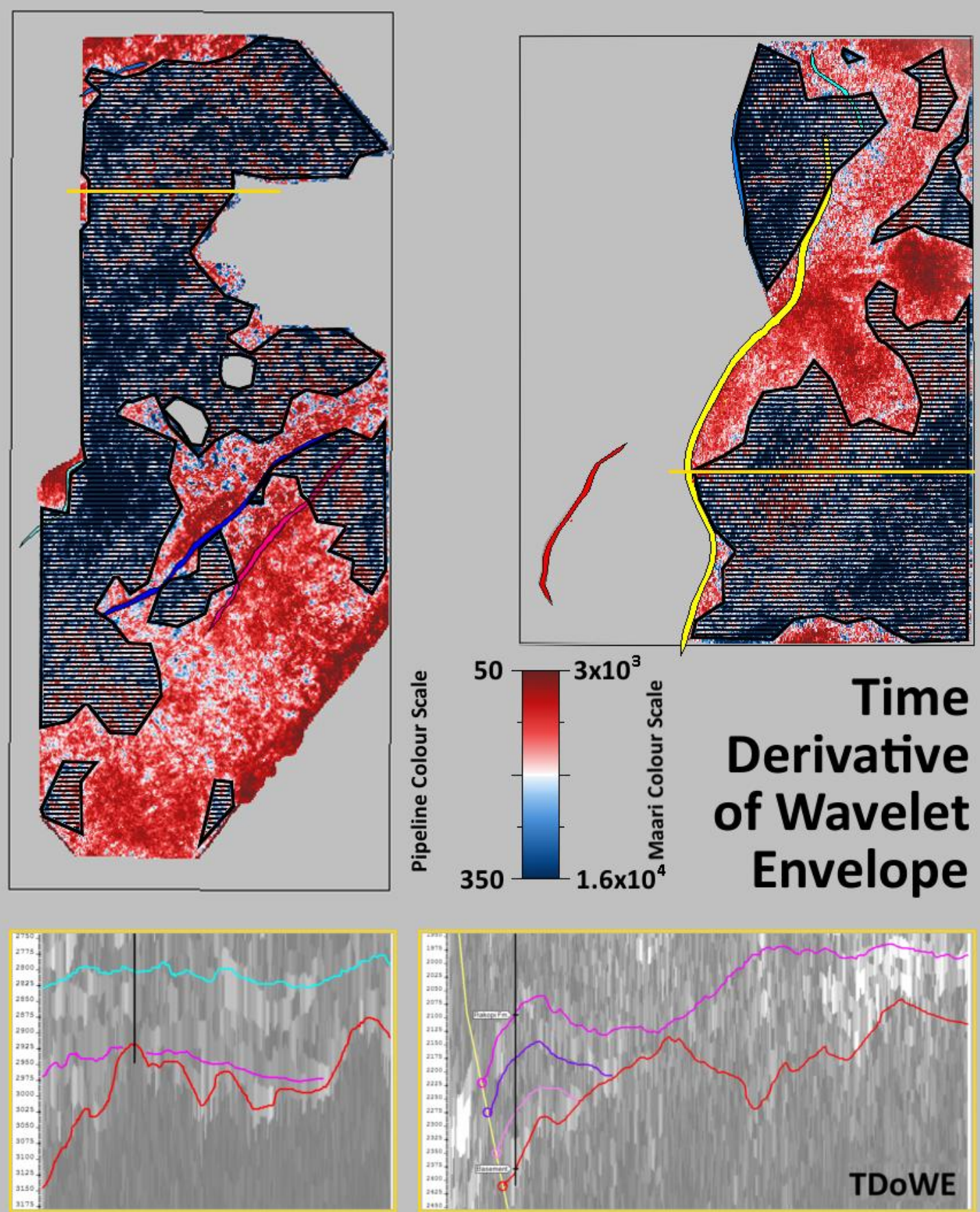

\section{Figure 7.3 Rakopi Formation Inferred Coal Distributions - Time Derivative of Wavelet Envelope}

Shown are the temporally-averaged RSA attribute values for the entire Rakopi Formation interval in the Pipeline (left) and Maari (right) 3D seismic reflection volumes. The colour scales are individual for each survey, and are denoted by the attribute values on either side of the inset scale. The black shaded areas superimposed represent the likely areas of coals. Beneath each survey is a representative 2D line, displaying the attribute values amongst the interpreted Cretaceous horizons (crossline 2169 in Pipeline, and crossline 1020 in Maari; see Figures 3.3 and 4.1), the location of which within the surveys is given by the horizontal yellow lines. 

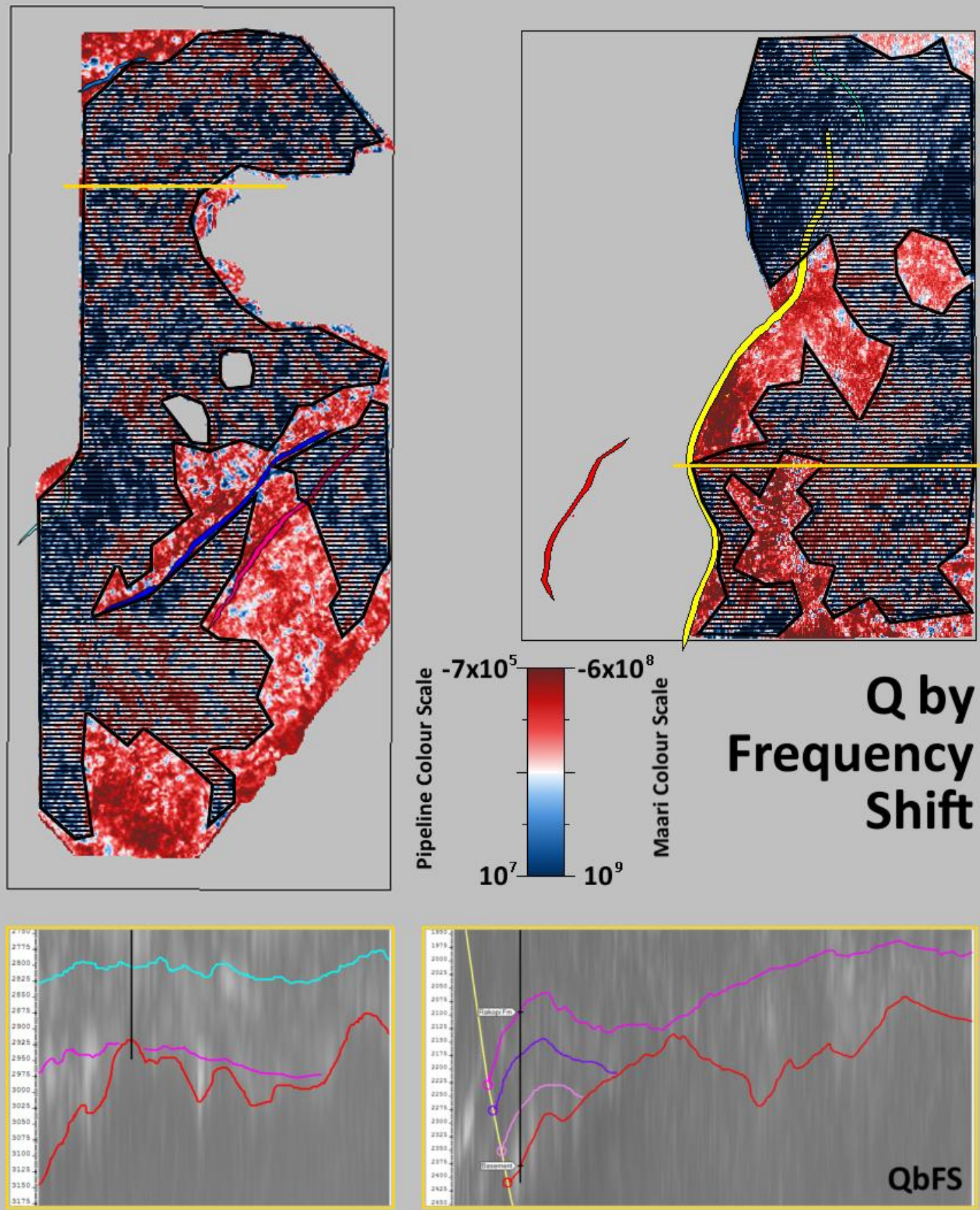

\section{Figure 7.4 Rakopi Formation Inferred Coal Distributions - Q by Frequency Shift}

Shown are the temporally-averaged RSA attribute values for the entire Rakopi Formation interval in the Pipeline (left) and Maari (right) 3D seismic reflection volumes. The colour scales are individual for each survey, and are denoted by the attribute values on either side of the inset scale. The black shaded areas superimposed represent the likely areas of coals. Beneath each survey is a representative 2D line, displaying the attribute values amongst the interpreted Cretaceous horizons (crossline 2169 in Pipeline, and crossline 1020 in Maari; see Figures 3.3 and 4.1), the location of which within the surveys is given by the horizontal yellow lines. 


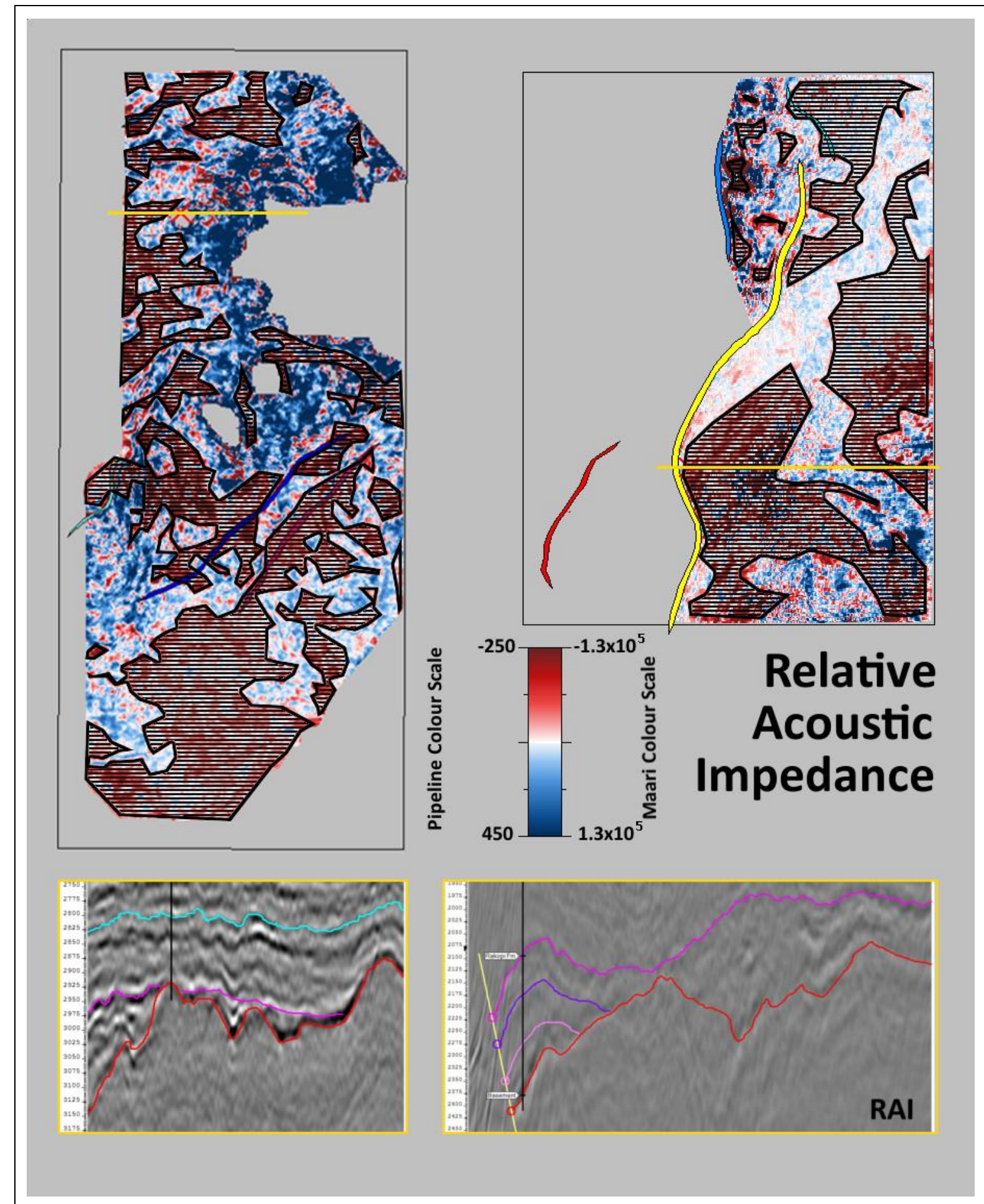

Figure 7.5 Rakopi Formation Inferred Coal Distributions - Relative Acoustic Impedance

Shown are the temporally-averaged RSA attribute values for the entire Rakopi Formation interval in the Pipeline (left) and Maari (right) 3D seismic reflection volumes. The colour scales are individual for each survey, and are denoted by the attribute values on either side of the inset scale. The black shaded areas superimposed represent the likely areas of coals. Beneath each survey is a representative 2D line, displaying the attribute values amongst the interpreted Cretaceous horizons (crossline 2169 in Pipeline, and crossline 1020 in Maari; see Figures 3.3 and 4.1), the location of which within the surveys is given by the horizontal yellow lines. 

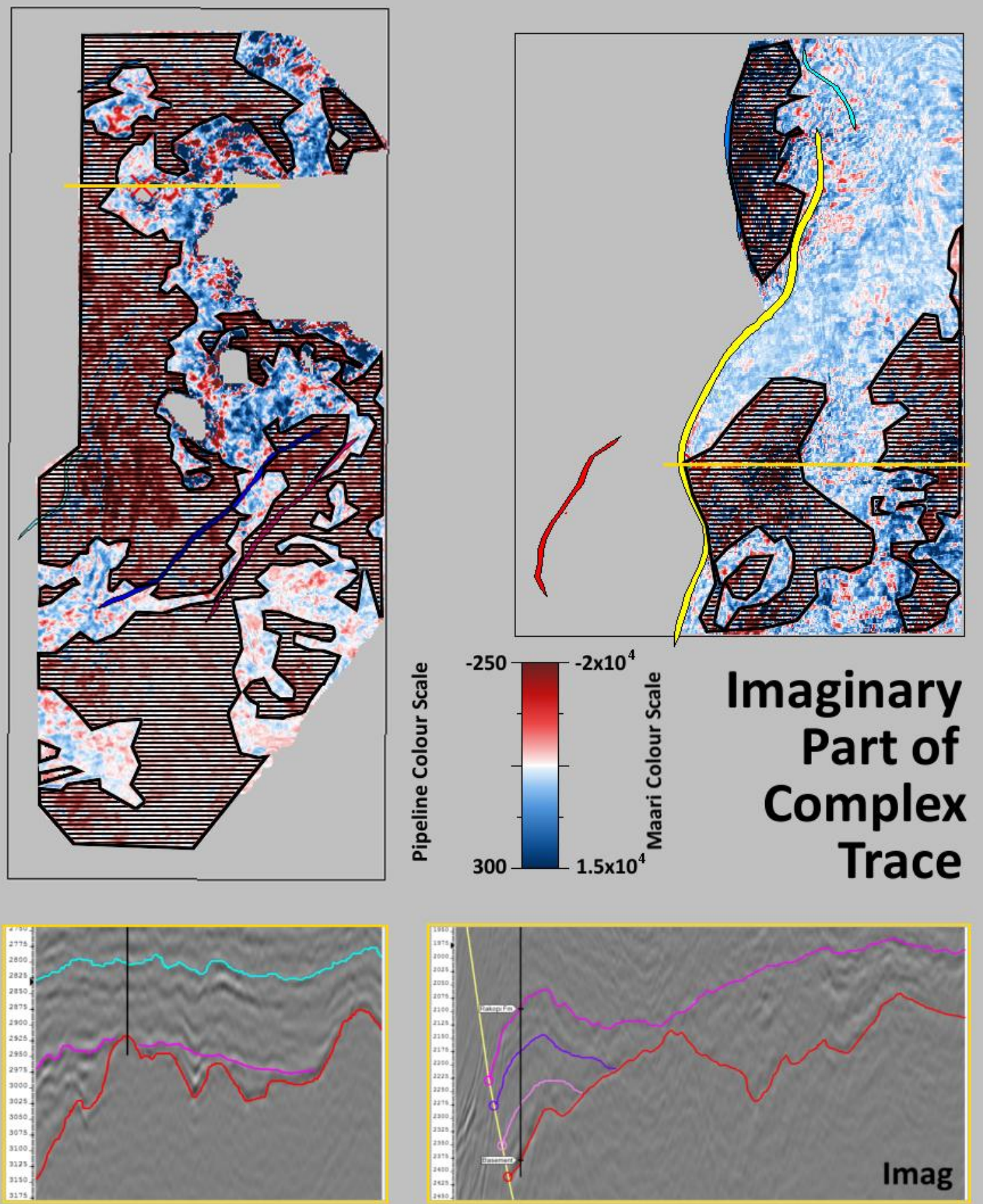

\section{Figure 7.6 Rakopi Formation Inferred Coal Distributions - Imaginary Part of Complex}

Trace

Shown are the temporally-averaged RSA attribute values for the entire Rakopi Formation interval in the Pipeline (left) and Maari (right) 3D seismic reflection volumes. The colour scales are individual for each survey, and are denoted by the attribute values on either side of the inset scale. The black shaded areas superimposed represent the likely areas of coals. Beneath each survey is a representative $2 \mathrm{D}$ line, displaying the attribute values amongst the interpreted Cretaceous horizons (crossline 2169 in Pipeline, and crossline 1020 in Maari; see Figures 3.3 and 4.1), the location of which within the surveys is given by the horizontal yellow lines. 
These figures display the inferred distributions for coals within this interval for each of the 6 RSAs separately. This analysis was done visually, by noting areas where the spatial distribution of higher (or lower, which correlated to coals for Category 2 RSAs) temporally-averaged RSA values is concentrated within the 3D volumes.

Note that thresholding to produce the polygons in Figures 7.1-7.6 has been subjectively assigned. The colour distributions used for this thresholding were individually set for each RSA, in order to best display the distribution of values by utilising as broad a colour spectrum as possible in each case. As such, the threshold for coals for each RSA is somewhat arbitrary, but still serves as an adequate starting point for the prediction of coals based on temporally-averaged RSA values.

Extrapolating from this, the coal distributions predicted by each RSA individually have been superimposed upon one another to produce a further set of figures, with any areas which are not predicted by the chosen RSAs being trimmed off, to create a "Venn Diagram" of the respective coal distributions, based on cumulative prediction by successive RSAs. Given that the 2 categories of coal-predicting RSAs appear to be responding to the coals in a different way (section 6.2.2), this was done separately for each category (Figures 7.7-7.8), before being done for all 6 chosen RSAs together (Figure 7.9).

The results of the coal constraint inferences are displayed in Table 7.1 below.

\begin{tabular}{|c|l|r|c|c|}
\hline $\begin{array}{c}\text { RSA } \\
\text { Category }\end{array}$ & \multicolumn{1}{|c|}{ Rock Solid Attribute (RSA) Name } & $\begin{array}{c}\text { Individual } \\
\text { RSAs }\end{array}$ & $\begin{array}{c}\text { Cumulative } \\
\text { by Category }\end{array}$ & $\begin{array}{c}\text { Cumulative } \\
\text { All RSAs }\end{array}$ \\
\hline \multirow{3}{*}{1} & Trace Envelope & $58.6 \%$ & & \\
\cline { 2 - 3 } & Wavelet Envelope & $61.3 \%$ & \multirow{2}{*}{$49.0 \%$} & \\
\cline { 2 - 3 } & Time Derivative of Wavelet Envelope & $57.9 \%$ & & \multirow{2}{*}{$13.9 \%$} \\
\cline { 2 - 3 } & Q by Frequency Shift & $65.8 \%$ & & \\
\hline \multirow{2}{*}{2} & Relative Acoustic Impedance & $44.3 \%$ & \multirow{2}{*}{$28.8 \%$} & \\
\cline { 2 - 3 } & Imaginary Part of Complex Trace & $50.0 \%$ & \\
\hline
\end{tabular}

Table 7.1 Rakopi Formation Inferred Coal Distribution Percentages. Refer to Figures 7.1-7.9. For RSA category descriptions see Section 6.2.2. 


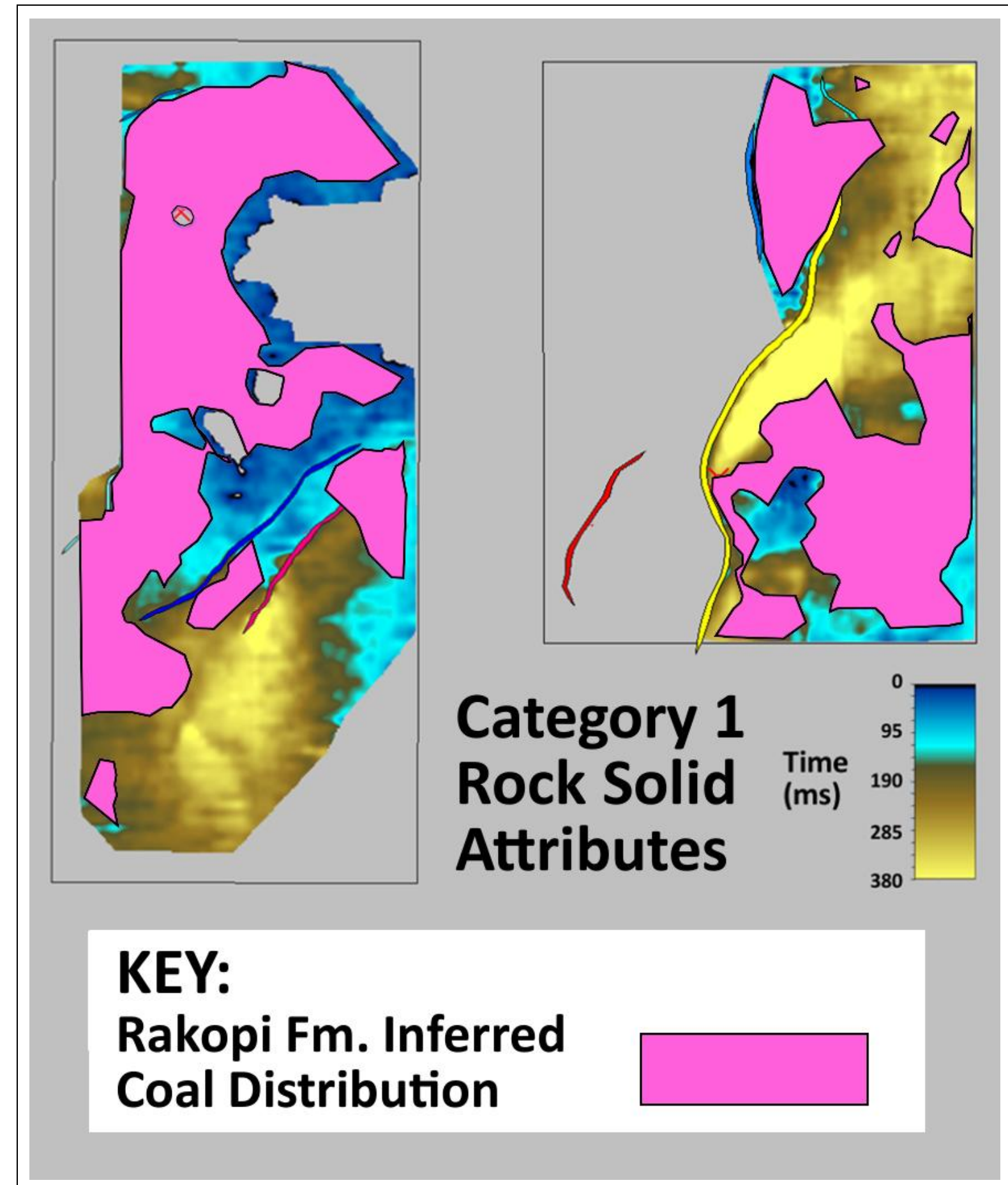

Figure 7.7 Inferred Coal Distributions - All Category 1 RSAs

Shown is the Rakopi Formation isochron map for the Pipeline (left) and Maari (right) 3D seismic reflection volumes, with the thickness in ms TWTT given by the inset colour scale. Superimposed atop in pink is the inferred distribution of Rakopi Formation coals (49\%), based on the overlap of areas predicted by all Category 1 RSAs (Figures 7.1-7.4). 

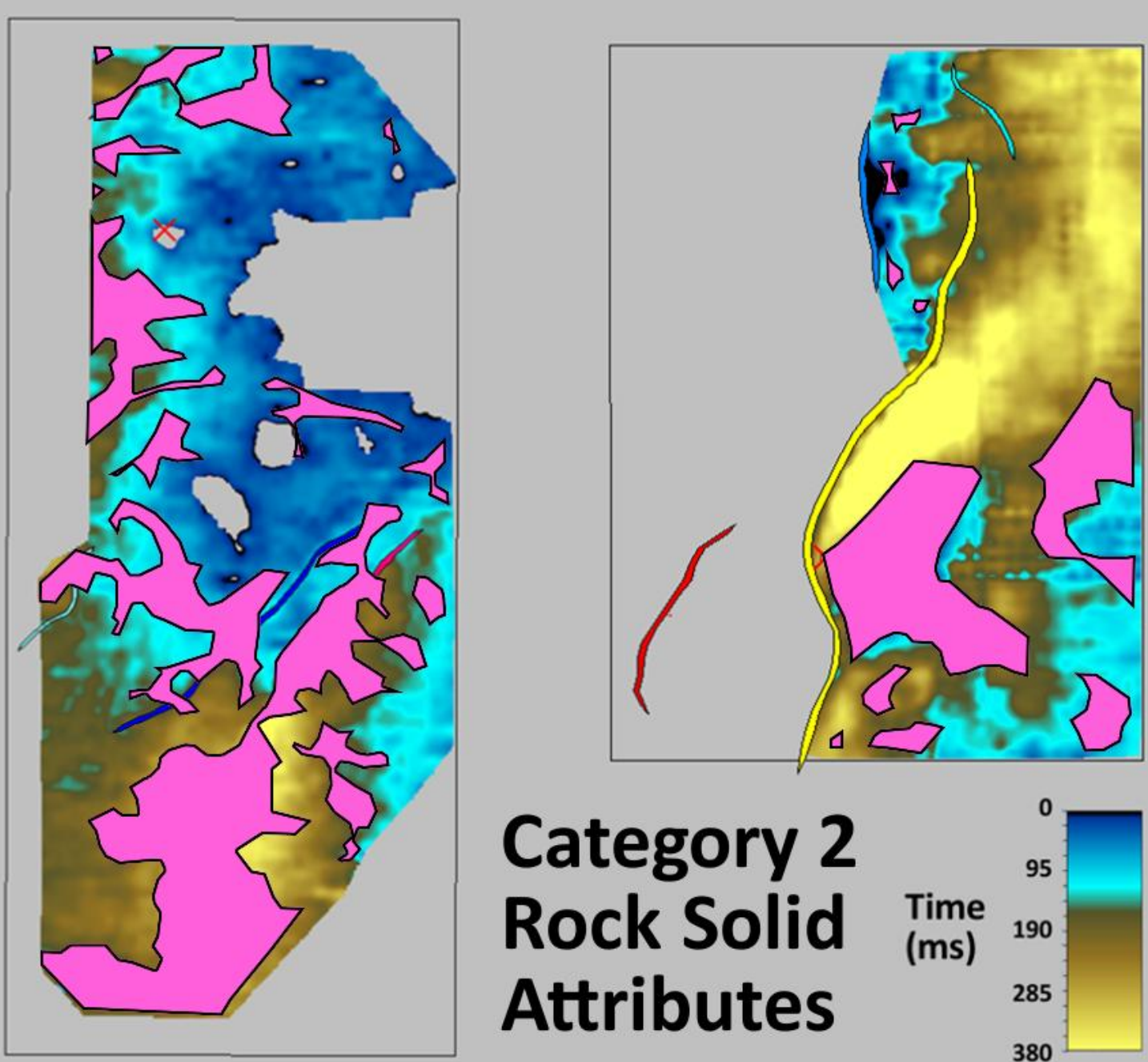

\section{Category 2 Rock Solid Attributes}

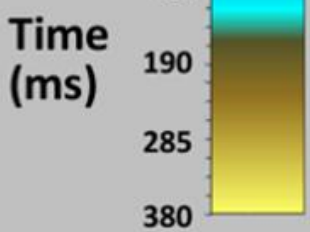

\section{KEY: \\ Rakopi Fm. Inferred Coal Distribution}

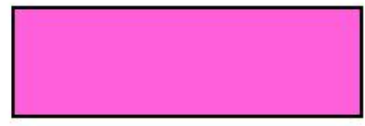

Figure 7.8 Inferred Coal Distributions - All Category 2 RSAs

Shown is the Rakopi Formation isochron map for the Pipeline (left) and Maari (right) 3D seismic reflection volumes, with the thickness in ms TWTT given by the inset colour scale. Superimposed atop in pink is the inferred distribution of Rakopi Formation coals (28.8\%), based on the overlap of areas predicted by all Category 2 RSAs (Figures 7.5-7.6). 


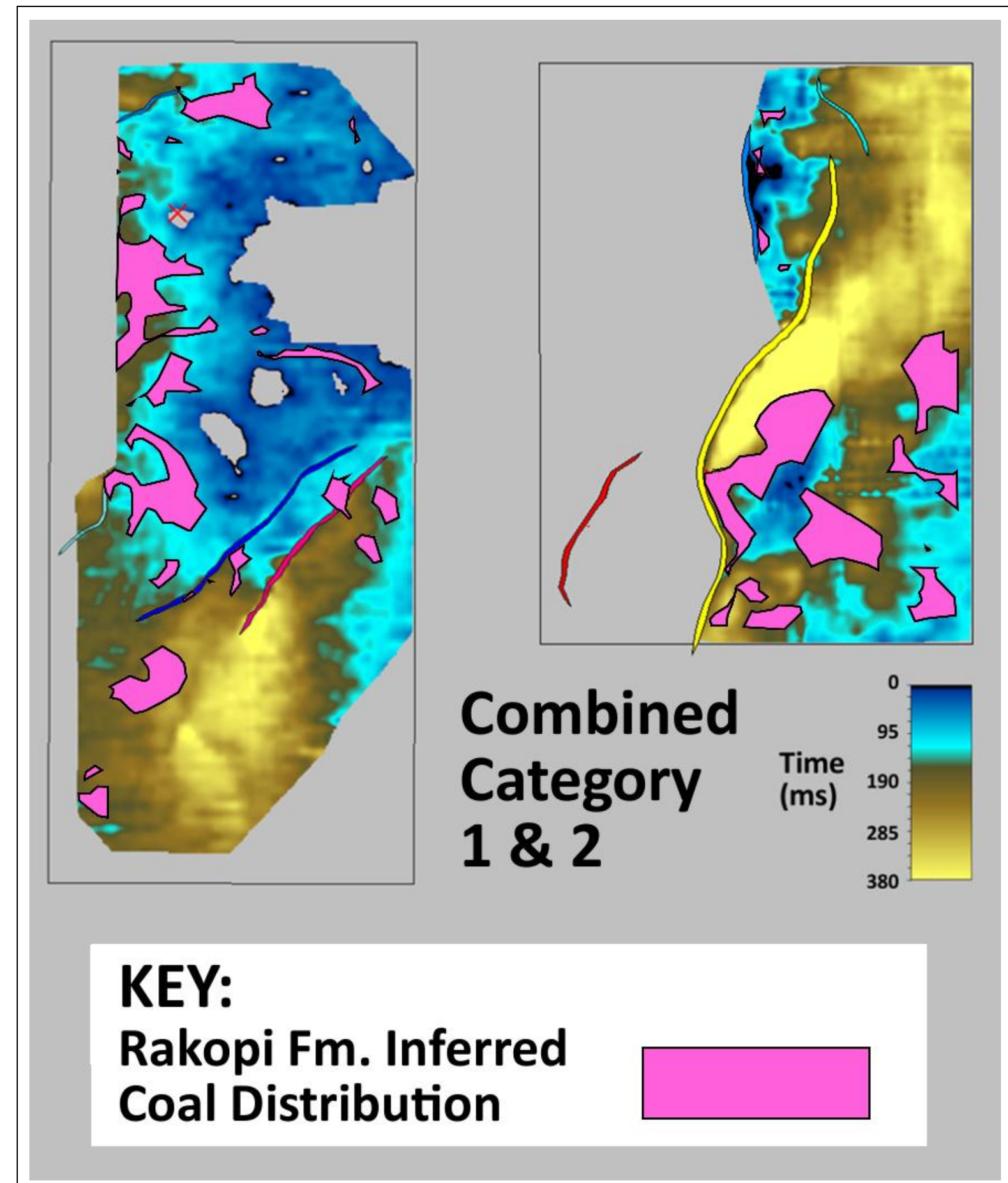

Figure 7.9 Inferred Coal Distribution - Combined Category $1 \& 2$ RSAs

Shown is the Rakopi Formation isochron map for the Pipeline (left) and Maari (right) 3D seismic reflection volumes, with the thickness in ms TWTT given by the inset colour scale. Superimposed atop in pink is the inferred distribution of Rakopi Formation coals (13.9\%), based on the overlap of areas predicted by all Category 1 and 2 RSAs (Figures 7.1-7.6). 


\subsection{Applications}

\subsubsection{Limitations and Uncertainty}

All of the attribute analysis work so far has been conducted by comparing a coal-rich interval to a sandy/silty-dominated interval, and observing the differences in averages and distributions of attribute outputs. However, the efficacy of this sort of technique relies upon the presence of a significant sandy/silty layer in the vicinity of the coaly facies for comparison.

Since the acquisition parameters (and thus absolute values for amplitude and other variables) differ across each seismic survey, it is difficult to come up with a method of attribute analysis which deals with absolute values; rather, any coal-predicting attribute formula will need to be based on the ratio of values between coaly and non-coaly intervals. While this uncertainty may be able to be ameliorated by an amplitude/phase normalisation process between datasets, it still poses challenges for the application of this kind of method, which by definition will be used in areas removed from well penetrations, and as such the lithologies of seismic units in these areas are less likely to be known with any certainty.

Additionally, it is acknowledged that the process of averaging outputted attribute values within a stratigraphic interval may cause some simplification of the data, which could lead to a loss of information, especially in cases where the formation being averaged is very thick. In any future application of this method to thick intervals, it may be prudent to iso-slice the interval into several vertical sections, each to be analysed separately.

\subsubsection{Applications to Other Data}

In order to apply the results of this project to further 3D seismic volumes for the identification of coaly facies, the following steps could be followed:

- Interpretation of the relevant sedimentary horizons, to define the potentially coal-rich interval

- Gridding of these horizons throughout the seismic volume or the area of interest to produce continuous surfaces

- Extraction of selected attributes from the seismic volume

- Averaging of the attribute values within each vertical interval of interest, constrained by the interpreted horizons

- Display of these attribute averages in pan view on the basemap

By visually scanning the basemap averages of attribute outputs extracted, it may be possible to narrow down the areas in which coals are more likely to be present, by noting areas of anomalously high values (as carried out in section 7.5, and shown by Figures 7.1-7.9). These areas could then be used as a starting point for more localised attribute extraction on a finer scale. 
If the surrounding lithology is known with some certainty, the stratigraphic sections of the seismic data which contain the highest averaged values of the coal-predicting attributes can be compared to the strata which are known to be silty/sandy, with the results analysed to determine the likelihood of the presence of coals.

However, this would still only give the average values for each given interval, and thus would be a low-resolution method, only giving the likelihood of coals being found within the whole vertical section. In order to gain a higher resolution method of coal identification, the data would need to be split into many subdivisions, with attributes averaged for each, and analysed separately. While this seems to be prohibitively laborious, it is likely that a simple routine could be established that would allow the procedure to be automated once the initial parameters have been determined.

\subsubsection{Ratios of RSA Values between Coaly and Non-Coaly Intervals}

Given that the absolute values of amplitude will vary between seismic surveys, it is the ratios of temporally-averaged RSA values between the coaly and non-coaly intervals which could be used to predict coal percentages in further seismic data unpenetrated by exploration wells (Coaly/Non Ratios).

In order to predict coal volumes accurately, a method of converting these Coaly/Non Ratios into a range of possible coal percentages needs to be established. To do this, more data must be obtained, to narrow the range of the mathematical relationship between the Coaly/Non Ratios and coal percentage volume. Once such an algorithm for each attribute (an Attribute/Coal Relationship) has been deduced more comprehensively by the inclusion of further data, it could potentially then be applied to unexplored seismic data to estimate coal volumes.

Table 7.2 shows the ratios between the temporally-averaged RSA values for coaly and non-coaly facies respectively. This illustrates the wide variation between the ratios for each attribute. Scale Test 2 was conducted in the smallest area directly surrounding the Maui-4 well (Figure 6.2), and as such it should be returning the most accurate values corresponding to the presence of coals, given that the lithology is most certain where it is observed at the well penetration.

Based on the observed coal content of the Lower Coals (43\%), Mangahewa Formation (21.3\%), and Upper Coals (10.6\%), it is expected that the Coaly/Non Ratios would reflect this, and would scale from the Lower Coals to the Upper Coals, correlating to relative coal volume. Comparing the ratios in Table 7.2 between Scale Test 2 and the Mangahewa Formation, it is only the Imaginary Part of Complex Trace attribute that returns a value that is predicted by the above.

It could be the case that there is some sort of threshold of coal volume, over which the attribute outputs change to represent this. It appears to be this way for the RSAs for which the Lower Coals are separate, and the Upper Coals and Mid Silts are basically identical distributions (e.g. Relative 
Acoustic Impedance, Time Derivative of Wavelet Envelope), although for these attributes it is likely that the Attribute/Coal Relationship is non-linear.

\begin{tabular}{|c|c|c|c|c|c|c|c|c|}
\hline & \multicolumn{2}{|c|}{$\begin{array}{l}\text { Total Rakopi } \\
\text { Subdivision }\end{array}$} & \multicolumn{2}{|c|}{ Scale Test 1} & \multicolumn{2}{|c|}{ Scale Test 2} & \multicolumn{2}{|c|}{$\begin{array}{l}\text { Mangahewa } \\
\text { Control Group }\end{array}$} \\
\hline \multirow{2}{*}{$\begin{array}{c}\text { Q by } \\
\text { Frequency } \\
\text { Shift }\end{array}$} & Lower:Mid & -0.83567 & Lower:Mid & -7.37638 & Lower:Mid & -1.55605 & \multirow{2}{*}{$\begin{array}{l}\text { Coaly: } \\
\text { Non- } \\
\text { Coaly }\end{array}$} & \multirow[t]{2}{*}{-2.16782} \\
\hline & Upper:Mid & 0.42013 & Upper:Mid & -2.31645 & Upper:Mid & -0.29286 & & \\
\hline \multirow{2}{*}{$\begin{array}{c}\text { Relative } \\
\text { Acoustic } \\
\text { Impedance }\end{array}$} & Lower:Mid & -18.7518 & Lower:Mid & -14.8522 & Lower:Mid & -8.57443 & \multirow{2}{*}{$\begin{array}{l}\text { Coaly: } \\
\text { Non- } \\
\text { Coaly }\end{array}$} & \multirow{2}{*}{-1.14624} \\
\hline & Upper:Mid & 0.411361 & Upper:Mid & 0.448339 & Upper:Mid & -1.04646 & & \\
\hline \multirow{2}{*}{$\begin{array}{l}\text { Imaginary } \\
\text { Part of } \\
\text { Complex } \\
\text { Trace }\end{array}$} & Lower:Mid & 778.2249 & Lower:Mid & -29.0209 & Lower:Mid & -7.07957 & \multirow{2}{*}{$\begin{array}{l}\text { Coaly: } \\
\text { Non- } \\
\text { Coaly }\end{array}$} & \multirow{2}{*}{-1.37786} \\
\hline & Upper:Mid & 4.136103 & Upper:Mid & 0.394629 & Upper:Mid & -1.49366 & & \\
\hline \multirow{2}{*}{$\begin{array}{c}\text { Time } \\
\text { Derivative } \\
\text { of Wavelet } \\
\text { Envelope }\end{array}$} & Lower:Mid & 1.293331 & Lower:Mid & 1.517239 & Lower:Mid & 1.413624 & \multirow{2}{*}{$\begin{array}{l}\text { Coaly: } \\
\text { Non- } \\
\text { Coaly }\end{array}$} & \multirow{2}{*}{2.244853} \\
\hline & Upper:Mid & 1.327224 & Upper:Mid & 1.430995 & Upper:Mid & 1.38161 & & \\
\hline \multirow{2}{*}{$\begin{array}{c}\text { Trace } \\
\text { Envelope }\end{array}$} & Lower:Mid & 1.404939 & Lower:Mid & 1.637642 & Lower:Mid & 1.579719 & \multirow{2}{*}{$\begin{array}{l}\text { Coaly: } \\
\text { Non- } \\
\text { Coaly }\end{array}$} & \multirow{2}{*}{2.706131} \\
\hline & Upper:Mid & 1.43148 & Upper:Mid & 1.616692 & Upper:Mid & 1.461435 & & \\
\hline \multirow{2}{*}{$\begin{array}{l}\text { Wavelet } \\
\text { Envelope }\end{array}$} & Lower:Mid & 1.470466 & Lower:Mid & 1.78872 & Lower:Mid & 1.797877 & \multirow{2}{*}{$\begin{array}{l}\text { Coaly: } \\
\text { Non- } \\
\text { Coaly }\end{array}$} & \multirow{2}{*}{2.508478} \\
\hline & Upper:Mid & 1.348148 & Upper:Mid & 1.461949 & Upper:Mid & 1.361227 & & \\
\hline
\end{tabular}

Table 7.2 Ratios of RSA Values in Coaly/Non-Coaly Intervals

Calculated from the average values for each RSA outputted from each interval sampled.

\subsection{Outlook}

The method of seismic attribute extraction and analysis heretofore described could potentially be applied to other 3D seismic reflection data, for the purpose of identifying and constraining coaly hydrocarbon source rocks in areas that are not penetrated by wells.

It would be useful to find a seismic section which contains a very high percentage of known coal seams (i.e. $70-80 \%$ intersected by a well), with a silty/sandy stratum in the same vertical section. By extracting the attributes from these, and comparing the Coaly/Non Ratios, this would produce results which would give a clearer picture of how the chosen attributes respond to very high levels of coals, as opposed to the levels of coals seen in the Lower Coals and Upper Coals respectively.

If more data is obtained, to display the full range of likely-occurring coal percentages by volume, a more quantitative sense will be gained of how the attributes respond to the increased volume of coals. If a rate of change can be observed between the coal percentage and the relative attribute outputs, then this will be able to be applied to other 3D datasets, to more accurately predict source rock volumes. 
The actions which could be taken to assess the robustness of these attributes as coal predictors is as follows:

- Find additional 3D seismic volumes with well penetrations and known coaly facies

- Iso-slice the vertical section surrounding the well into 100ms slices (or sufficient resolution)

- Measure or estimate the coal percentage volume for each of the horizontal iso-slices

- Extract the chosen attributes from a small section of the data surrounding the well

- Average attributes for each iso-slice

From this, each interval's attribute averages can be assessed, and then the Coaly/Non Ratios can be recorded, and correlated to the coal percentage of each respective vertical interval to further constrain the Attribute/Coal Relationship.

After a few such tests as this, it should be apparent whether this method can be developed into a robust coal predictor.

\subsection{Implications for Petroleum Systems Models}

If the selected attributes are found to be a robust predictor of coaly facies, and a method can be developed to utilise them to locate coals in areas removed from well penetrations, this will have practical applications. Namely, it will assist in any volumetric calculations of hydrocarbon charge undertaken as part of drilling risk assessment, increasing accuracy, lowering risk, and ultimately reducing costs.

There have been a suite of 6 RSA attributes which have been identified as responding to the presence of coal rich intervals, either responding to the percentage of coal by volume (Category 1 ) or the absolute presence of a higher percentage of coal (Category 2). These RSAs produce repeatable results based on trials at different scales and in different intervals. Based on the occurrence of extreme values of these RSAs when viewed as average values within the Rakopi Formation as a whole, the likely areas of high coal concentration have been mapped within the Maari and Pipeline 3D seismic volumes.

This method of attribute extraction and analysis has potential to be applied to other seismic, and with further work could potentially be used to conduct volumetric calculations of coal volumes within a formation. 


\subsection{Conclusions}

\subsubsection{Summary}

This project has shown that the coals in the southwest offshore Taranaki Basin are overestimated within the Cretaceous Rakopi Formation, and has succeeded in constraining them further based on temporally-averaged attribute value frequency distributions in coaly and non-coaly intervals, which were subject to numerous control tests.

\subsubsection{Project Achievements}

This project investigated the utility of extracted seismic attributes for the purpose of identifying Cretaceous age coaly hydrocarbon source rocks within the southern Taranaki Basin, New Zealand. This was undertaken through interpretation of the relevant strata in the 3D seismic data present in the study area, and subsequent extraction and analysis of seismic attributes from selected intervals.

In particular, this project has:

- Interpreted the Cretaceous and selected Paleogene strata within the Maari and Pipeline 3D volumes

- Constrained the distribution of the Rakopi Formation in the study area by seismic interpretation of the Basement and Top Rakopi Formation

- Identified a suite of 6 seismic attributes (Seisware ${ }^{\mathrm{TM}} \mathrm{RSAs}$ ) which correlate strongly to the increased presence of coaly facies

- Estimated the coal distribution within the Rakopi Formation in the Pipeline and Maari 3D seismic volumes from the amplitude maps of the 6 selected RSAs

As such, this project has achieved its aim, and has been a valuable first step in the direction of being able to apply a volumetric calculation to seismic data to constrain the total percentage of coaly facies for the purpose of increased accuracy of the risk assessment of petroleum systems models.

\subsubsection{Recommendation}

As shown in Section 7.5, the distribution of coals within the Rakopi Formation can be constrained to a distribution throughout a maximum of 65.8\% (as predicted by Q by Frequency Shift, see Figure 7.4 and Section 7.3.4), and as little as $13.9 \%$ of the total area of the formation (as predicted by the overlap of all 6 selected RSAs, see Figure 7.9). As such, the total hydrocarbons generated by the basin have been overestimated in petroleum systems models thus far. It is recommended that the models be adjusted to account for this lessened coal percentage by volume, instead of the entire Rakopi Formation being modelled as source rock. Ideally, the same method of attribute extraction and analysis would be conducted in other 3D surveys in the Taranaki Basin which contain the Cretaceous 
interval, in order to collect more data. From this, a more accurate estimate of the coal percentage of the Cretaceous can be made, for the purpose of increased accuracy of hydrocarbon charge models in the basin.

\subsubsection{Applications}

The development and application of a method of seismic attribute analysis to predict coaly hydrocarbon source rocks in other areas is beyond the scope of this project. However, given further work, it may be possible to come up with a method, using a process similar to that outlined in Section 7.3 . 


\section{References}

Allaby, M. 2013. A Dictionary of Geology and Earth Sciences. $4^{\text {th }}$ Edition. Oxford University Press.

Allen, P.A., \& Allen, J.R. 2013. Basin Analysis - Principles and Application to Petroleum Play Assessment. $3^{\text {rd }}$ Edition.

Armstrong, P.A., Chapman, D.S., Funnell, R.H., Allis, R.G. \& Kamp, P.J.J. 1996. Thermal modelling and hydrocarbon generation in an active-margin Basin: Taranaki Basin, New Zealand. American Association of Petroleum Geologists Bulletin, 1996, Col. 80(8), pp1216.

Ballance, P.F. 1976. Evolution of the Upper Cenozoic Magmatic Arc and Plate Boundary in Northern New Zealand. Earth and Planetary Science Letters, Vol. 28, pp356-370.

Barnes, A.E. 1993. Instantaneous Spectral Bandwidth and Dominant Frequency with Applications to Seismic Reflection Data. Geophysics. Vol. 58, No. 3. Pp 419-428.

Boggs, S. 1995. Principles of Sedimentology and Stratigraphy. $5^{\text {th }}$ Edition. Pearson Education Inc.

Brown, A.R. 2004. Interpretation of Three-Dimensional Seismic Data. $6^{\text {th }}$ Edition. The American Association of Petroleum Geologists and the Society of Exploration Geophysicists.

Browne, G.H., Kennedy, E.M., Constable, R.M., Raine, J.I., Crouch, E.M. \& Sykes, R. 2008. An outcrop-based study of the economically significant Late Cretaceous Rakopi Formation, northwest Nelson, Taranaki Basin, New Zealand. New Zealand Journal of Geology and Geophysics. 51:4, pp295-315.

Bull, S., Hill, M. G., Strogen, D. P., Arnot, M., Seebeck, H., Kroeger, K. F., Zhu, H. 2015. Seismic interpretation, static modelling and velocity modelling of the southern Taranaki Basin. (4D Taranaki Project), GNS Science Report 2016/02.

Chopra, S. \& Marfurt, K.J. 2007. Seismic Attributes for Prospect Identification and Reservoir Characterization. Society of Exploration Geophysicists.

Coulombe, C.A. \& Bird, D.N. 1996. Transmission filtering by high-amplitude reflection coefficients: Theory, practice, and processing considerations. The Leading Edge, 1996.

Gaina, C, Muller, D.R., Royer, J-Y., Stock, J., Hardebeck, J. \& Symonds, P. 1998. The tectonic history of the Tasman Sea: A puzzle with 13 pieces. Journal of Geophysical Research, Vol. 103, No. B6, pp12,413-12,433. 
Griffin, A. 2010. GNS Science North Tasman-1 Well Summary Sheet.

Griffin, A. 2011. GNS Science Maui-4 Well Summary Sheet.

Griffin, A. 2013.a. GNS Science Ariki-1 Well Summary Sheet

Griffin, A. 2013.b. GNS Science Cape Farewell-1 Well Summary Sheet.

Griffin, A. 2013.c. GNS Science Cook-1 Well Summary Sheet.

Griffin, A. 2013.d. GNS Science Fresne-1 Well Summary Sheet.

Griffin, A. 2013.e. GNS Science Tane-1 Well Summary Sheet.

Hart, B.S. 1999. Definition of subsurface stratigraphy, structure and rock properties from 3-D seismic data. Earth Science Reviews 47 (1999), pp189-218.

Holt, W.E. \& Stern, T.A. 1994. Subduction, platform subsidence, and foreland thrust loading: The late Tertiary development of Taranaki Basin, New Zealand.

Hughes, V.J. \& Kennett, B.L.N. 1983. The nature of seismic reflections from coal seams. First Break February 1983/9.

Institute of Geological \& Nuclear Sciences Limited. 2002. GNS Science Taranga-1 Well Summary Sheet (authors unspecified).

Kearey, P., Brooks, M., \& Hill, I. 2002. An Introduction to Geophysical Exploration. Blackwell Science Ltd.

King, P.R. 2000. New Zealand's changing configuration in the last 100 million years: plate tectonics, basin development, and depositional setting. 2000 New Zealand Petroleum Conference Proceedings. 19-22 March 2000.

King, P.R., Naish, T.R., Browne, G.H., Field, B.D., Edbrooke, S.W. (compilers), 1999. Cretaceous to Recent sedimentary patterns in New Zealand. Institute of Geological and Nuclear Sciences folio series 1, version 1999.1. Folder with xx p, 1 enclosure. Lower Hutt, New Zealand: Institute of Geological \& Nuclear Sciences Limited.

King, P.R. \& Thrasher, G.P. 1996. Cretaceous-Cenozoic geology and petroleum systems of the Taranaki Basin, NZ. Institute of Geological and Nuclear Sciences Monograph 13. 
Kroeger, K.F., Funnell, R., Arnot, M. J., Bull, S., Hill, M. \& Zhu, H. 2016. Reassessment of Exploration Risks in Taranaki Basin Related to Gondwana Margin Evolution and Establishment of an Active Plate Boundary in New Zealand Using Integrative 3-D Basin Modelling. Search and Discovery Article \#10834.

Jackson, C.A.-L., Grunhagen, H., Howell, J.A., Larsen, A.L., Andersson, A., Boen, F. \& Groth, A. 2010. 3D seismic imaging of lower delta-plain beach ridges: lower Brent Group, northern North Sea. Journal of the Geological Society, London, Vol. 167, 2010, pp1225-1236.

Mitchum, R.M., Vail, P.R. \& Sangree, J.B. 1977. Seismic stratigraphy and global changes of sea level, part 6: stratigraphic interpretation of seismic reflection patterns in depositional sequences. Payton, C.E. ed. Seismic Stratigraphy - Applications to Hydrocarbon Exploration. AAPG Memoir 26: pp117-133.

Muir, R.J., Bradshaw, J.D., Weaver, S.D. \& Laird, M.G. 2000. The influence of basement structure on the evolution of the Taranaki Basin, New Zealand. Journal of the Geological Society, London, Vol. 157, 2000, pp1179-1185.

New Zealand Petroleum and Minerals website. http://www.nzpam.govt.nz/cms.

Nicol, A., Walsh, J., Berryman, K. \& Nodder, S. 2005. Growth of a normal fault by the accumulation of slip over millions of years. Journal of Structural Geology 27 (2005) pp327-342.

Pilaar, W.F.H. \& Wakefield, L.L. 1978. Structural and Statigraphic Evolution of the Taranaki Basin, Offshore North Island, New Zealand. APEA Journal, Vol. 18, pp93-101.

Palmer, J.A. \& Andrews, P.B. 1993. Cretaceous-Tertiary Sedimentation and Implied Tectonic Controls on the Structural Evolution of the Taranaki Basin, New Zealand. In: Southern Pacific Sedimentary Basins, pp309-328. Elsevier Science Publishers, Amsterdam.

Rock Solid Images. 2016. http://www.rocksolidimages.com/attributes-revisited/\#_Toc328470857.

Quan, Y. \& Harris, J.M. 1997. Seismic attenuation tomography using the frequency shift method. Geophysics, Vol. 62, No. 3, pp895-905

Raine, J.I. 2004. Palynology of coal seam samples, Pakawau Group.

Reilly, C., Nicol, A., Walsh, J.J., \& Seebeck, H. 2015. Evolution of faulting and plate boundary deformation in the Southern Taranaki Basin, New Zealand. Tectonophysics 651-652 (2015) pp 1-18. 
Robertson, J.D. \& Nogami, H.H. 1984. Complex Seismic Trace Analysis of Thin Beds. Geophysics. Vol 49, No. 4. Pp 344-352.

Roncaglia, L. 2010.a. GNS Science Pukeko-1 Well Summary Sheet.

Roncaglia, L. 2010.b. GNS Science Tahi-1 Well Summary Sheet.

Roncaglia, L., Griffin, A., Tamin, \& Boyes, A. 2012. GNS Science Takapou-1 Well Summary Sheet.

Sahoo, T.R., King, P.R., Bland, K.J., Strogen, D.P., Sykes, R. \& Bache, F. 2014. Tectono-

sedimentary evolution and source rock distribution of the mid to Late Cretaceous succession in the

Great South Basin, New Zealand. APPEA Journal 2014. Pp259-274.

Sherwood, A.M., Lindqvist, J.K., Newman, J., \& Sykes, R. 1992. Depositional controls on Cretaceous coals and coal measures in New Zealand. Controls on the Distribution and Quality of Cretaceous Coals. Geological Society of America Special Paper 267. Pp 325-346.

Stern, T.A. \& Davey, F.J. 1990. Deep seismic expression of a foreland basin: Taranaki Basin, New Zealand. Geology, Vol. 18, pp979-982.

Stern, T.A., Stratford, W.R., Salmon, M.L. 2006. Subduction evolution and mantle dynamics at a continental margin: central North Island, New Zealand. Reviews of Geophysics 44: RG4002.

Sykes, R., Snowdon, L.R., \& Johansen, P.E. 2004. Leaf biomass - a new paradigm for sourcing the terrestrial oils of Taranaki Basin. Petroleum Exploration Society of Australia, special publication.

Sykes, R., Volk, H., George, S.C., Ahmed, M., Higgs, K.E., Johansen, P.E. \& Snowdon, L.R. 2014. Marine influence helps preserve the oil potential of coaly course rocks: Eocene Mangahewa Formation, Taranaki Basin, New Zealand. Organic Geochemistry 66. Pp 140-163.

Taner, M.T. 2003. Attributes Revisited. Rock Solid Images (RSI).

Taner, M.T., Koehler, F. \& Sheriff, R.E. 1979. Complex Seismic Trace Analysis. Geophysics. Vol 44, No. 6. Pp 1041-1063.

Thompson, J.G. 1982. Hydrocarbon source rock analyses of Pakawau Group and Kapuni Formation sediments, northwest Nelson and offshore South Taranaki, New Zealand. New Zealand Journal of Geology and Geophysics, 25:2, pp141-148.

Thrasher, G.P. 1992. Last Cretaceous Geology of the Taranaki Basin. PhD thesis, Victoria University of Wellington. 
Uruski, C.I. 2008. Deepwater Taranaki, New Zealand: structural development and petroleum potential. Exploration Geophysics 39, Pp 94-107.

Voggenreiter, W.R. 1993. Structure and evolution of the Kapuni Anticline, Taranaki Basin, New Zealand: Evidence from the Kapuni 3D seismic survey. New Zealand Journal of Geology and Geophysics, 36:1, pp77-94.

Wizevich, M.C., Thrasher, G.P., Bussell, M.R., Wilson, G.J. \& Collen, J.D. 1992. Evidence for marine deposition in the Late Cretaceous Pakawau group, northwest Nelson. New Zealand Journal of Geology and Geophysics, 35:3, pp363-369.

Wizevich, M.C. 1994. Sedimentary evolution of the onshore Pakawau Subbasin: rift sediments of the Taranaki Basin deposited during Tasman Sea spreading. Evolution of the Tasman Sea Basin. Rotterdam, A.A. Balkema. Pp. 83-104.

Wood, R.A., Funnell, R.H., King, P.R., Matthews, E.R., Thrasher, G.O., Killops, S.D. \& Scadden, P.G. 1998. Evolution of the Taranaki Basin - Hydrocarbon Maturation and Migration with Time. NZ Petroleum Conference 1998. 


\section{Appendix A}

\subsection{Amplitude Attributes}

The following appendix displays the amplitude maps which were generated by the 19 calculations in Seisware ${ }^{\mathrm{TM}}$ based on amplitude, as described in Chapter 5. Each attribute image has its abbreviated name in the lower right. The full names and descriptions of each amplitude attribute calculation are listed below each figure. The results of the extraction of these amplitude-based attributes (which were calculated in the bottom 50ms of the Rakopi Formation interval in the Maari and Pipeline 3D seismic volumes, as outlined in Section 5.1.2) can be divided into 3 basic subcategories, based on the distribution of high and low values within the seismic volume (see Sections 5.1.2-5.1.4).

Each of the figures in this appendix displays the same layout. The Pipeline 3D volume on the left, and the Maari 3D volume on the right. Within these, the calculated amplitude values are displayed as a surface, with the values represented by different colours on an inset scale bar. Note that the values in each respective 3D volume are not on the same scale, and the values for each are shown to either side of the inset colour bar. 

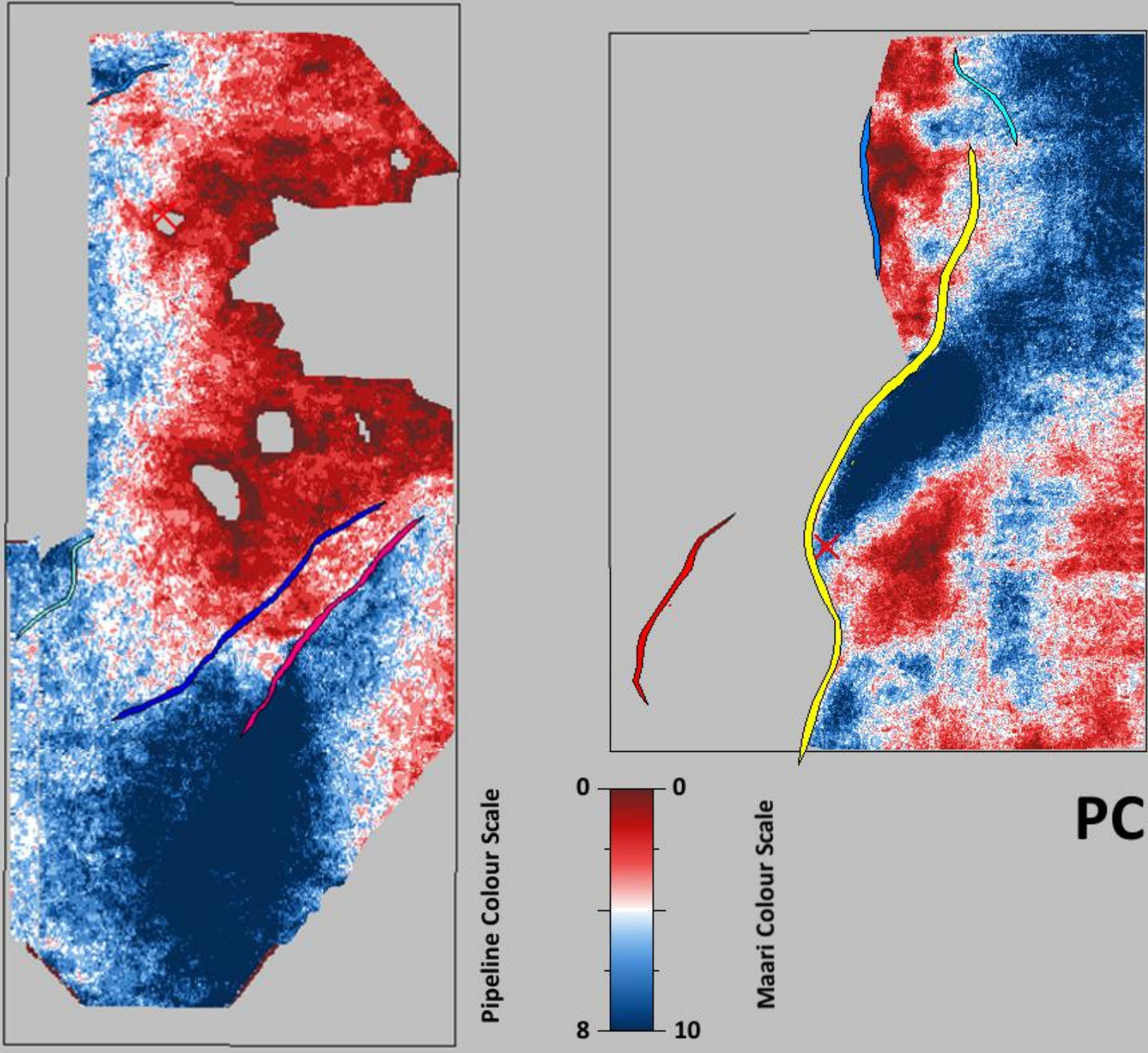

\section{Figure 9.1 Type 1 Amplitude Attribute Maps - Peak Count}

Shown is the horizon generated by this attribute calculation on the Rakopi Formation interval of the Pipeline (left), and Maari (right) 3D seismic volumes, which have their own scales either side of the inset colour bar. Type 1 Amplitude Maps show a strong visual correlation to the Rakopi Formation thickness (see Appendix A section 9.1), as given by the Rakopi Formation Isochron Map (Figure 4.2). The description of the attribute calculation is given below (taken from Seisware ${ }^{\mathrm{TM}}$ ).

\section{Peak Count (PC):}

This will compute the number of above-zero peaks in the sample set.

Please note that zero-crossing horizons work best with this attribute when using a one or two horizon window.

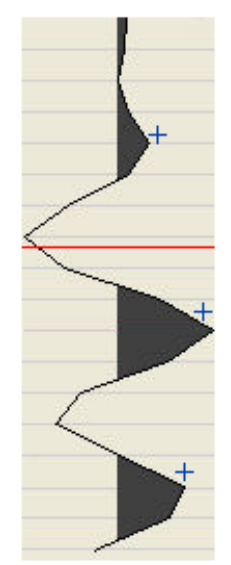



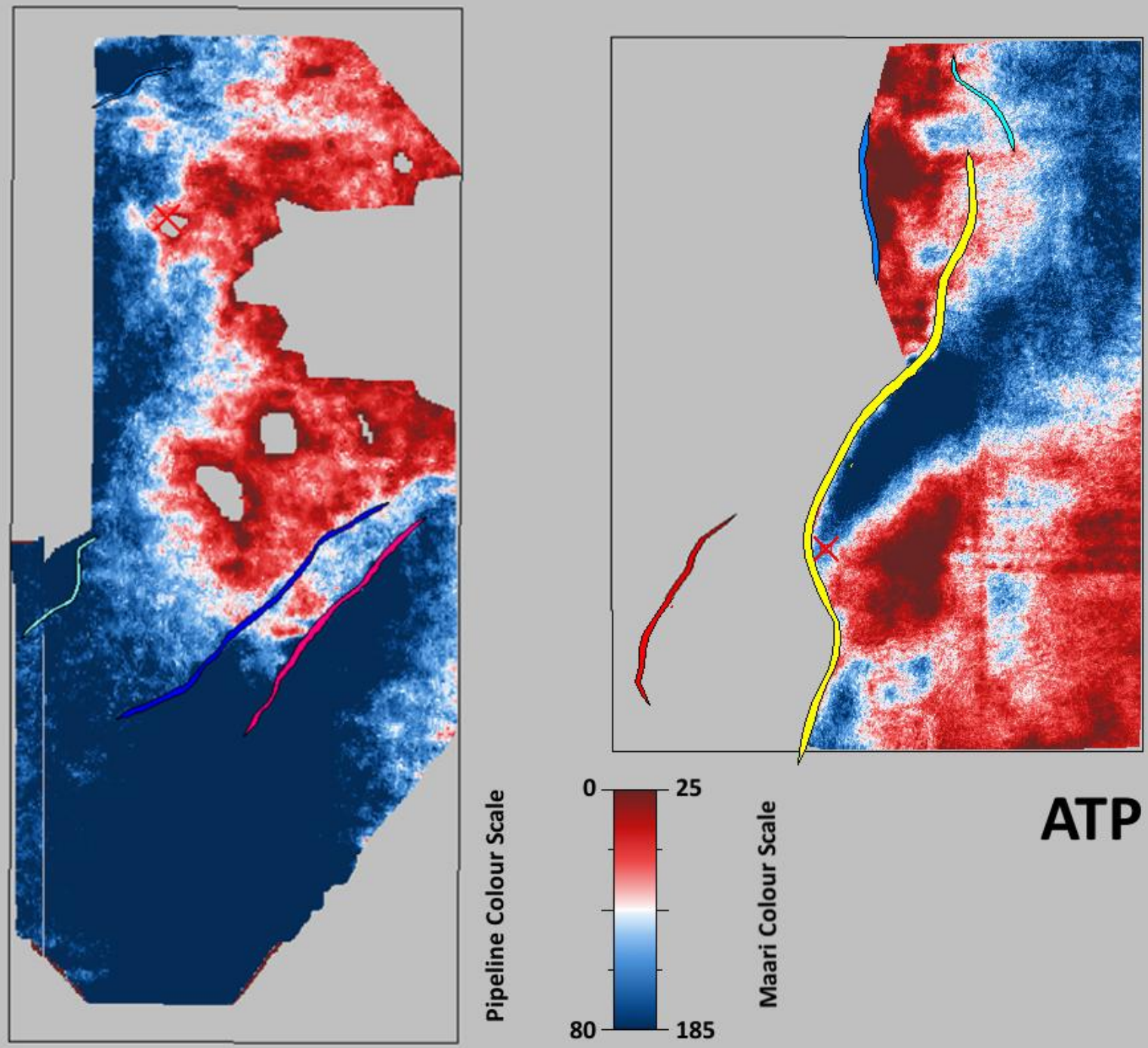

ATP

\section{Figure 9.2 Type 1 Amplitude Attribute Maps - Average Thickness of Peak}

Shown is the horizon generated by this attribute calculation on the Rakopi Formation interval of the Pipeline (left), and Maari (right) 3D seismic volumes, which have their own scales either side of the inset colour bar. Type 1 Amplitude Maps show a strong visual correlation to the Rakopi Formation thickness (see Appendix A section 9.1), as given by the Rakopi Formation Isochron Map (Figure 4.2). The description of the attribute calculation is given below (taken from Seisware ${ }^{\mathrm{TM}}$ ).

Amplitude Thickness of Peak (ATP):

This attribute will compute the number of milliseconds over which the peak lies. A "peak" is any value that is larger than the threshold value specified. Given a threshold of zero, the image to the left shows the samples that would be counted. Interpolated values are used for accuracy.

In this sample, the result will be Thickness A + Thickness B + Thickness C.

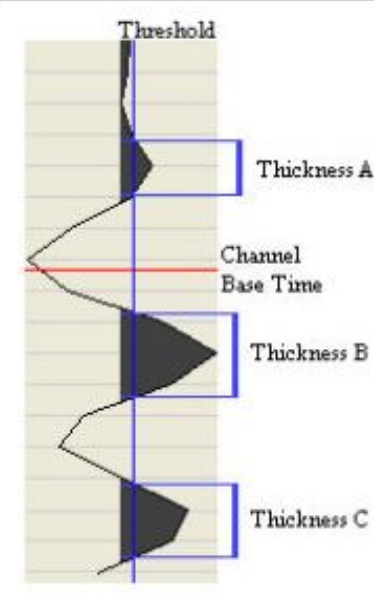



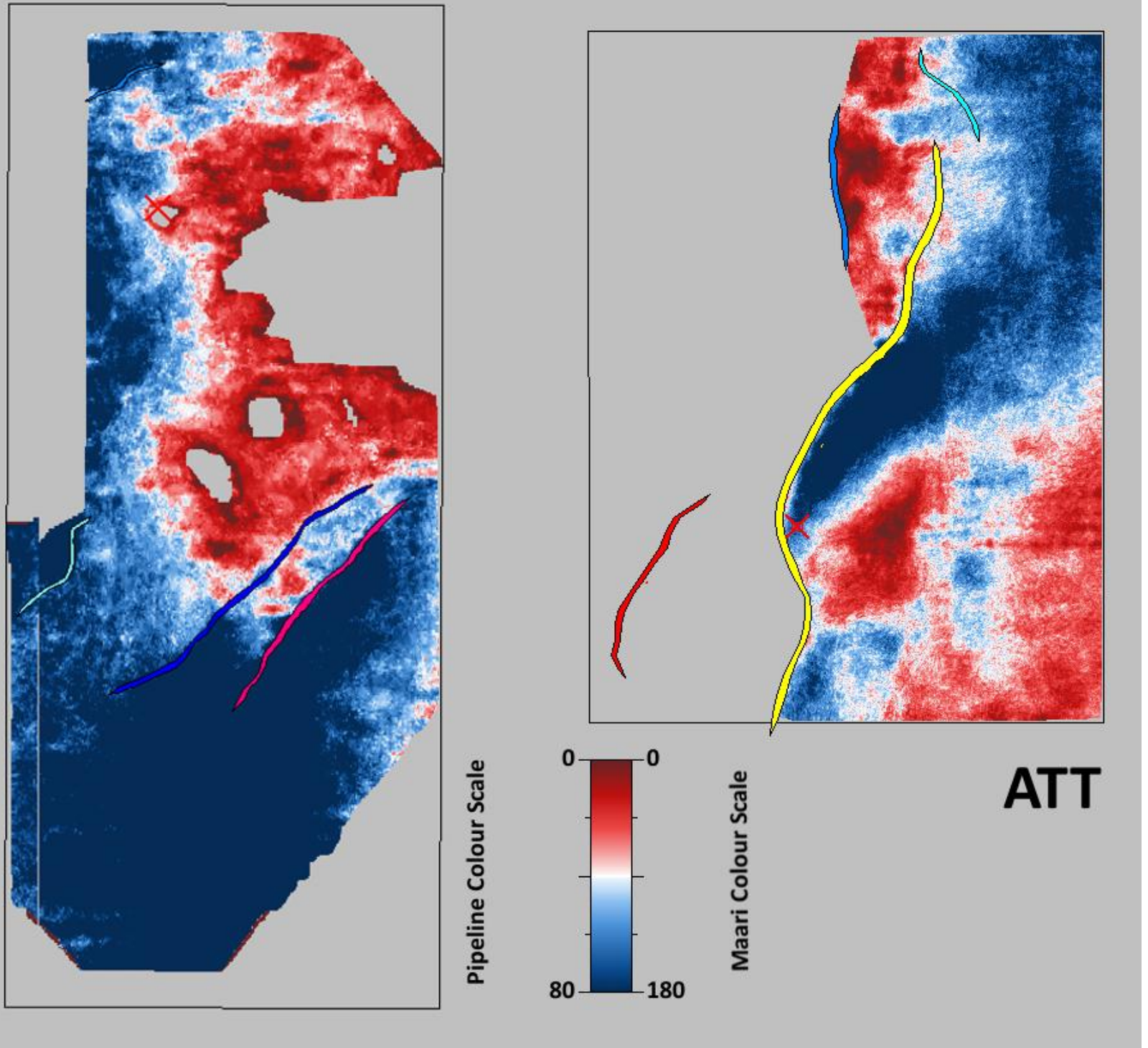

\section{Figure 9.3 Type 1 Amplitude Attribute Maps - Amplitude Thickness of Trough}

Shown is the horizon generated by this attribute calculation on the Rakopi Formation interval of the Pipeline (left), and Maari (right) 3D seismic volumes, which have their own scales either side of the inset colour bar. Type 1 Amplitude Maps show a strong visual correlation to the Rakopi Formation thickness (see Appendix A section 9.1), as given by the Rakopi Formation Isochron Map (Figure 4.2). The description of the attribute calculation is given below (taken from Seisware ${ }^{\mathrm{TM}}$ ).

\section{Amplitude Thickness of Trough (ATI):}

This attribute will compute the number of milliseconds over which the trough lies. A "trough" is any value that is smaller than the threshold value specified. Given a threshold of zero, the image to the left shows the samples that would be counted. Interpolated values are used for accuracy.

In this sample, the result will be Thickness A + Thickness B

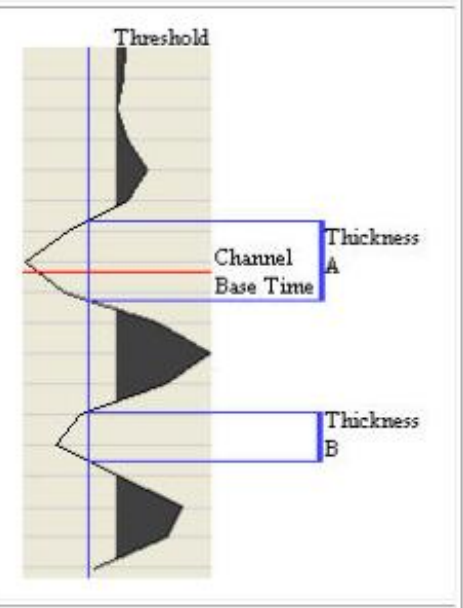




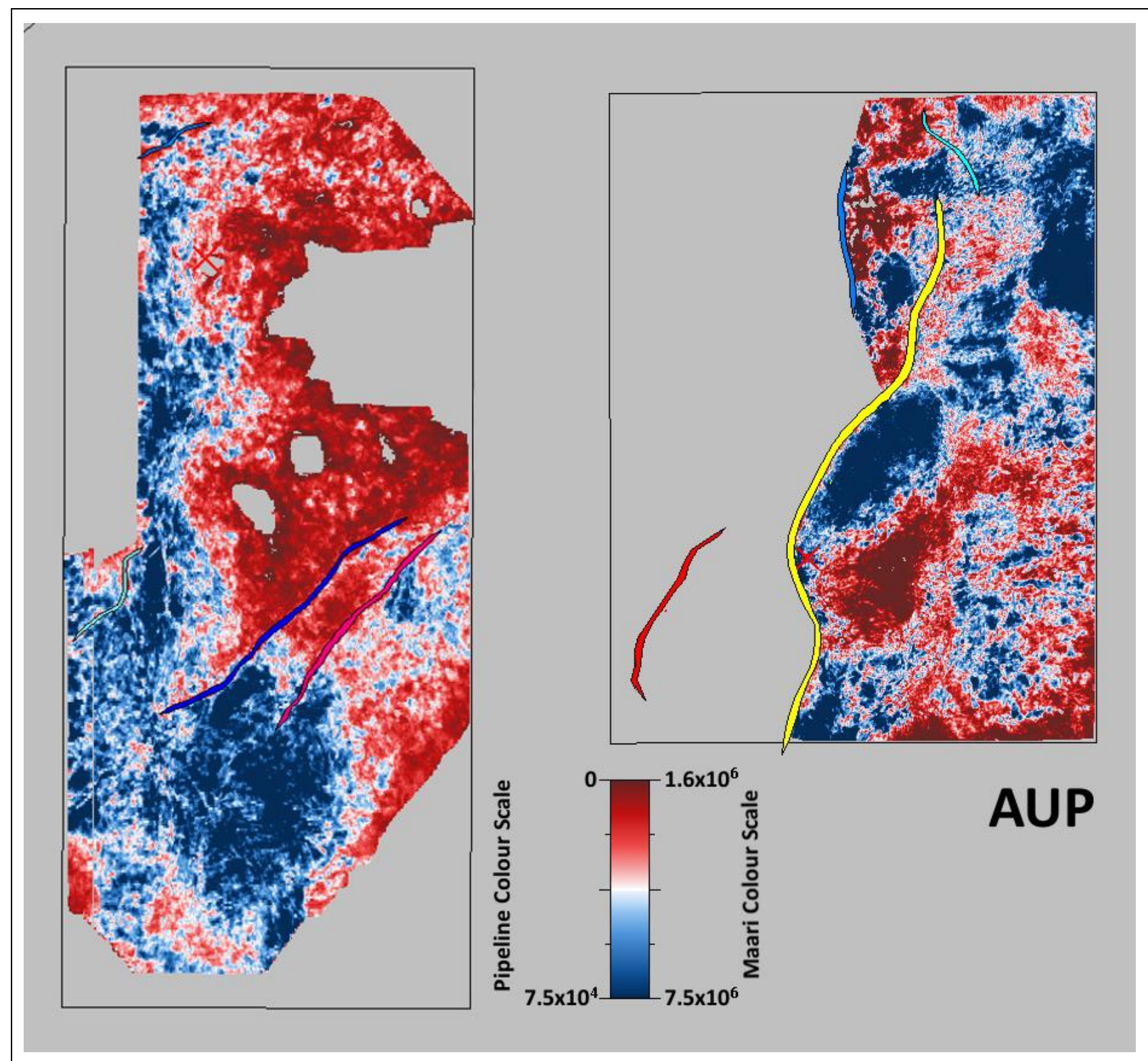

Figure 9.4 Type 1 Amplitude Attribute Maps - Area Under Peak

Shown is the horizon generated by this attribute calculation on the Rakopi Formation interval of the Pipeline (left), and Maari (right) 3D seismic volumes, which have their own scales either side of the inset colour bar. Type 1 Amplitude Maps show a strong visual correlation to the Rakopi Formation thickness (see Appendix A section 9.1), as given by the Rakopi Formation Isochron Map (Figure 4.2). The description of the attribute calculation is given below (taken from Seisware ${ }^{\mathrm{TM}}$ ).

Area Under Peak (AUP):

This attribute will compute the area under the peak. Again, a "peak" is any value that is larger than the threshold value specified. Area is defined as the sample value multiplied by the sample rate and is summed for all samples that are a "peak". Given a threshold of zero, the image to the left shows the areas that would be summed up. Interpolated values are used for accuracy.

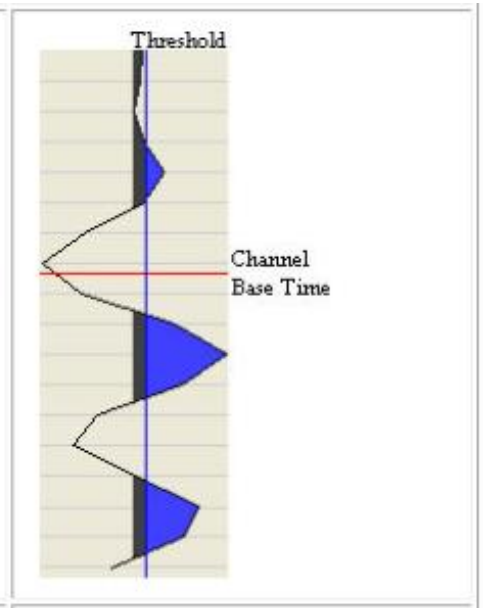




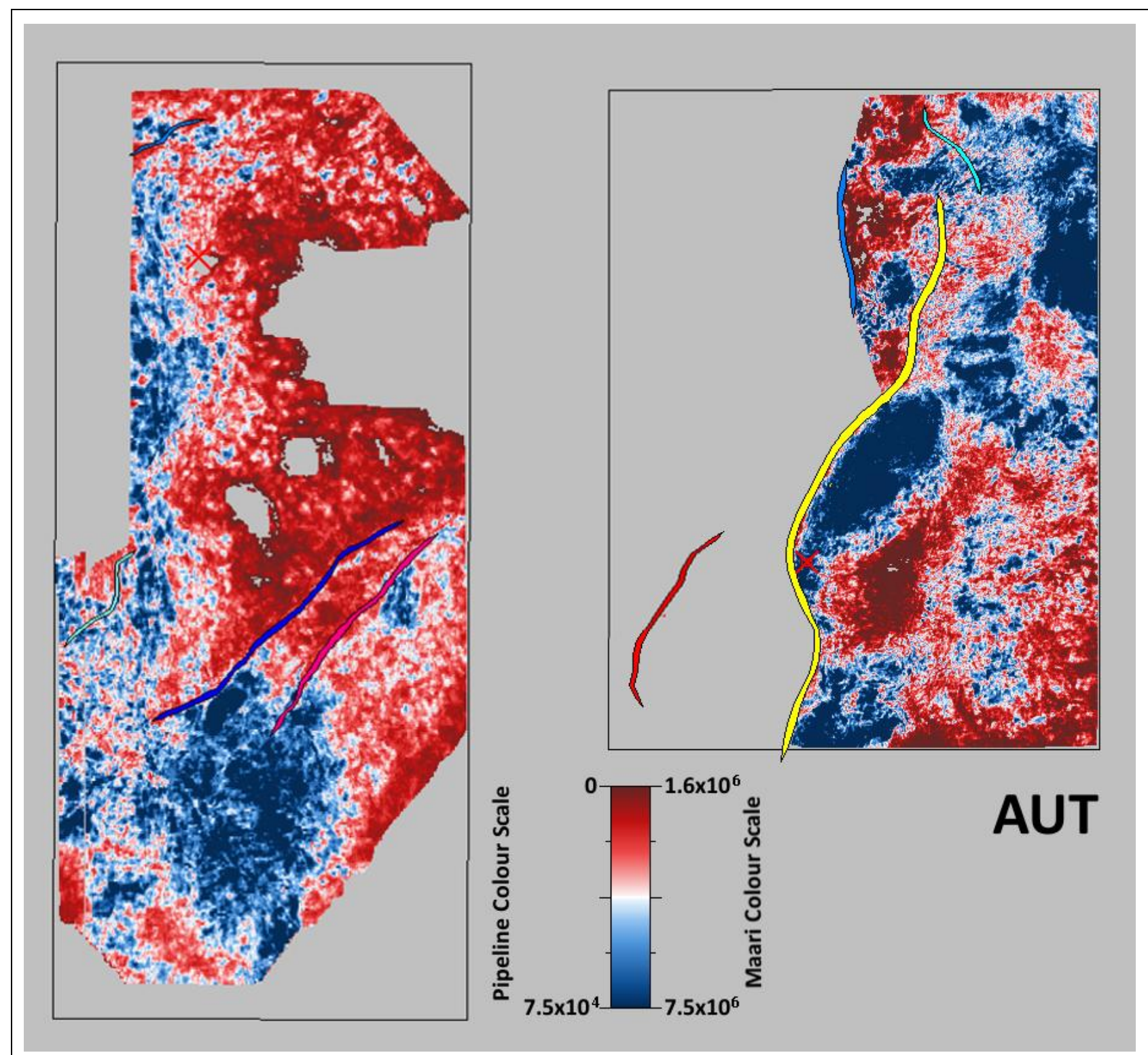

\section{Figure 9.5 Type 1 Amplitude Attribute Maps - Area Under Trough}

Shown is the horizon generated by this attribute calculation on the Rakopi Formation interval of the Pipeline (left), and Maari (right) 3D seismic volumes, which have their own scales either side of the inset colour bar. Type 1 Amplitude Maps show a strong visual correlation to the Rakopi Formation thickness (see Appendix A section 9.1), as given by the Rakopi Formation Isochron Map (Figure 4.2). The description of the attribute calculation is given below (taken from Seisware ${ }^{\mathrm{TM}}$ ).

Area Under Trough (AUT):

This attribute will compute the area under the trough. Again, a "trough" is any value that is smaller than the threshold value specified. Area is defined as the sample value multiplied by the sample rate and is summed for all samples that are a "trough". Given a threshold of zero, the image to the left shows the area that would be summed up. Interpolated values are used for accuracy.

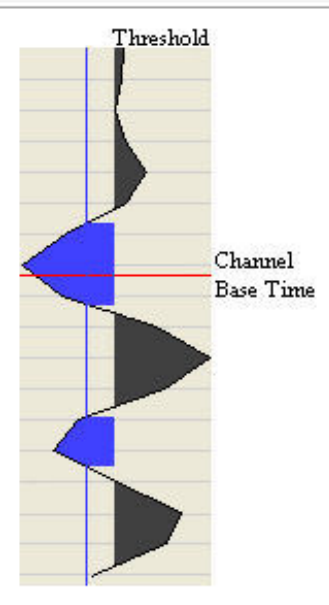




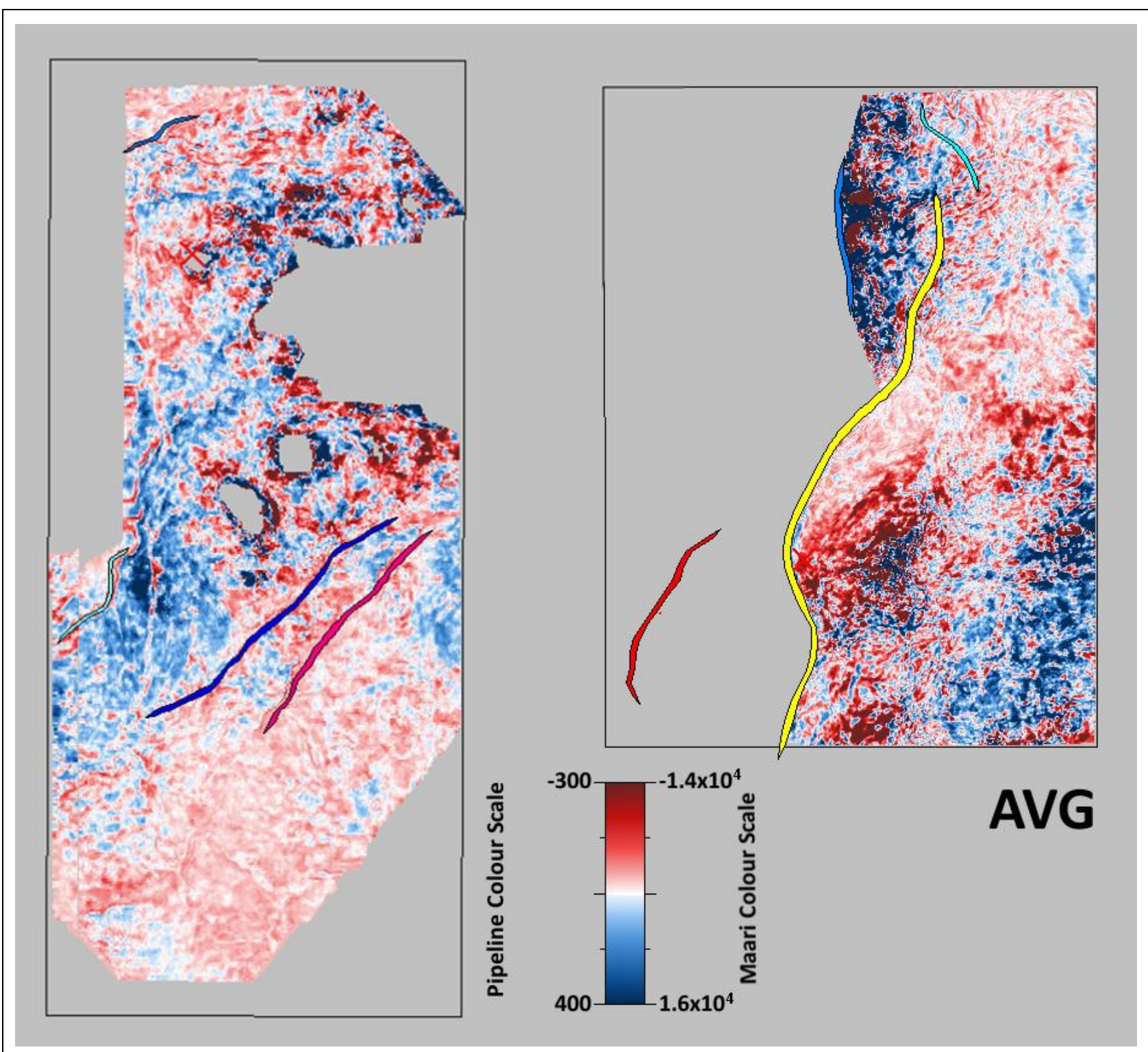

Figure 9.6 Type 1 Amplitude Attribute Maps - Average Value

Shown is the horizon generated by this attribute calculation on the Rakopi Formation interval of the Pipeline (left), and Maari (right) 3D seismic volumes, which have their own scales either side of the inset colour bar. Type 1 Amplitude Maps show a strong visual correlation to the Rakopi Formation thickness (see Appendix A section 9.1), as given by the Rakopi Formation Isochron Map (Figure 4.2). The description of the attribute calculation is given below (taken from Seisware ${ }^{\mathrm{TM}}$ ).

\section{Average Value (AVG):}

This attribute will sum all the sample values within the window and divide by the number of samples. The threshold is ignored.

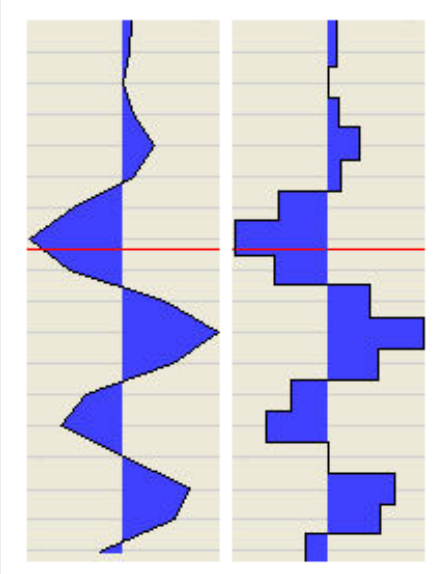



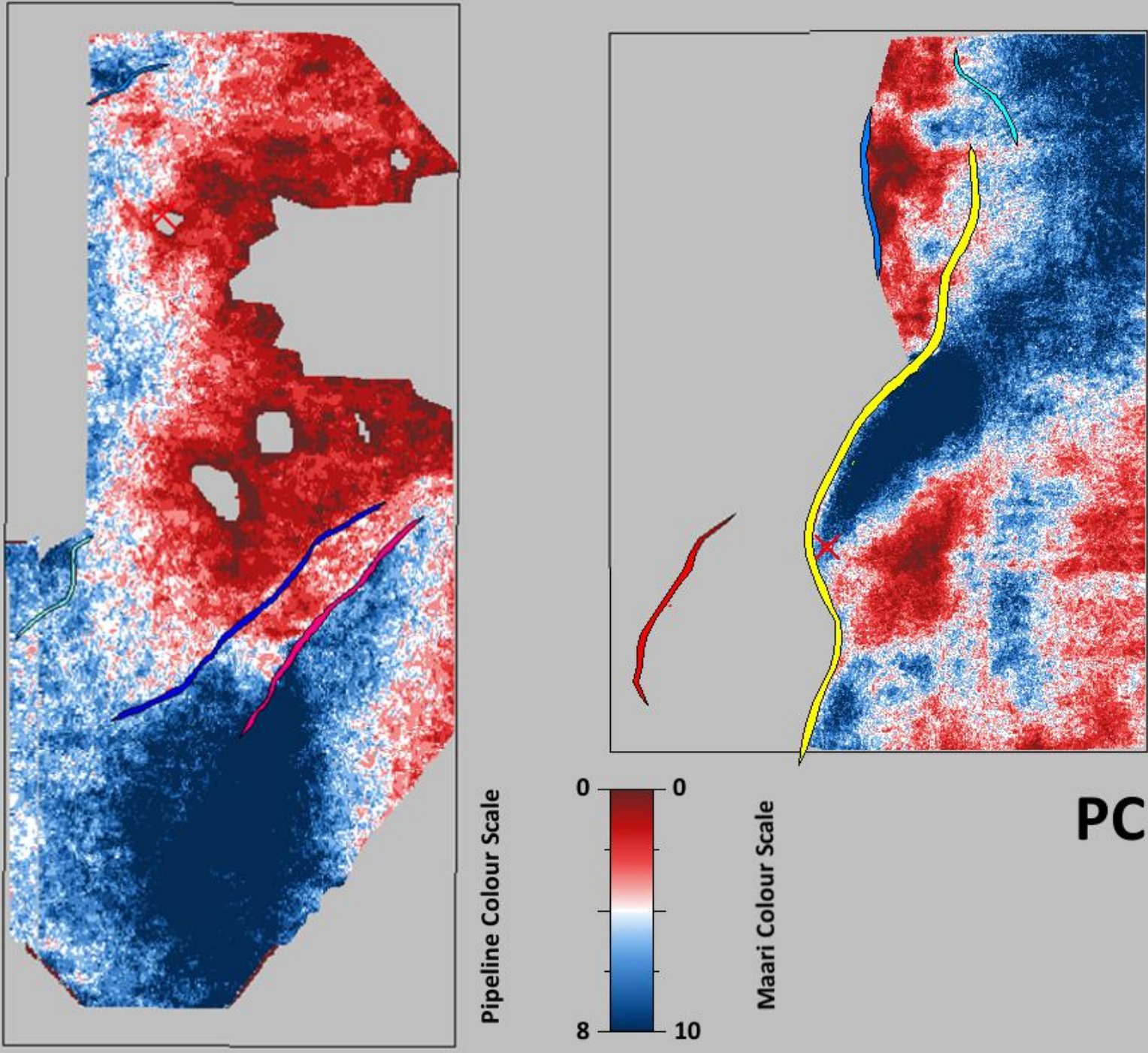

\section{Figure 9.7 Type 1 Amplitude Attribute Maps - Peak Count}

Shown is the horizon generated by this attribute calculation on the Rakopi Formation interval of the Pipeline (left), and Maari (right) 3D seismic volumes, which have their own scales either side of the inset colour bar. Type 1 Amplitude Maps show a strong visual correlation to the Rakopi Formation thickness (see Appendix A section 9.1), as given by the Rakopi Formation Isochron Map (Figure 4.2). The description of the attribute calculation is given below (taken from Seisware ${ }^{\mathrm{TM}}$ ).

\section{Peak Count (PC):}

This will compute the number of above-zero peaks in the sample set.

Please note that zero-crossing horizons work best with this attribute when using a one or two horizon window.

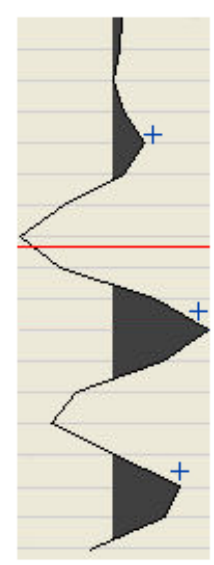




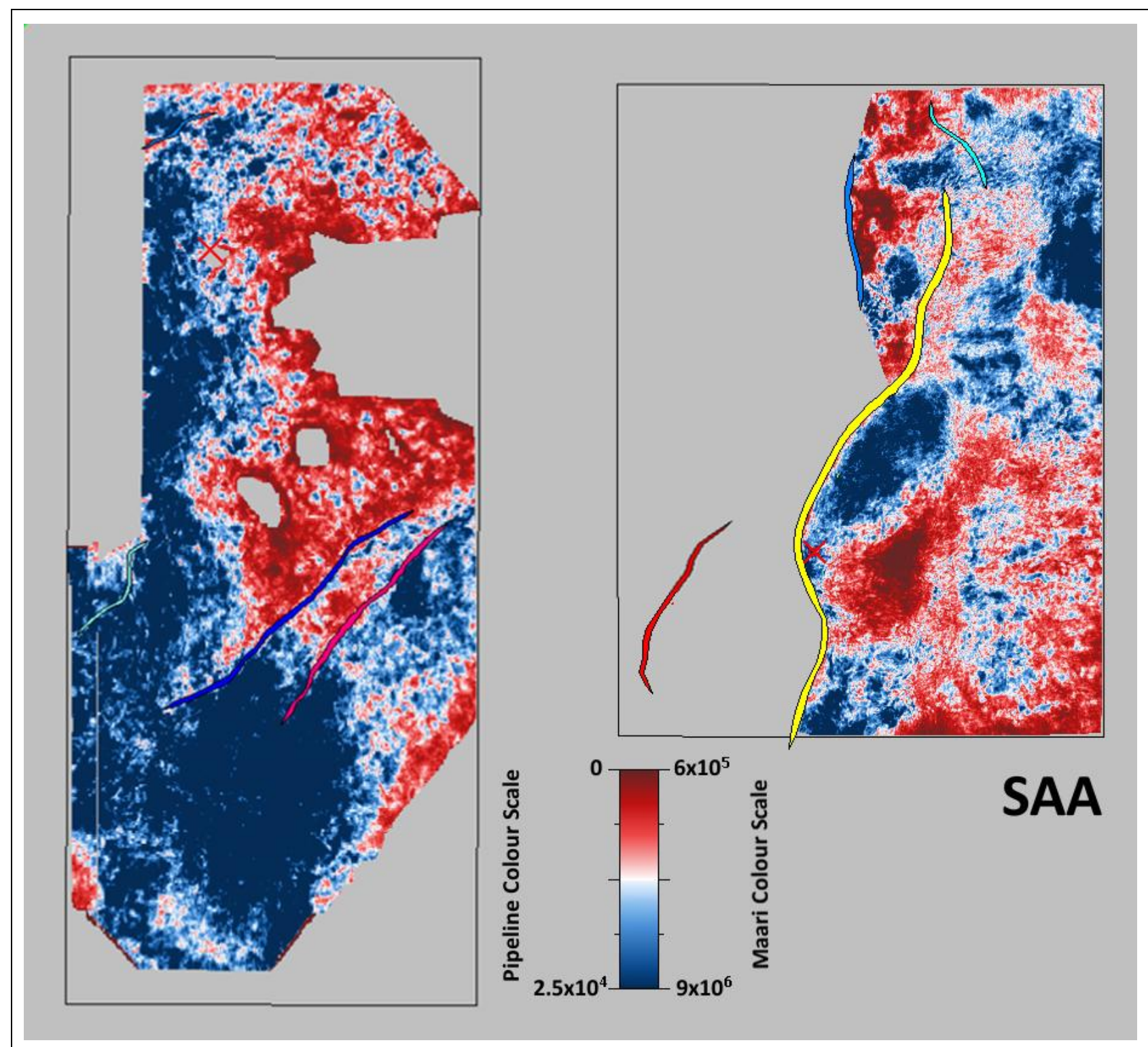

\section{Figure 9.8 Type 1 Amplitude Attribute Maps - Sum of Absolute Amplitudes}

Shown is the horizon generated by this attribute calculation on the Rakopi Formation interval of the Pipeline (left), and Maari (right) 3D seismic volumes, which have their own scales either side of the inset colour bar. Type 1 Amplitude Maps show a strong visual correlation to the Rakopi Formation thickness (see Appendix A section 9.1), as given by the Rakopi Formation Isochron Map (Figure 4.2). The description of the attribute calculation is given below (taken from Seisware ${ }^{\mathrm{TM}}$ ).

Sum of Absolute Amplitudes:

Computes the sum of the absolute value of all amplitudes within the window.

$$
x_{s a a}=\left|x_{1}\right|+\left|x_{2}\right|+\left|x_{3}\right|+\ldots+\left|x_{n}\right|
$$



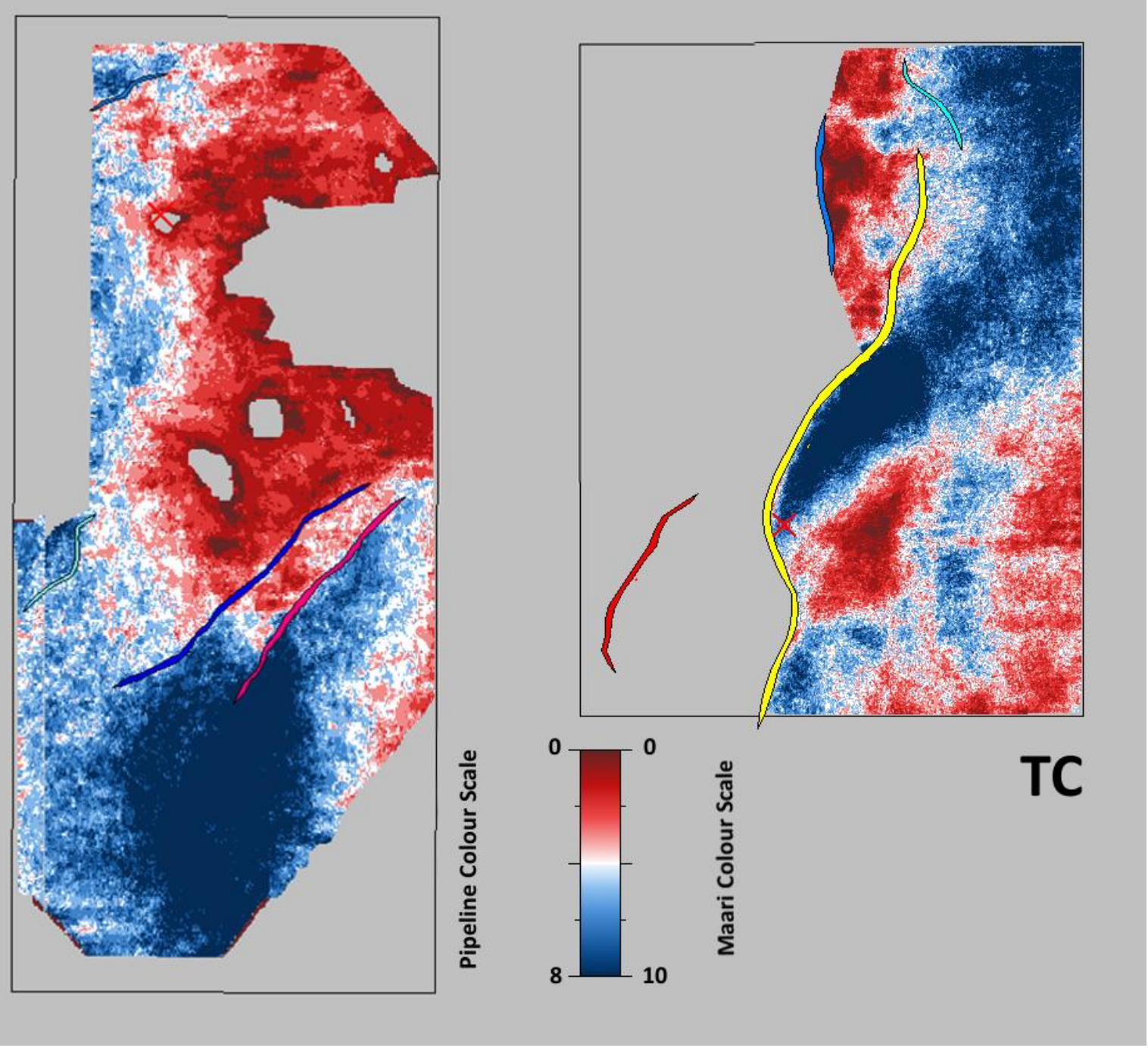

\section{Figure 9.9 Type 1 Amplitude Attribute Maps - Trough Count}

Shown is the horizon generated by this attribute calculation on the Rakopi Formation interval of the Pipeline (left), and Maari (right) 3D seismic volumes, which have their own scales either side of the inset colour bar. Type 1 Amplitude Maps show a strong visual correlation to the Rakopi Formation thickness (see Appendix A section 9.1), as given by the Rakopi Formation Isochron Map (Figure 4.2). The description of the attribute calculation is given below (taken from Seisware ${ }^{\mathrm{TM}}$ ).

\section{Trough Count (PC):}

This will compute the number of below-zero troughs in the sample set.

Please note that zero-crossing horizons work best with this attribute when using a one or two horizon window.

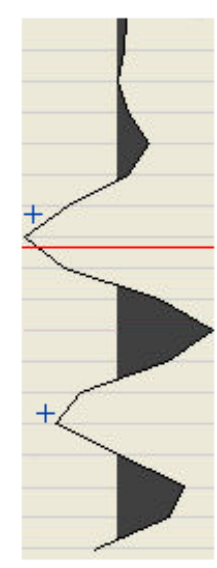




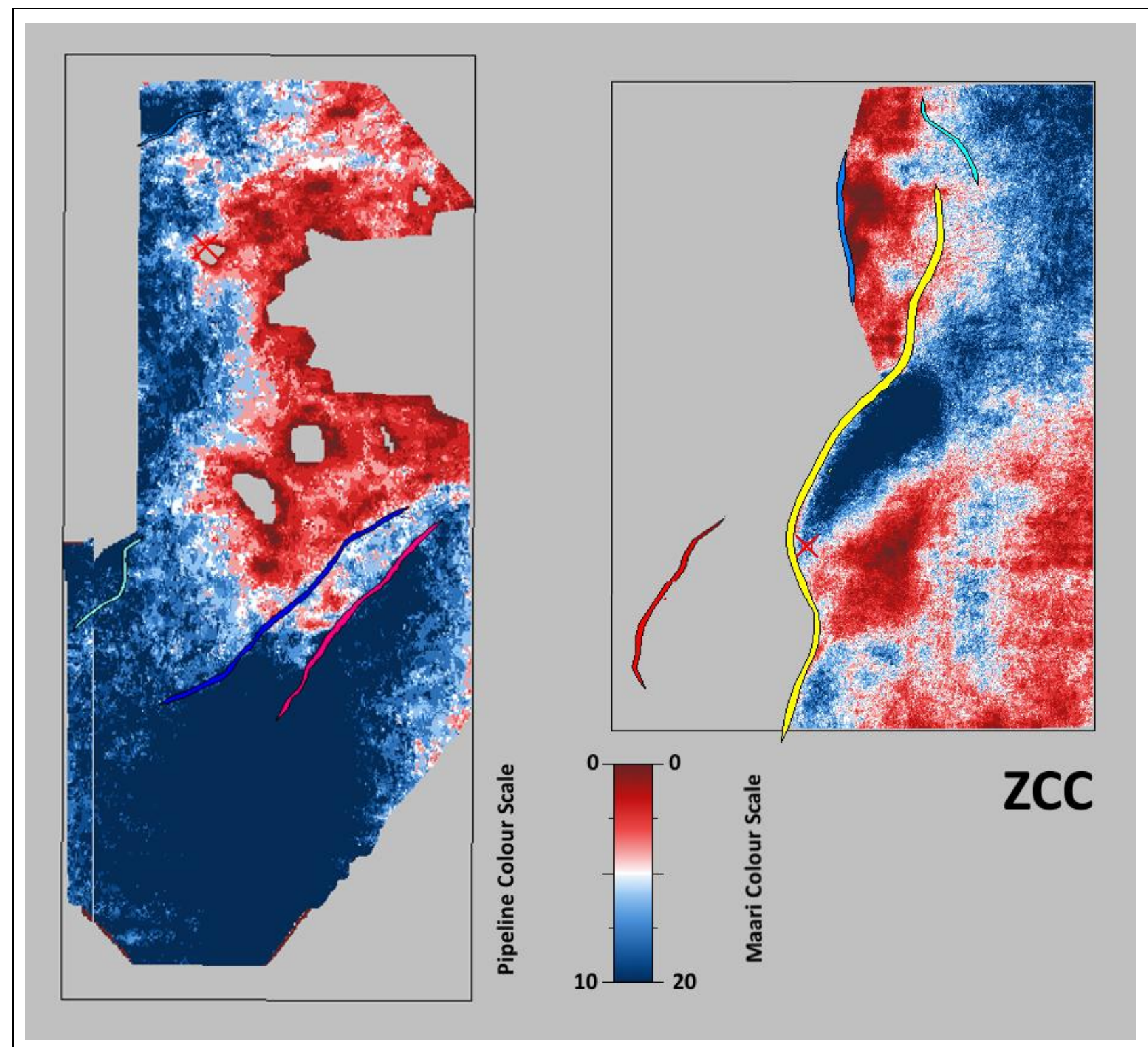

\section{Figure 9.10 Type 1 Amplitude Attribute Maps - Zero Crossing Count}

Shown is the horizon generated by this attribute calculation on the Rakopi Formation interval of the Pipeline (left), and Maari (right) 3D seismic volumes, which have their own scales either side of the inset colour bar. Type 1 Amplitude Maps show a strong visual correlation to the Rakopi Formation thickness (see Appendix A section 9.1), as given by the Rakopi Formation Isochron Map (Figure 4.2). The description of the attribute calculation is given below (taken from Seisware ${ }^{\mathrm{TM}}$ ).

Zero Crossing Count (ZCC):

This will compute the number of zero crossings in the sample set.

Please note that peak or trough horizons work best with this attribute when using a one or two horizon window.

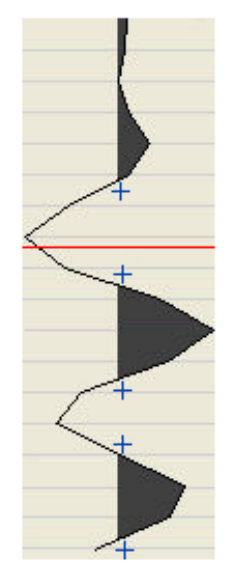




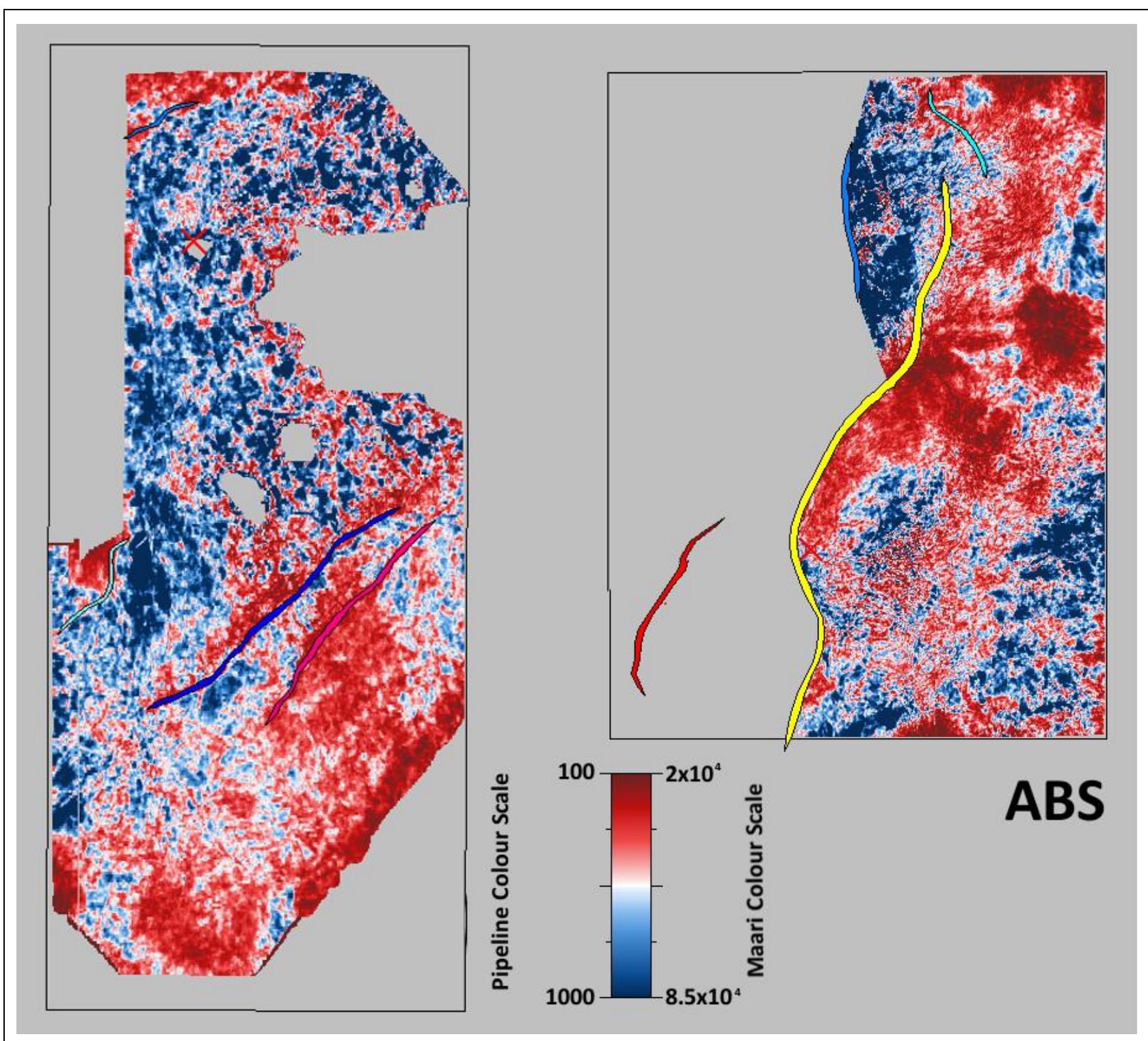

Figure 9.11 Type 2 Amplitude Attribute Maps - Average Absolute

Shown is the horizon generated by this attribute calculation on the Rakopi Formation interval of the Pipeline (left), and Maari (right) 3D seismic volumes, which have their own scales either side of the inset colour bar. Type 2 Amplitude Maps still show a visual correlation with the Rakopi Formation thickness (see Appendix A section 9.1), as given by the Rakopi Formation Isochron Map (Figure 4.2), but have some variations which it does not predict. The description of the attribute calculation is given below (taken from Seisware ${ }^{\mathrm{TM}}$ ).

Average Absolute (ABS):

This attributes will sum the absolute value for all samples within the window and divide by the number of samples. The threshold is ignored.

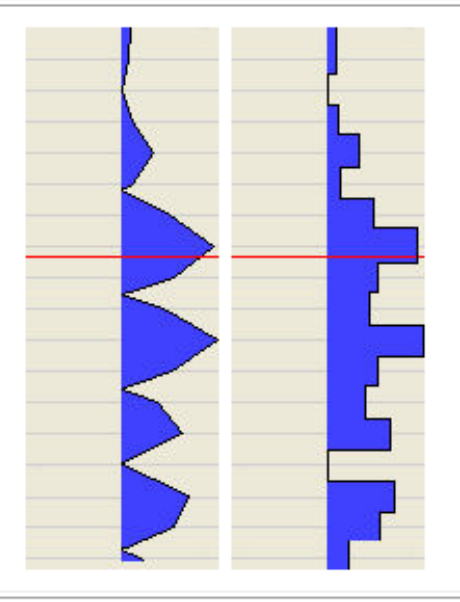



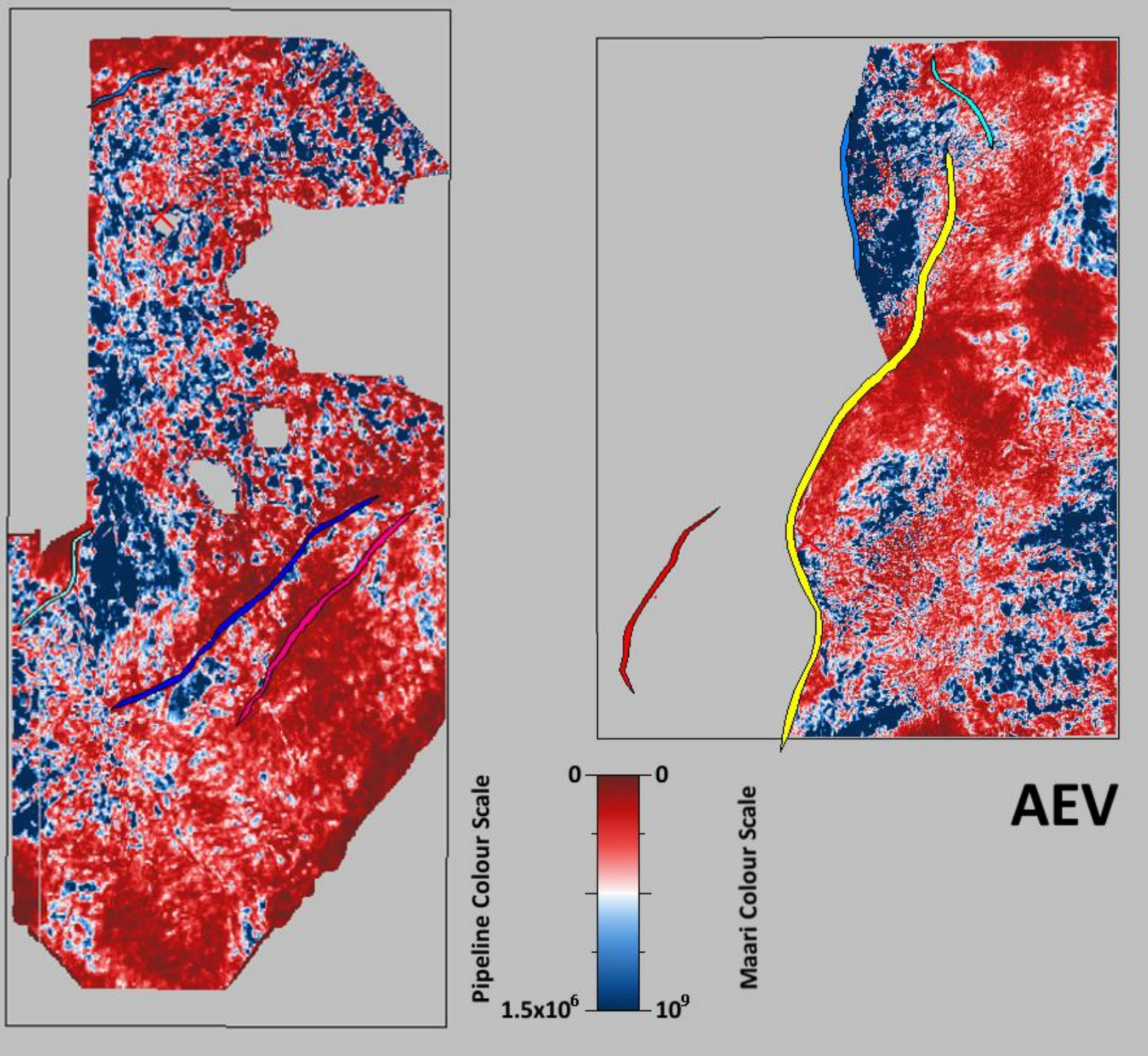

Figure 9.12 Type 2 Amplitude Attribute Maps - Average Energy Value

Shown is the horizon generated by this attribute calculation on the Rakopi Formation interval of the Pipeline (left), and Maari (right) 3D seismic volumes, which have their own scales either side of the inset colour bar. Type 2 Amplitude Maps still show a visual correlation with the Rakopi Formation thickness (see Appendix A section 9.1), as given by the Rakopi Formation Isochron Map (Figure 4.2), but have some variations which it does not predict. The description of the attribute calculation is given below (taken from Seisware ${ }^{\mathrm{TM}}$.

\section{Average Energy Value:}

This will compute the average of the squared amplitudes.

$$
x_{a e}=\frac{x_{1}^{2}+x_{2}^{2}+x_{3}^{2}+\ldots+x_{n}^{2}}{n}
$$




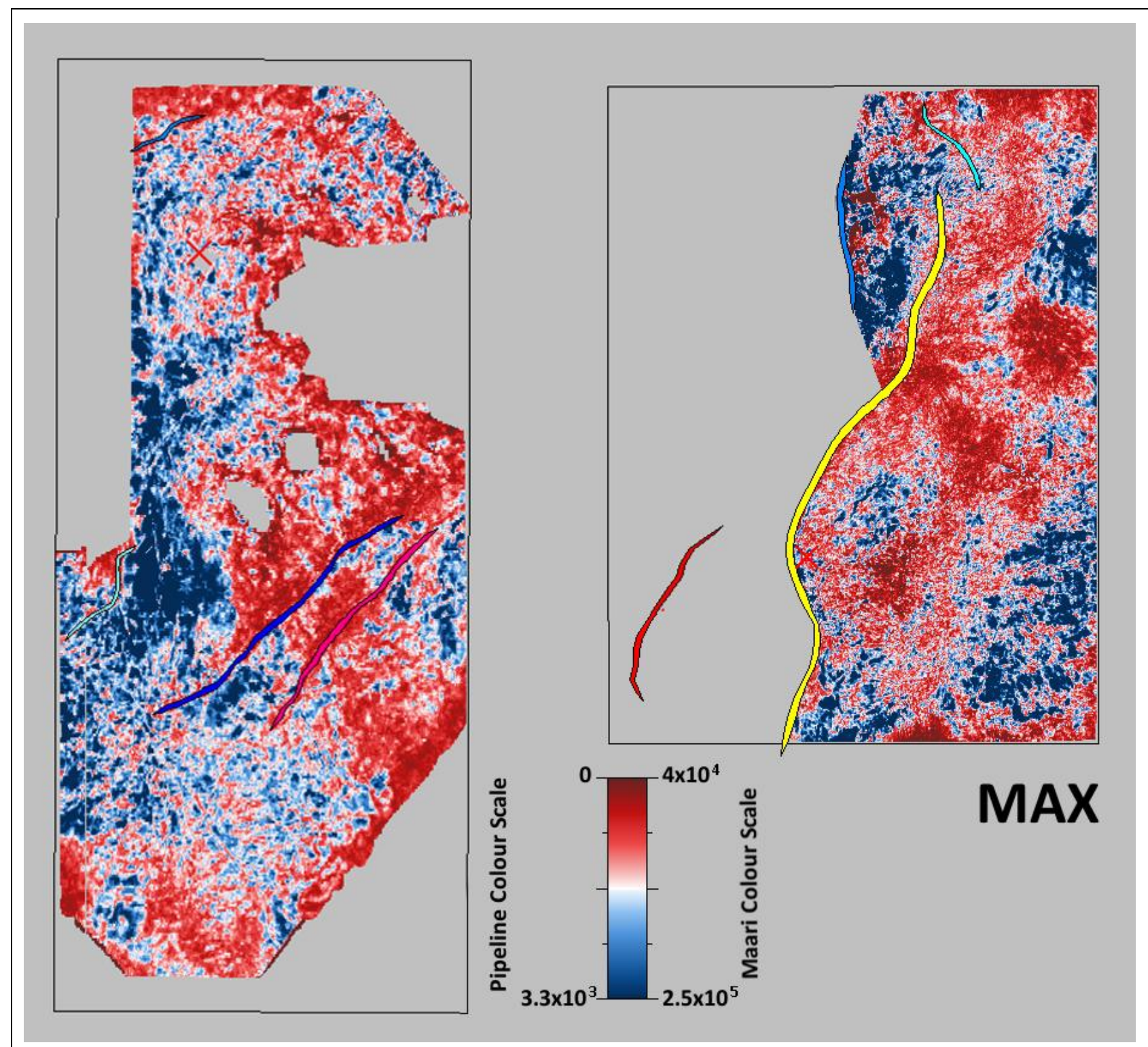

\section{Figure 9.13 Type 2 Amplitude Attribute Maps - Maximum Value}

Shown is the horizon generated by this attribute calculation on the Rakopi Formation interval of the Pipeline (left), and Maari (right) 3D seismic volumes, which have their own scales either side of the inset colour bar. Type 2 Amplitude Maps still show a visual correlation with the Rakopi Formation thickness (see Appendix A section 9.1), as given by the Rakopi Formation Isochron Map (Figure 4.2), but have some variations which it does not predict. The description of the attribute calculation is given below (taken from Seisware ${ }^{\mathrm{TM}}$ ).

Maximum Value (MAX):

This will determine the largest value within the window. The threshold is ignored. The blue area indicates the maximum sample.

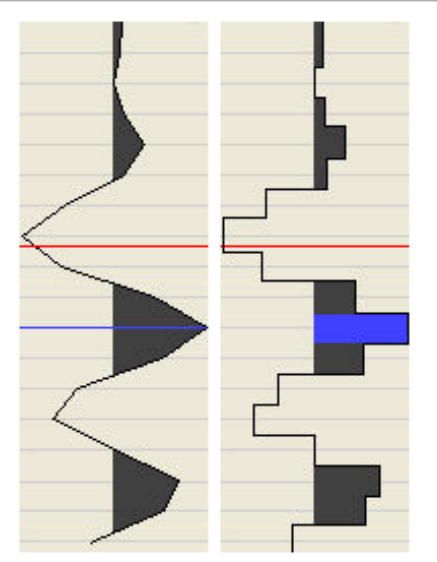




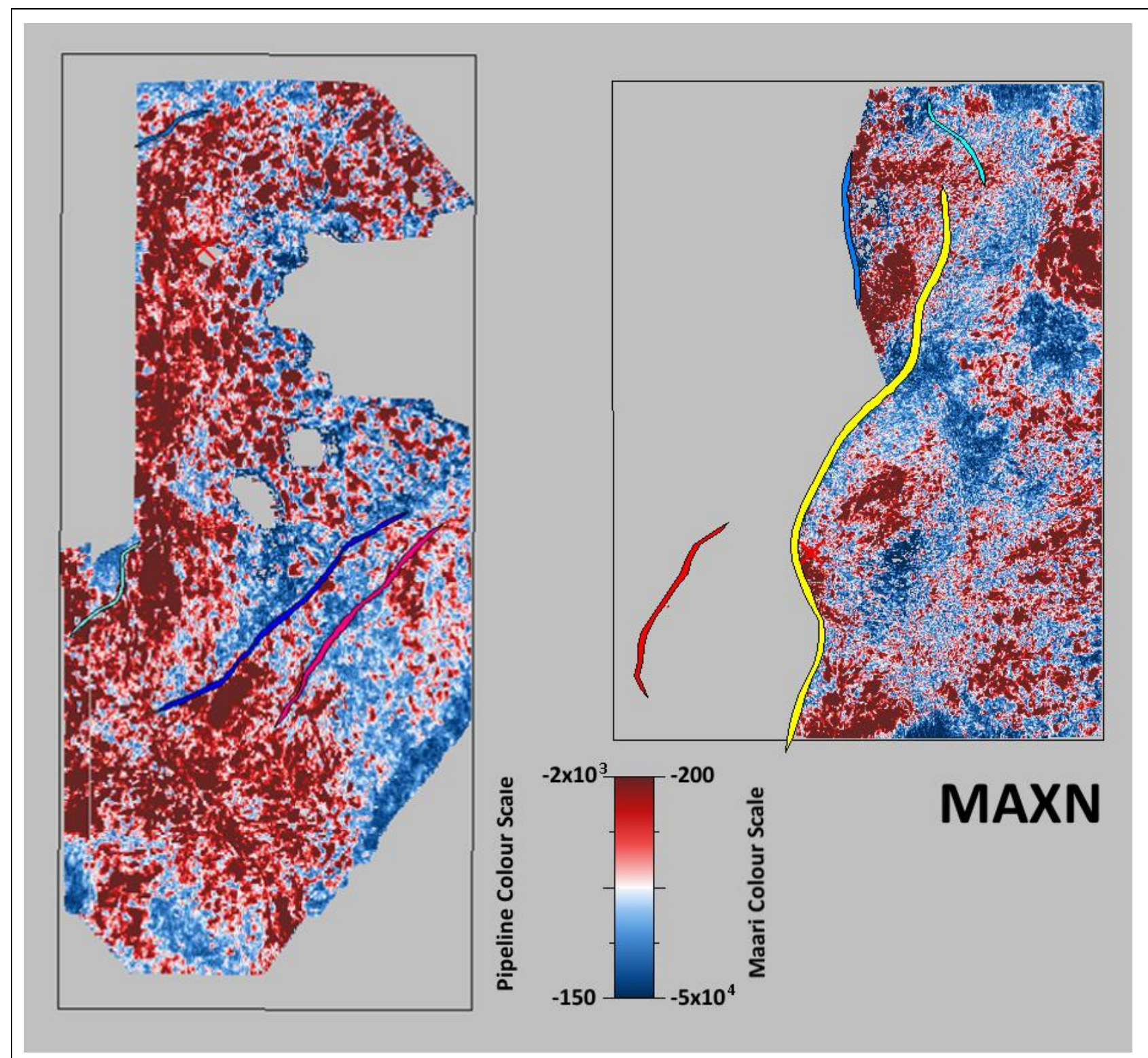

Figure 9.14 Type 2 Amplitude Attribute Maps - Max Negative Value

Shown is the horizon generated by this attribute calculation on the Rakopi Formation interval of the Pipeline (left), and Maari (right) 3D seismic volumes, which have their own scales either side of the inset colour bar. Type 2 Amplitude Maps still show a visual correlation with the Rakopi Formation thickness (see Appendix A section 9.1), as given by the Rakopi Formation Isochron Map (Figure 4.2), but have some variations which it does not predict. The description of the attribute calculation is given below (taken from Seisware $\left.{ }^{\mathrm{TM}}\right)$.

Max Negative Value (MAXN):

This will determine the largest negative value within the window. A negative value is any value that is less than zero. The threshold is ignored. The blue area indicates the maximum negative sample.

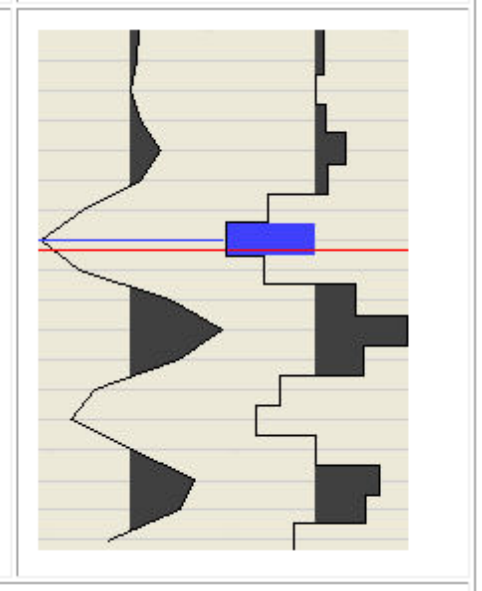




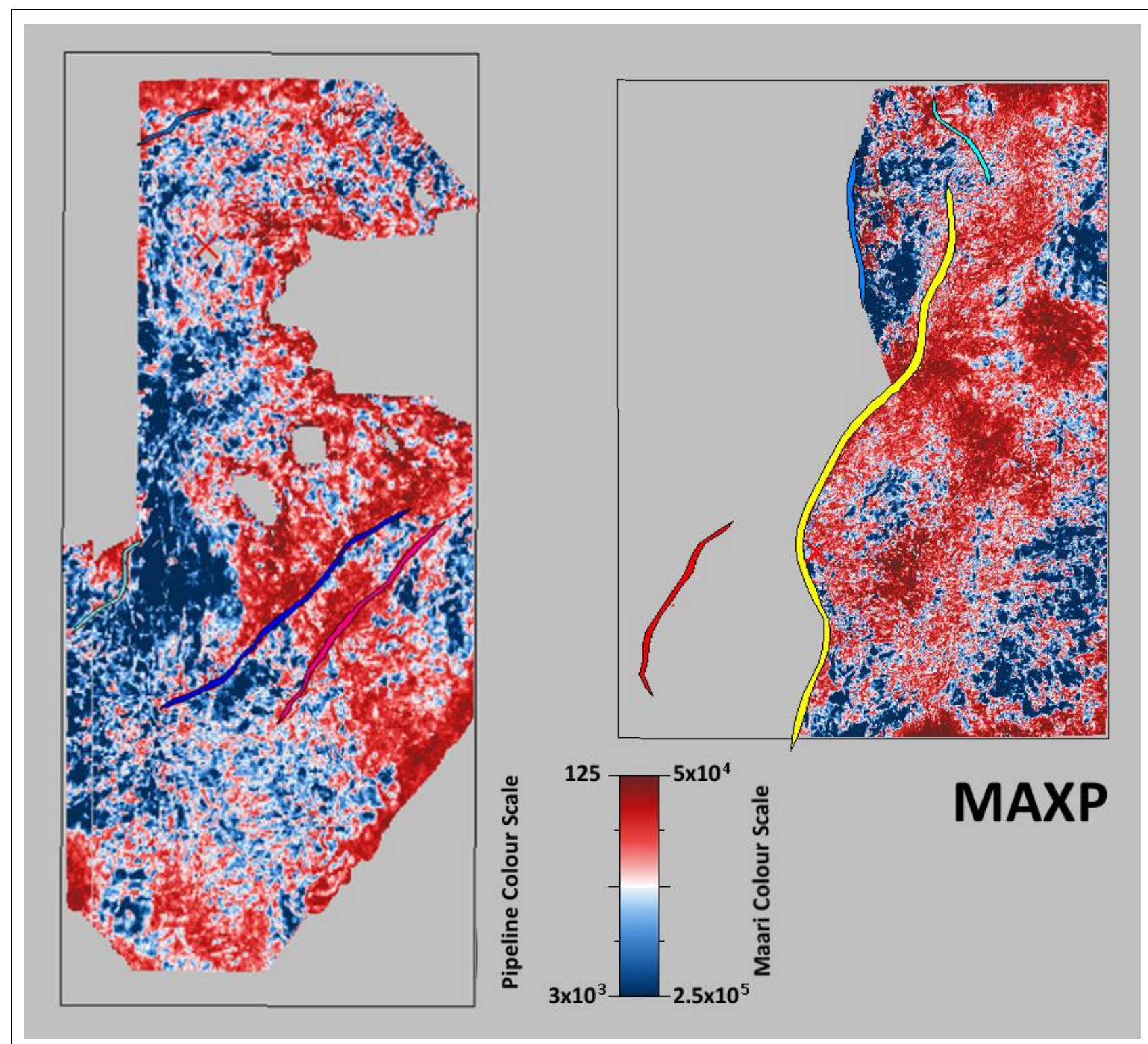

\section{Figure 9.15 Type 2 Amplitude Attribute Maps - Max Positive Value}

Shown is the horizon generated by this attribute calculation on the Rakopi Formation interval of the Pipeline (left), and Maari (right) 3D seismic volumes, which have their own scales either side of the inset colour bar. Type 2 Amplitude Maps still show a visual correlation with the Rakopi Formation thickness (see Appendix A section 9.1), as given by the Rakopi Formation Isochron Map (Figure 4.2), but have some variations which it does not predict. The description of the attribute calculation is given below (taken from Seisware ${ }^{\mathrm{TM}}$ ).

Max Positive Value (MAXP):

This will determine the largest positive value within the window. A positive value is any value that is greater than zero. The threshold is ignored. The blue area indicates the maximum positive sample.

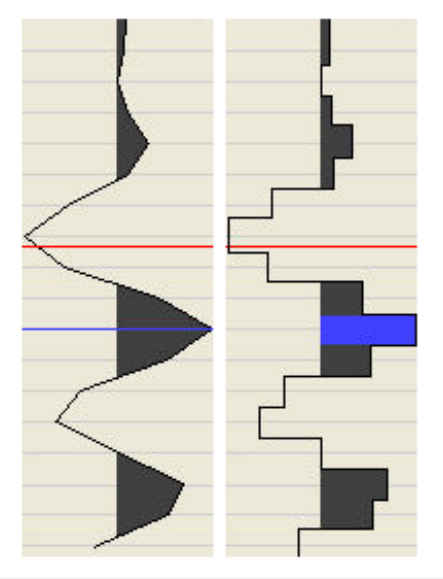



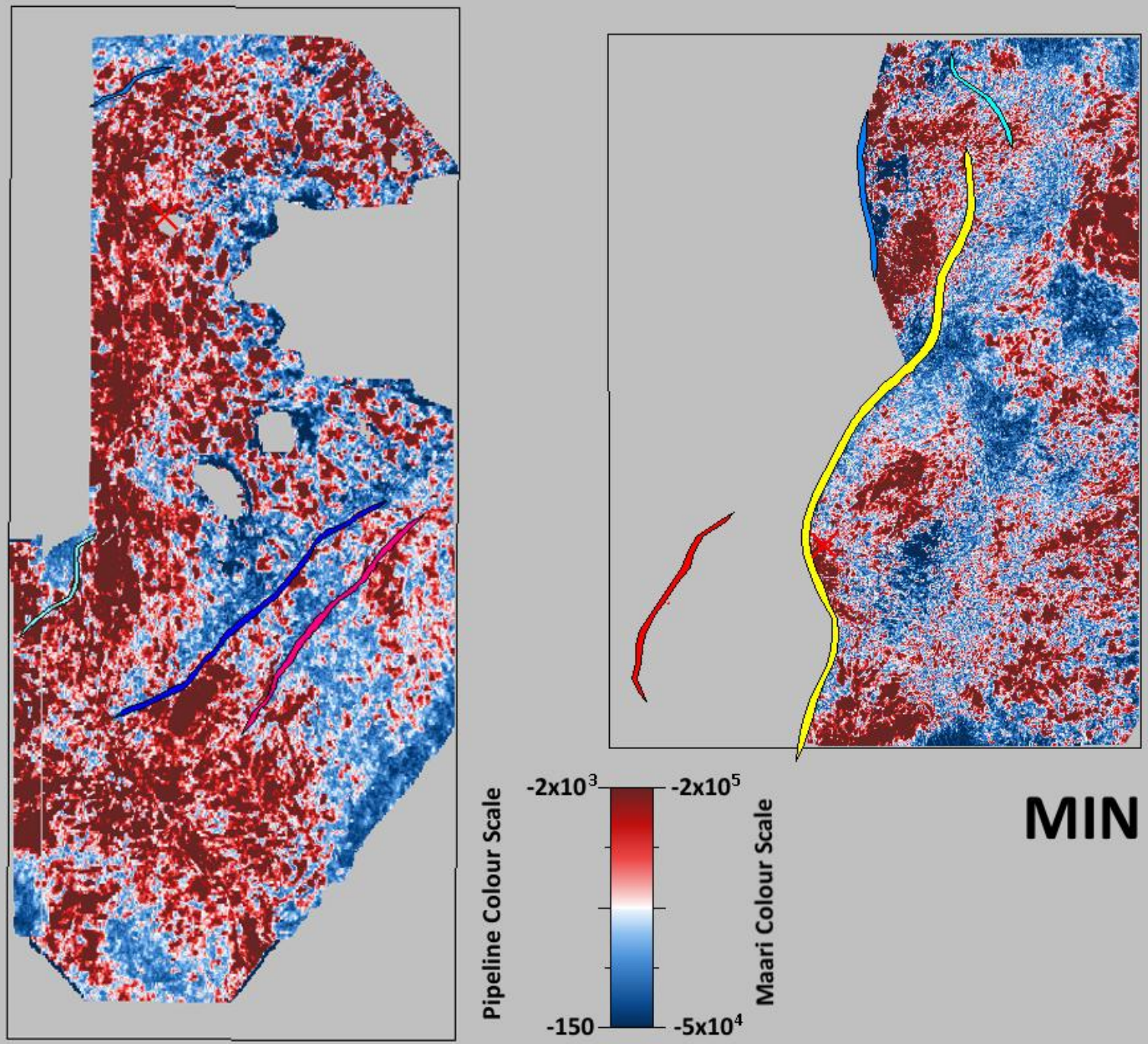

MIN

\section{Figure 9.16 Type 2 Amplitude Attribute Maps - Minimum Value}

Shown is the horizon generated by this attribute calculation on the Rakopi Formation interval of the Pipeline (left), and Maari (right) 3D seismic volumes, which have their own scales either side of the inset colour bar. Type 2 Amplitude Maps still show a visual correlation with the Rakopi Formation thickness (see Appendix A section 9.1), as given by the Rakopi Formation Isochron Map (Figure 4.2), but have some variations which it does not predict. The description of the attribute calculation is given below (taken from Seisware ${ }^{\mathrm{TM}}$ ).

\section{Minimum Value (MIN):}

This will determine the smallest value within the window. The threshold is ignored. The blue area indicates the minimum sample.

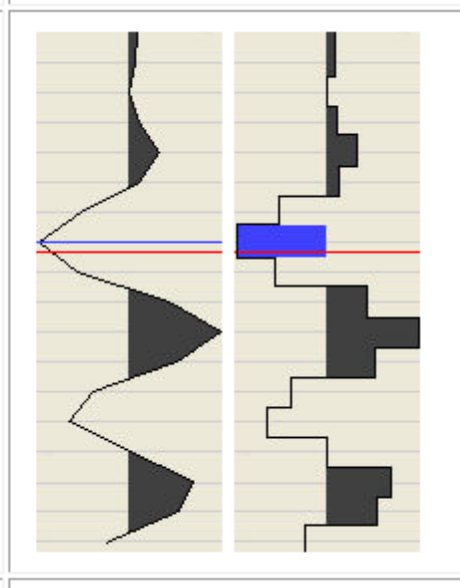



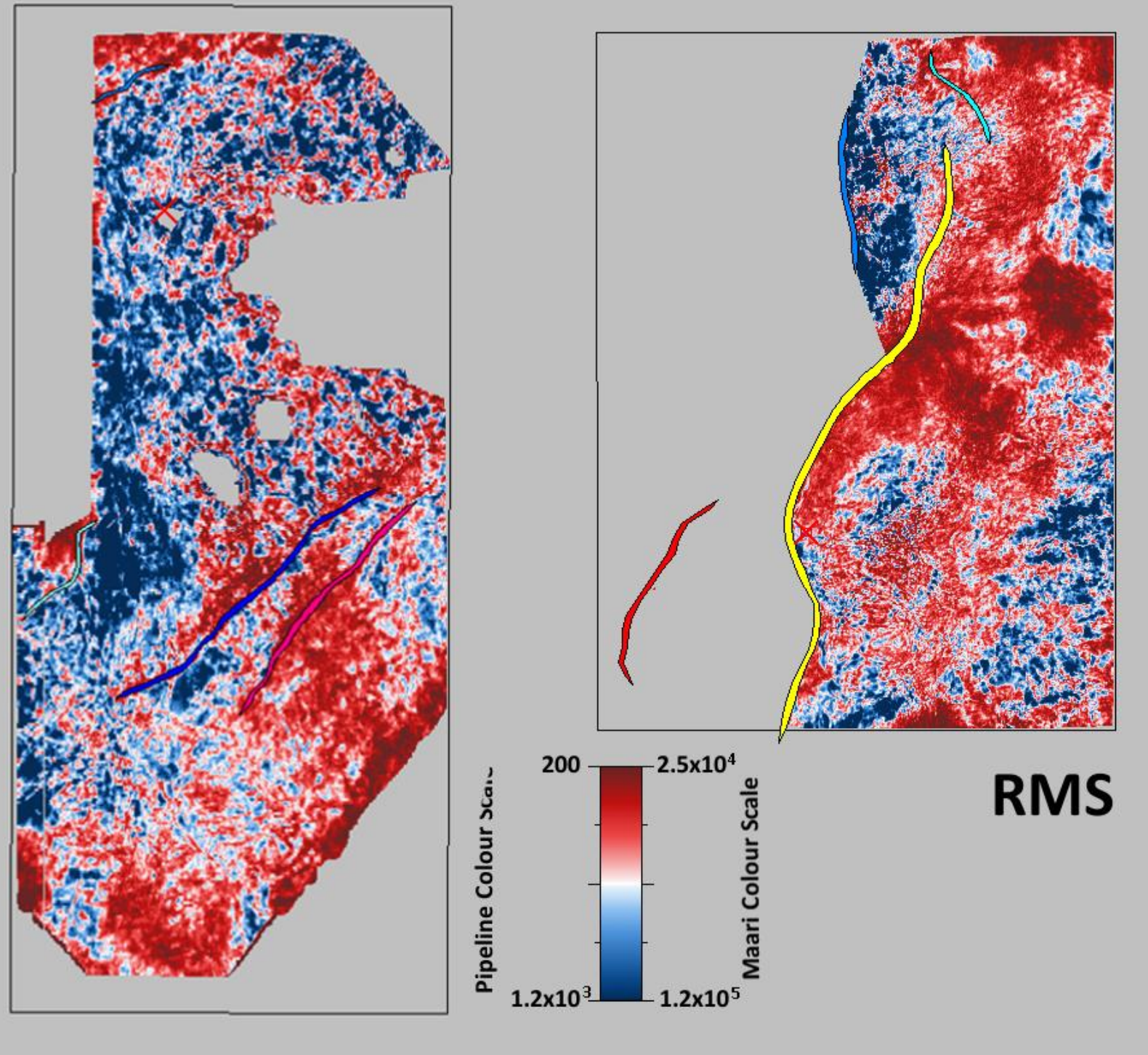

\section{Figure 9.17 Type 2 Amplitude Attribute Maps - RMS Value}

Shown is the horizon generated by this attribute calculation on the Rakopi Formation interval of the Pipeline (left), and Maari (right) 3D seismic volumes, which have their own scales either side of the inset colour bar. Type 2 Amplitude Maps still show a visual correlation with the Rakopi Formation thickness (see Appendix A section 9.1), as given by the Rakopi Formation Isochron Map (Figure 4.2), but have some variations which it does not predict. The description of the attribute calculation is given below (taken from Seisware ${ }^{\mathrm{TM}}$ ).

\section{RMS Value (RMS):}

This will compute the RMS of all the data within the window using the formula:

$$
x_{r m s}=\sqrt{\frac{x_{1}{ }^{2}+x_{2}{ }^{2}+\ldots+x^{n}}{n}}
$$




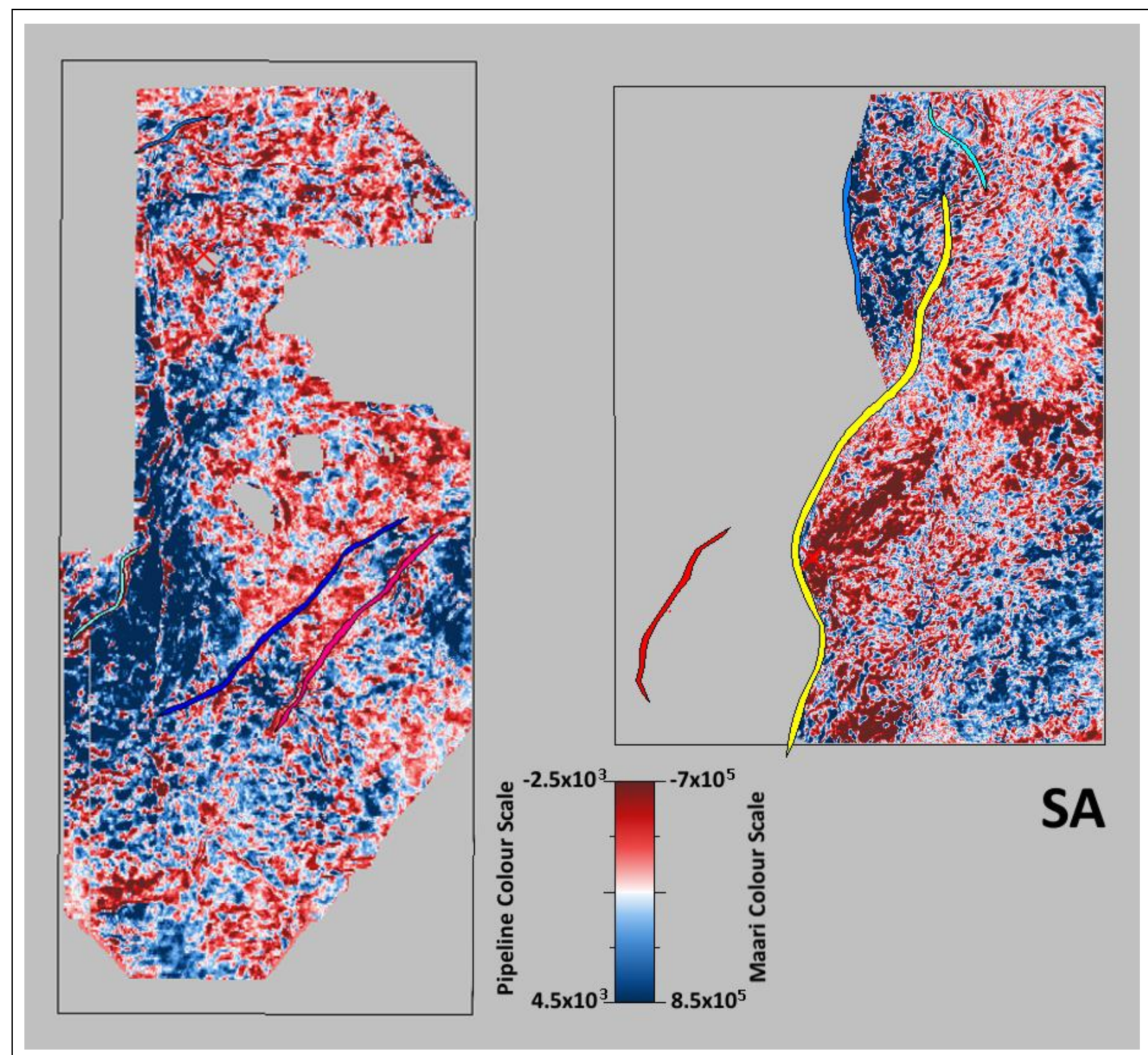

\section{Figure 9.18 Type 3 Amplitude Attribute Maps - Sum of Amplitudes}

Shown is the horizon generated by this attribute calculation on the Rakopi Formation interval of the Pipeline (left), and Maari (right) 3D seismic volumes, which have their own scales either side of the inset colour bar. Type 3 Amplitude Maps show no observable correlation to the Rakopi Formation thickness (see Appendix A section 9.1), as given by the Rakopi Formation Isochron Map (Figure 4.2). As such, they are likely responding to a lithological feature. The description of the attribute calculation is given below (taken from Seisware ${ }^{\mathrm{TM}}$ ).

\section{Sum of Amplitudes:}

Sum of all amplitudes in the window.

$$
x_{s a}=x_{1}+x_{2}+x_{3}+\ldots+x_{n}
$$




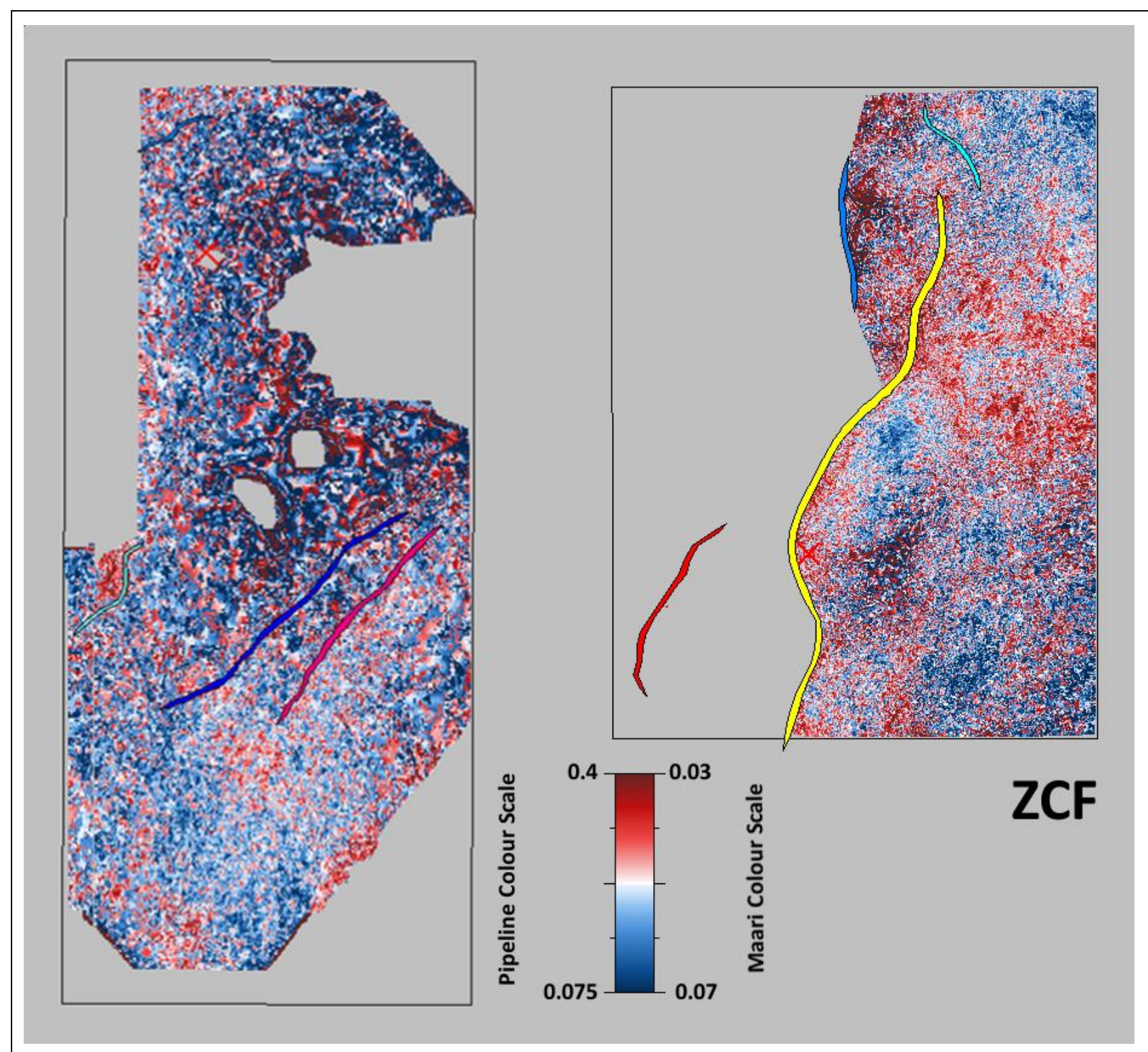

\section{Figure 9.19 Type 3 Amplitude Attribute Maps - Zero Crossing Frequency}

Shown is the horizon generated by this attribute calculation on the Rakopi Formation interval of the Pipeline (left), and Maari (right) 3D seismic volumes, which have their own scales either side of the inset colour bar. Type 3 Amplitude Maps show no observable correlation to the Rakopi Formation thickness (see Appendix A section 9.1), as given by the Rakopi Formation Isochron Map (Figure 4.2). As such, they are likely responding to a lithological feature. The description of the attribute calculation is given below (taken from Seisware ${ }^{\mathrm{TM}}$ ).

Zero Crossing Frequency (ZCF):

This will compute the number of zero crossings in the sample set divided by the number of samples.

Please note that peak or trough horizons work best with this attribute when using a one or two horizon window.

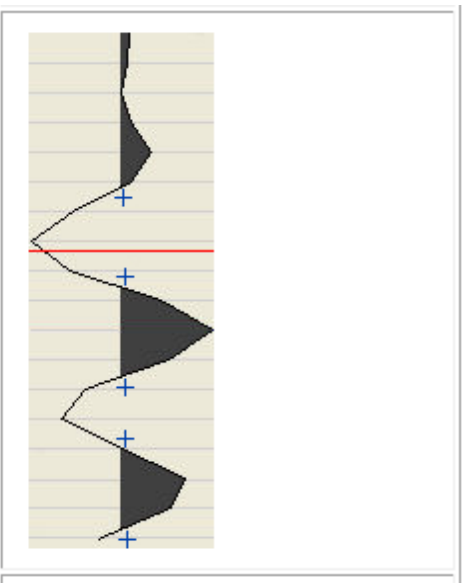




\section{Appendix B}

\subsection{Rakopi Formation RSA Amplitude Maps}

This appendix displays the full results of the Rock Solid Attributes (RSAs) which were extracted from the Rakopi Formation interval in the study area, as described in Section 5.2. The list of RSAs which were extracted from the data, along with their brief descriptions, is given by Table 4.1. For more information about RSAs, see Taner (2003) or Rock Solid Images (2016).

The following attribute output images all display the same information. The basemaps within the Pipeline and Maari 3D volumes are displaying the averaged values of the RSAs extracted from the Rakopi interval of the Cretaceous strata. Note that the colour scales are different for the 2 volumes respectively, but the scales are annotated on each side. The representative $2 \mathrm{D}$ lines below the volumes show the attribute as it is displayed, and their location within the 3D is shown by the horizontal yellow lines. In most cases, the gain has been adjusted on the 2D lines, and the range of displayed values on the basemaps, have been altered in order to best represent any variations. The Maui-4 and Pukeko-1 wells are shown by the red crosses underneath the yellow seismic lines. 

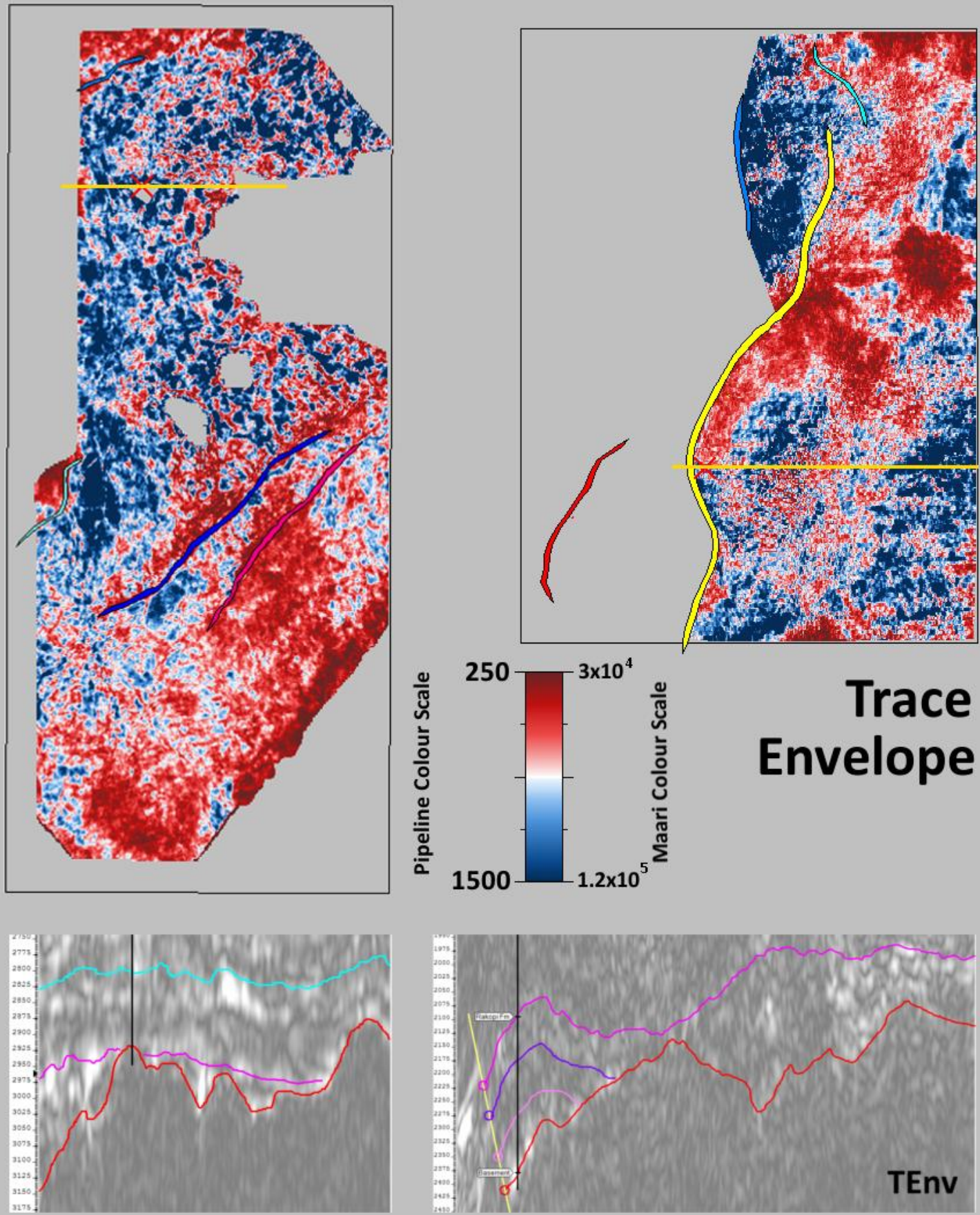

\section{Figure 10.1 Rakopi Formation RSA Data - Trace Envelope}

Shown are the values of this attribute, temporally averaged within the Rakopi Formation interval of the Pipeline (top left), and Maari (top right) 3D seismic volumes, which have individual colour scales (see inset colour bar). The representative 2D lines below the basemaps show the attribute outputs when viewed in 2D. For more information on the averaging process, see Figure 5.1, and for the map location, see Figure 1.1. 

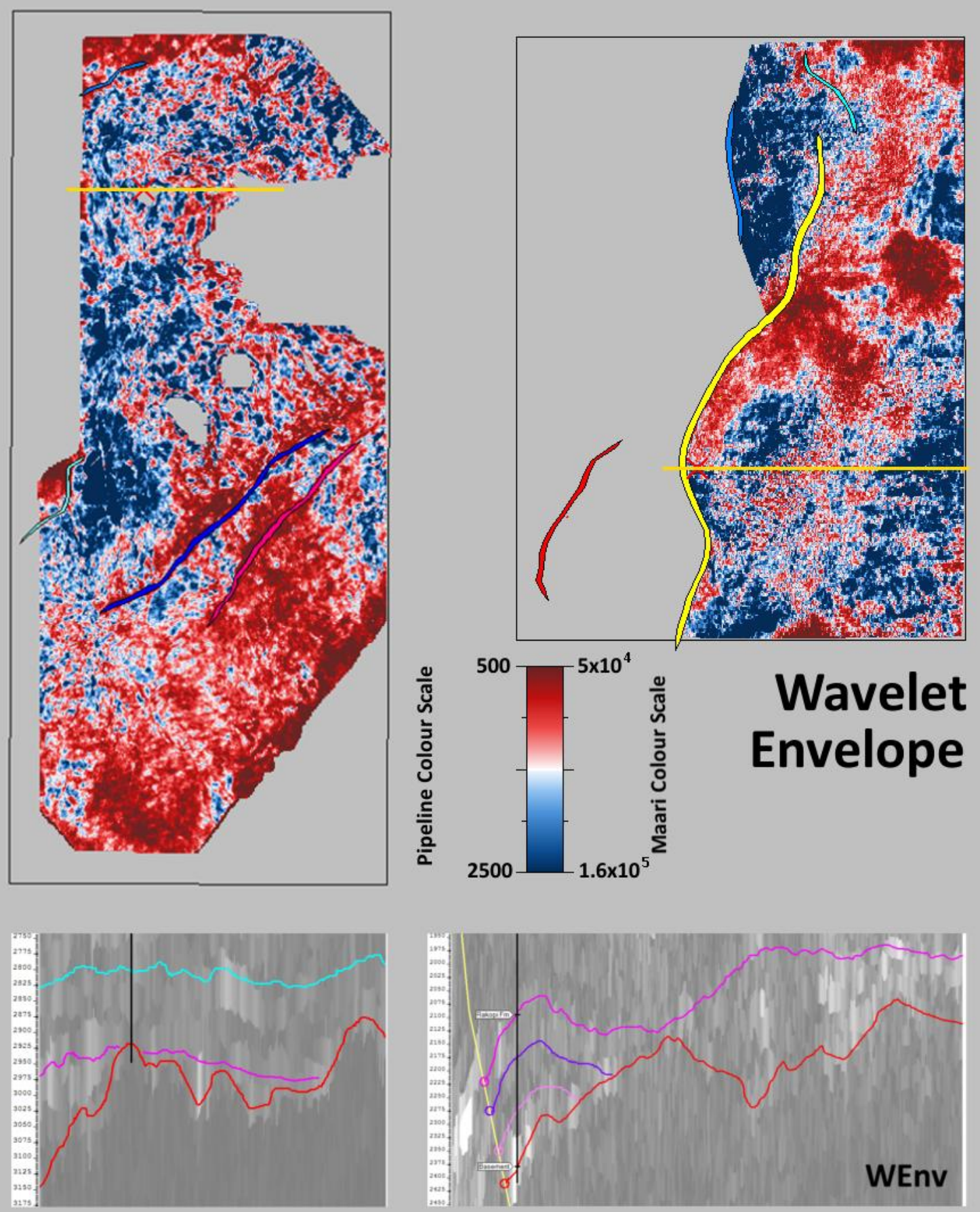

\section{Figure 10.2 Rakopi Formation RSA Data - Wavelet Envelope}

Shown are the values of this attribute, temporally averaged within the Rakopi Formation interval of the Pipeline (top left), and Maari (top right) 3D seismic volumes, which have individual colour scales (see inset colour bar). The representative 2D lines below the basemaps show the attribute outputs when viewed in 2D. For more information on the averaging process, see Figure 5.1, and for the map location, see Figure 1.1. 


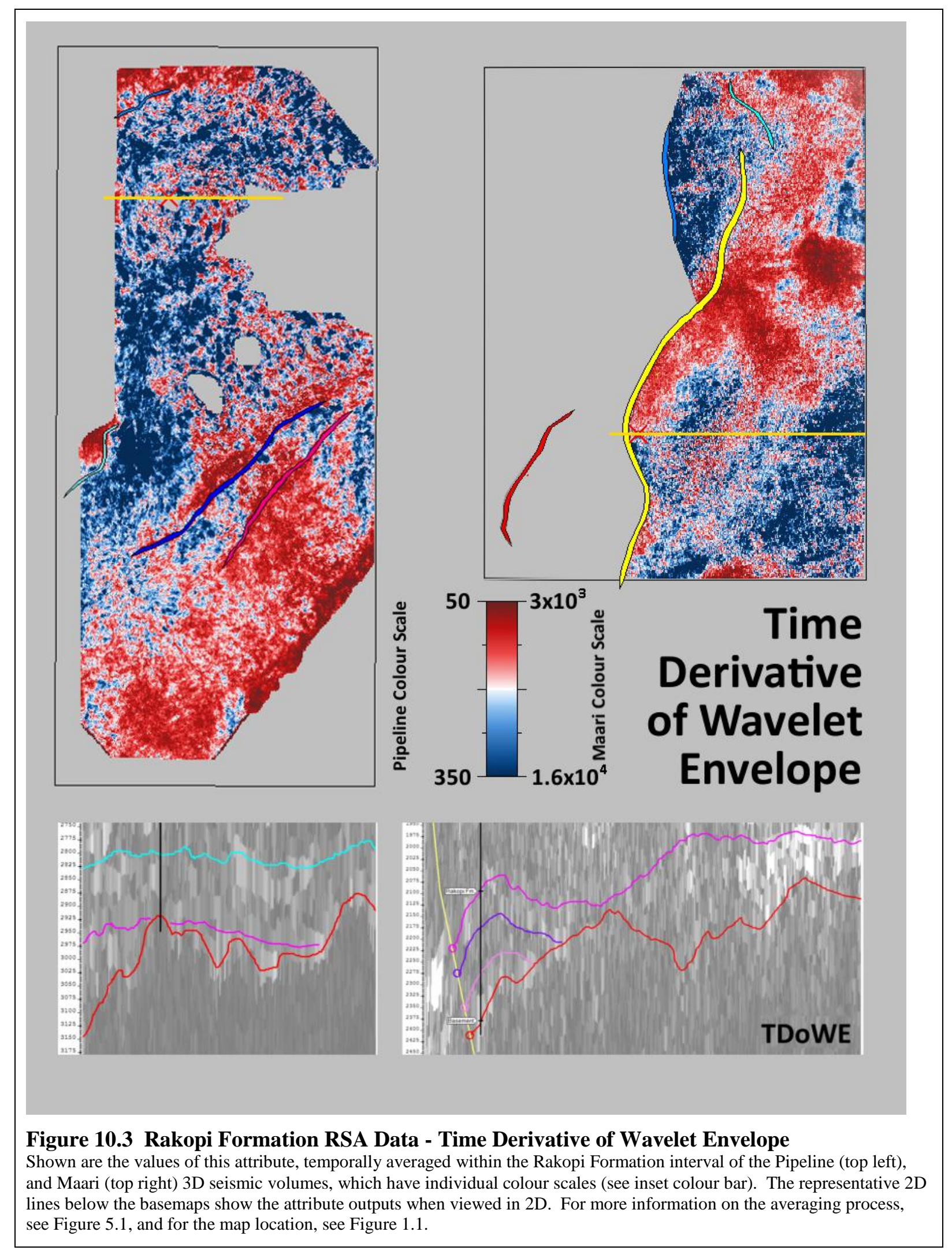



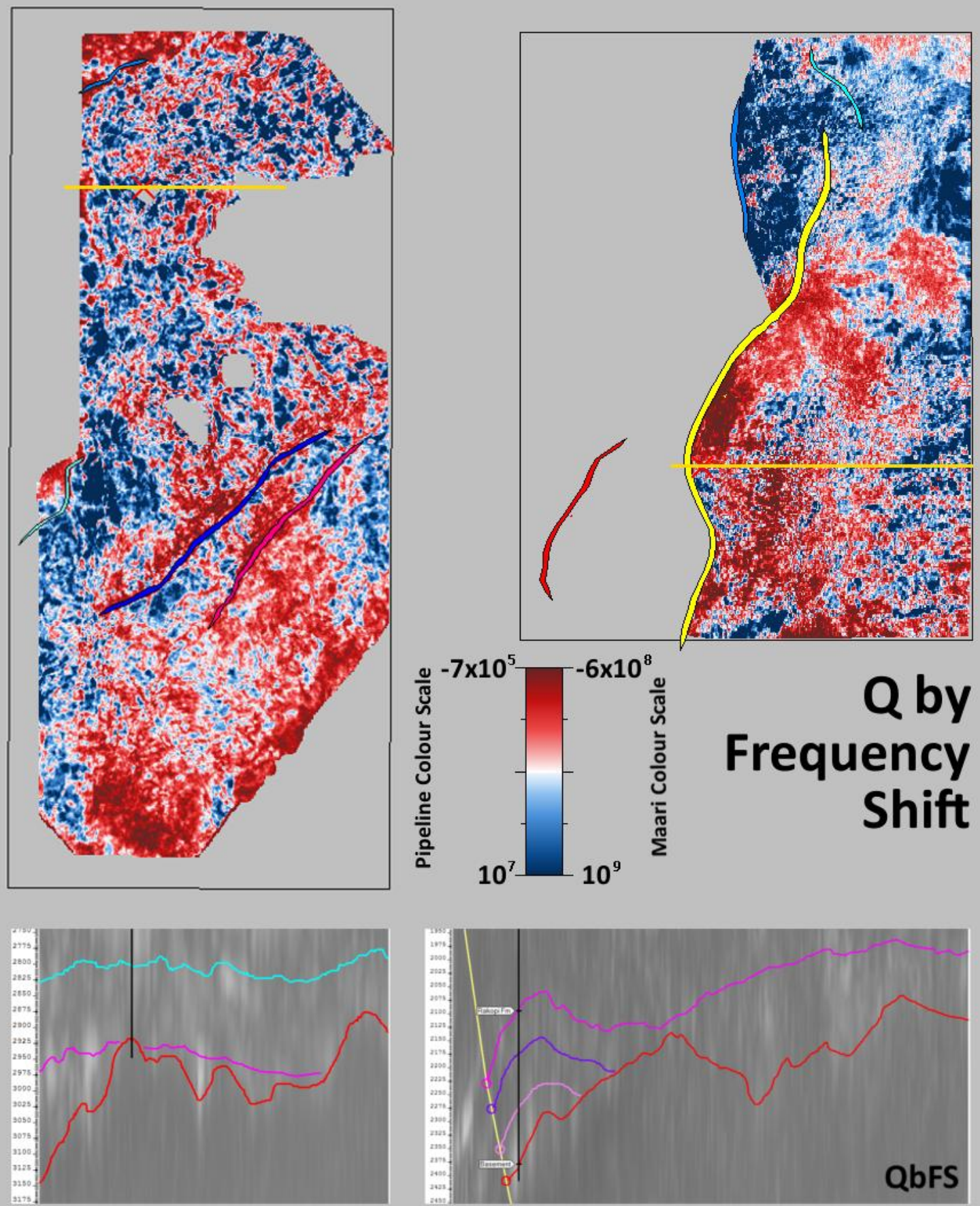

Figure 10.4 Rakopi Formation RSA Data - Q by Frequency Shift

Shown are the values of this attribute, temporally averaged within the Rakopi Formation interval of the Pipeline (top left), and Maari (top right) 3D seismic volumes, which have individual colour scales (see inset colour bar). The representative 2D lines below the basemaps show the attribute outputs when viewed in 2D. For more information on the averaging process, see Figure 5.1, and for the map location, see Figure 1.1. 


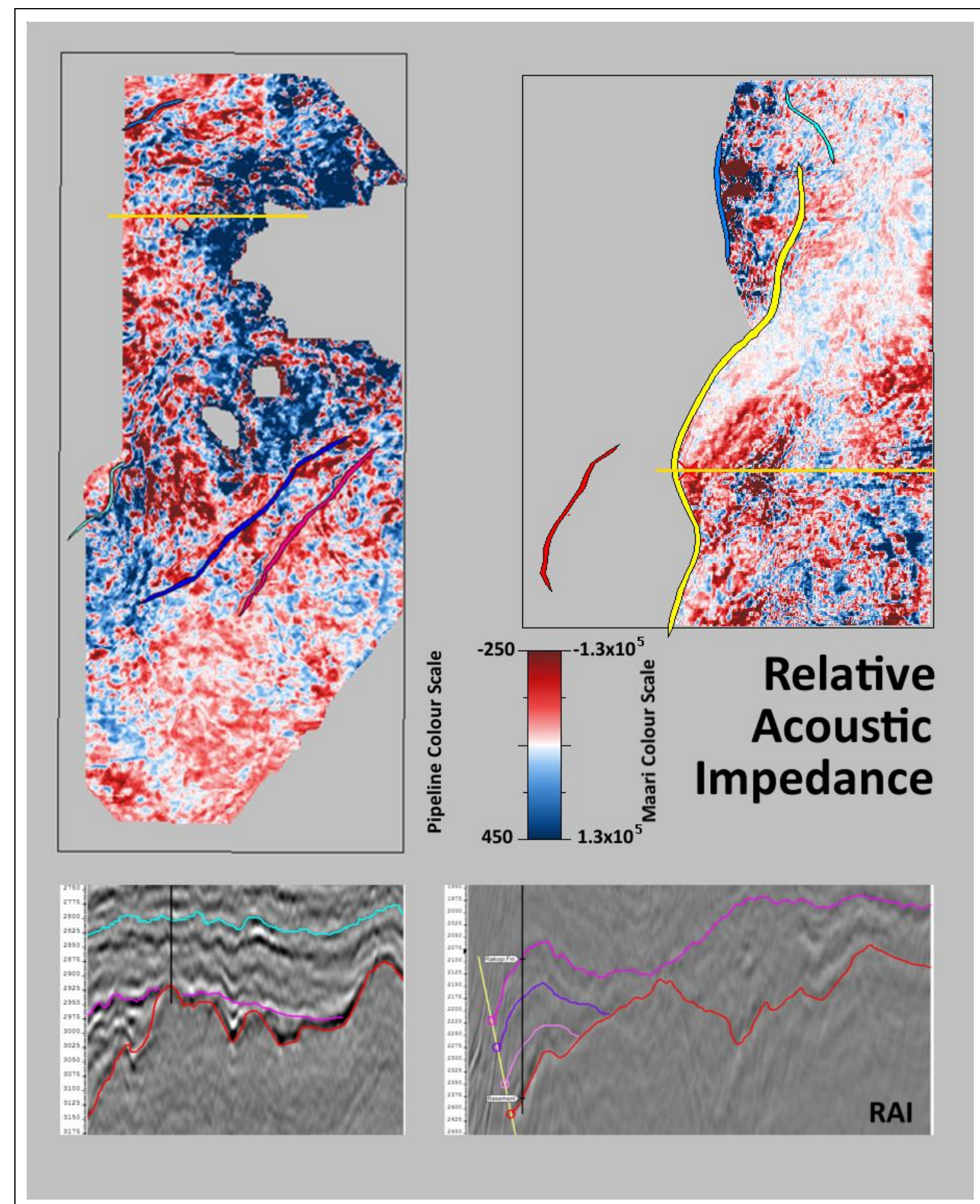

\section{Figure 10.5 Rakopi Formation RSA Data - Relative Acoustic Impedance}

Shown are the values of this attribute, temporally averaged within the Rakopi Formation interval of the Pipeline (top left), and Maari (top right) 3D seismic volumes, which have individual colour scales (see inset colour bar). The representative 2D lines below the basemaps show the attribute outputs when viewed in 2D. For more information on the averaging process, see Figure 5.1, and for the map location, see Figure 1.1. 

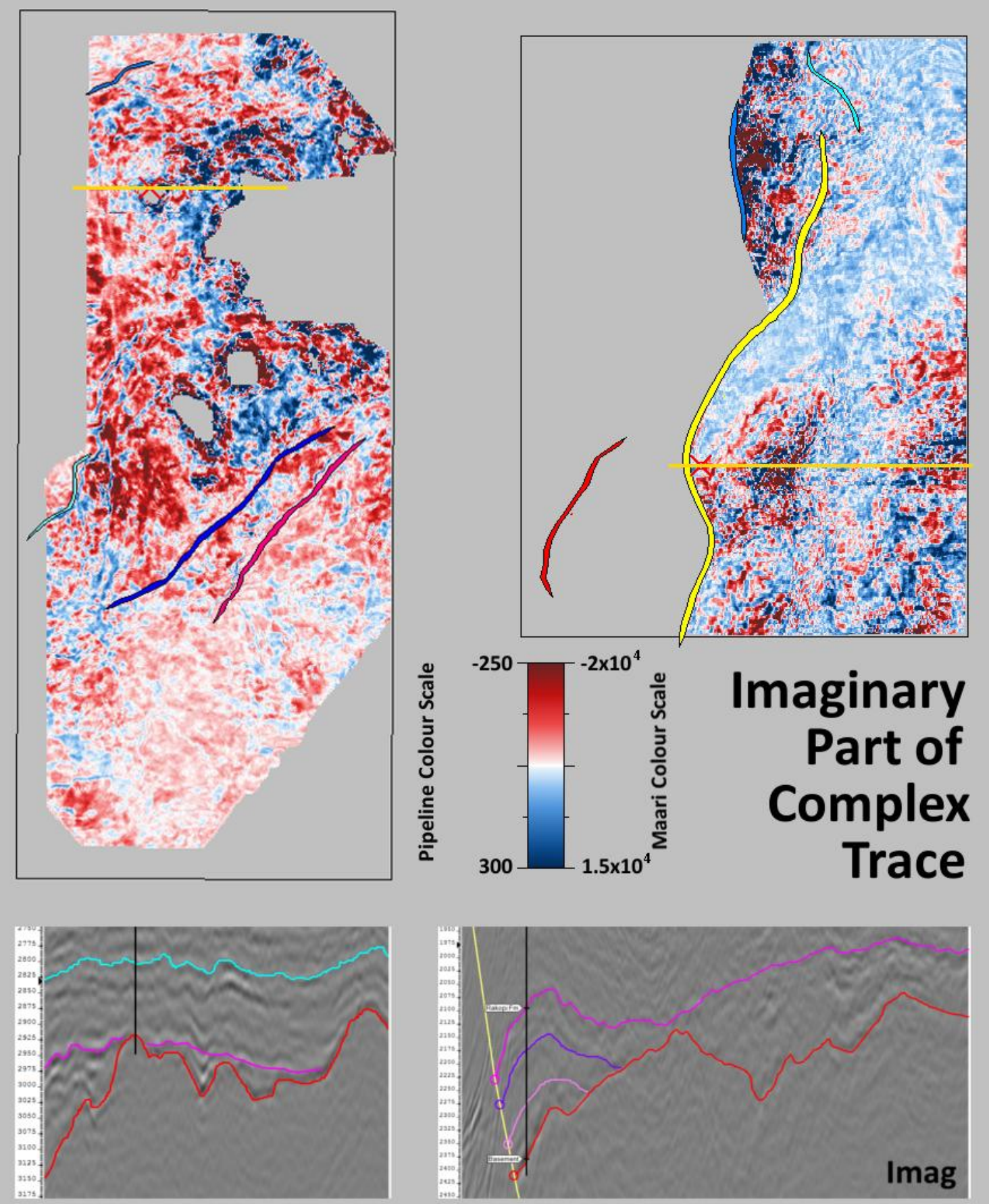

\section{Figure 10.6 Rakopi Formation RSA Data - Imaginary Part of Complex Trace}

Shown are the values of this attribute, temporally averaged within the Rakopi Formation interval of the Pipeline (top left), and Maari (top right) 3D seismic volumes, which have individual colour scales (see inset colour bar). The representative 2D lines below the basemaps show the attribute outputs when viewed in 2D. For more information on the averaging process, see Figure 5.1, and for the map location, see Figure 1.1. 

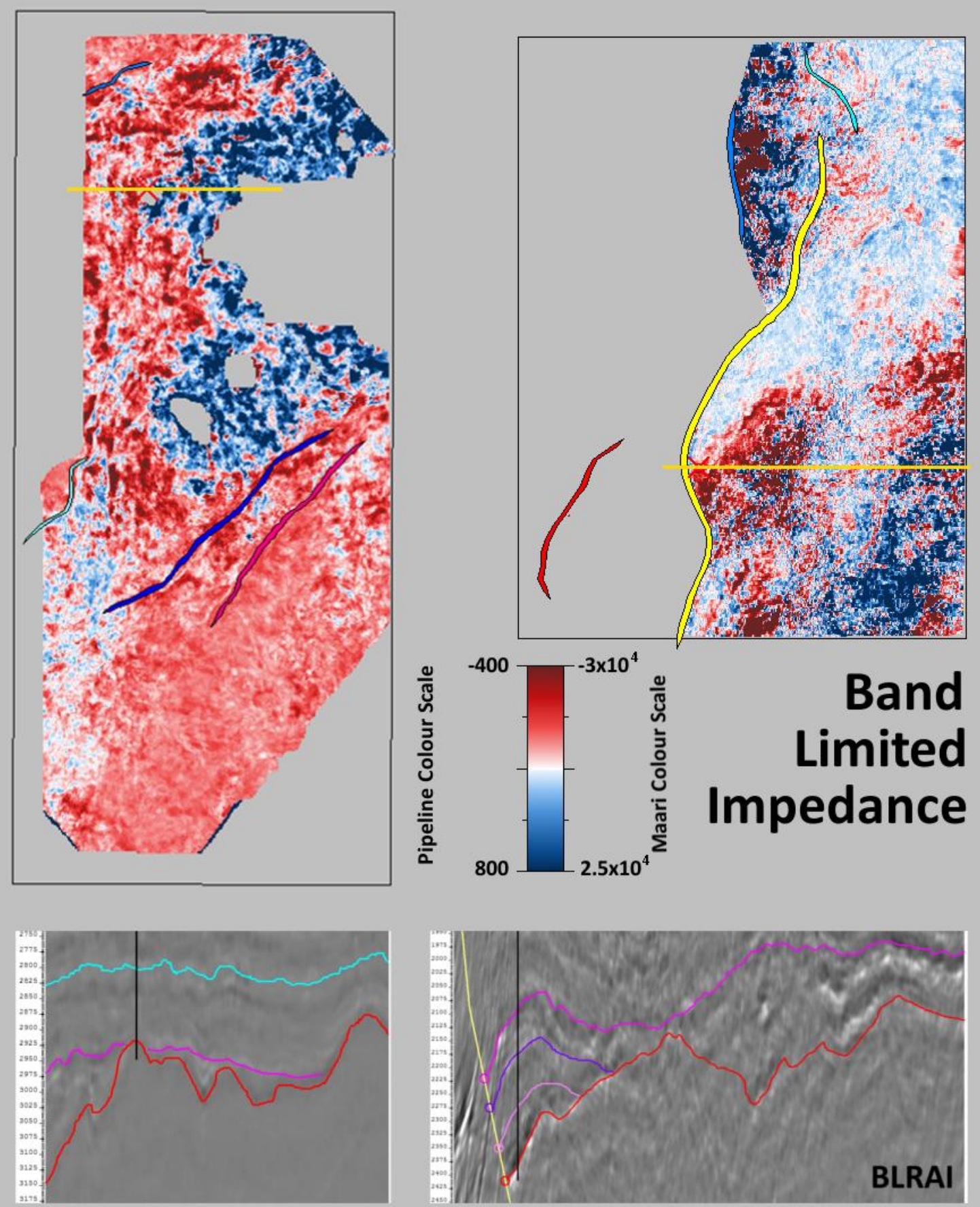

Figure 10.7 Rakopi Formation RSA Data - Band Limited Relative Acoustic Impedance

Shown are the values of this attribute, temporally averaged within the Rakopi Formation interval of the Pipeline (top left), and Maari (top right) 3D seismic volumes, which have individual colour scales (see inset colour bar). The representative 2D lines below the basemaps show the attribute outputs when viewed in 2D. For more information on the averaging process, see Figure 5.1, and for the map location, see Figure 1.1. 

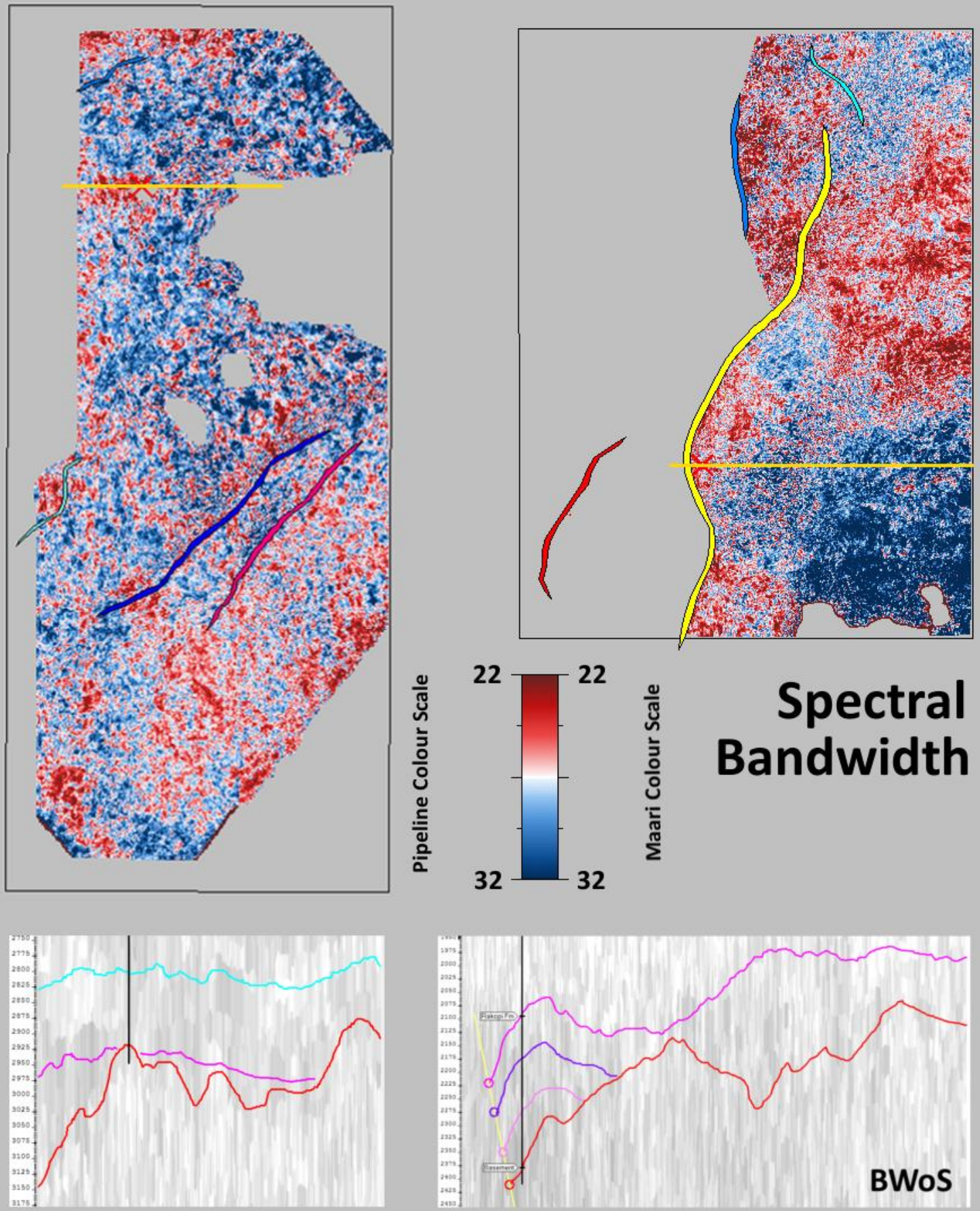

Figure 10.8 Rakopi Formation RSA Data - Spectral Bandwidth

Shown are the values of this attribute, temporally averaged within the Rakopi Formation interval of the Pipeline (top left), and Maari (top right) 3D seismic volumes, which have individual colour scales (see inset colour bar). The representative 2D lines below the basemaps show the attribute outputs when viewed in 2D. For more information on the averaging process, see Figure 5.1, and for the map location, see Figure 1.1. 

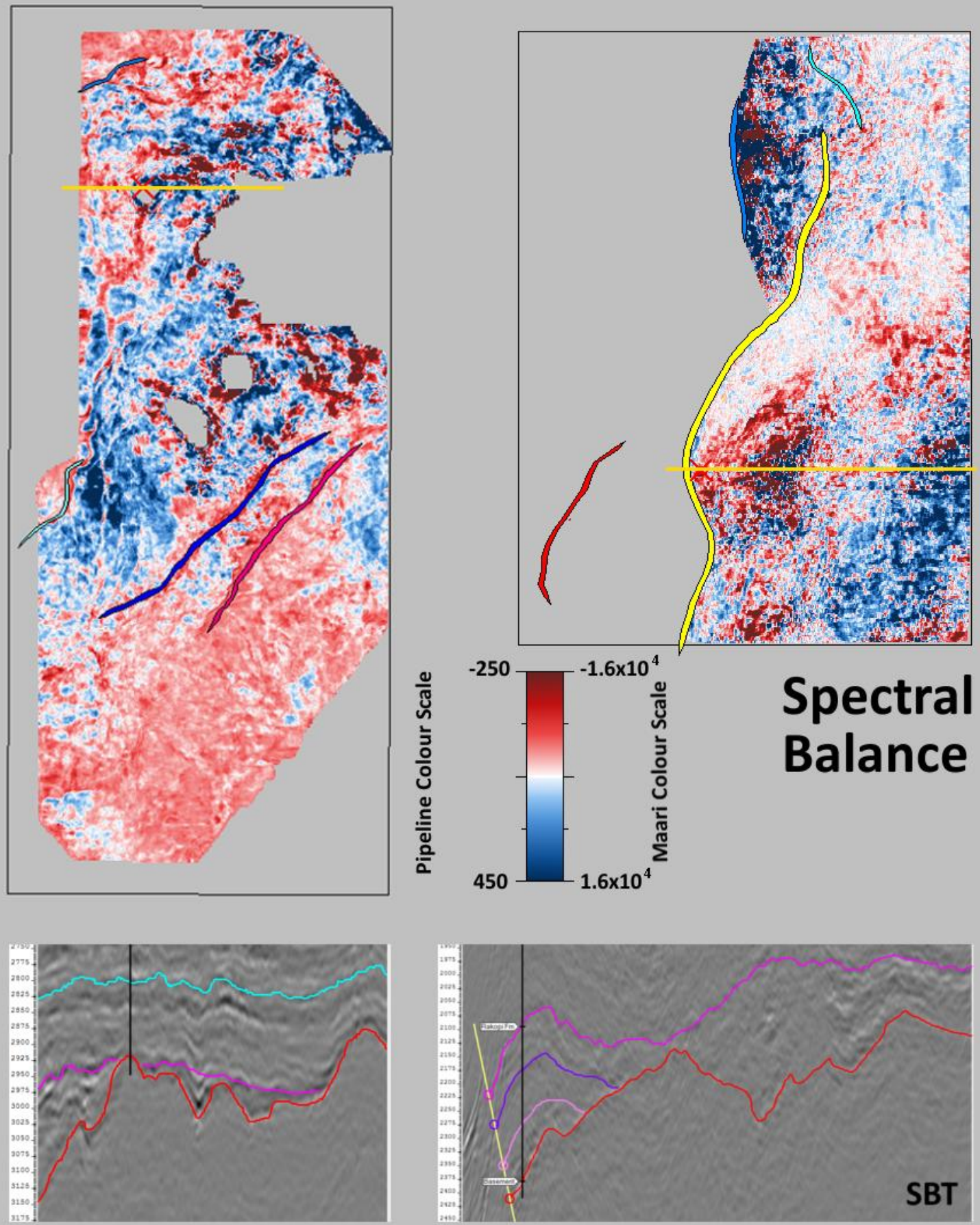

\section{Figure 10.9 Rakopi Formation RSA Data - Spectral Balance}

Shown are the values of this attribute, temporally averaged within the Rakopi Formation interval of the Pipeline (top left), and Maari (top right) 3D seismic volumes, which have individual colour scales (see inset colour bar). The representative 2D lines below the basemaps show the attribute outputs when viewed in 2D. For more information on the averaging process, see Figure 5.1, and for the map location, see Figure 1.1. 

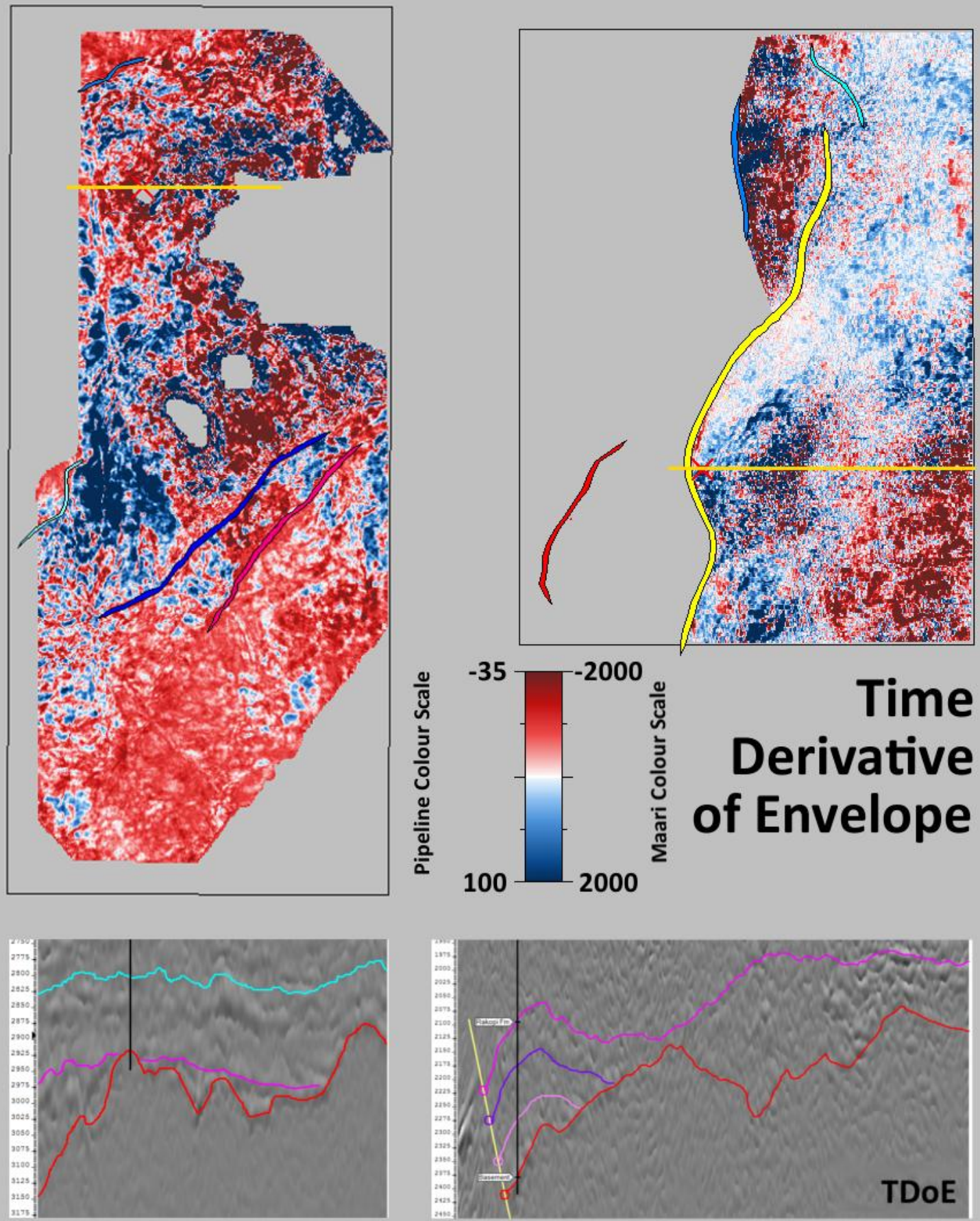

Figure 10.10 Rakopi Formation RSA Data - Time Derivative of Envelope

Shown are the values of this attribute, temporally averaged within the Rakopi Formation interval of the Pipeline (top left), and Maari (top right) 3D seismic volumes, which have individual colour scales (see inset colour bar). The representative 2D lines below the basemaps show the attribute outputs when viewed in 2D. For more information on the averaging process, see Figure 5.1, and for the map location, see Figure 1.1. 

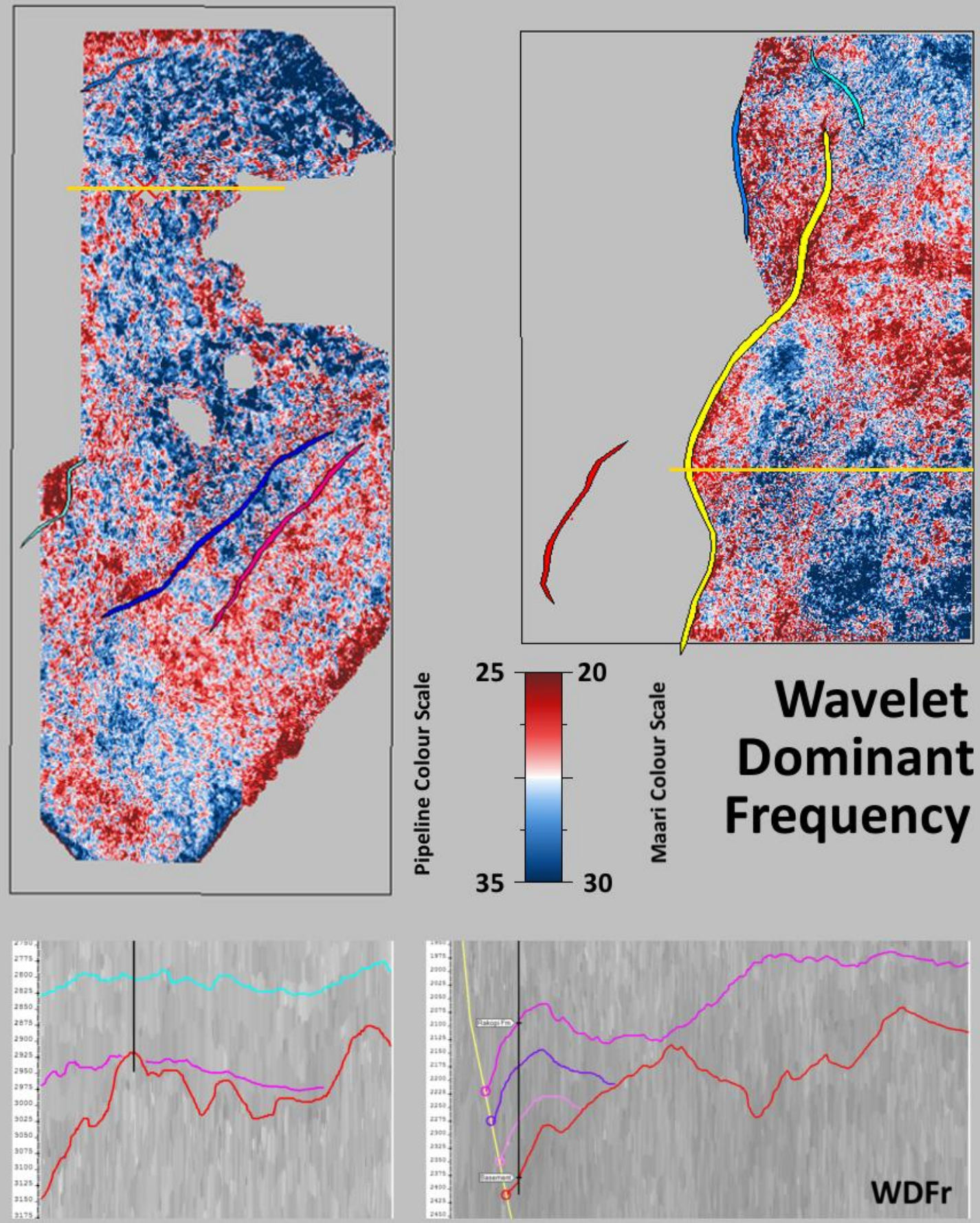

Figure 10.11 Rakopi Formation RSA Data - Wavelet Dominant Frequency

Shown are the values of this attribute, temporally averaged within the Rakopi Formation interval of the Pipeline (top left), and Maari (top right) 3D seismic volumes, which have individual colour scales (see inset colour bar). The representative 2D lines below the basemaps show the attribute outputs when viewed in 2D. For more information on the averaging process, see Figure 5.1, and for the map location, see Figure 1.1. 

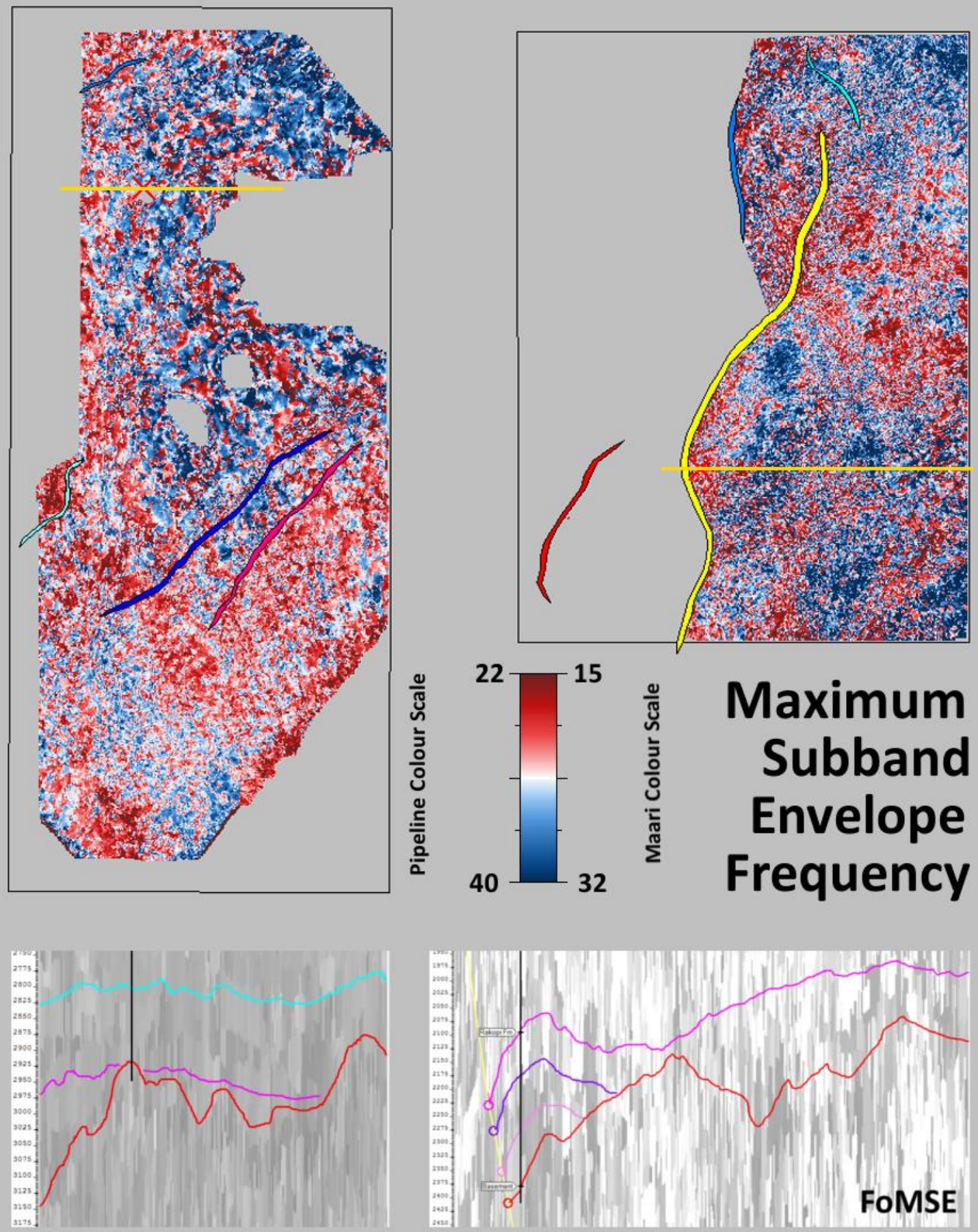

Figure 10.12 Rakopi Formation RSA Data - Maximum Subband Envelope Frequency

Shown are the values of this attribute, temporally averaged within the Rakopi Formation interval of the Pipeline (top left), and Maari (top right) 3D seismic volumes, which have individual colour scales (see inset colour bar). The representative 2D lines below the basemaps show the attribute outputs when viewed in 2D. For more information on the averaging process, see Figure 5.1, and for the map location, see Figure 1.1. 

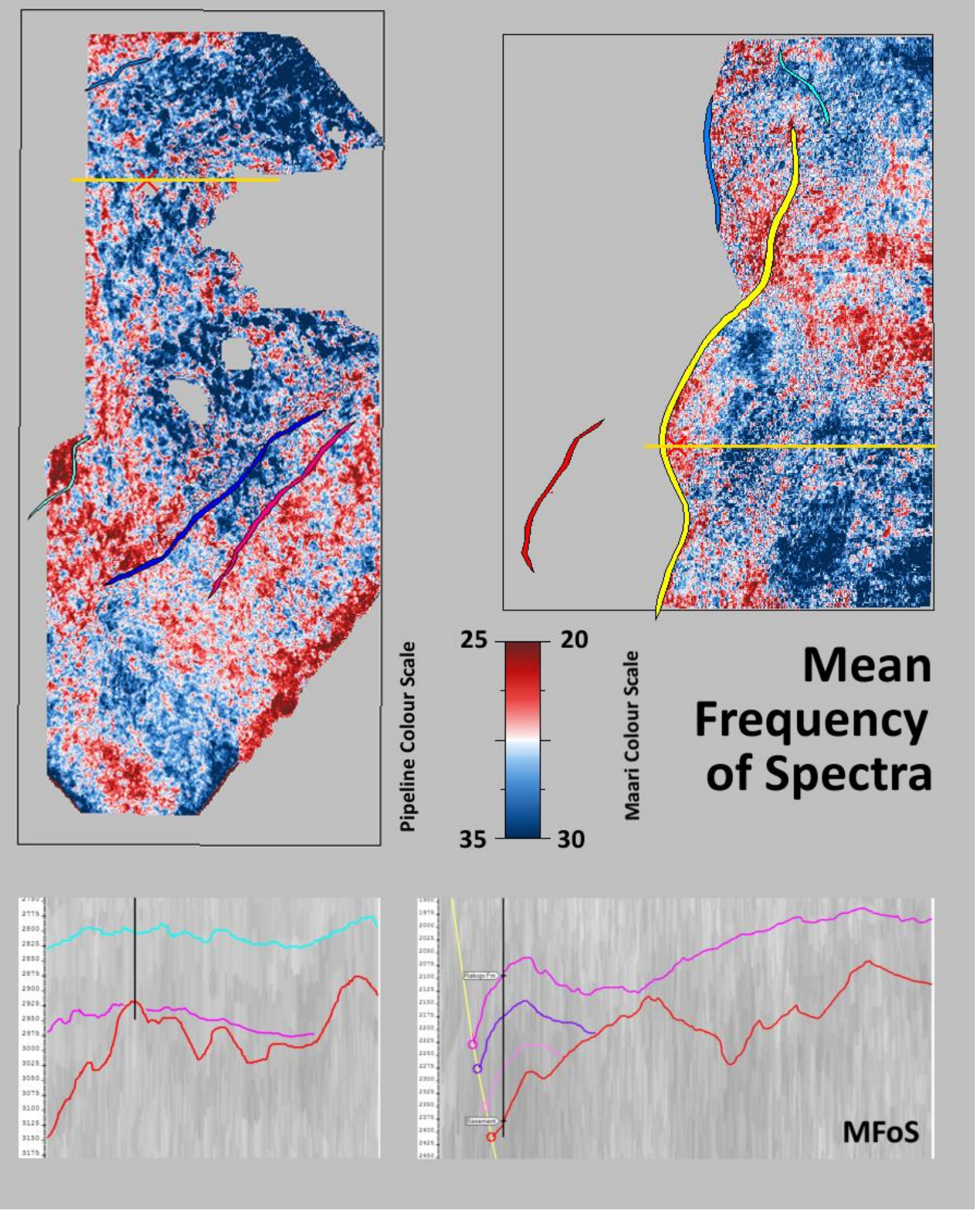

\section{Figure 10.13 Rakopi Formation RSA Data - Mean Frequency of Spectra}

Shown are the values of this attribute, temporally averaged within the Rakopi Formation interval of the Pipeline (top left), and Maari (top right) 3D seismic volumes, which have individual colour scales (see inset colour bar). The representative 2D lines below the basemaps show the attribute outputs when viewed in 2D. For more information on the averaging process, see Figure 5.1, and for the map location, see Figure 1.1. 

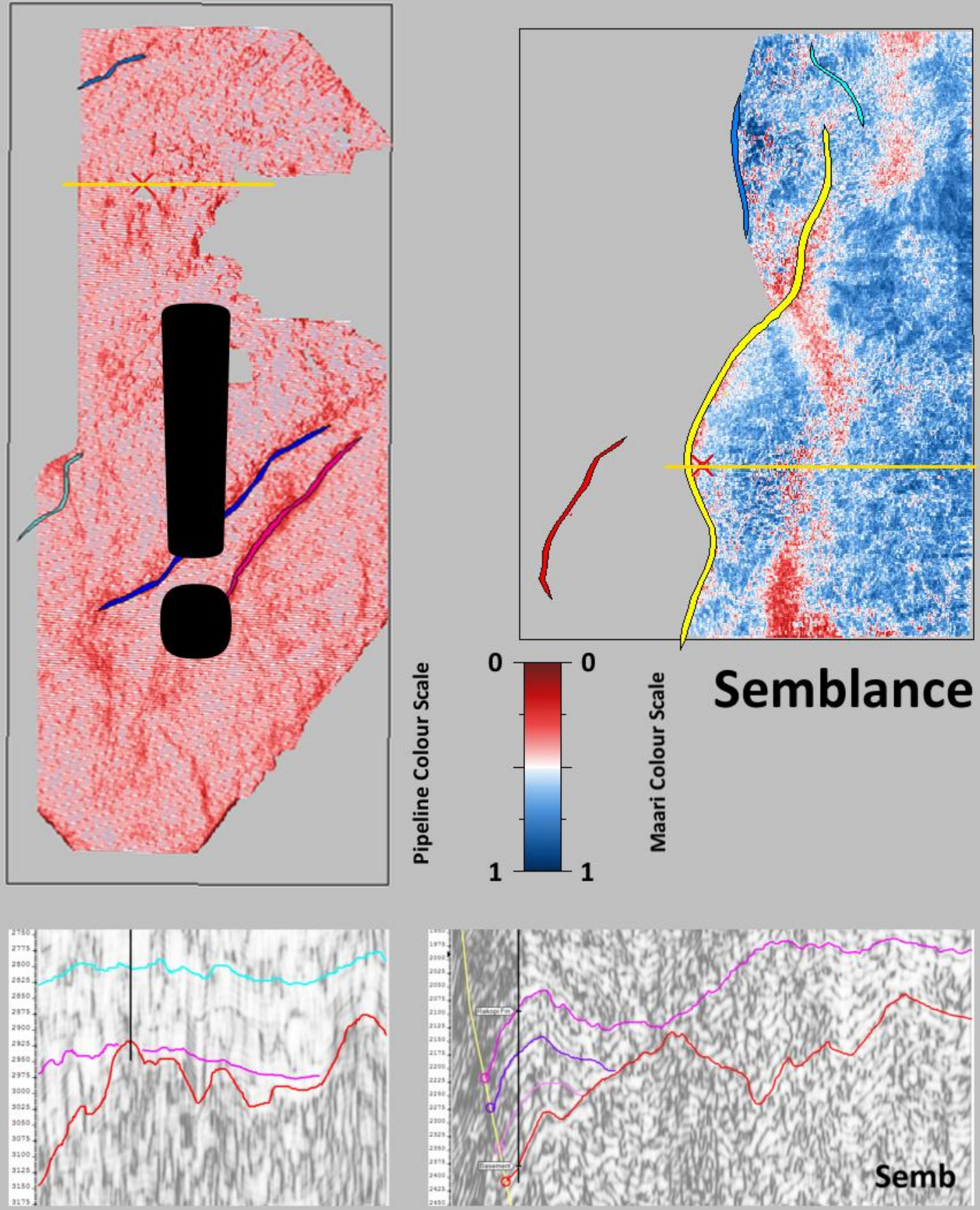

\section{Figure 10.14 Rakopi Formation RSA Data - Semblance}

Shown are the values of this attribute, temporally averaged within the Rakopi Formation interval of the Pipeline (top left), and Maari (top right) 3D seismic volumes, which have individual colour scales (see inset colour bar). The representative 2D lines below the basemaps show the attribute outputs when viewed in 2D. For more information on the averaging process, see Figure 5.1, and for the map location, see Figure 1.1.

Note: The Pipeline 3D volume was not able to be loaded correctly into Seisware ${ }^{\mathrm{TM}}$. Every second trace was nulled, which was not a problem for most of the work done, but since Semblance compares adjacent traces, it was not able to be displayed properly as an attribute amplitude map. 

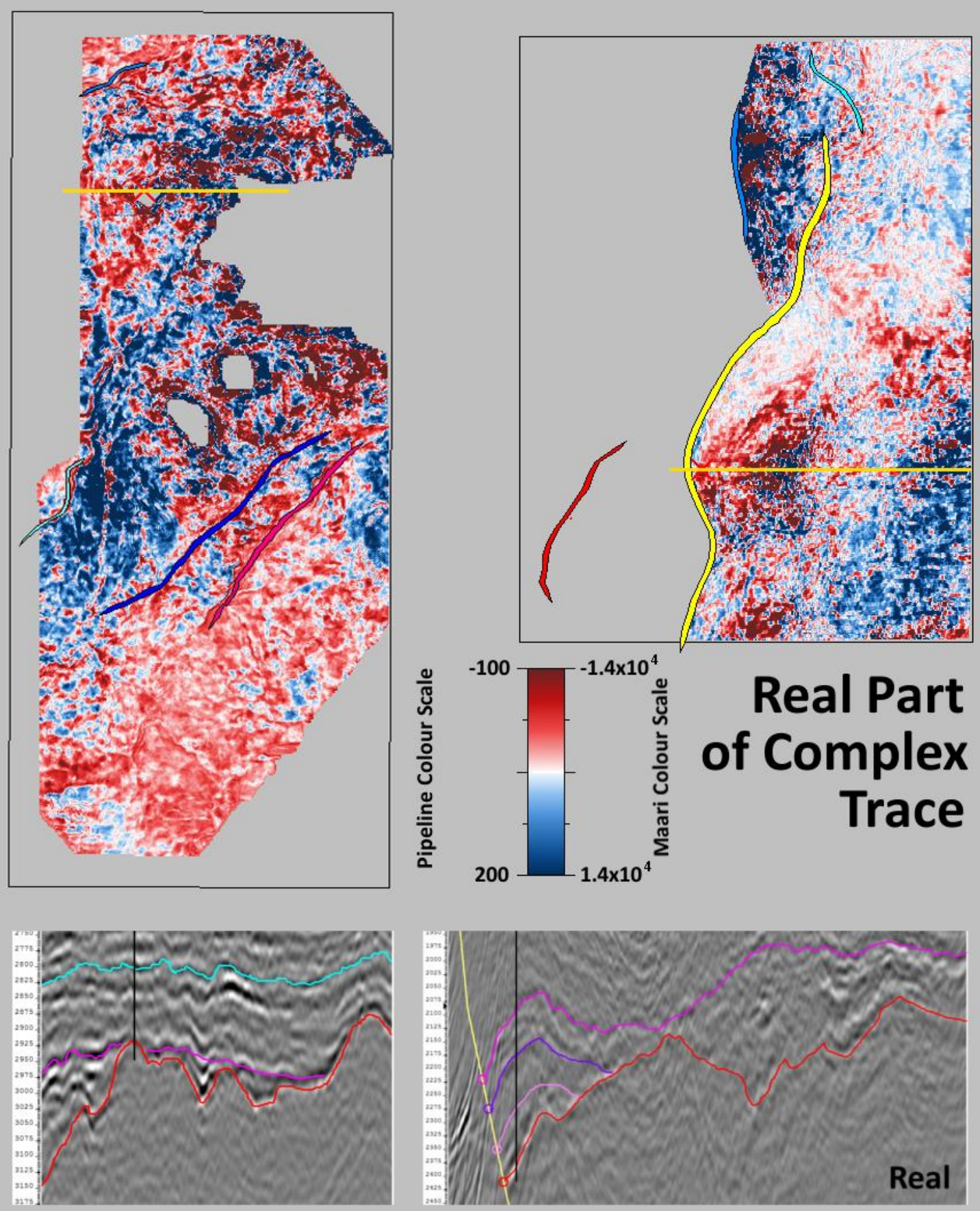

\section{Figure 10.15 Rakopi Formation RSA Data - Real Part of Complex Trace}

Shown are the values of this attribute, temporally averaged within the Rakopi Formation interval of the Pipeline (top left), and Maari (top right) 3D seismic volumes, which have individual colour scales (see inset colour bar). The representative 2D lines below the basemaps show the attribute outputs when viewed in 2D. For more information on the averaging process, see Figure 5.1, and for the map location, see Figure 1.1. 


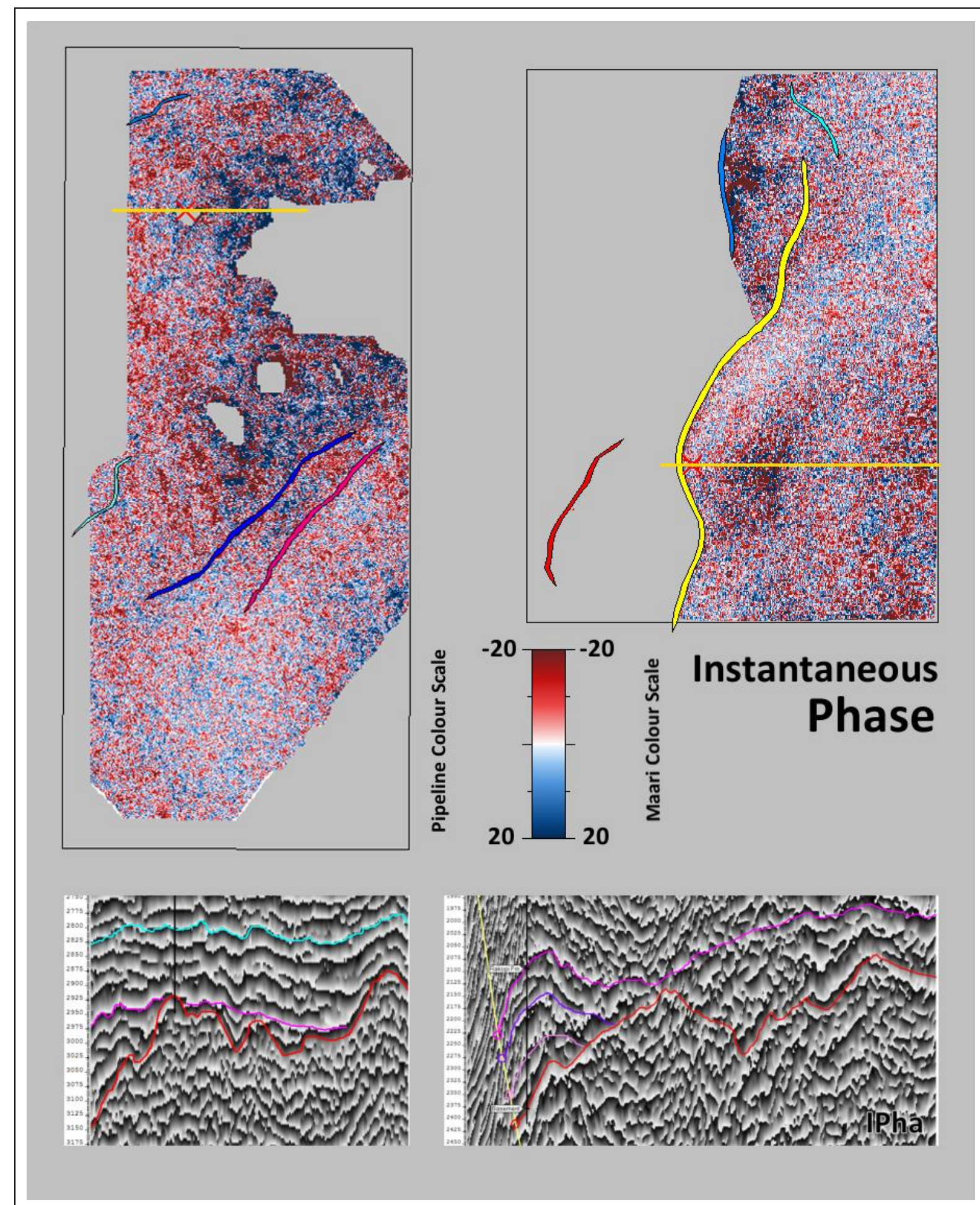

Figure 10.16 Rakopi Formation RSA Data - Instantaneous Phase

Shown are the values of this attribute, temporally averaged within the Rakopi Formation interval of the Pipeline (top left), and Maari (top right) 3D seismic volumes, which have individual colour scales (see inset colour bar). The representative 2D lines below the basemaps show the attribute outputs when viewed in 2D. For more information on the averaging process, see Figure 5.1, and for the map location, see Figure 1.1. 

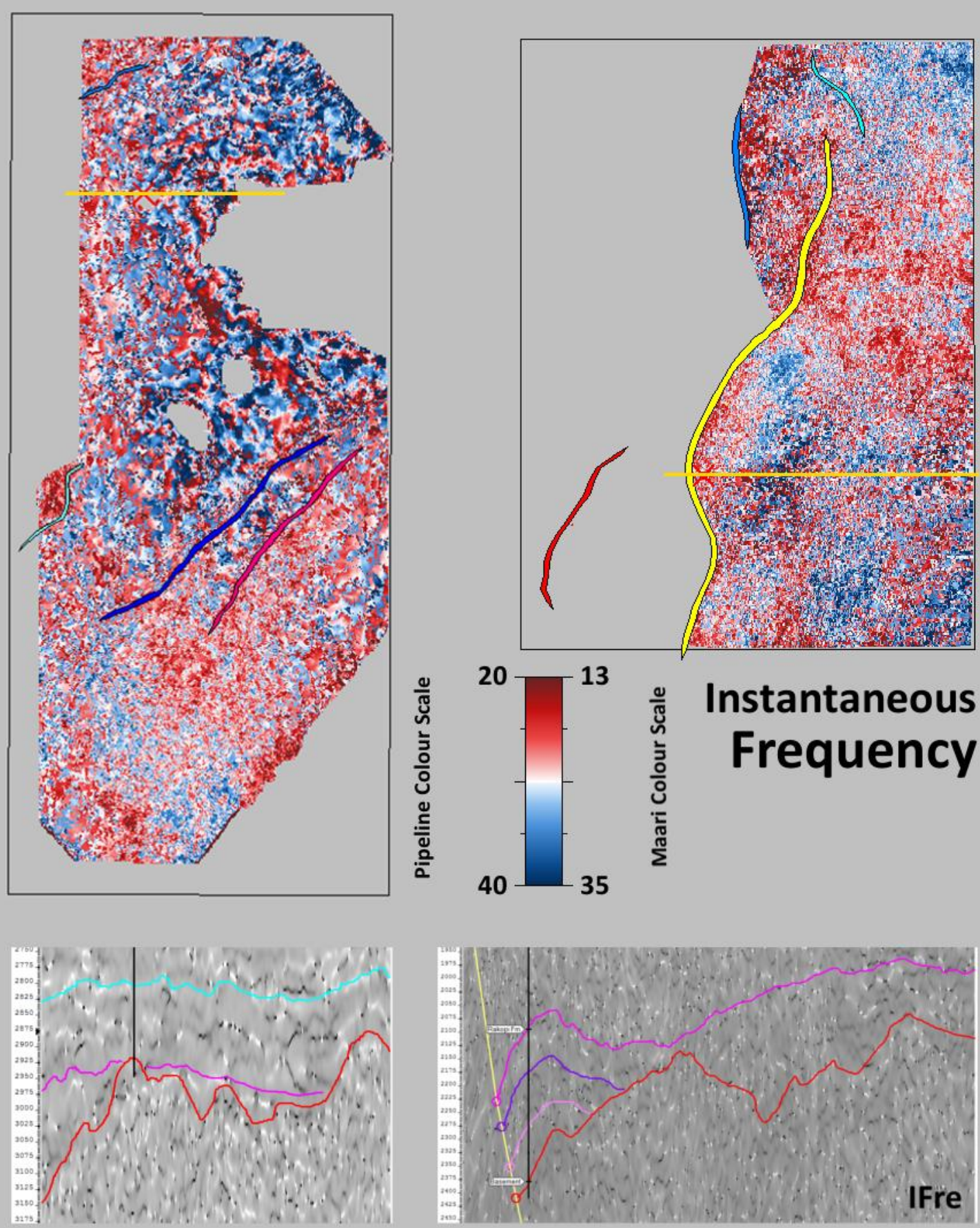

\section{Figure 10.17 Rakopi Formation RSA Data - Instantaneous Frequency}

Shown are the values of this attribute, temporally averaged within the Rakopi Formation interval of the Pipeline (top left), and Maari (top right) 3D seismic volumes, which have individual colour scales (see inset colour bar). The representative 2D lines below the basemaps show the attribute outputs when viewed in 2D. For more information on the averaging process, see Figure 5.1, and for the map location, see Figure 1.1. 

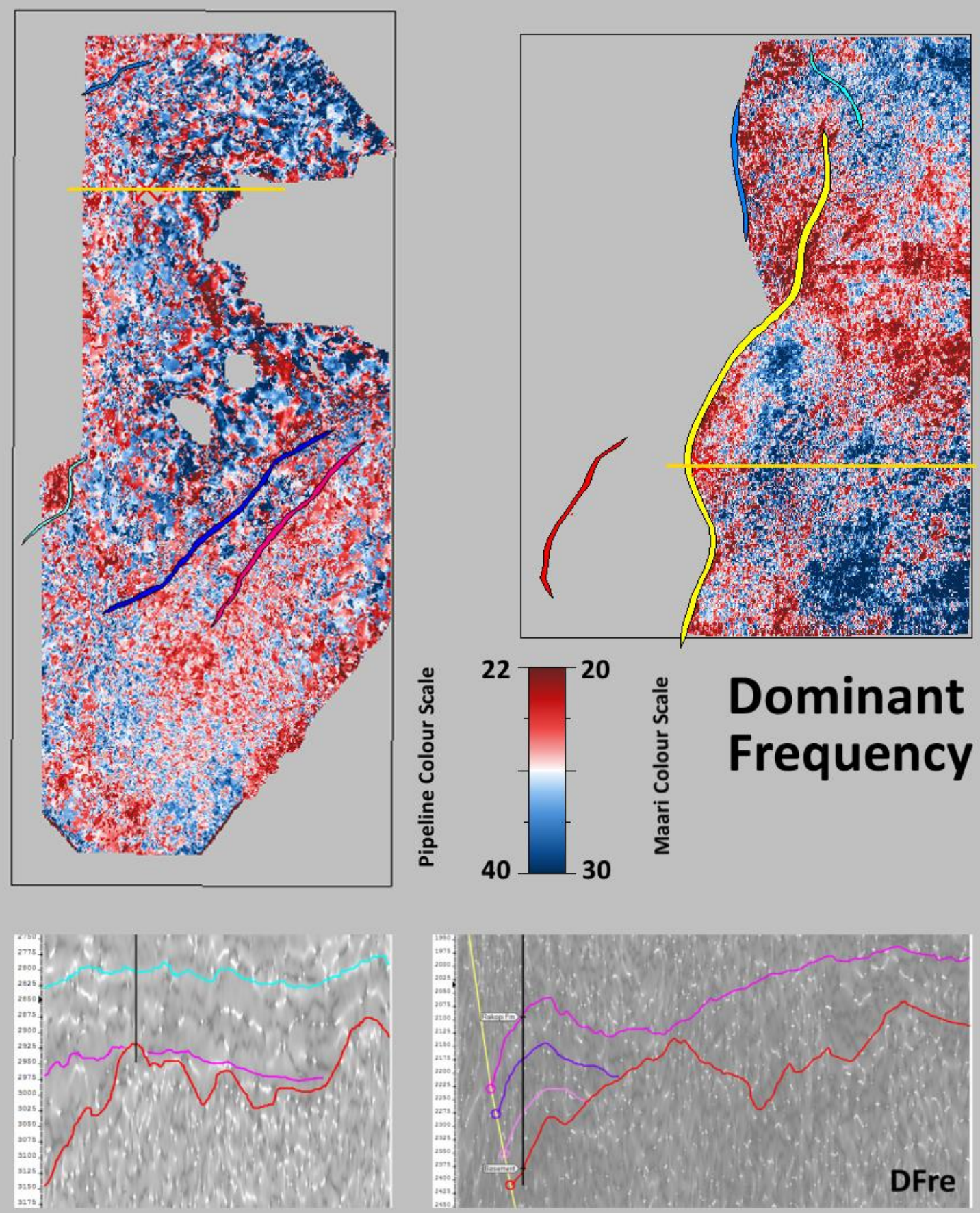

Figure 10.18 Rakopi Formation RSA Data - Dominant Frequency

Shown are the values of this attribute, temporally averaged within the Rakopi Formation interval of the Pipeline (top left), and Maari (top right) 3D seismic volumes, which have individual colour scales (see inset colour bar). The representative 2D lines below the basemaps show the attribute outputs when viewed in 2D. For more information on the averaging process, see Figure 5.1, and for the map location, see Figure 1.1. 

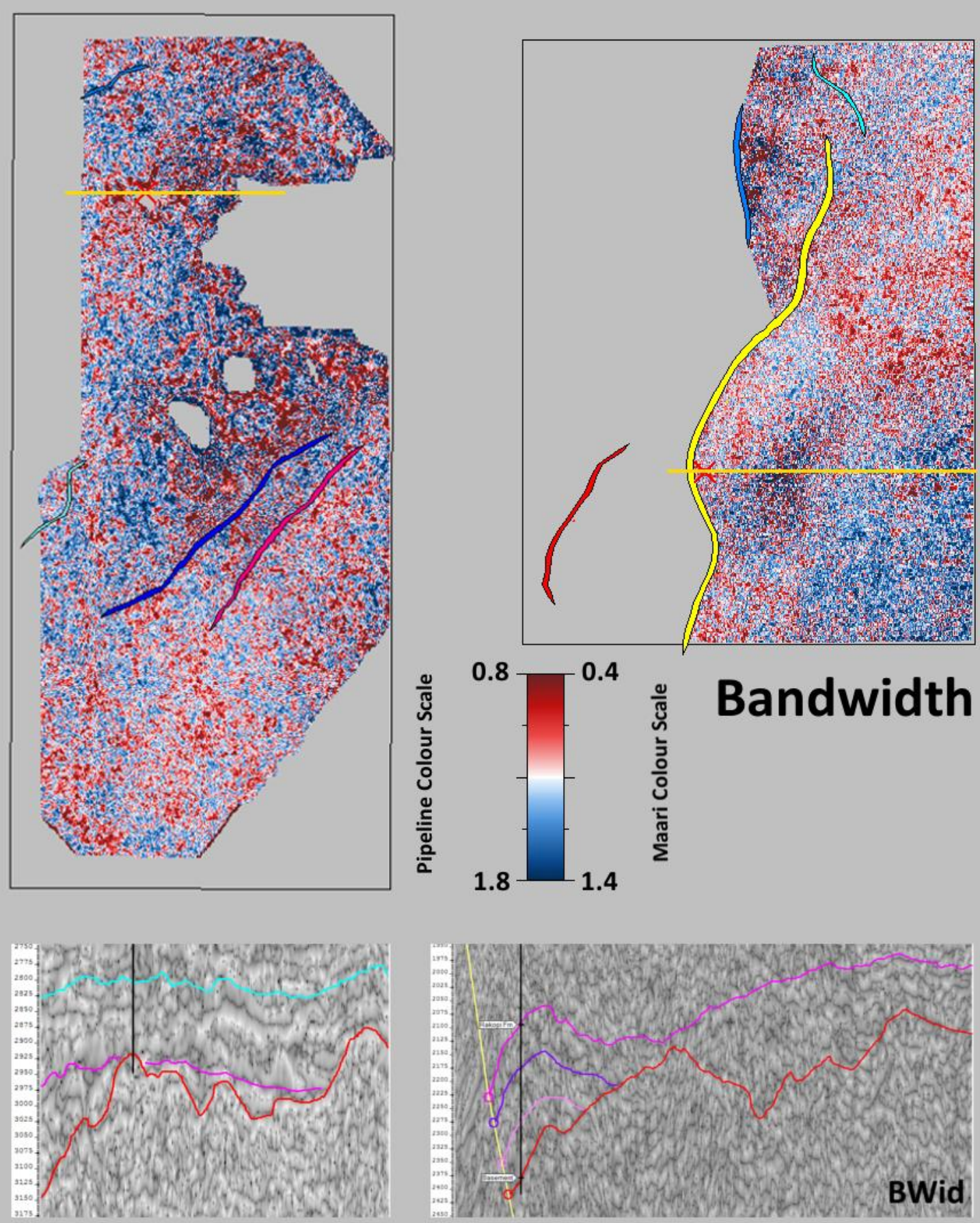

\section{Figure 10.19 Rakopi Formation RSA Data - Bandwidth}

Shown are the values of this attribute, temporally averaged within the Rakopi Formation interval of the Pipeline (top left), and Maari (top right) 3D seismic volumes, which have individual colour scales (see inset colour bar). The representative 2D lines below the basemaps show the attribute outputs when viewed in 2D. For more information on the averaging process, see Figure 5.1, and for the map location, see Figure 1.1. 

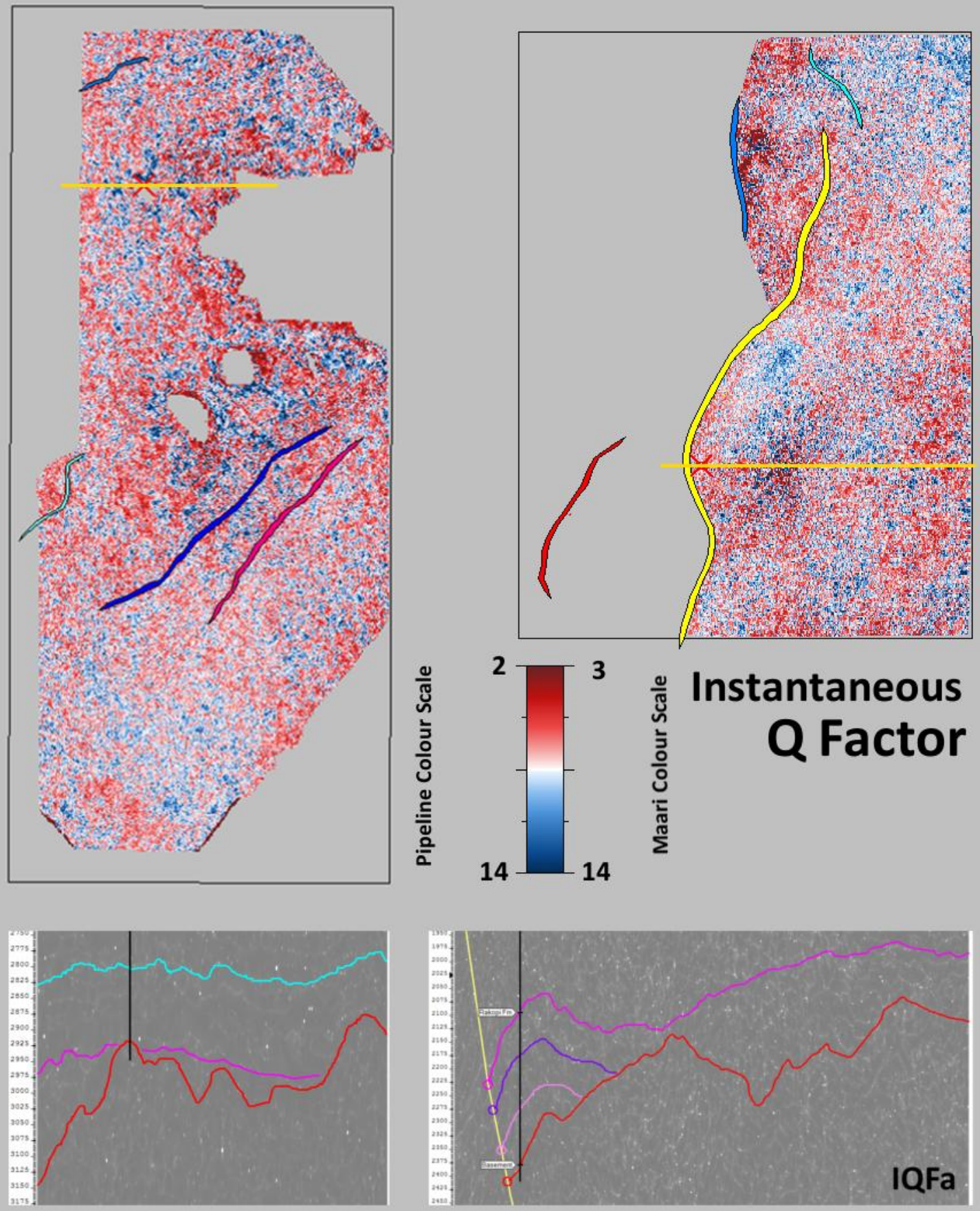

\section{Figure 10.20 Rakopi Formation RSA Data - Instantaneous Q Factor}

Shown are the values of this attribute, temporally averaged within the Rakopi Formation interval of the Pipeline (top left), and Maari (top right) 3D seismic volumes, which have individual colour scales (see inset colour bar). The representative 2D lines below the basemaps show the attribute outputs when viewed in 2D. For more information on the averaging process, see Figure 5.1, and for the map location, see Figure 1.1. 

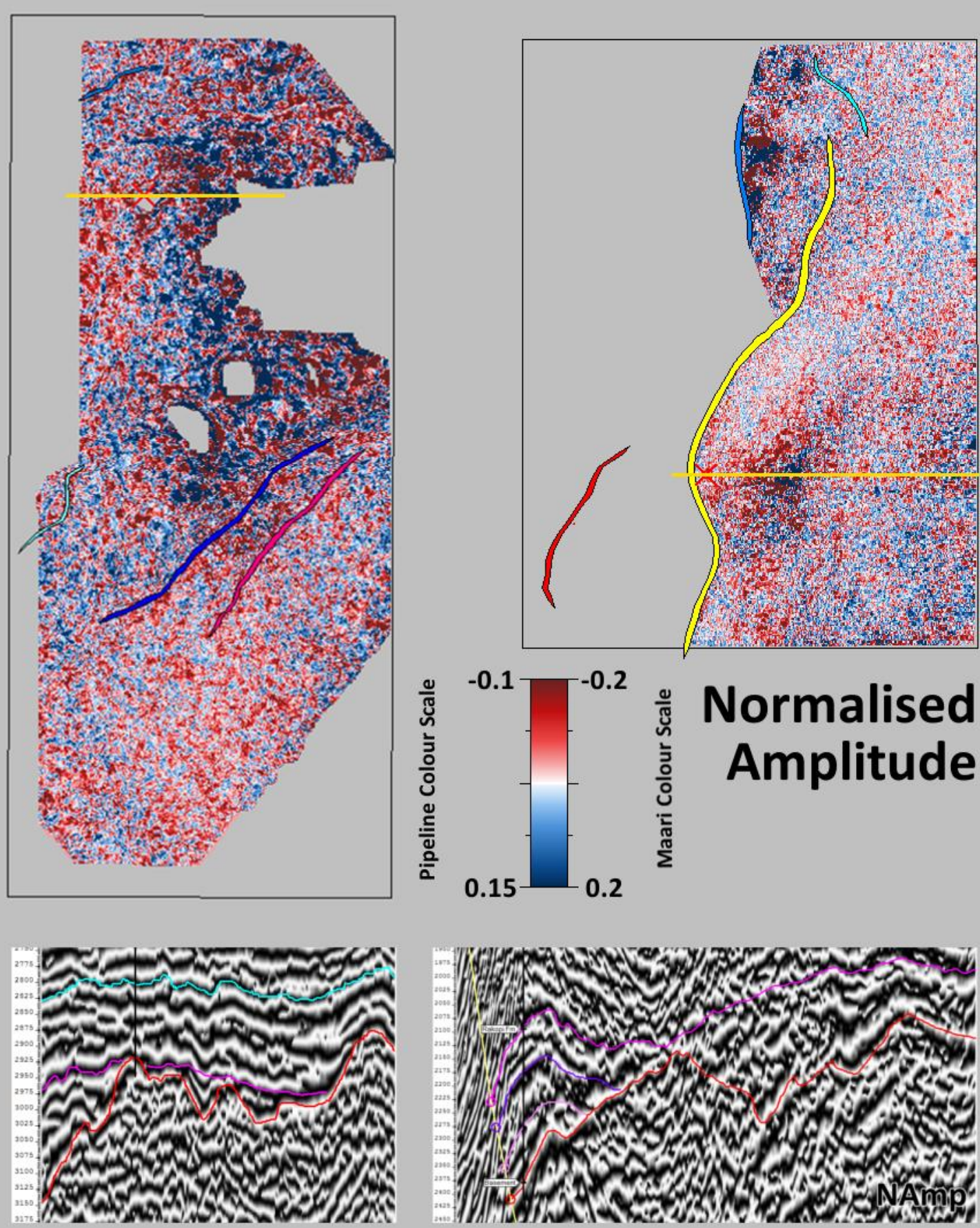

Figure 10.21 Rakopi Formation RSA Data - Normalised Amplitude

Shown are the values of this attribute, temporally averaged within the Rakopi Formation interval of the Pipeline (top left), and Maari (top right) 3D seismic volumes, which have individual colour scales (see inset colour bar). The representative 2D lines below the basemaps show the attribute outputs when viewed in 2D. For more information on the averaging process, see Figure 5.1, and for the map location, see Figure 1.1. 

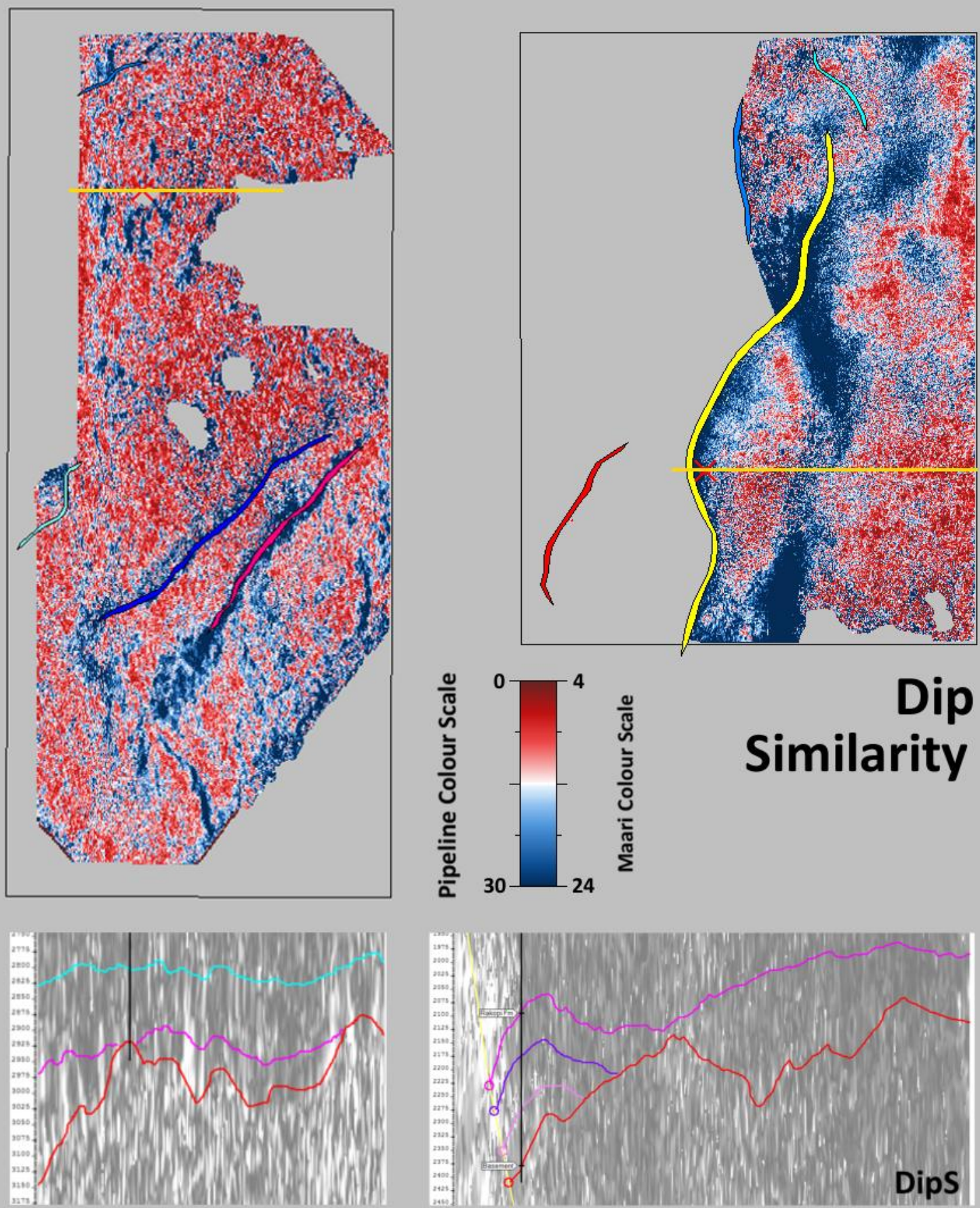

Figure 10.22 Rakopi Formation RSA Data - Dip Similarity

Shown are the values of this attribute, temporally averaged within the Rakopi Formation interval of the Pipeline (top left), and Maari (top right) 3D seismic volumes, which have individual colour scales (see inset colour bar). The representative 2D lines below the basemaps show the attribute outputs when viewed in 2D. For more information on the averaging process, see Figure 5.1, and for the map location, see Figure 1.1. 

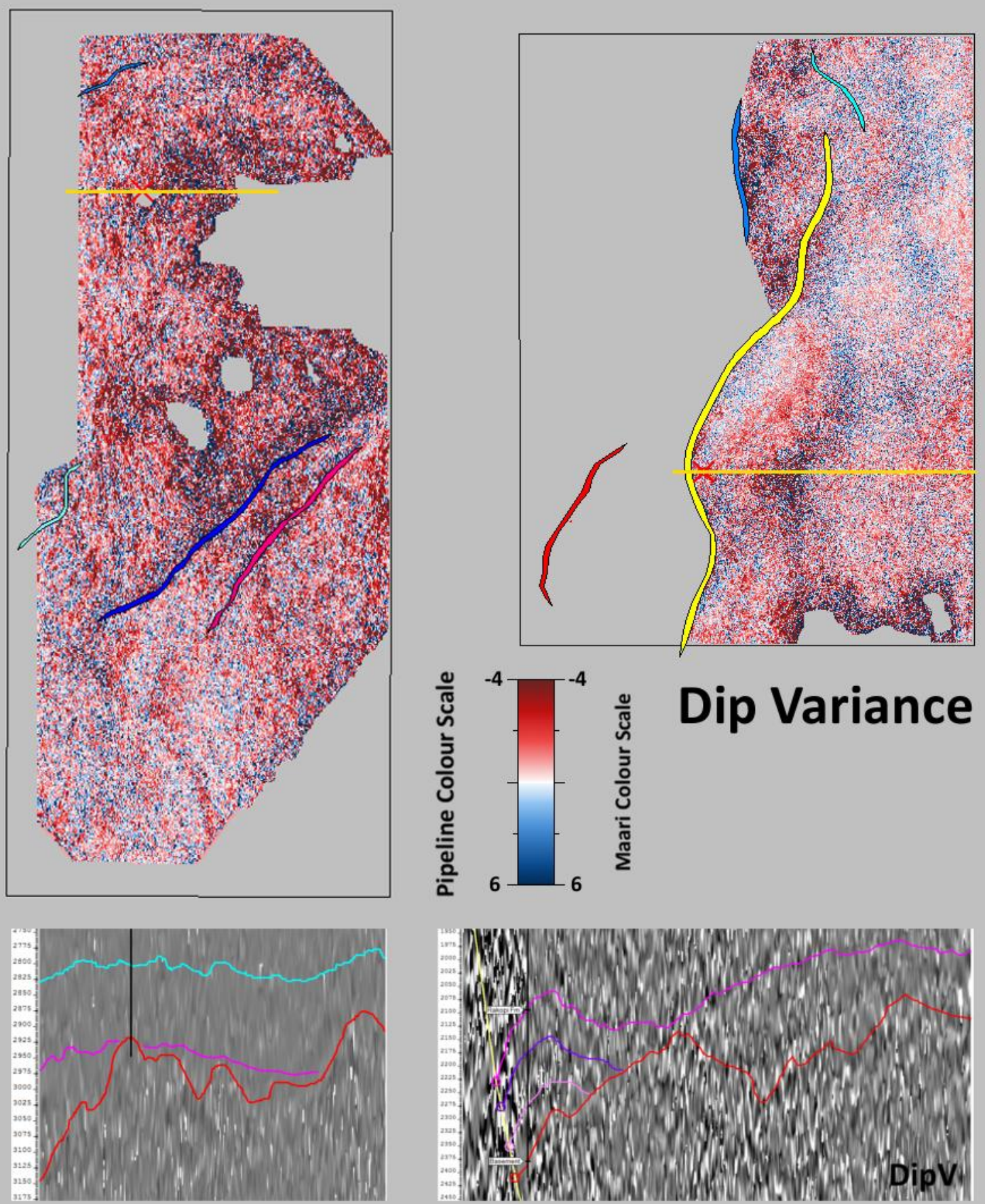

\section{Figure 10.23 Rakopi Formation RSA Data - Dip Variance}

Shown are the values of this attribute, temporally averaged within the Rakopi Formation interval of the Pipeline (top left), and Maari (top right) 3D seismic volumes, which have individual colour scales (see inset colour bar). The representative 2D lines below the basemaps show the attribute outputs when viewed in 2D. For more information on the averaging process, see Figure 5.1, and for the map location, see Figure 1.1. 


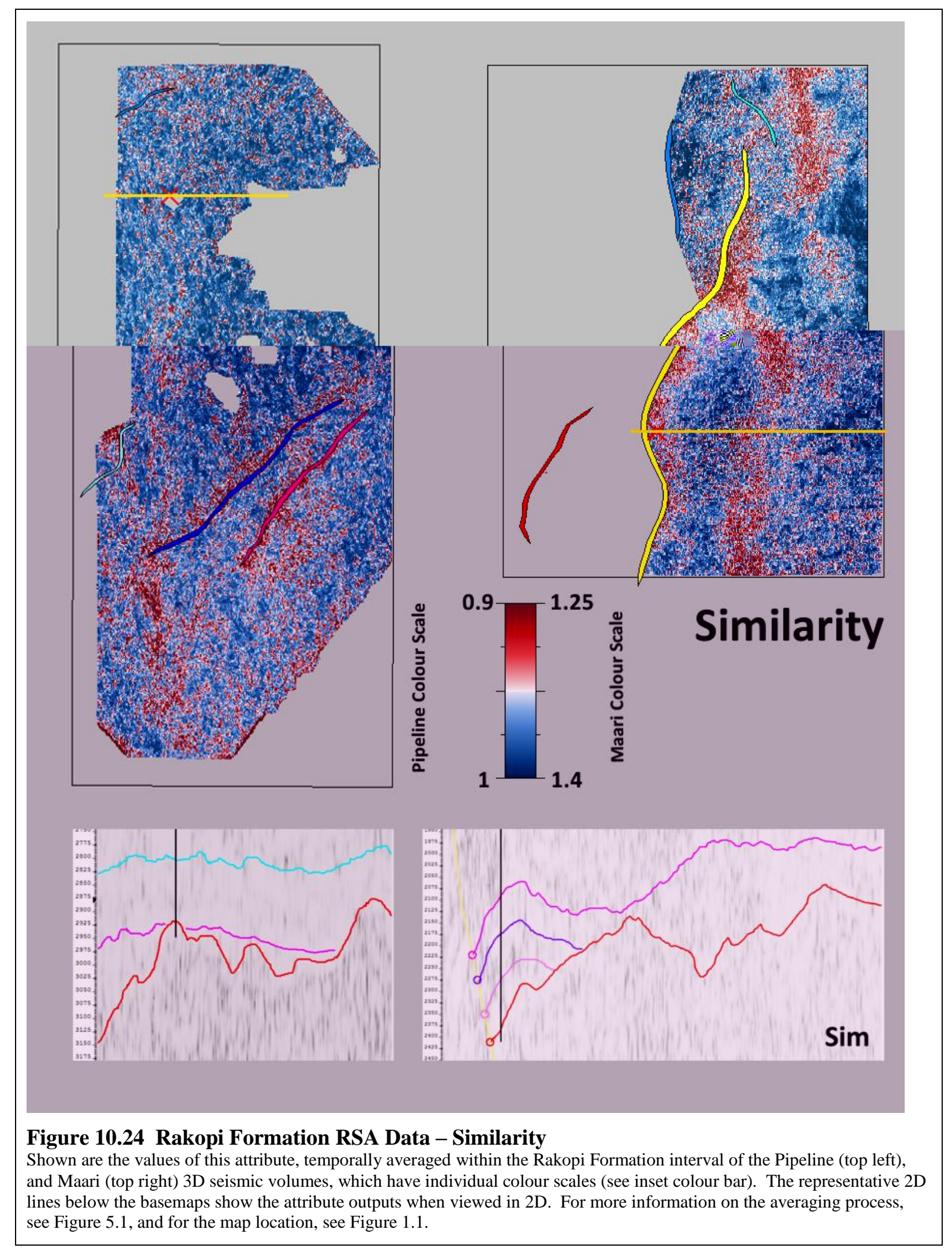




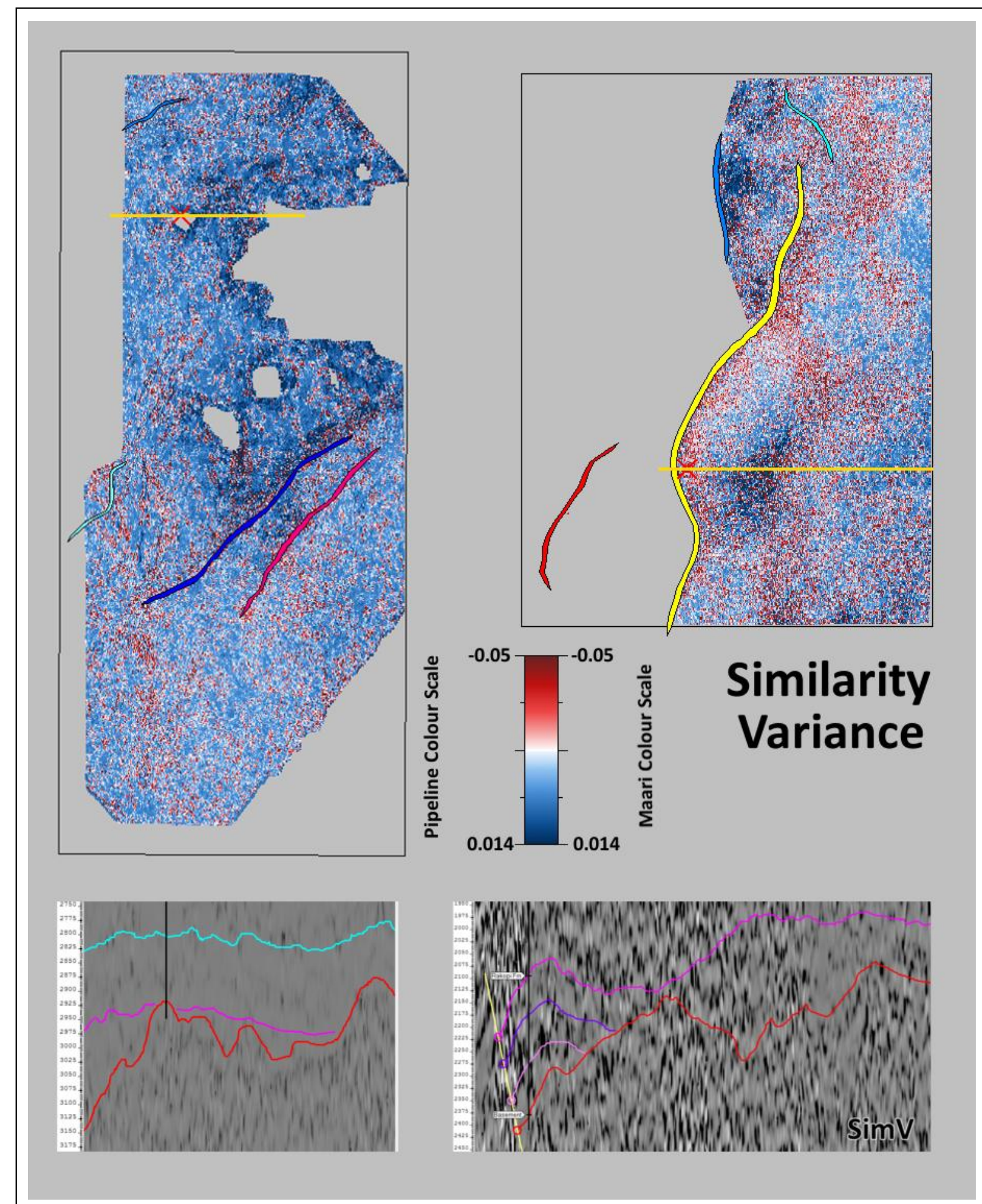

\section{Figure 10.25 Rakopi Formation RSA Data - Similarity Variance}

Shown are the values of this attribute, temporally averaged within the Rakopi Formation interval of the Pipeline (top left), and Maari (top right) 3D seismic volumes, which have individual colour scales (see inset colour bar). The representative 2D lines below the basemaps show the attribute outputs when viewed in 2D. For more information on the averaging process, see Figure 5.1, and for the map location, see Figure 1.1. 


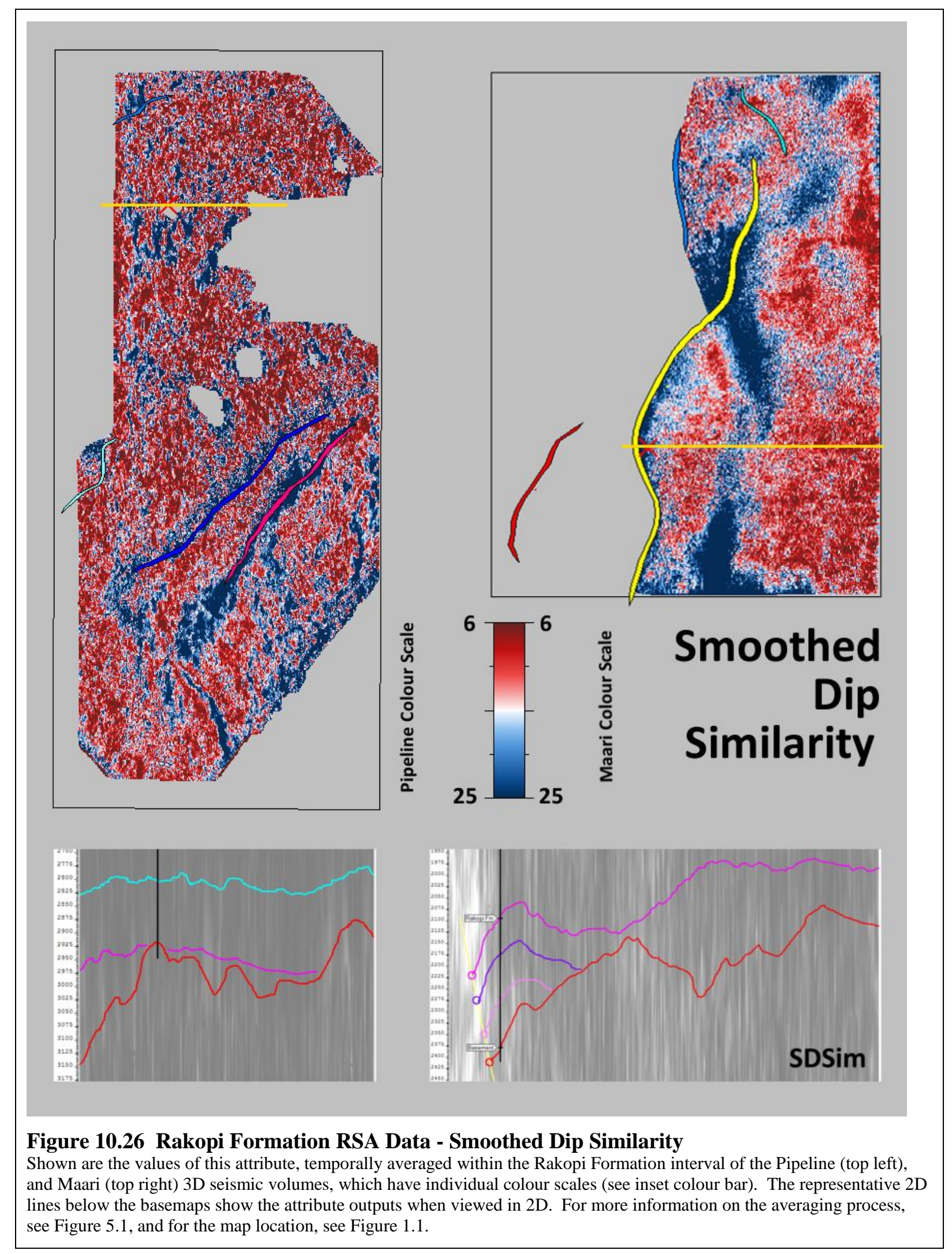



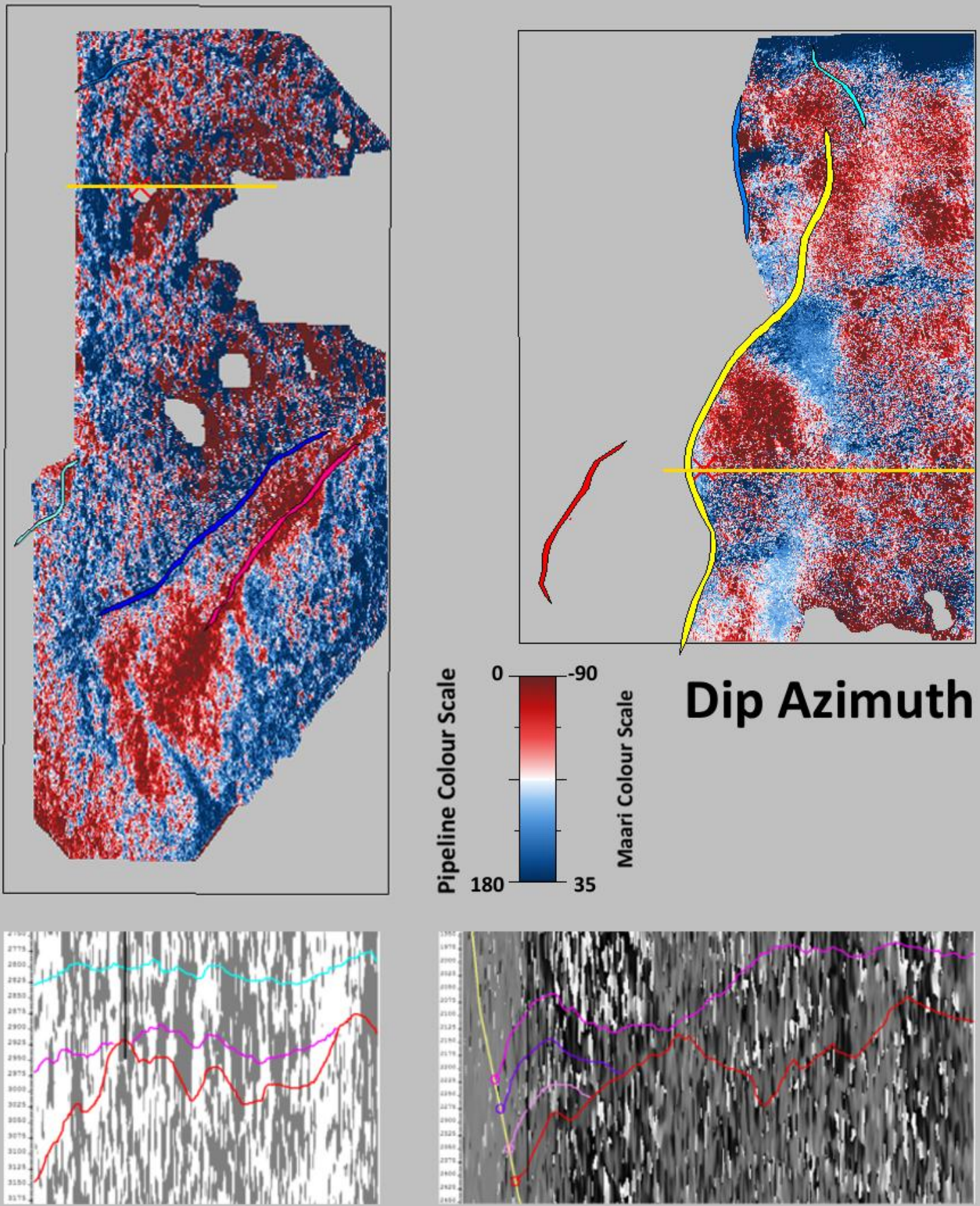

\section{Figure 10.27 Rakopi Formation RSA Data - Dip Azimuth}

Shown are the values of this attribute, temporally averaged within the Rakopi Formation interval of the Pipeline (top left), and Maari (top right) 3D seismic volumes, which have individual colour scales (see inset colour bar). The representative 2D lines below the basemaps show the attribute outputs when viewed in 2D. For more information on the averaging process, see Figure 5.1, and for the map location, see Figure 1.1. 


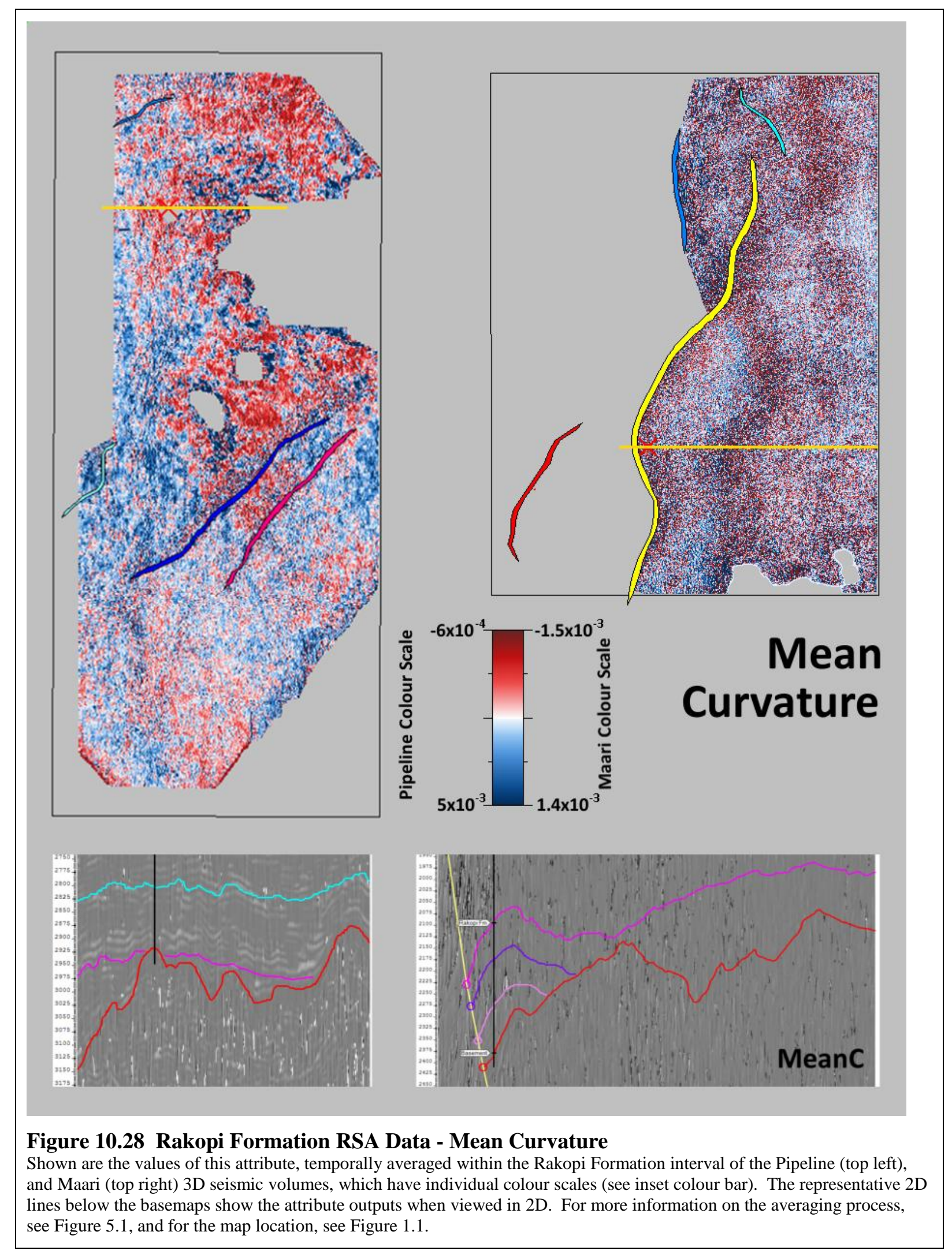




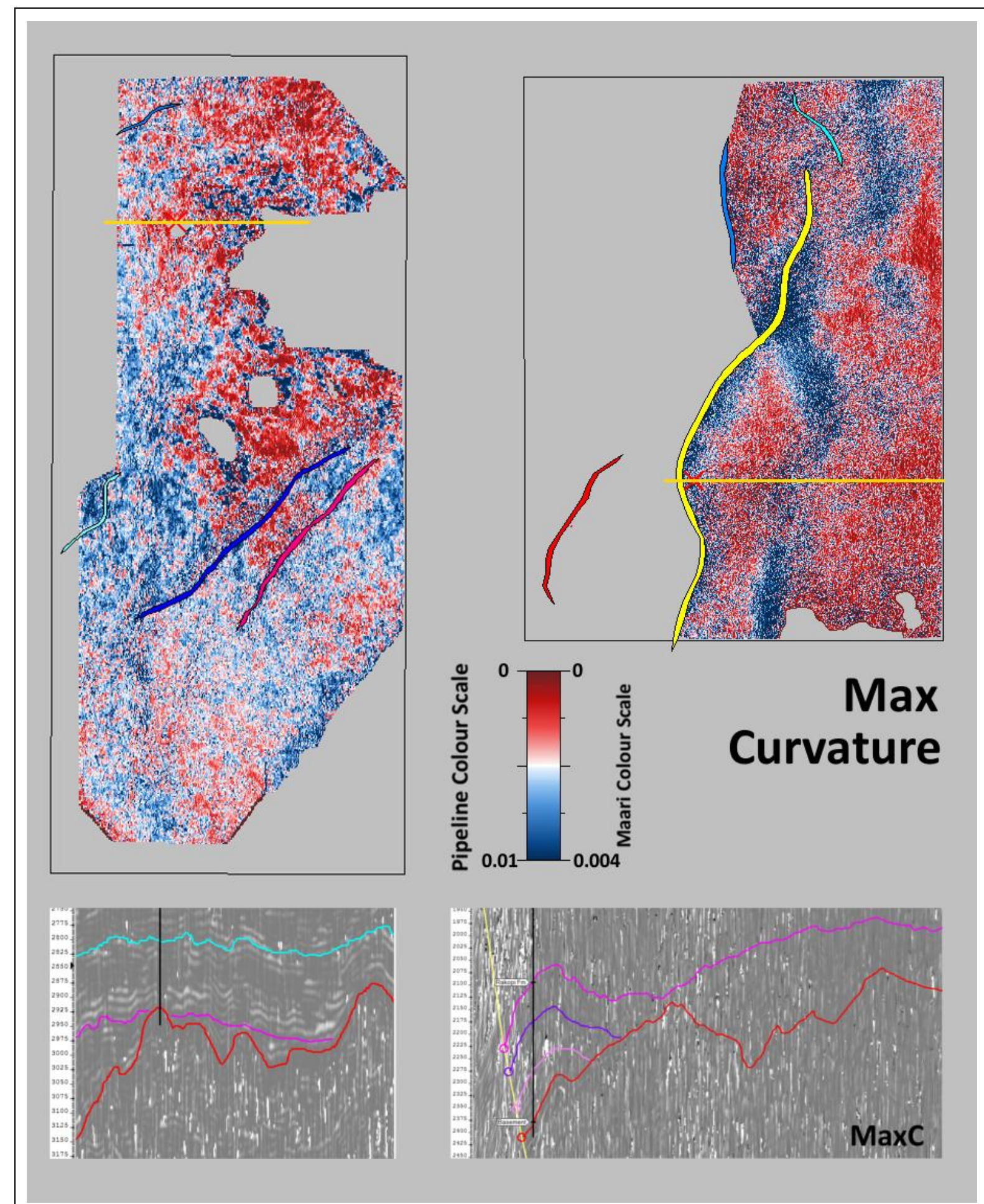

Figure 10.29 Rakopi Formation RSA Data - Max Curvature

Shown are the values of this attribute, temporally averaged within the Rakopi Formation interval of the Pipeline (top left), and Maari (top right) 3D seismic volumes, which have individual colour scales (see inset colour bar). The representative 2D lines below the basemaps show the attribute outputs when viewed in 2D. For more information on the averaging process, see Figure 5.1, and for the map location, see Figure 1.1. 

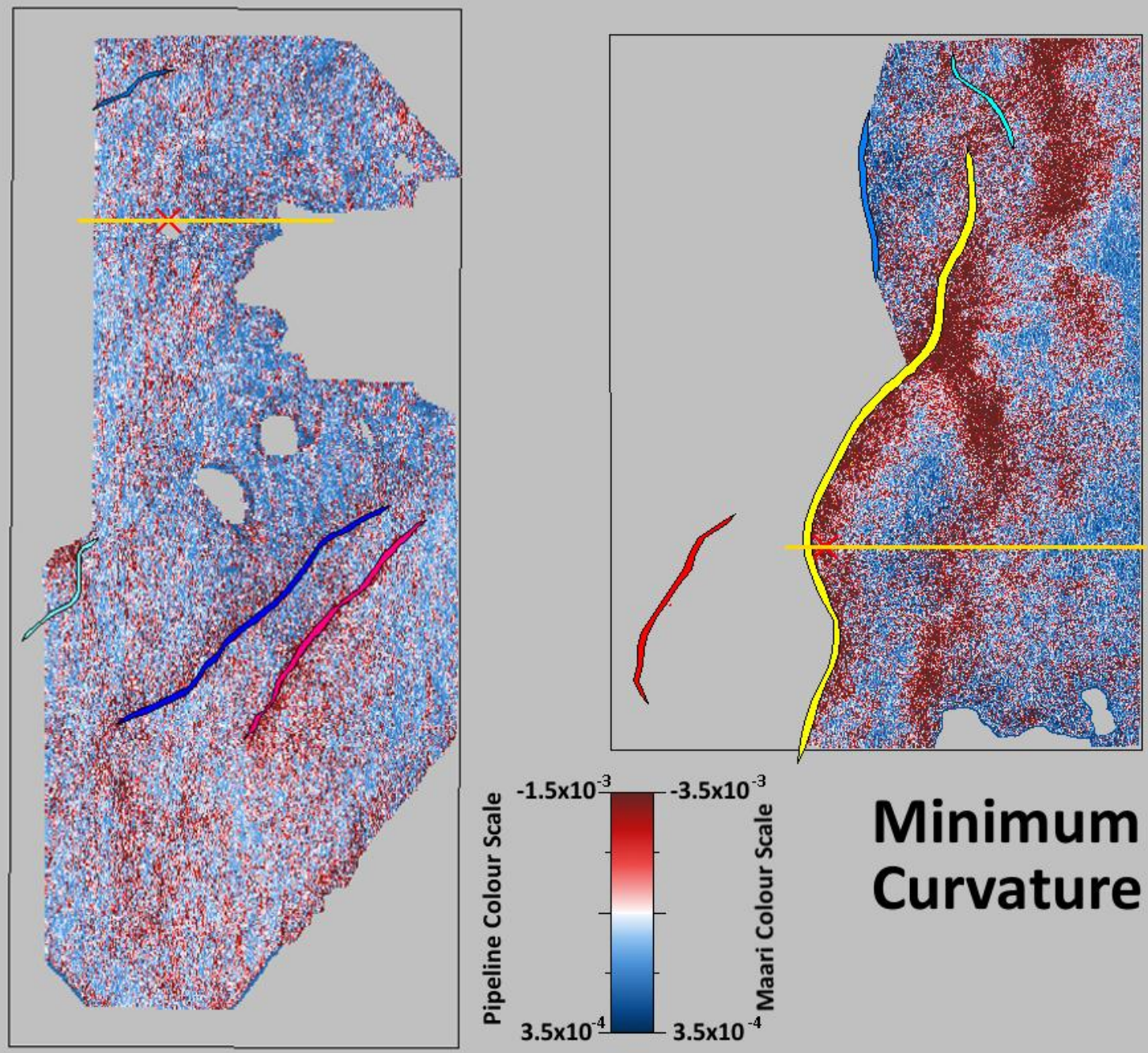

\section{Minimum Curvature}
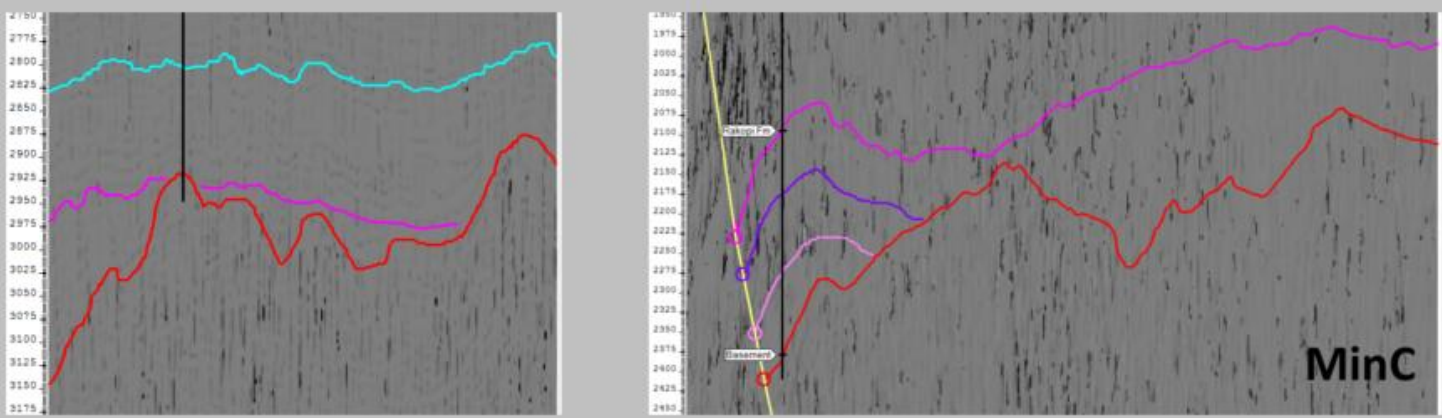

\section{Figure 10.30 Rakopi Formation RSA Data - Minimum Curvature}

Shown are the values of this attribute, temporally averaged within the Rakopi Formation interval of the Pipeline (top left), and Maari (top right) 3D seismic volumes, which have individual colour scales (see inset colour bar). The representative 2D lines below the basemaps show the attribute outputs when viewed in 2D. For more information on the averaging process, see Figure 5.1, and for the map location, see Figure 1.1. 


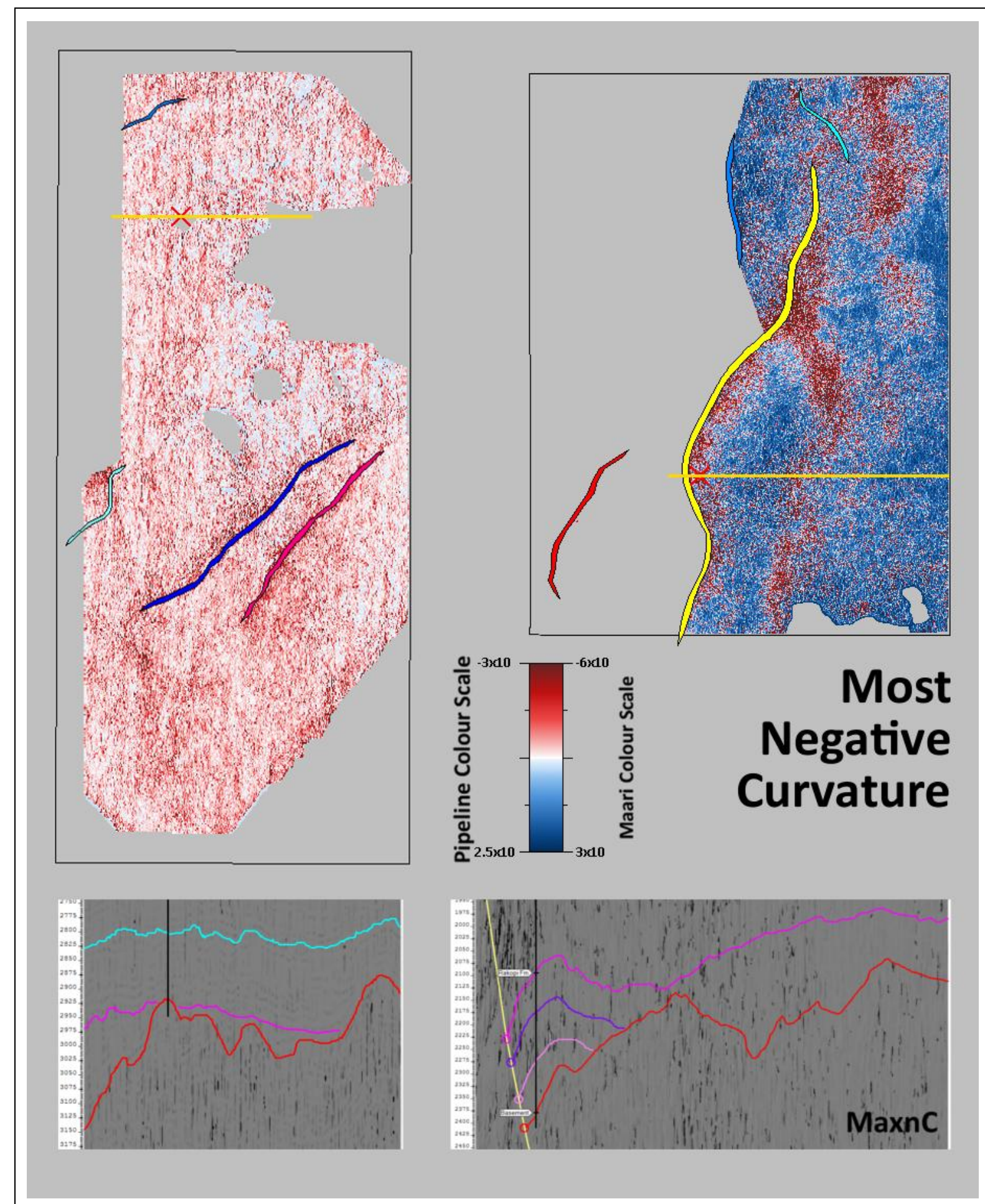

\section{Figure 10.31 Rakopi Formation RSA Data - Most Negative Curvature}

Shown are the values of this attribute, temporally averaged within the Rakopi Formation interval of the Pipeline (top left), and Maari (top right) 3D seismic volumes, which have individual colour scales (see inset colour bar). The representative 2D lines below the basemaps show the attribute outputs when viewed in 2D. For more information on the averaging process, see Figure 5.1, and for the map location, see Figure 1.1. 

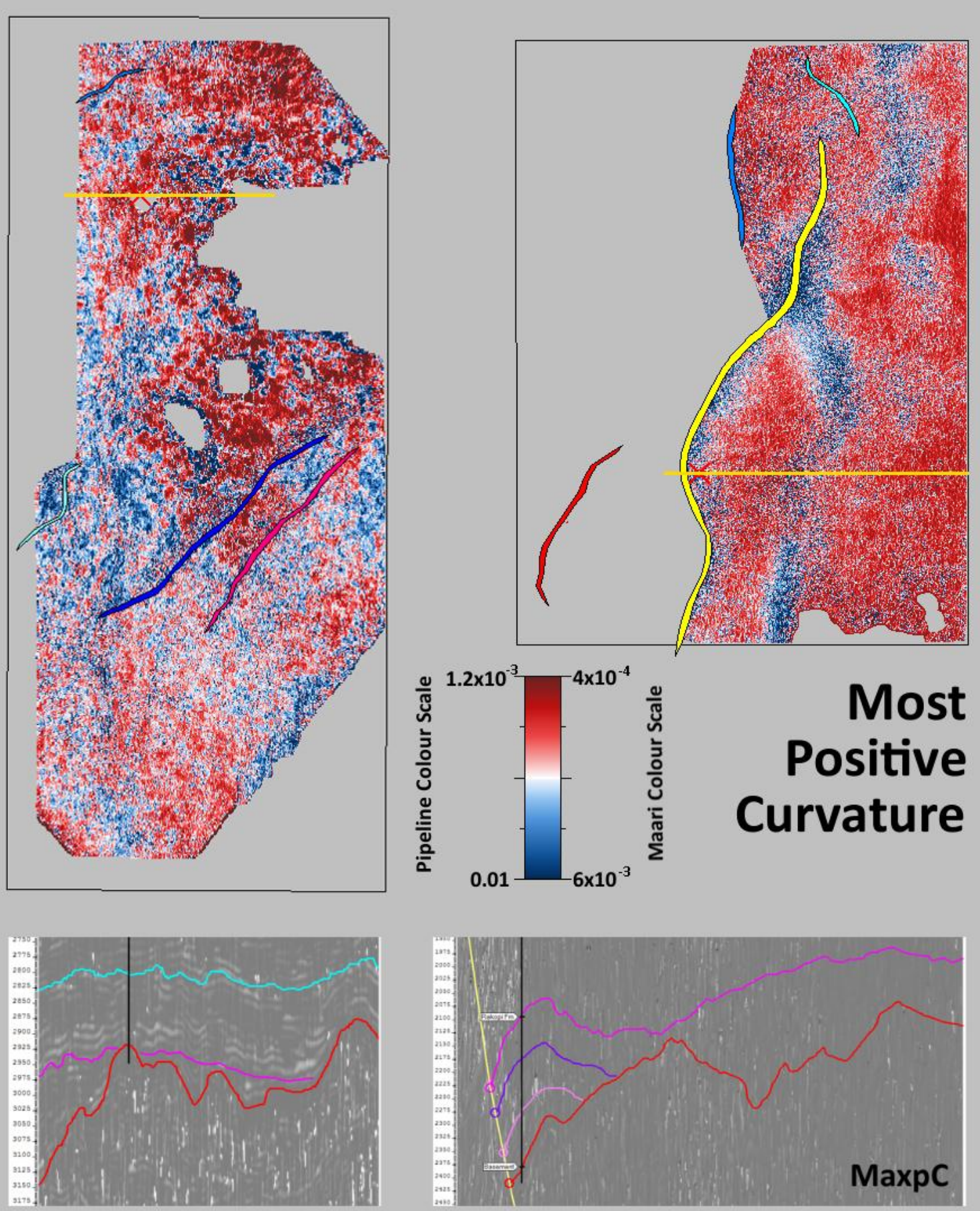

\section{Figure 10.32 Rakopi Formation RSA Data - Most Positive Curvature}

Shown are the values of this attribute, temporally averaged within the Rakopi Formation interval of the Pipeline (top left), and Maari (top right) 3D seismic volumes, which have individual colour scales (see inset colour bar). The representative 2D lines below the basemaps show the attribute outputs when viewed in 2D. For more information on the averaging process, see Figure 5.1, and for the map location, see Figure 1.1. 


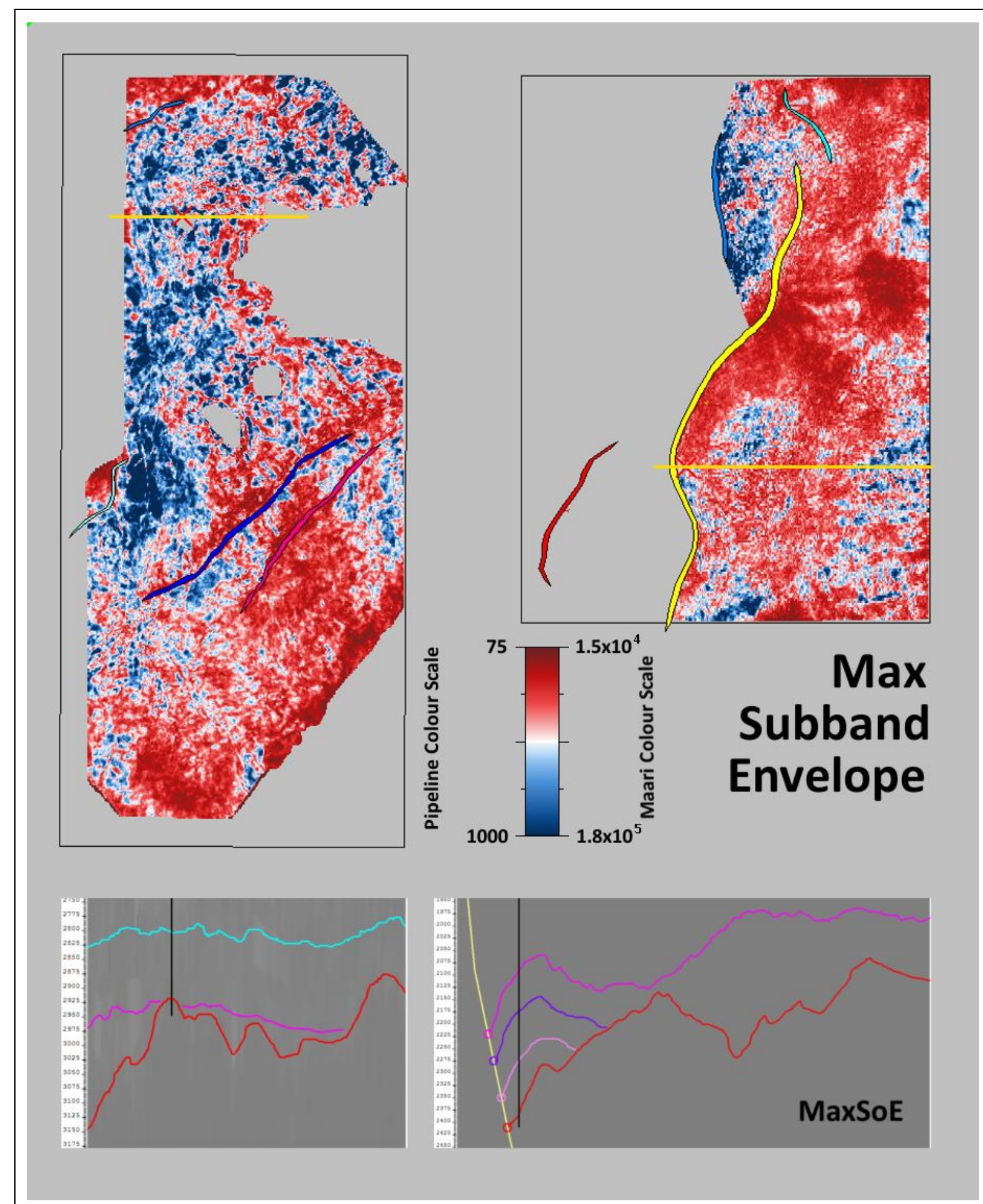

Figure 10.33 Rakopi Formation RSA Data - Maximum Subband of Envelope

Shown are the values of this attribute, temporally averaged within the Rakopi Formation interval of the Pipeline (top left), and Maari (top right) 3D seismic volumes, which have individual colour scales (see inset colour bar). The representative 2D lines below the basemaps show the attribute outputs when viewed in 2D. For more information on the averaging process, see Figure 5.1, and for the map location, see Figure 1.1. 


\section{Appendix C}

\subsection{RSA Averages and Frequency Counts within the Rakopi Subdivision}

The enclosed figures show the outputted results of the Rock Solid Attribute (RSA) extraction and averaging in the intra-formational seismic packages (Lower Coals, Mid Silts, and Upper Coals, as described by Section 4.5.3, and displayed in Figure 4.4) of the Rakopi Formation, in a small window around the Maui-4 well in the Maari 3D volume (the Rakopi Subdivision) (Figure 6.16).

Note that the following RSA attributes are the 19 which did not show significant difference between the frequency distributions of the 3 seismic packages of the Rakopi Subdivision, with the other 14 being displayed in Figures 6.1-6.15. 


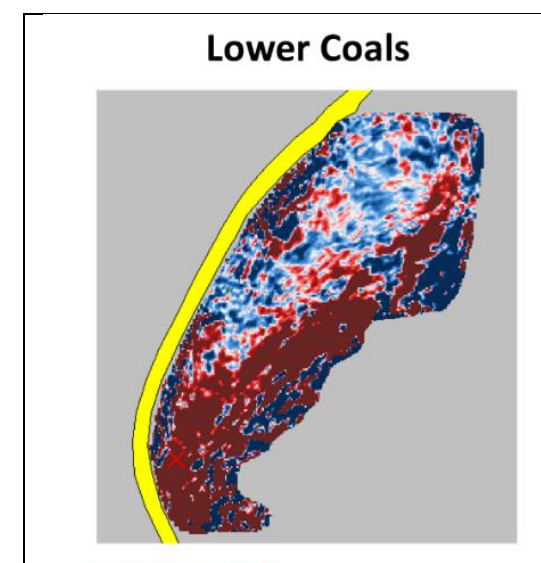

$-10^{4}$ $6 \times 10^{3}$
Mid Silts

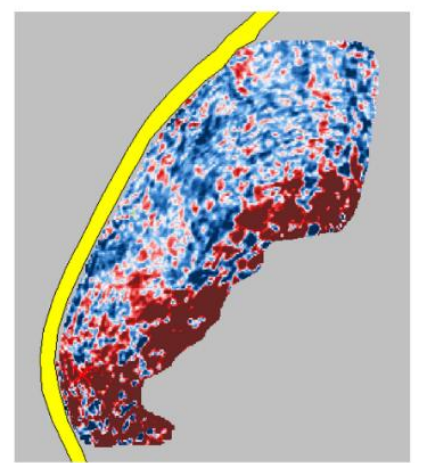

Real Part of Complex Trace

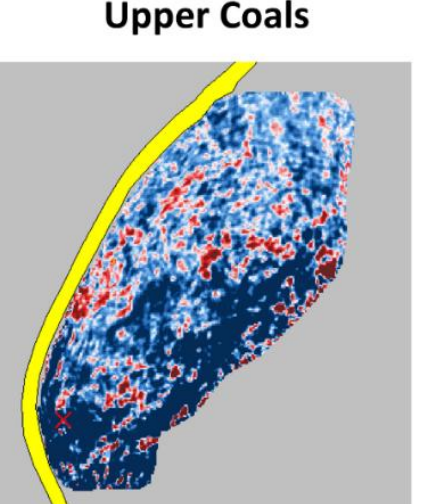

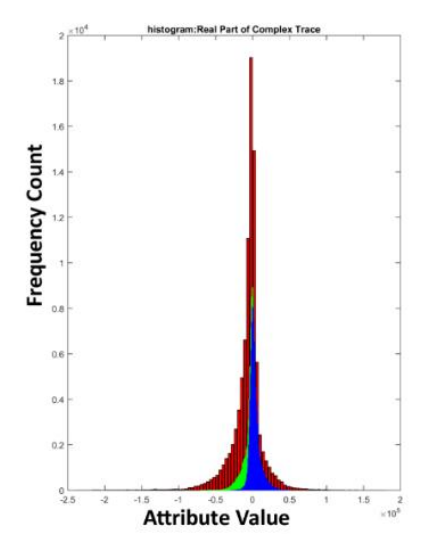

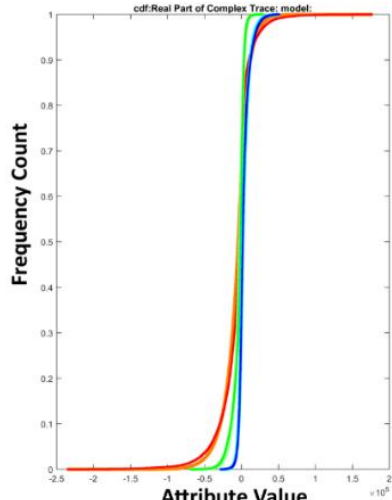

Bi-Exponential Distribution

Figure 11.1 RSA Averages and Frequency Distributions in the Rakopi Subdivision - Real Part of Complex Trace

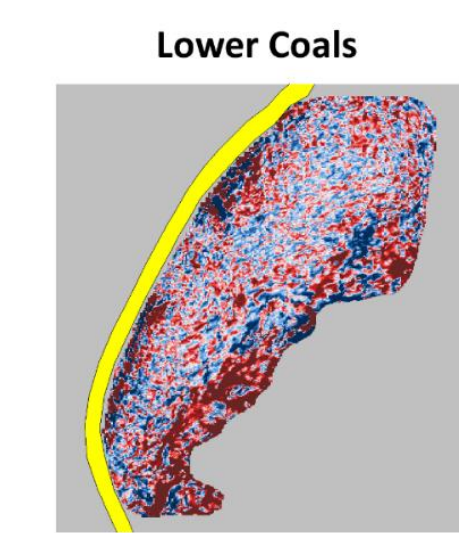

$-30$

Colour Scale

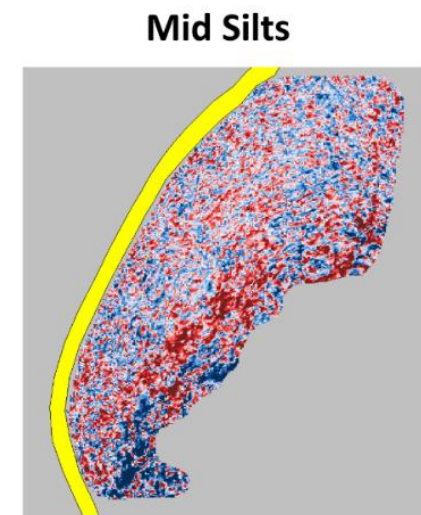

Upper Coals

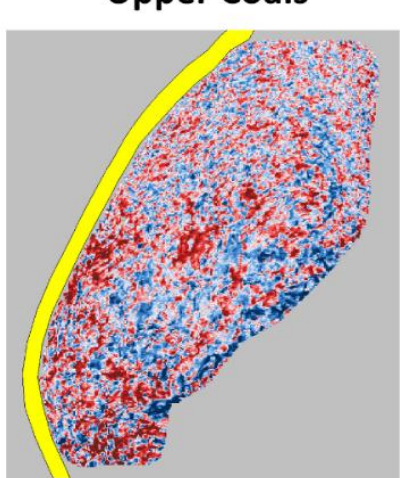

Instantaneous Phase
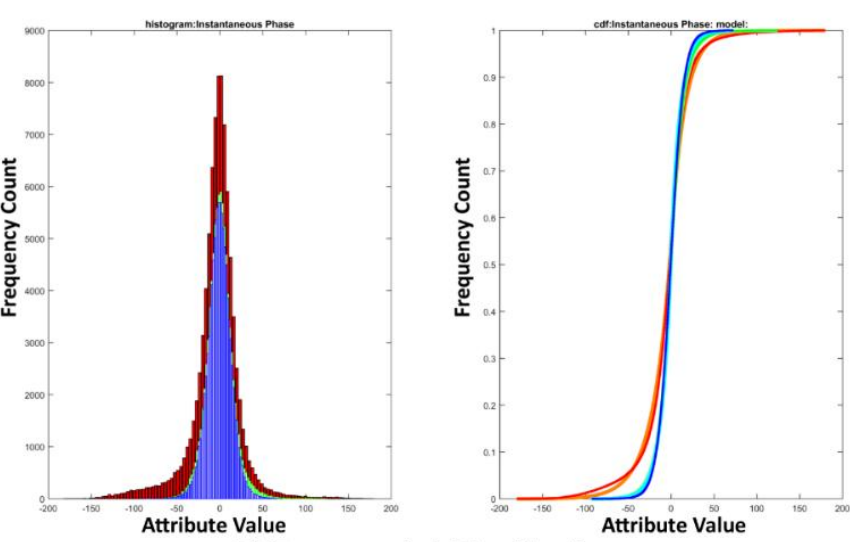

Bi-Exponential Distribution

Figure 11.2 RSA Averages and Frequency Distributions in the Rakopi Subdivision - Instantaneous Phase 


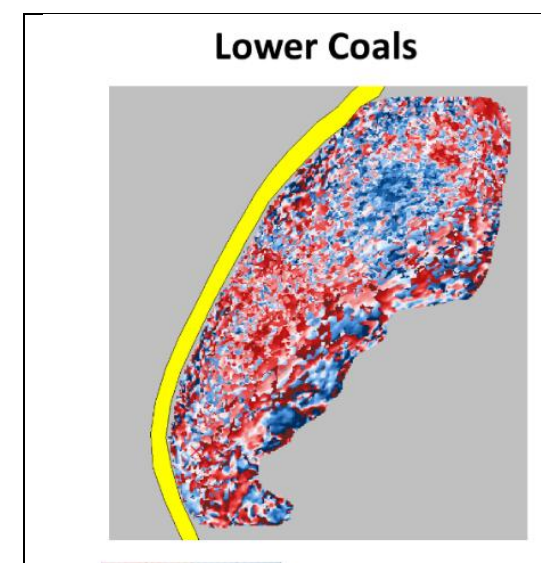

9 36
Mid Silts

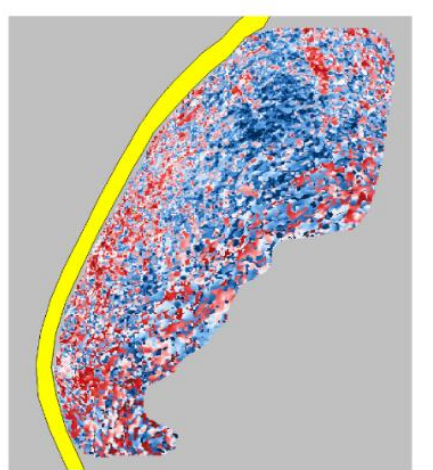

Instantaneous Frequency
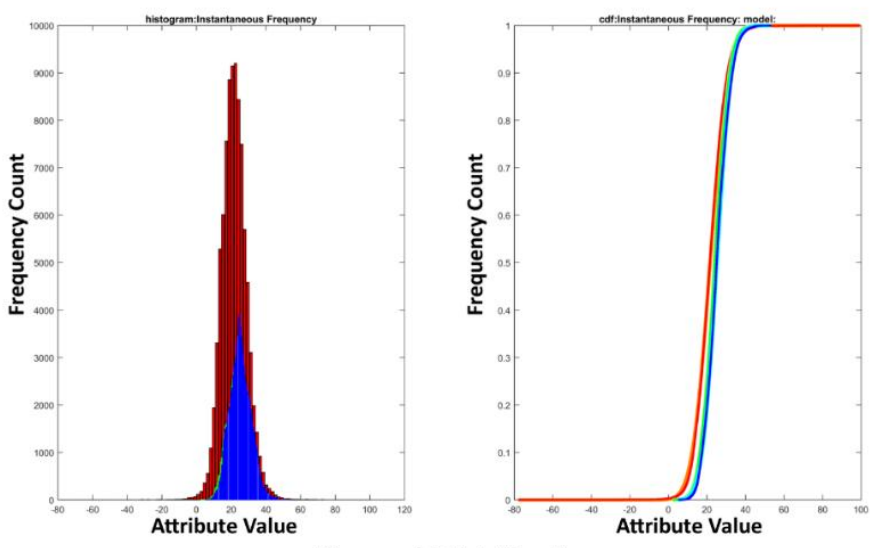

Normal Distribution

Figure 11.3 RSA Averages and Frequency Distributions in the Rakopi Subdivision - Instantaneous Frequency

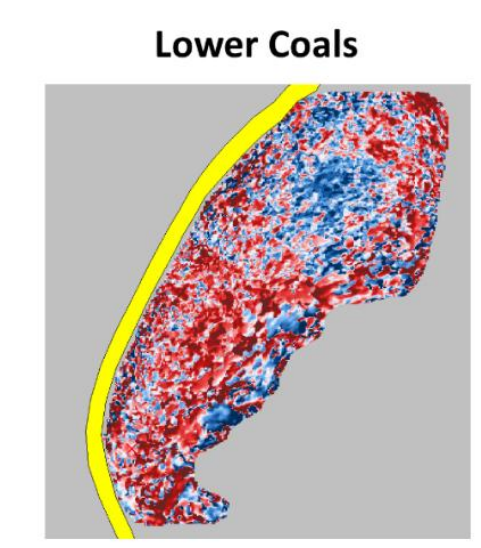

14

Colour Scale

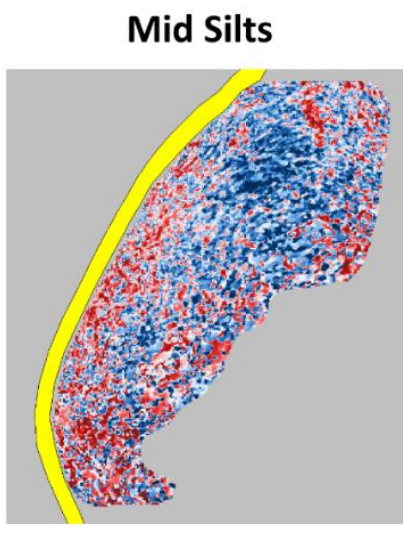

Figure 11.4 RSA Averages and Frequency Distributions in the Rakopi Subdivision - Dominant Frequency

Upper Coals

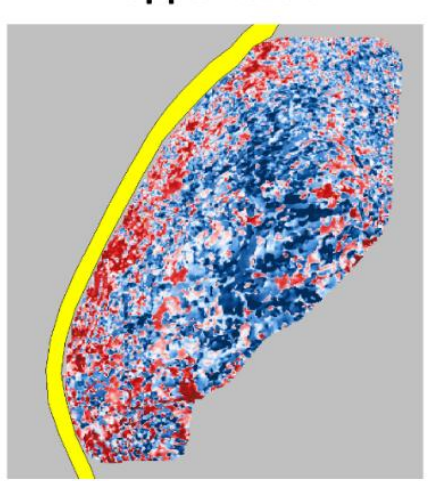

Dominant Frequency

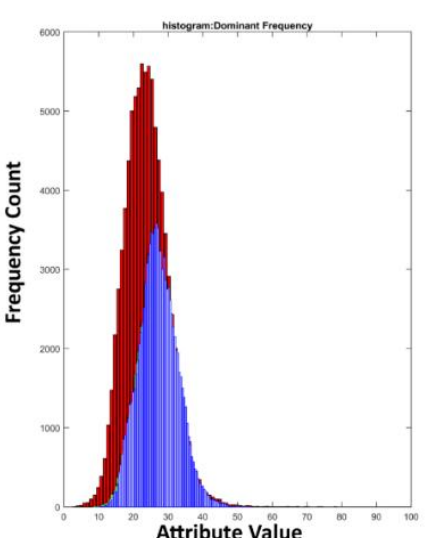

Log Normal Distribution

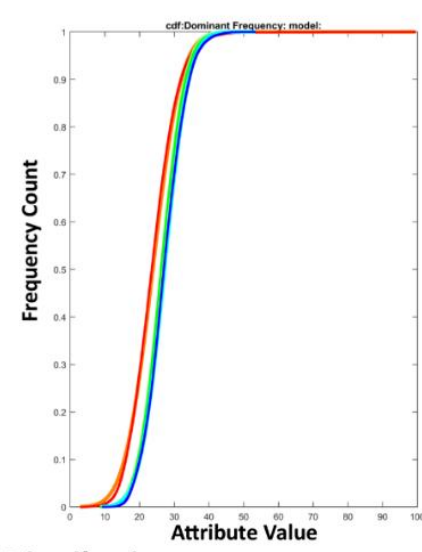

Attribute Value 


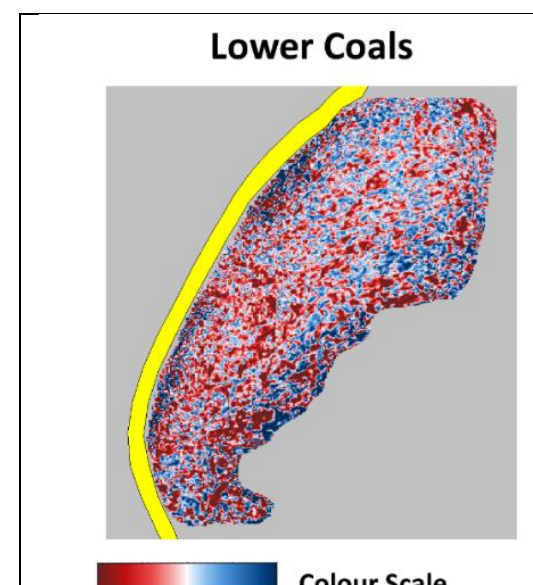

0.4

1.5

\section{Mid Silts}

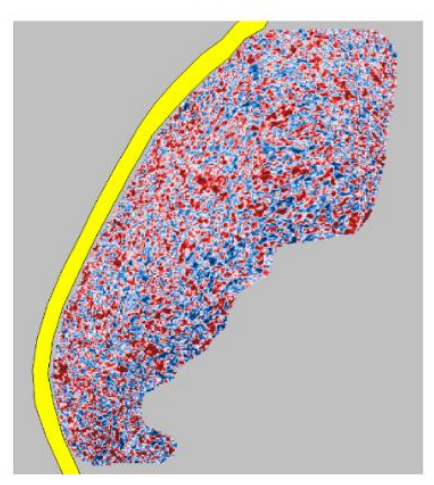

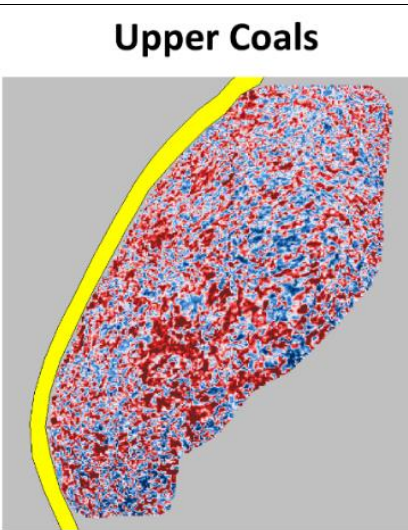

Bandwidth
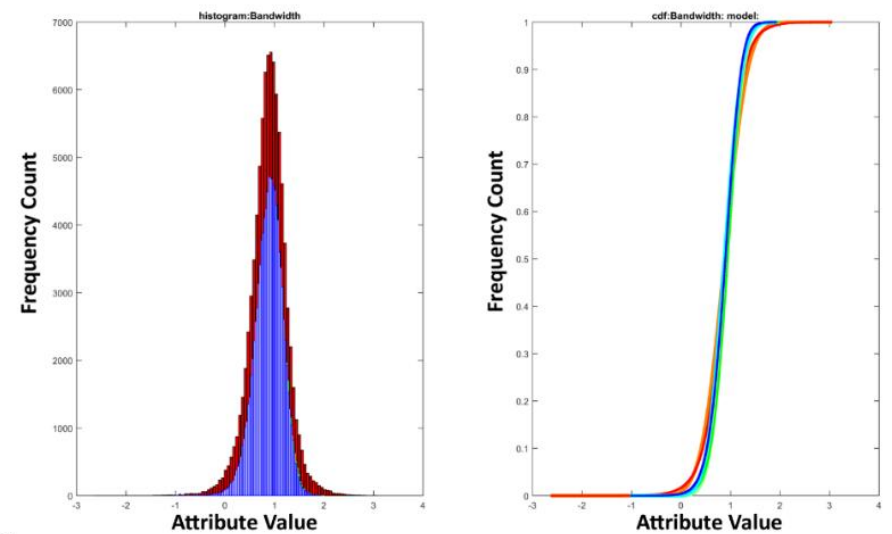

Log Normal Distribution

Figure 11.5 RSA Averages and Frequency Distributions in the Rakopi Subdivision - Bandwidth

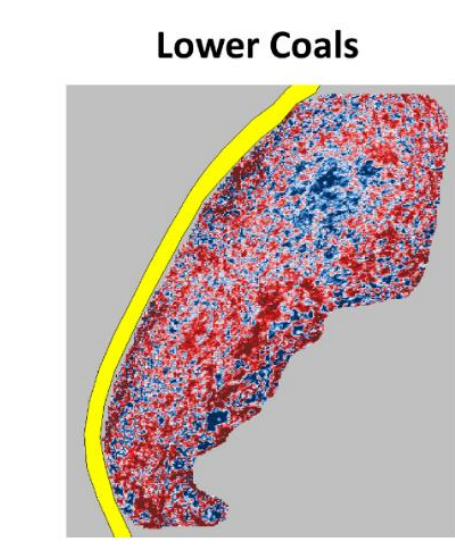

4

12

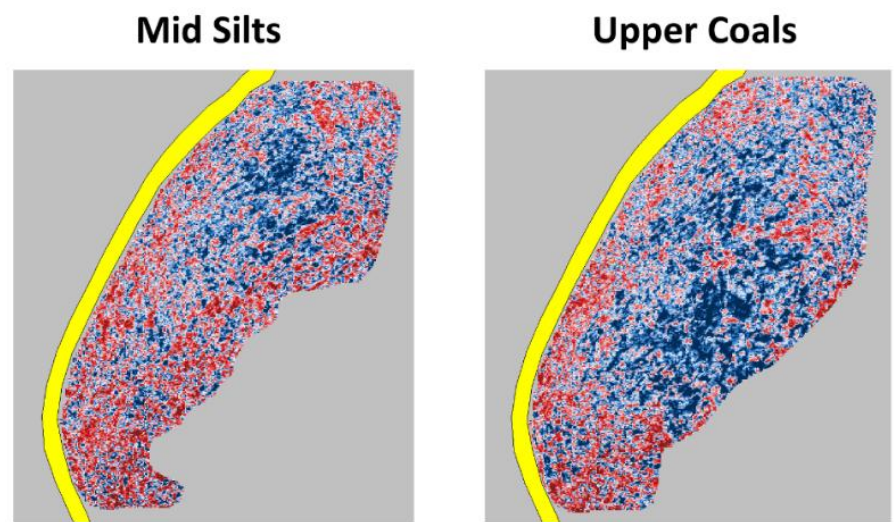

Instantaneous Q Factor

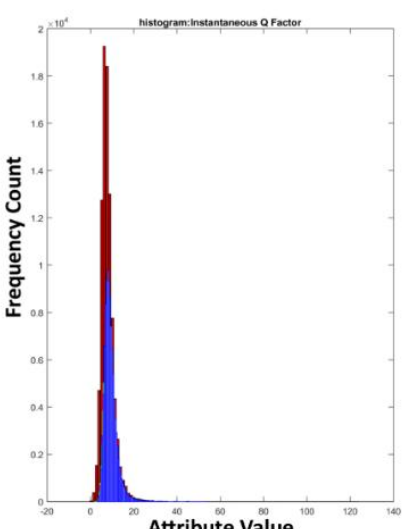

Attribute Value

Log Normal Distribution

Figure 11.6 RSA Averages and Frequency Distributions in the Rakopi Subdivision - Instantaneous Q Factor 


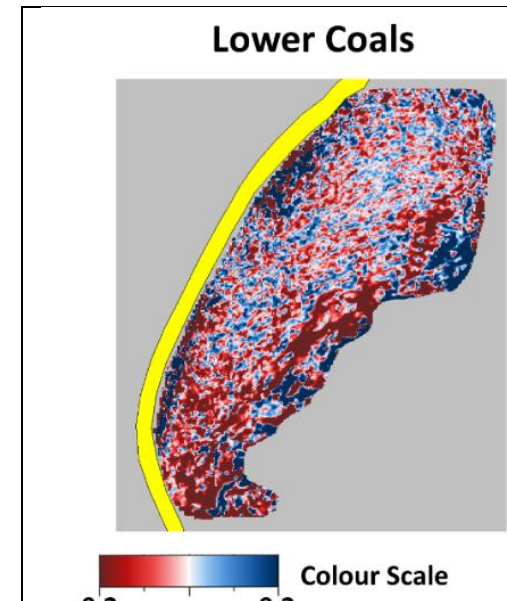

Mid Silts

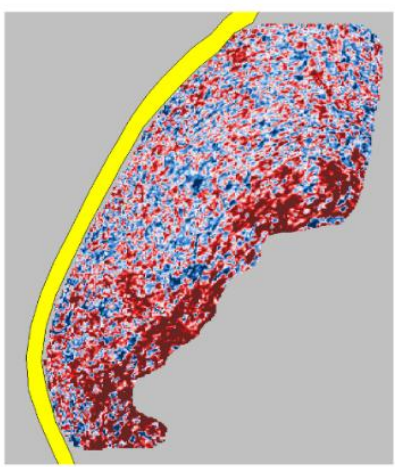

\section{Upper Coals}
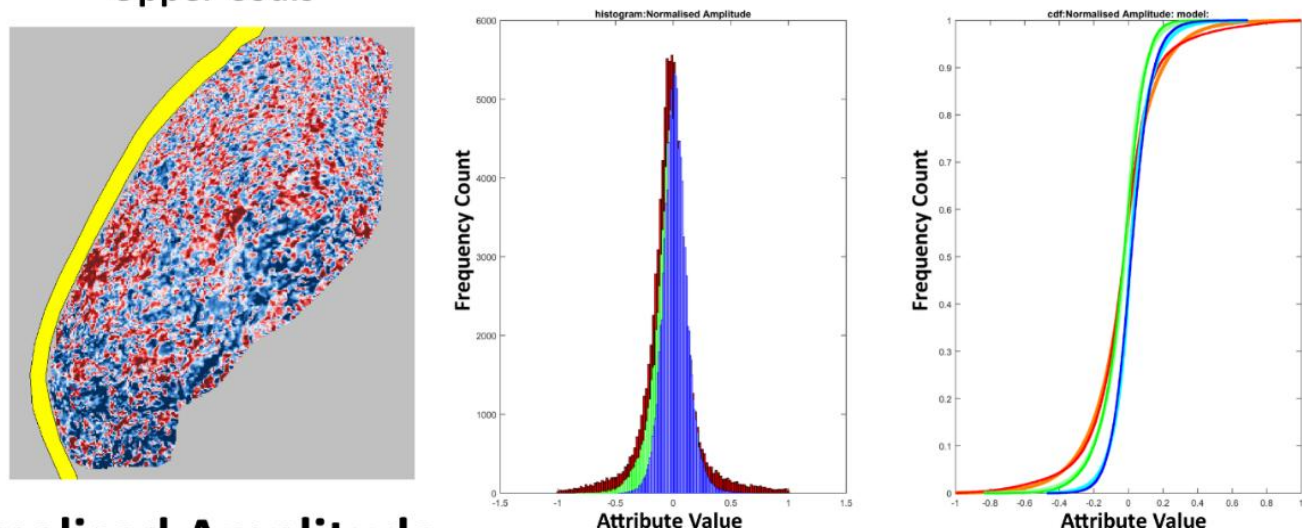

Normalised Amplitude

Bi-Exponential Distribution

Figure 11.7 RSA Averages and Frequency Distributions in the Rakopi Subdivision - Normalised Amplitude

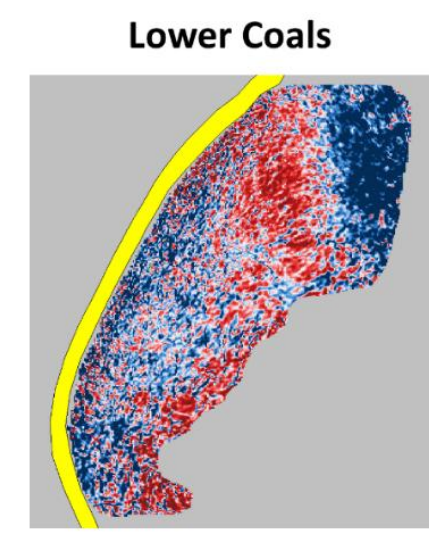

5

Colour Scale
Mid Silts

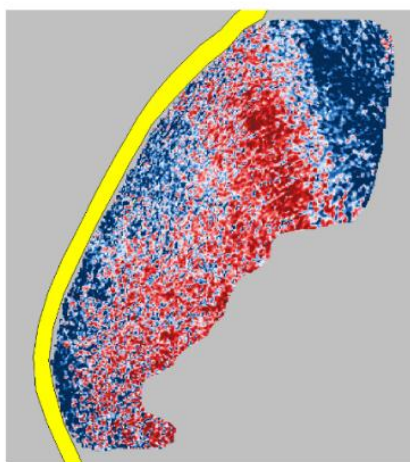

Figure 11.8 RSA Averages and Frequency Distributions in the Rakopi Subdivision - Dip Similarity 


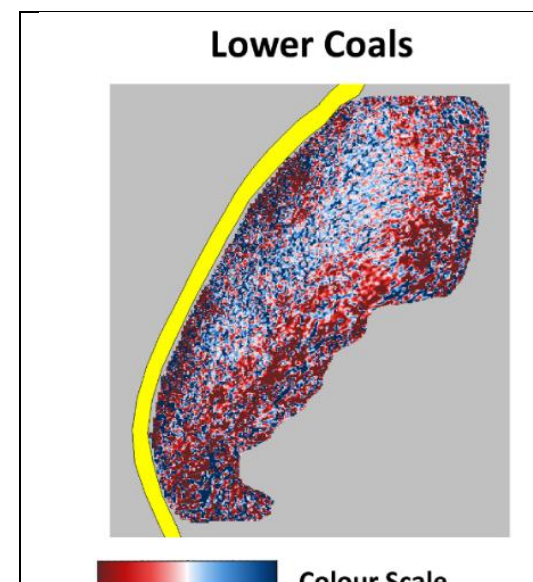

$-3.5$

3.5
Mid Silts

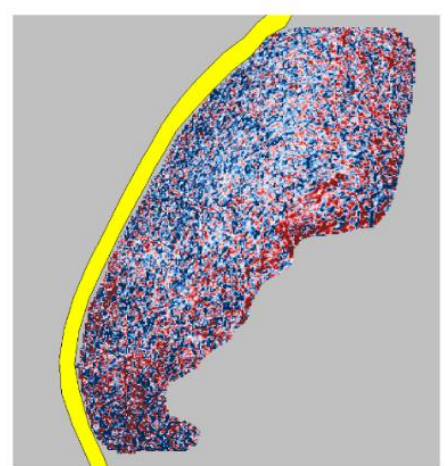

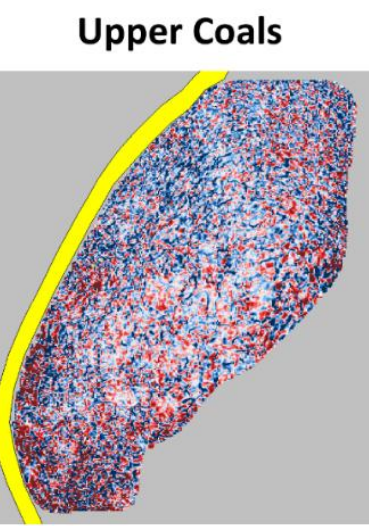

Dip Variance
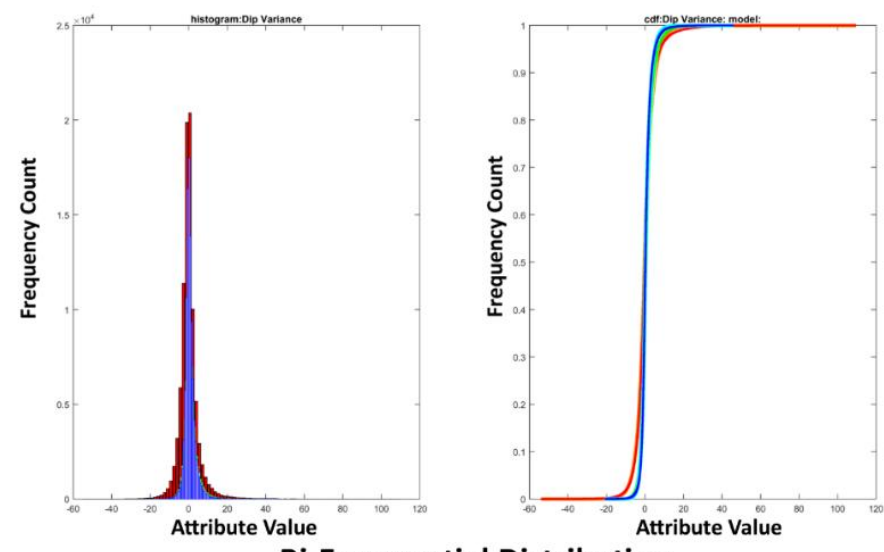

Bi-Exponential Distribution

Figure 11.9 RSA Averages and Frequency Distributions in the Rakopi Subdivision - Dip Variance

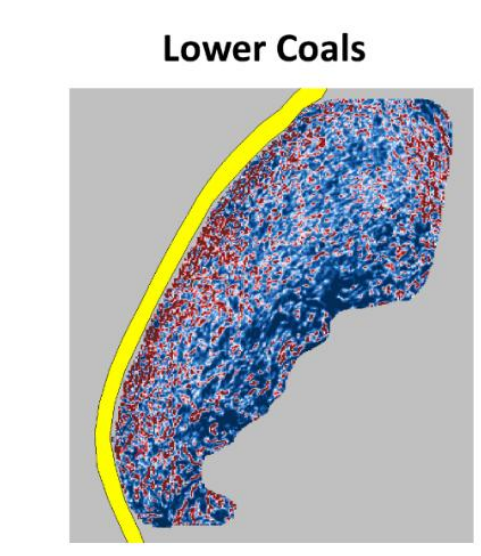

1.25

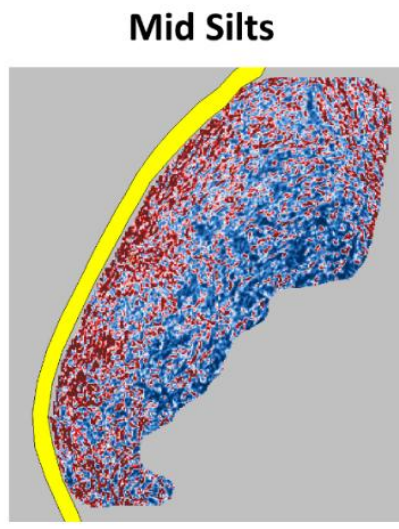

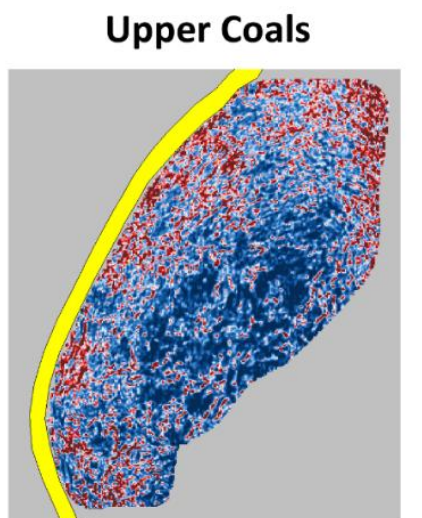

Similarity

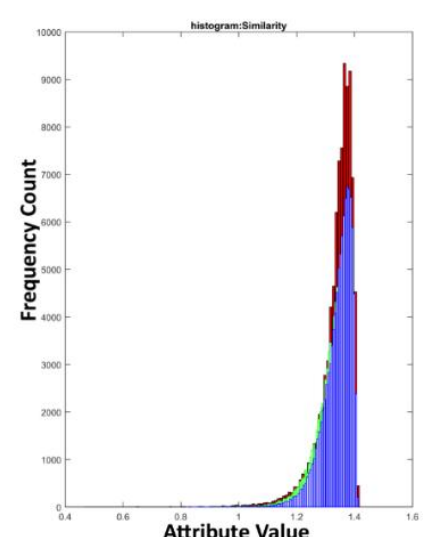

Log Normal Distribution

Figure 11.10 RSA Averages and Frequency Distributions in the Rakopi Subdivision - Similarity 

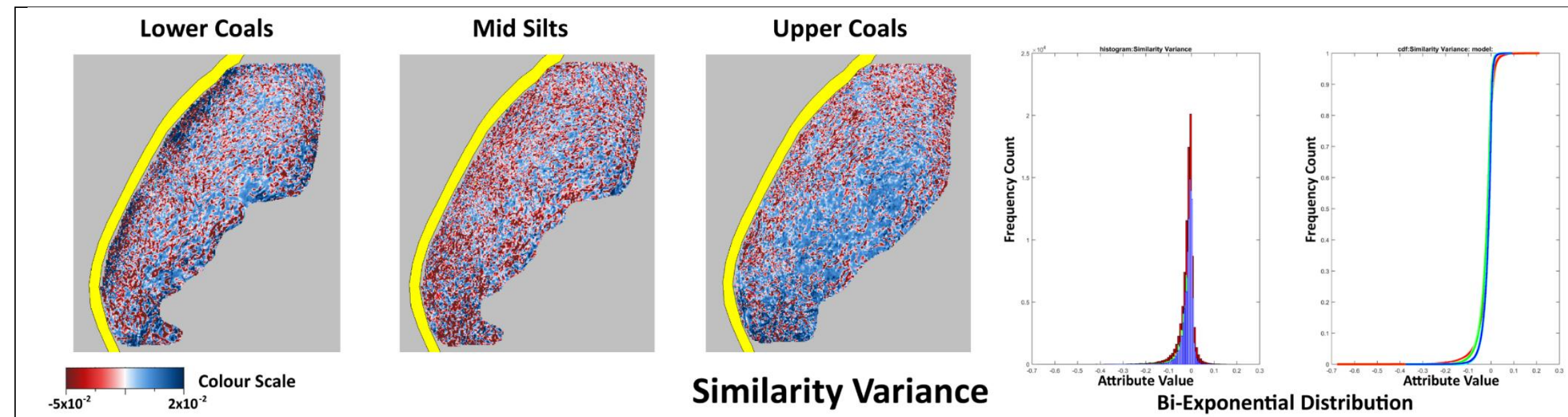

Similarity Variance

Bi-Exponential Distribution

Figure 11.11 RSA Averages and Frequency Distributions in the Rakopi Subdivision - Similarity Variance
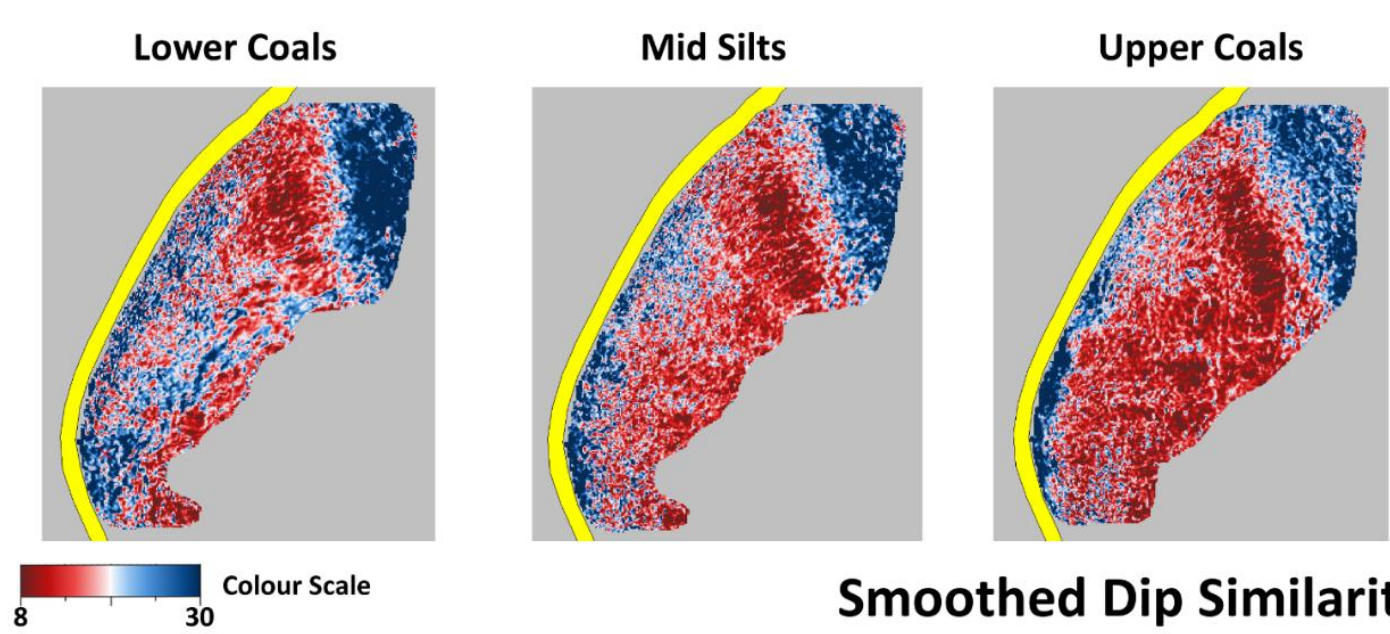

Smoothed Dip Similarity
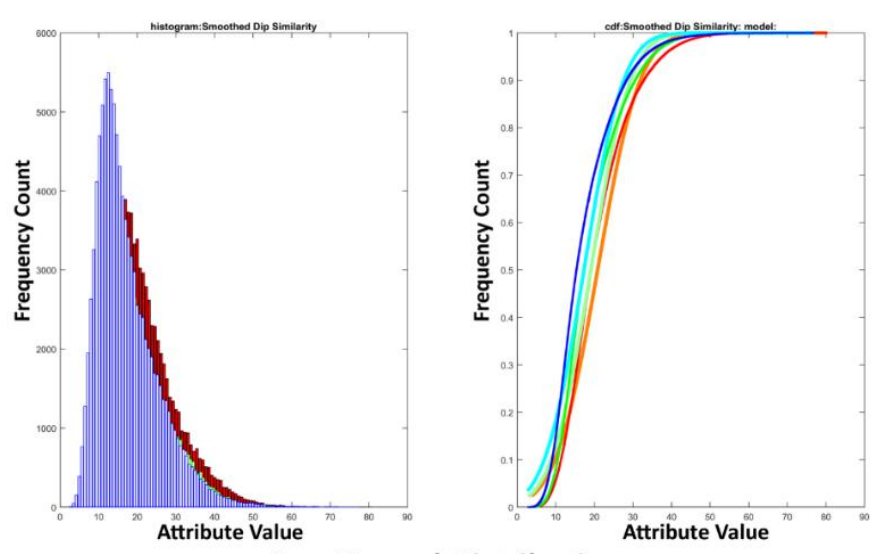

Log Normal Distribution

Figure 11.12 RSA Averages and Frequency Distributions in the Rakopi Subdivision - Smoothed Dip of Maximum Similarity 


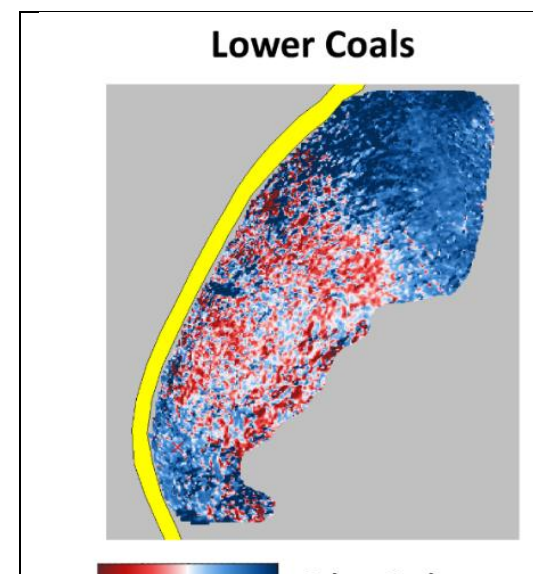

$-150$

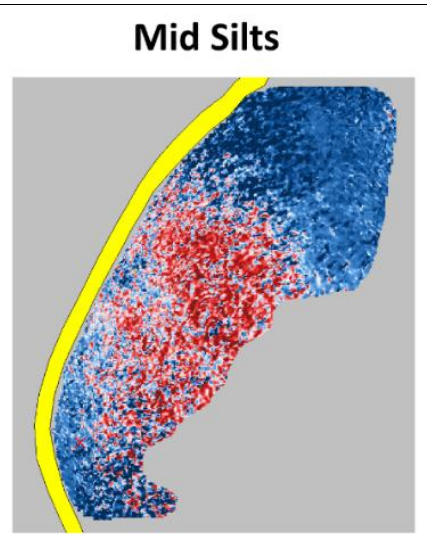

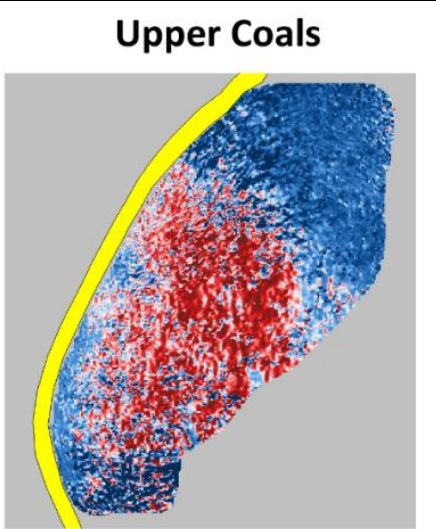

Dip Azimuth

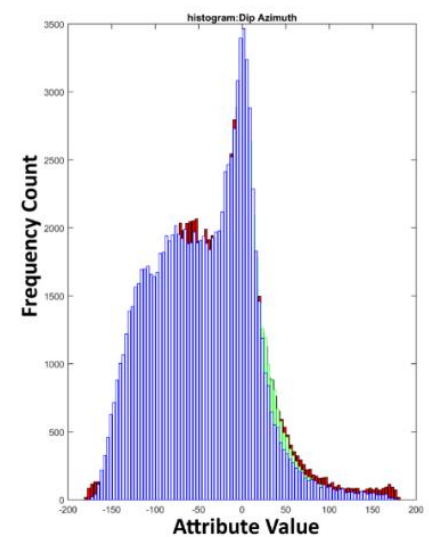

Bi-Exponential Distribution

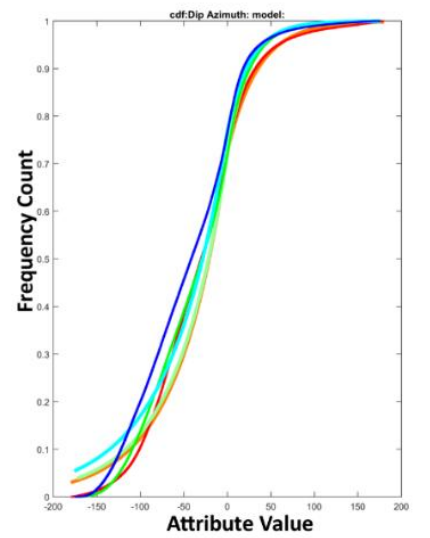

n

Figure 11.13 RSA Averages and Frequency Distributions in the Rakopi Subdivision - Dip Azimuth

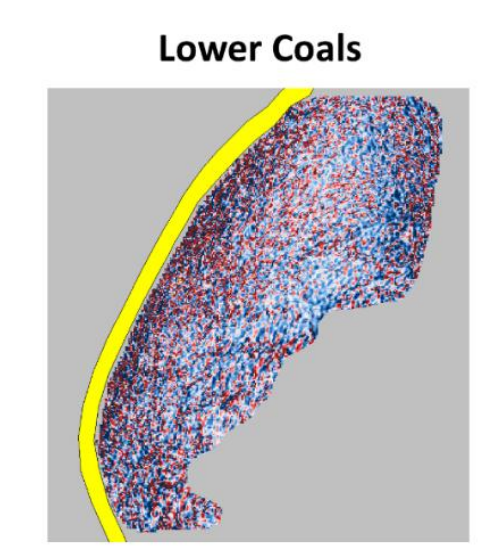

$-2 \times 10^{-3}$

Colour Scale

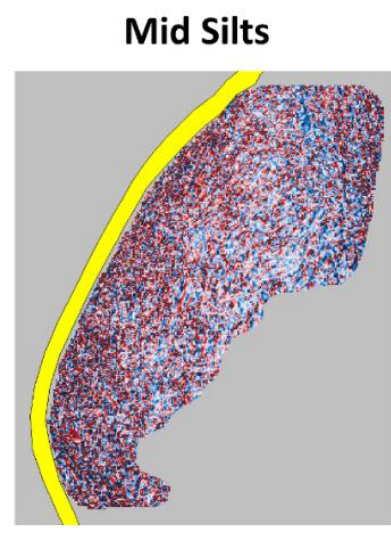

Figure 11.14 RSA Averages and Frequency Distributions in the Rakopi Subdivision - Mean Curvature 


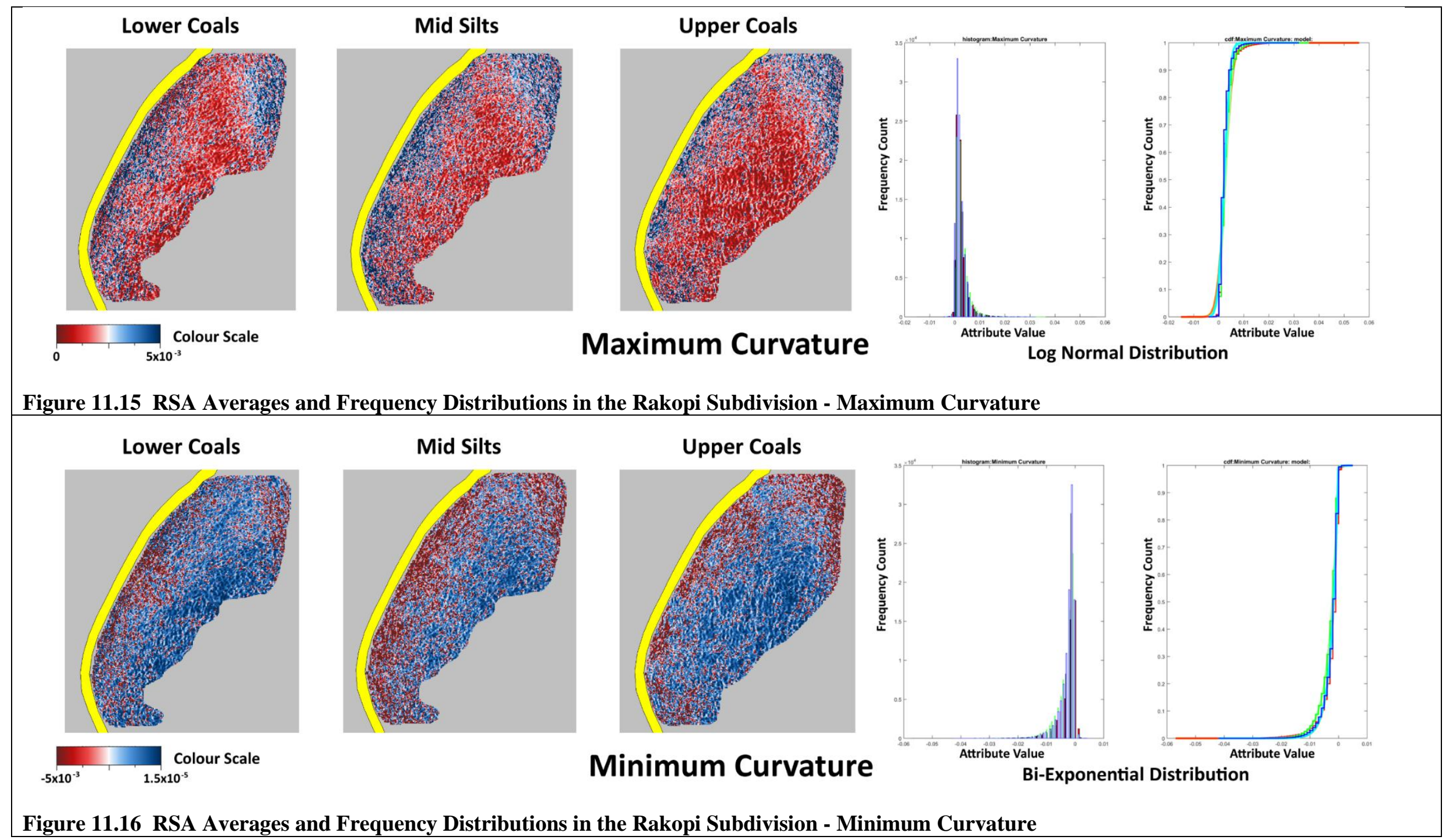



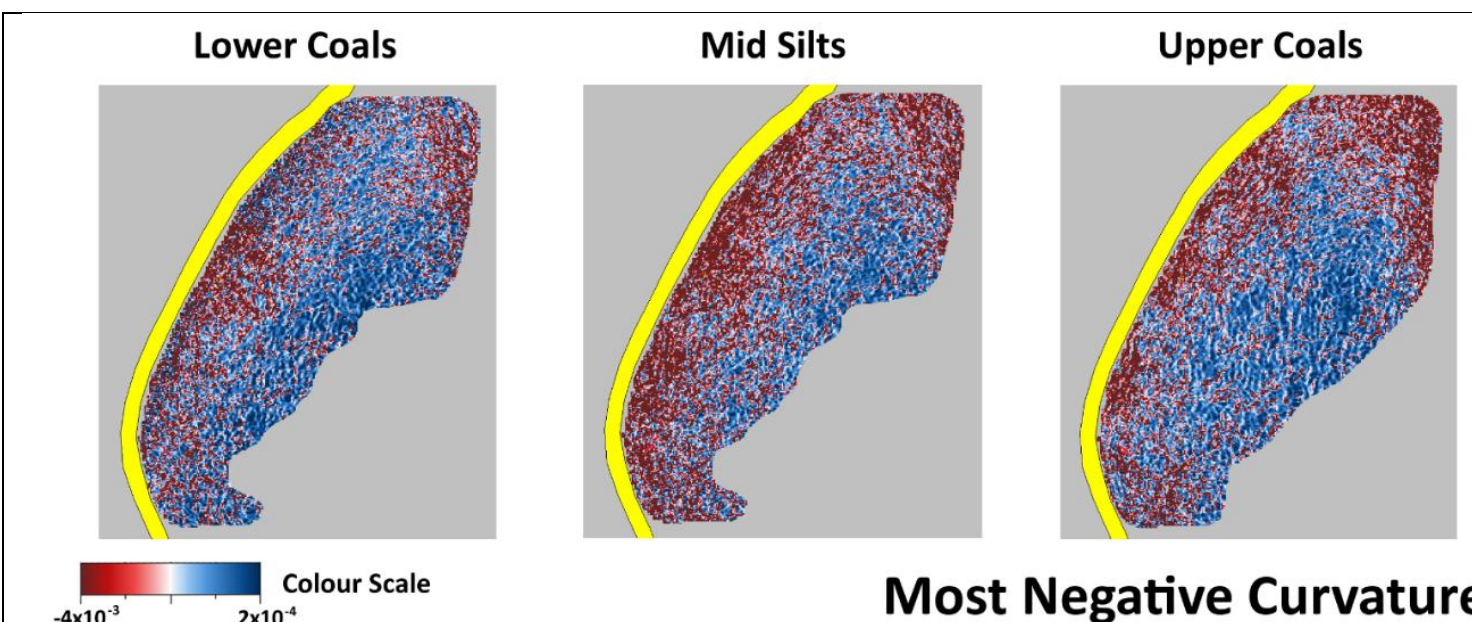

Most Negative Curvature
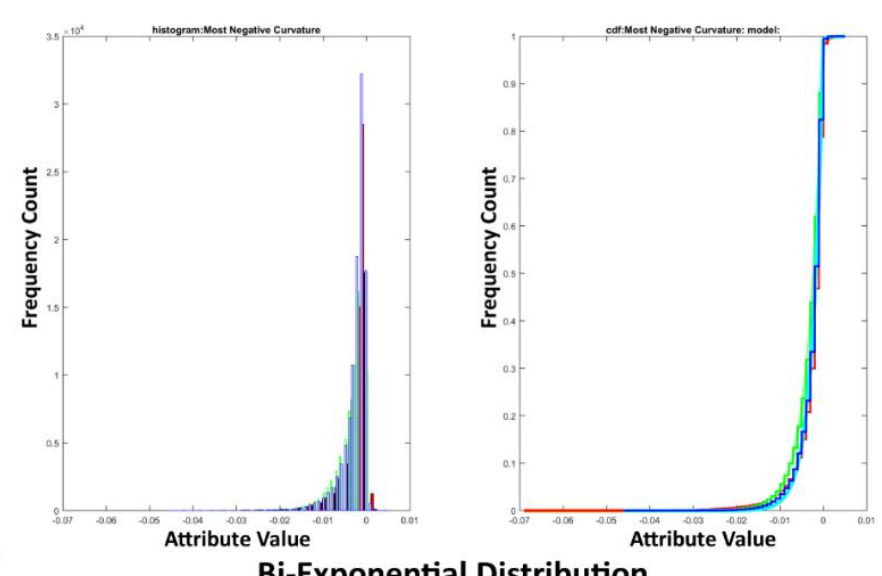

Bi-Exponential Distribution

Figure 11.17 RSA Averages and Frequency Distributions in the Rakopi Subdivision - Most Negative Curvature

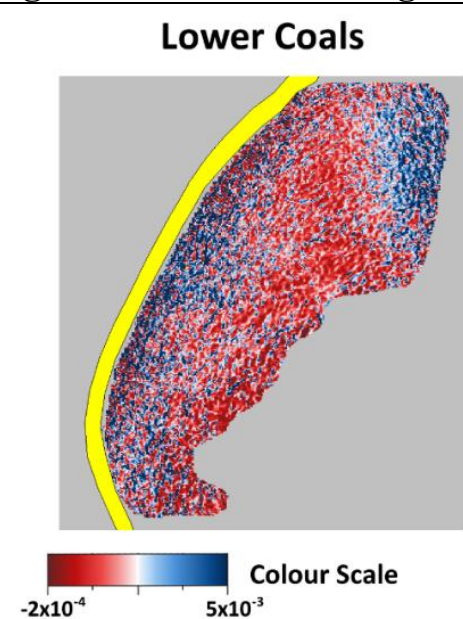
Mid Silts

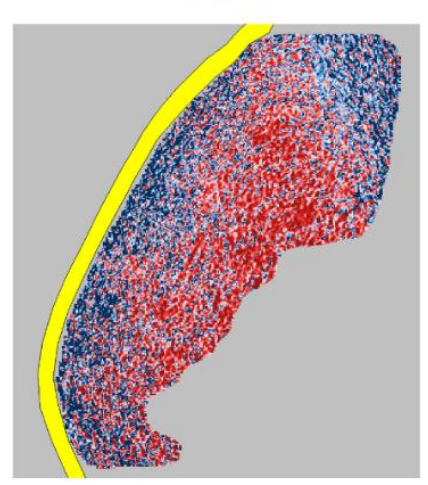

Most Positive Curvature
Upper Coals
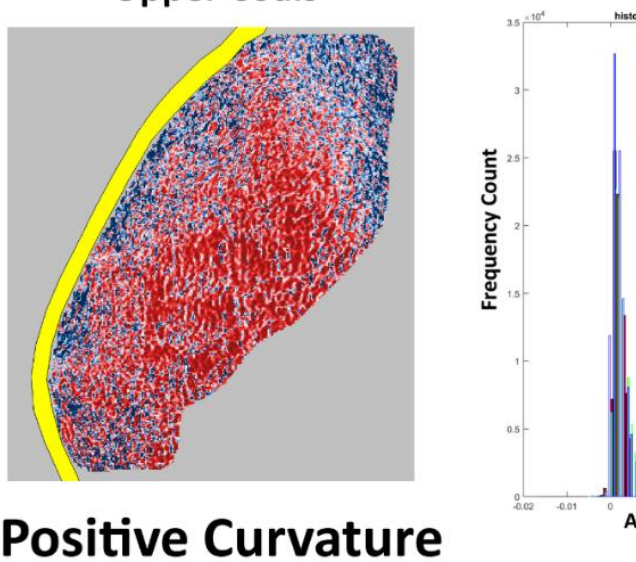

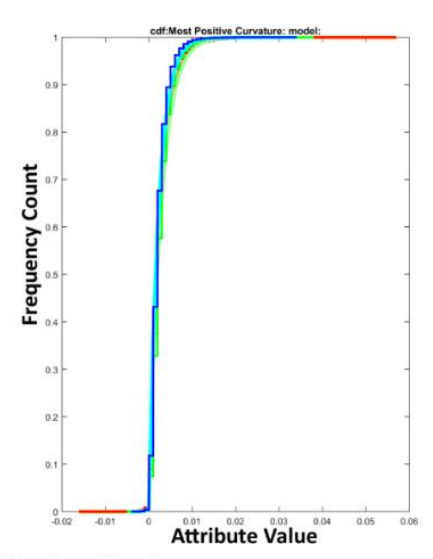

Bi-Exponential Distribution

Figure 11.18 RSA Averages and Frequency Distributions in the Rakopi Subdivision - Most Positive Curvature 


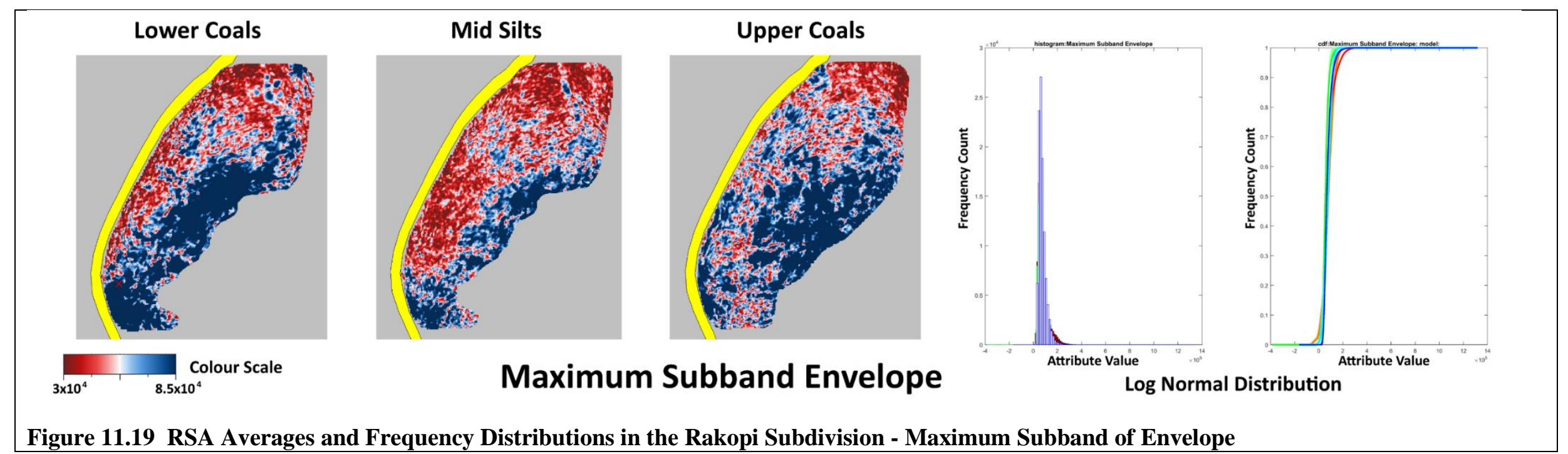




\section{Appendix D}

\subsection{RSA Control Tests Statistical Analysis}

This appendix contains all of the results of the RSA control tests carried out in Chapter 6 which did not show enough meaningful variation to be included in the thesis body. 


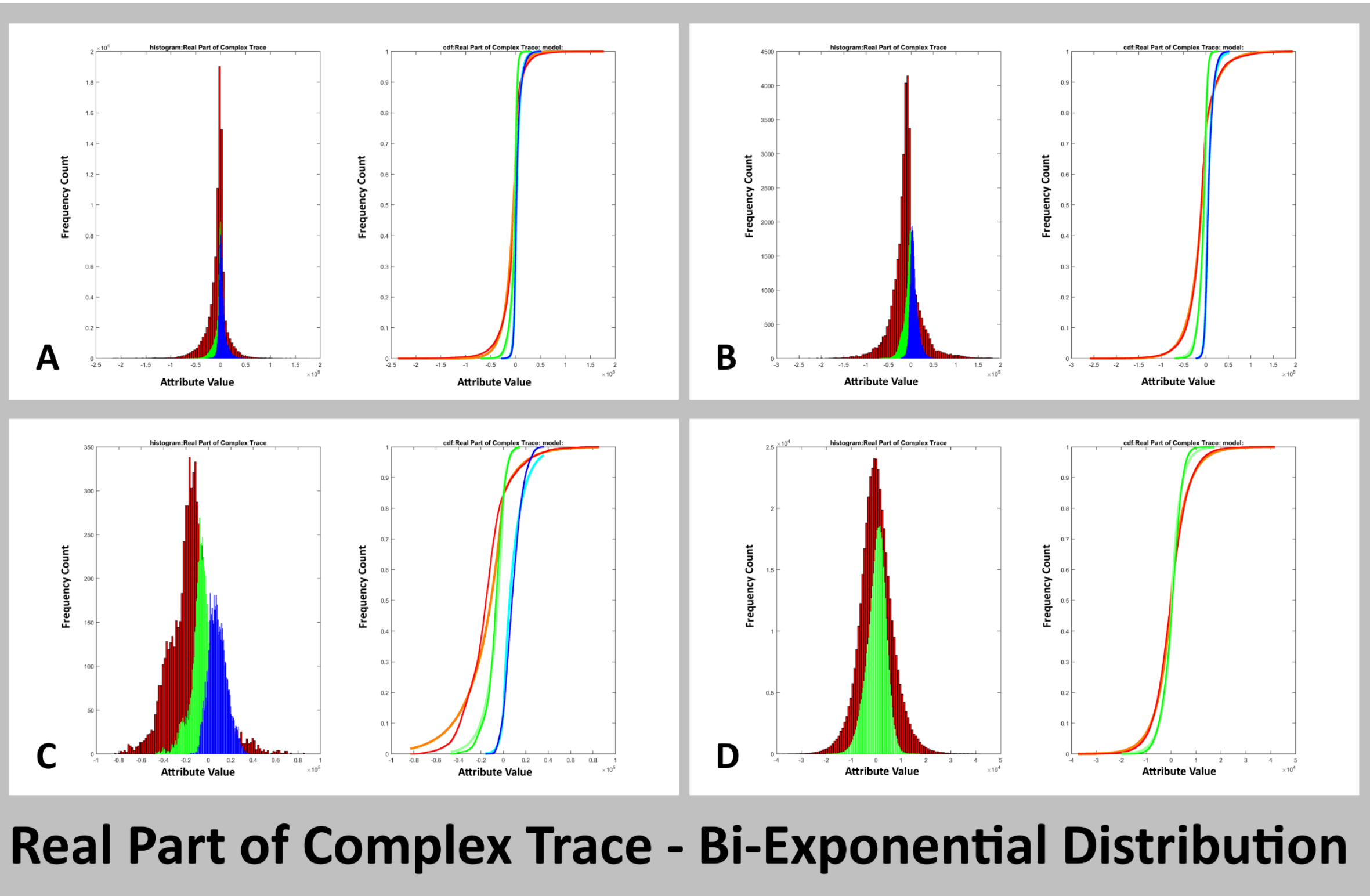

Figure 12.1 RSA Control Tests Frequency Distributions - Real Part of Complex Trace 


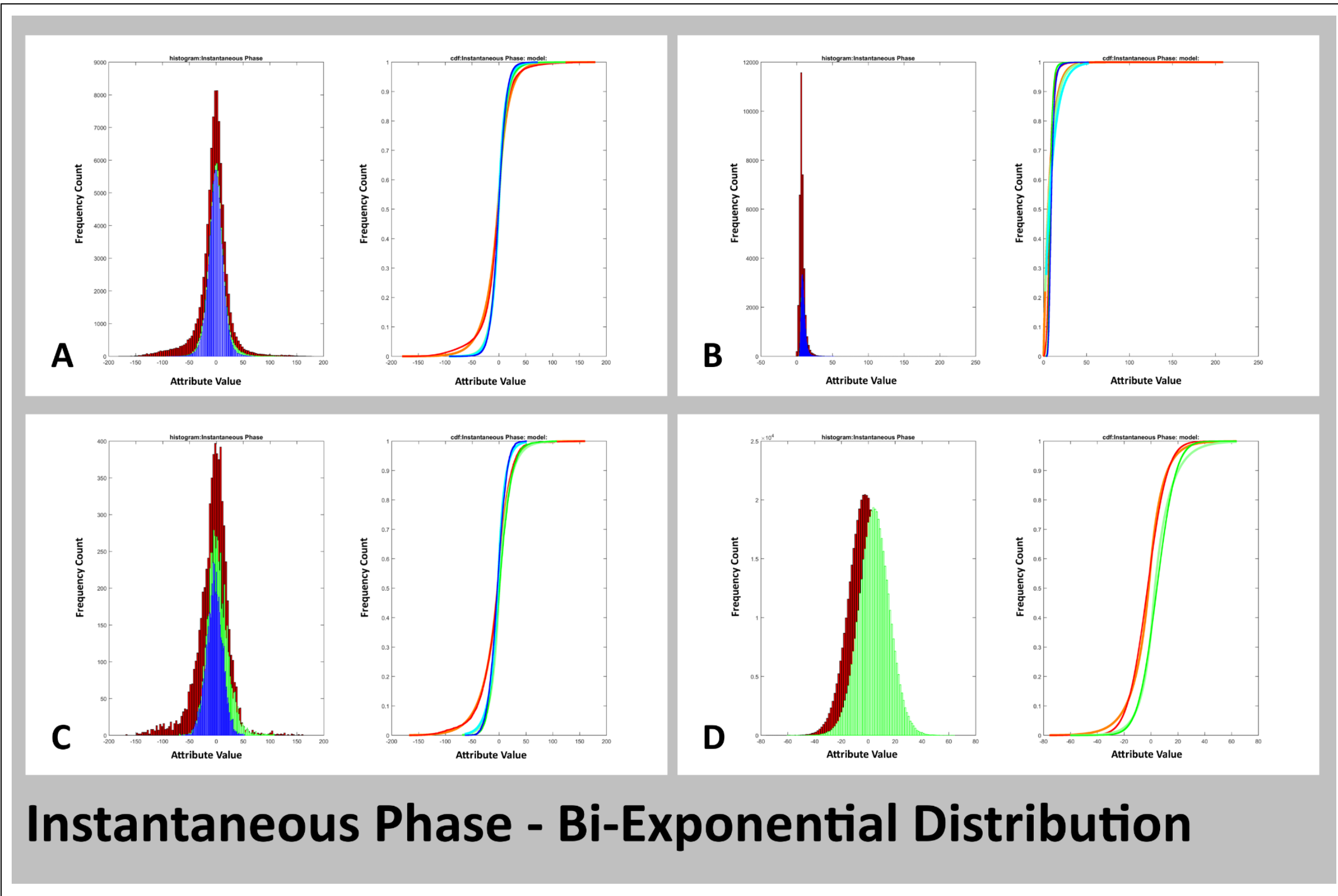

Figure 12.2 RSA Control Tests Frequency Distributions - Instantaneous Phase 


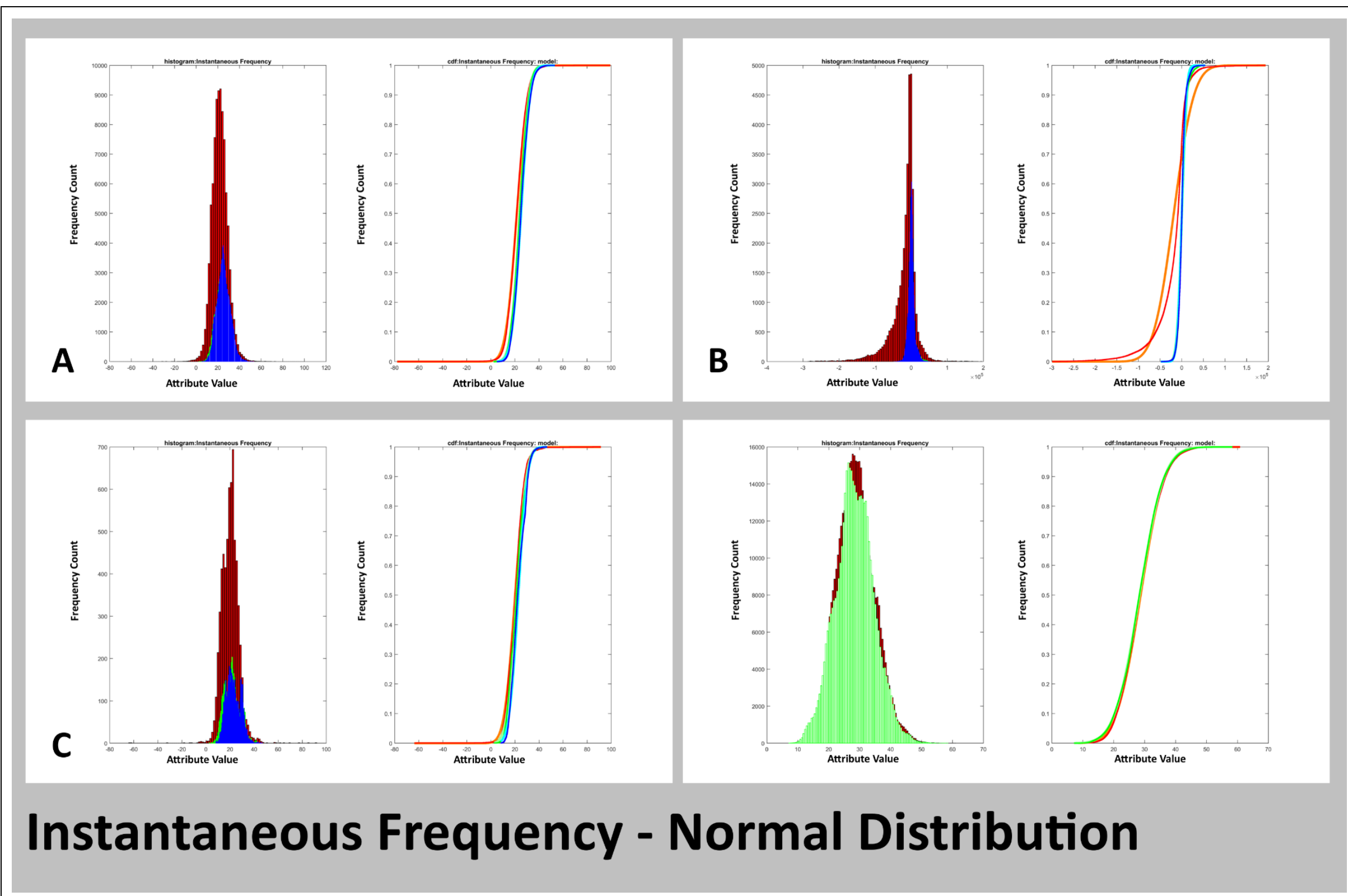

Figure 12.3 RSA Control Tests Frequency Distributions - Instantaneous Frequency 


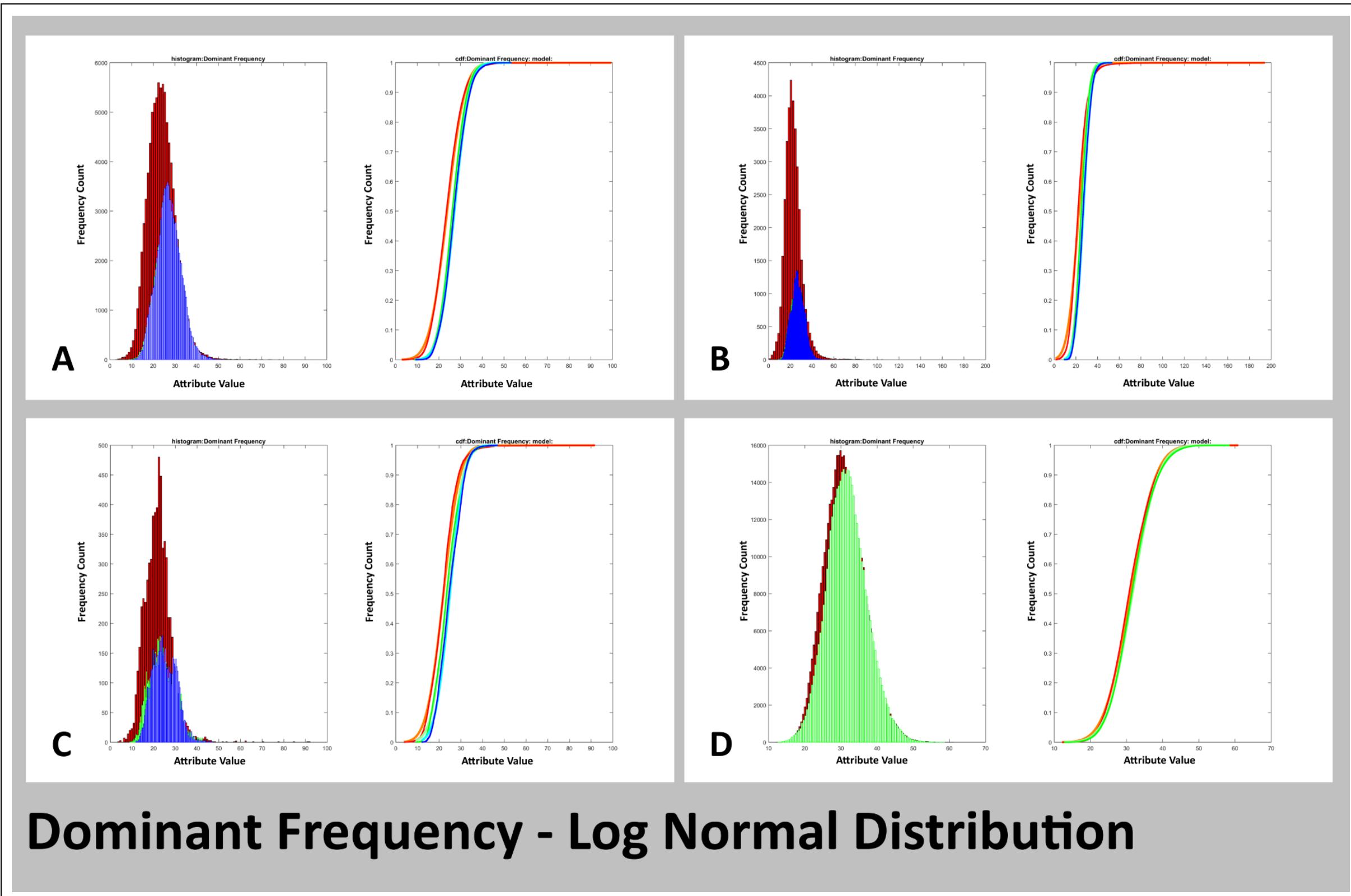

Figure 12.4 RSA Control Tests Frequency Distributions - Dominant Frequency 


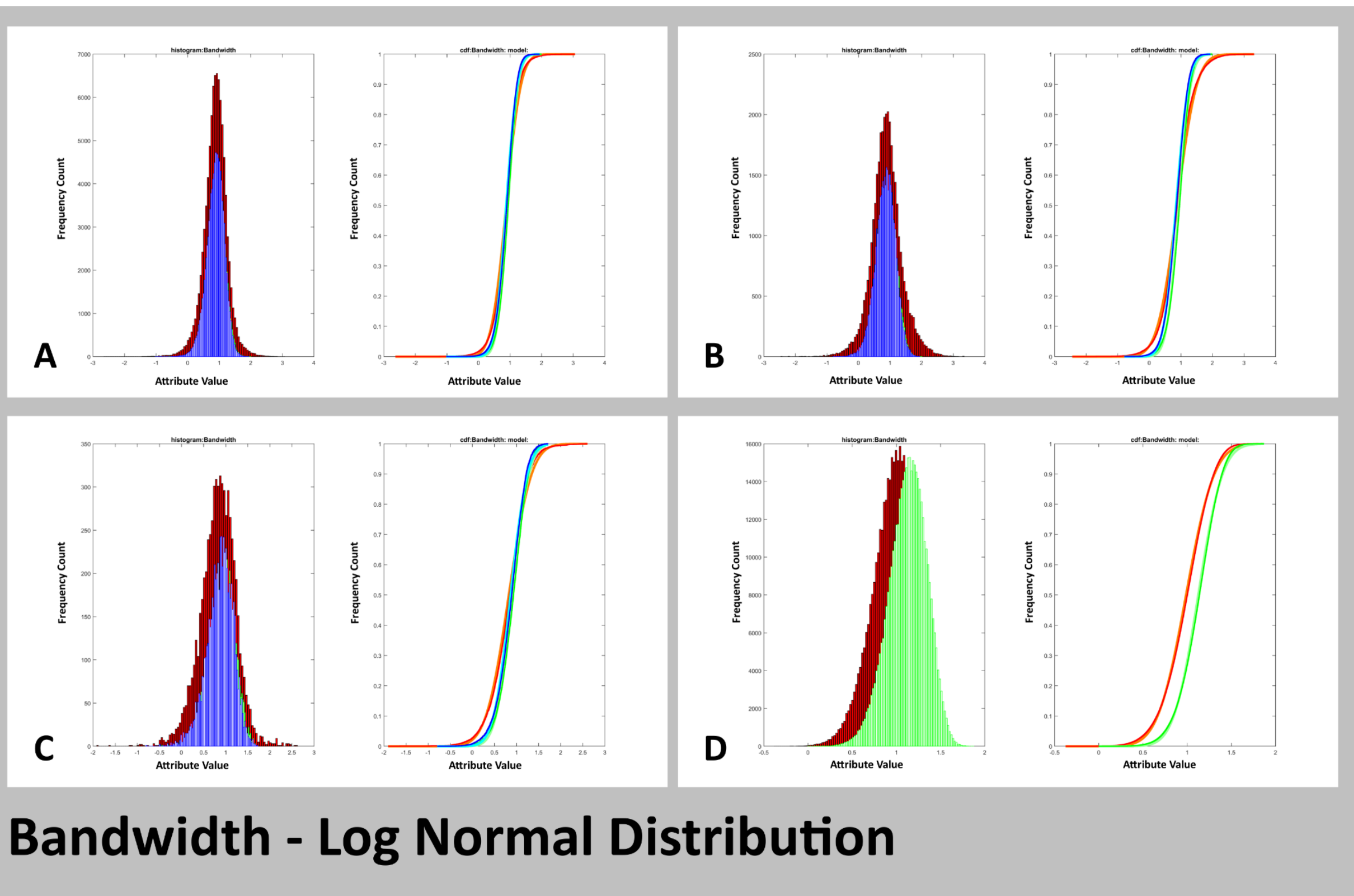

Figure 12.5 RSA Control Tests Frequency Distributions - Bandwidth 


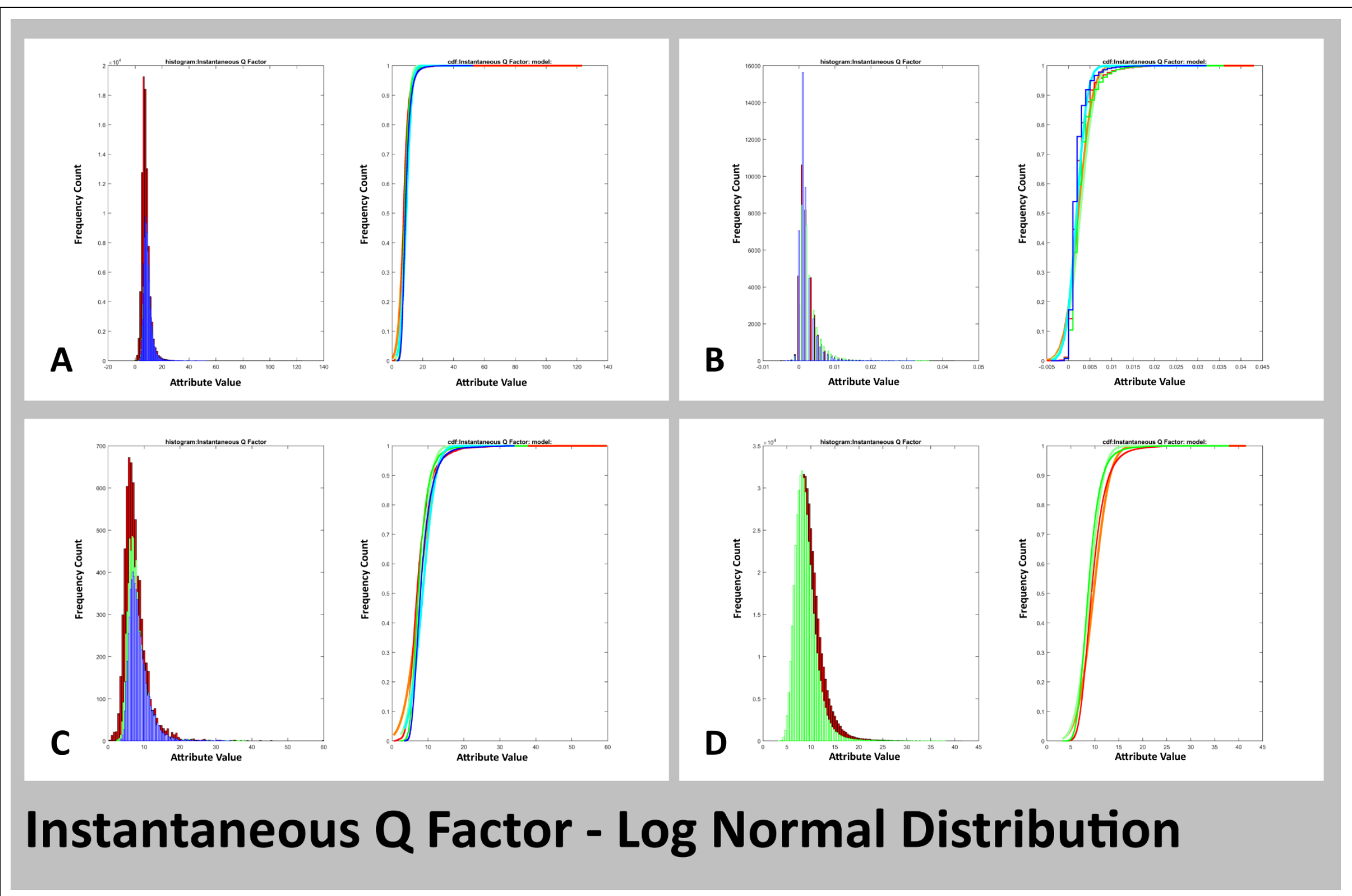

Figure 12.6 RSA Control Tests Frequency Distributions - Instantaneous Q Factor 


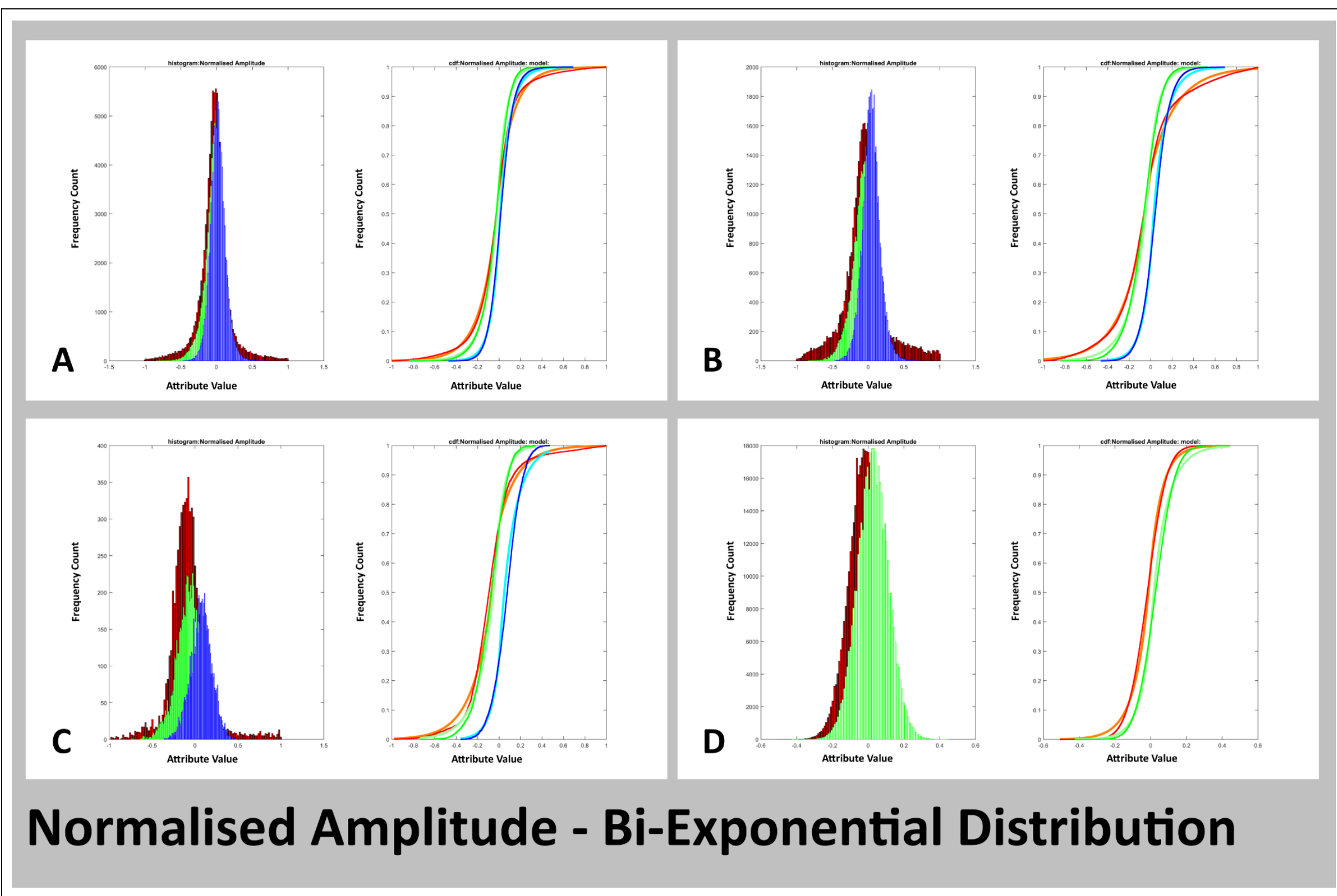

Figure 12.7 RSA Control Tests Frequency Distributions - Normalised Amplitude 


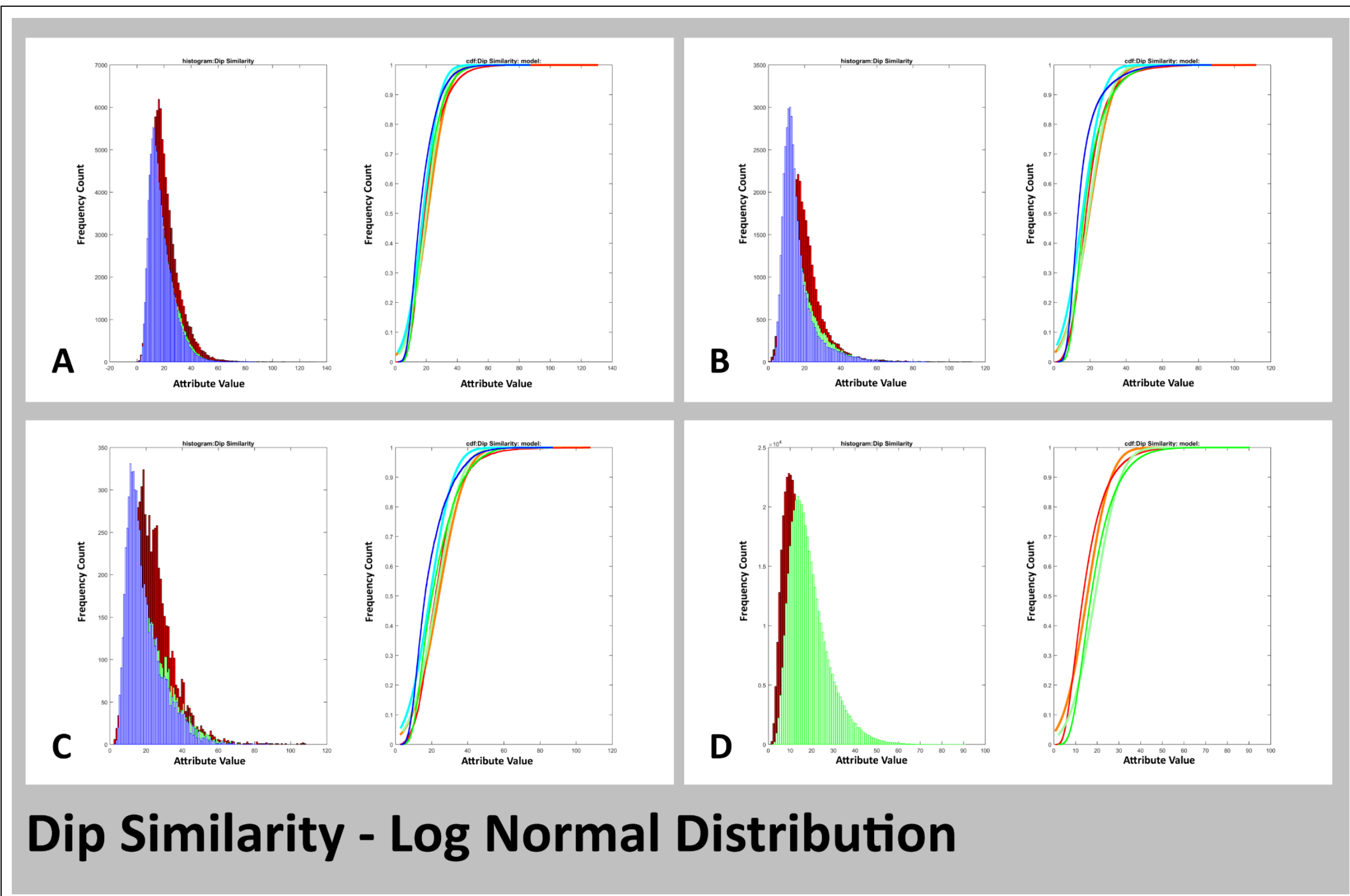

Figure 12.8 RSA Control Tests Frequency Distributions - Dip Similarity 


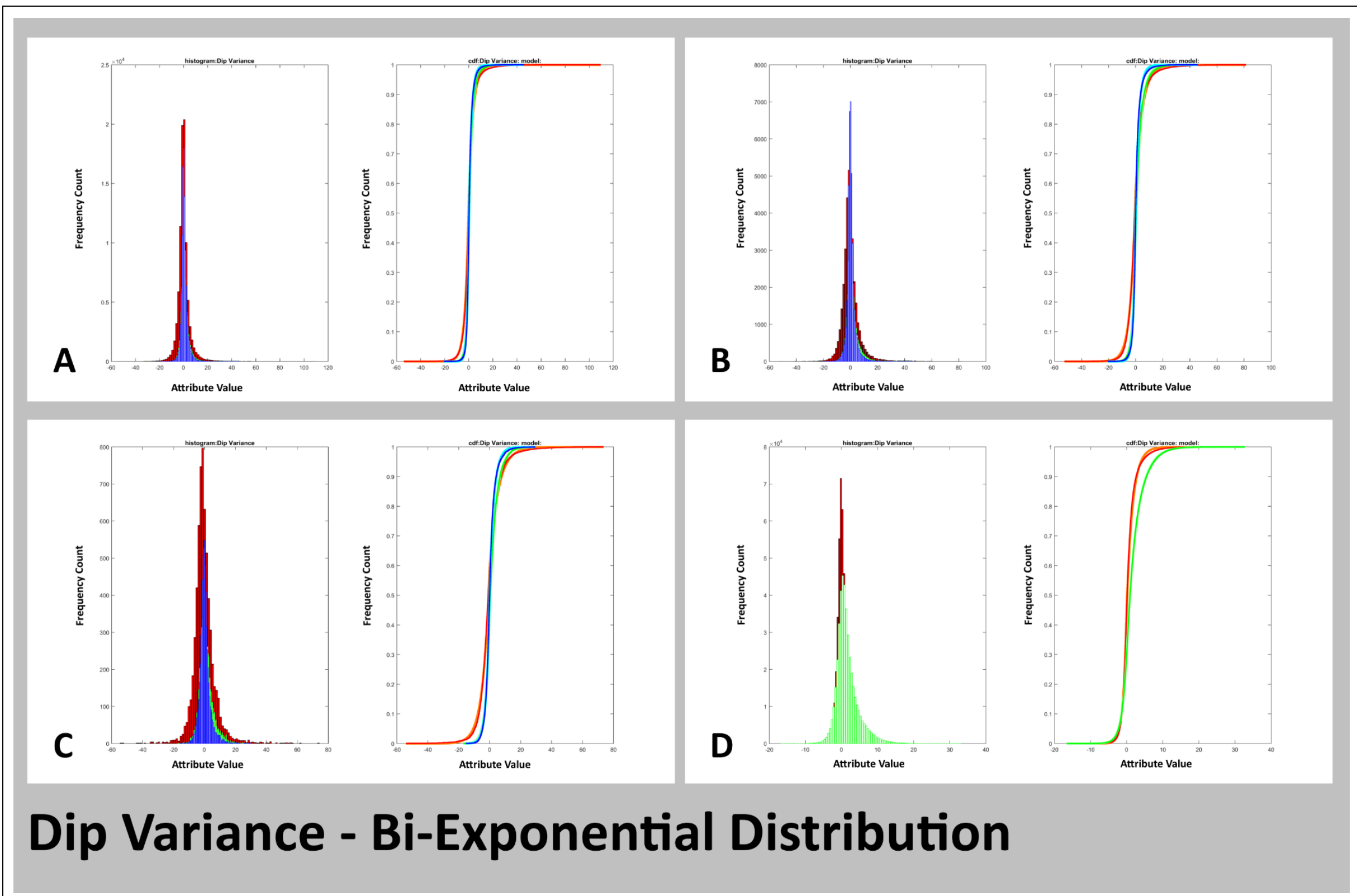

Figure 12.9 RSA Control Tests Frequency Distributions - Dip Variance 


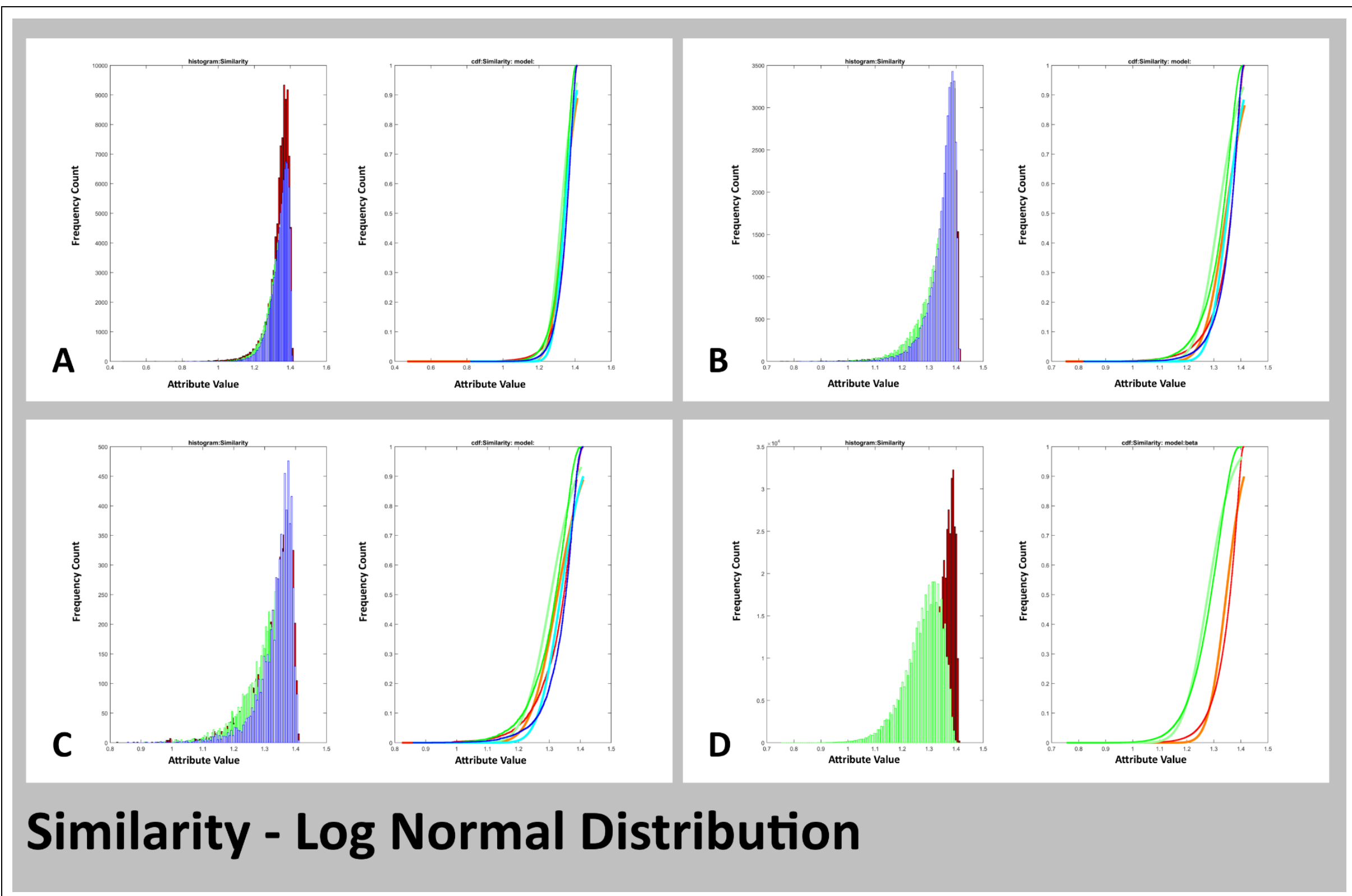

Figure 12.10 RSA Control Tests Frequency Distributions - Similarity 

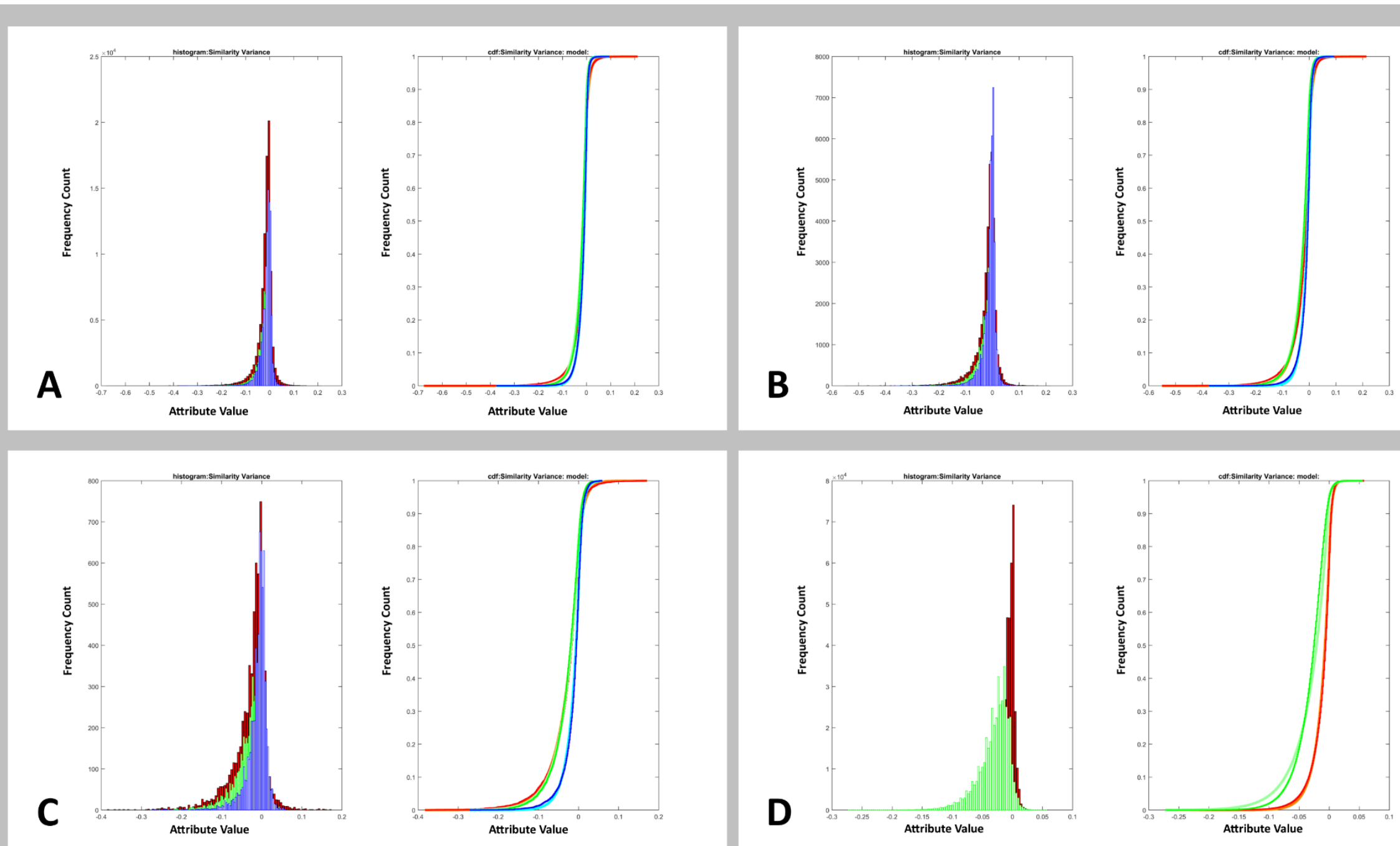

\section{Similarity Variance - Bi-Exponential Distribution}




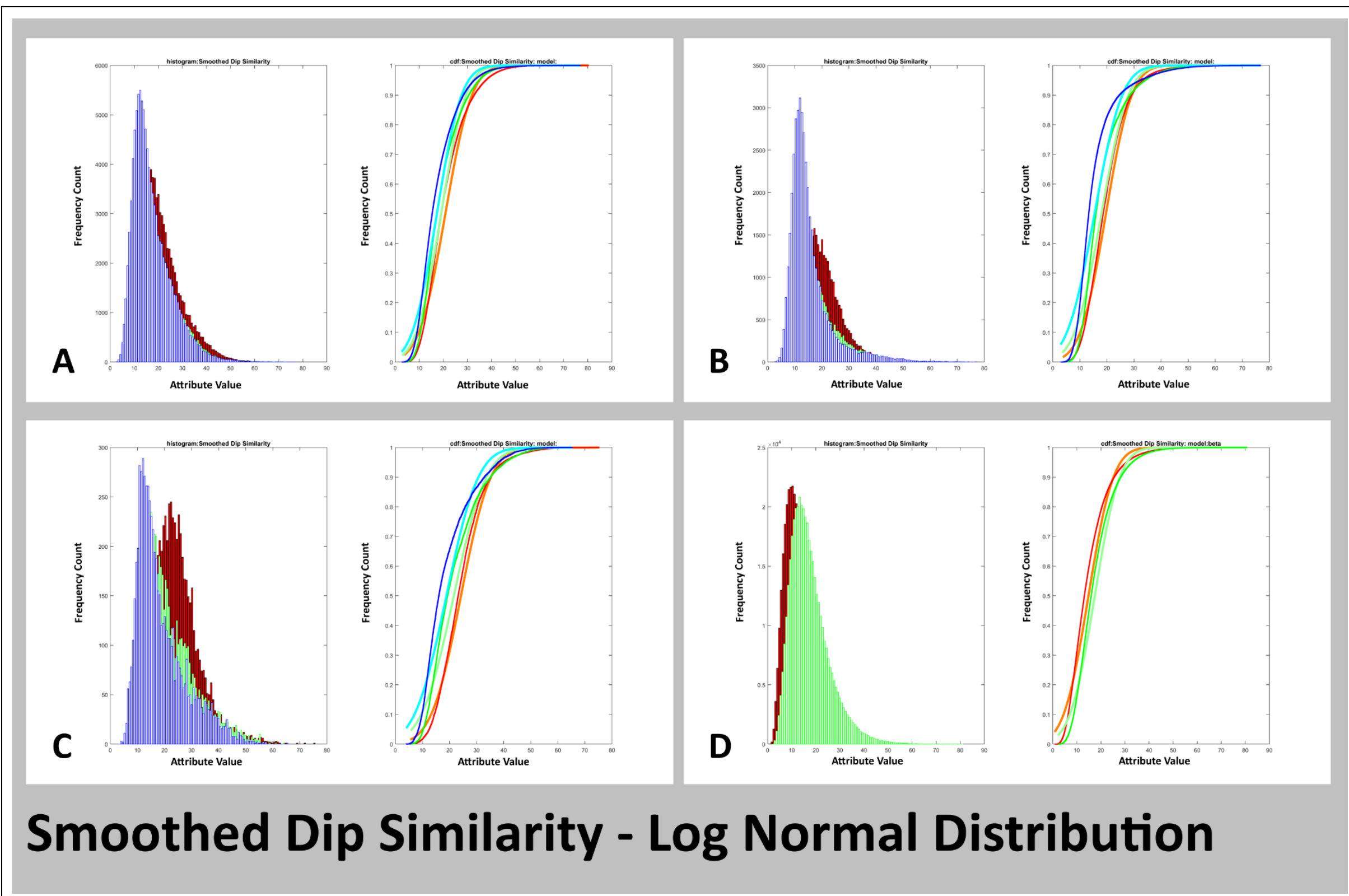

Figure 12.12 RSA Control Tests Frequency Distributions - Smoothed Dip of Maximum Similarity 


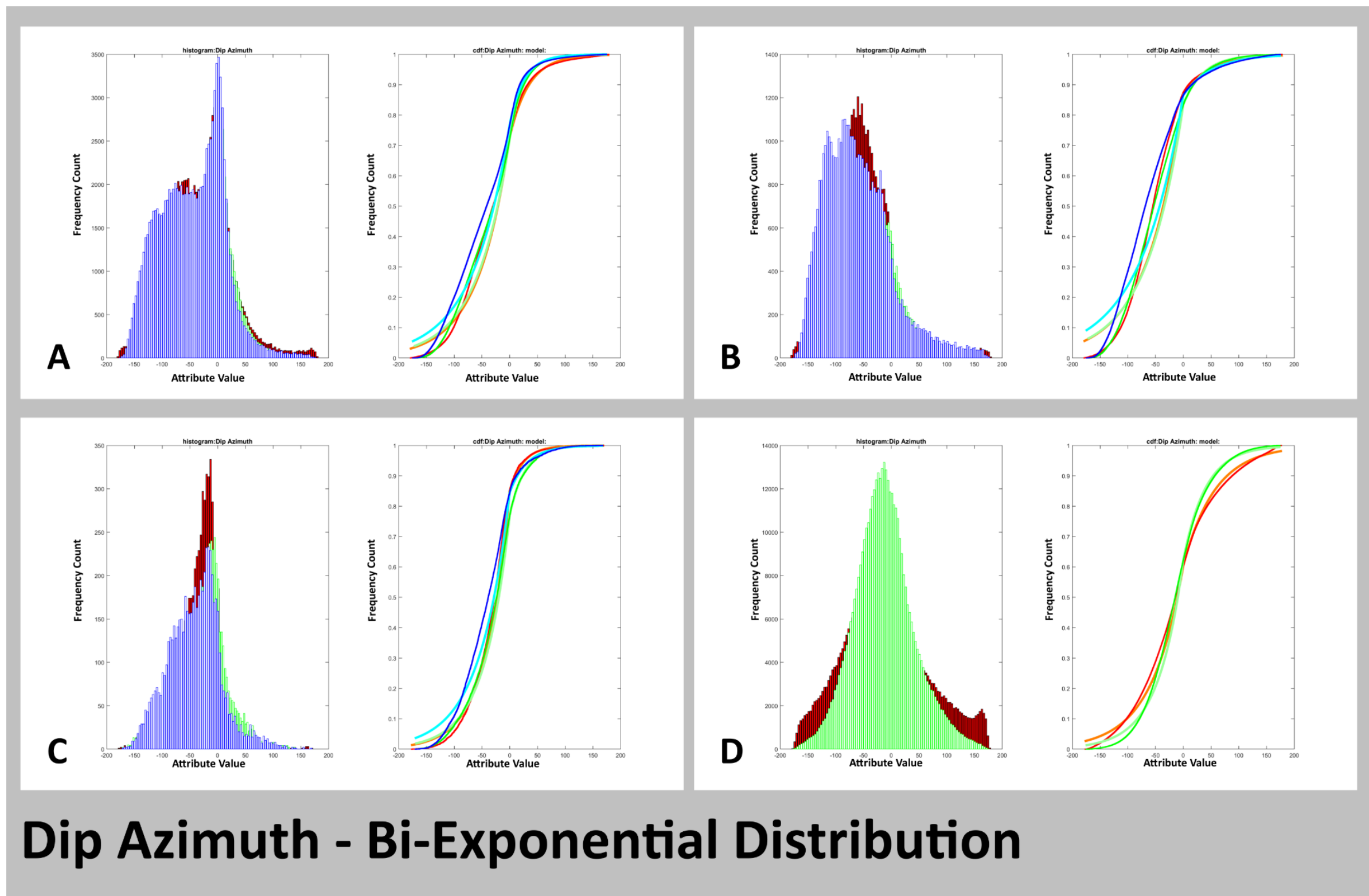

Figure 12.13 RSA Control Tests Frequency Distributions - Dip Azimuth 


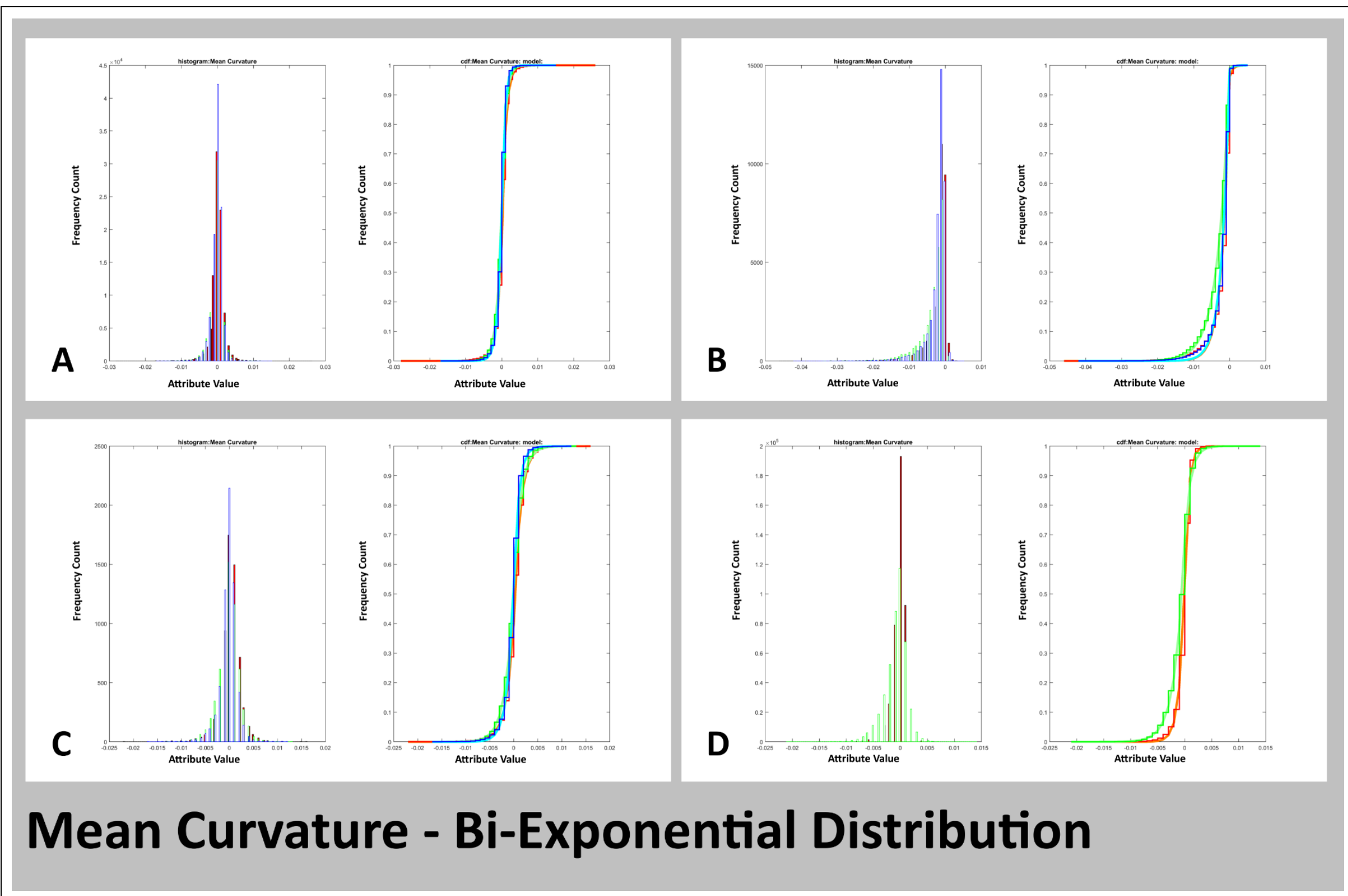

Figure 12.14 RSA Control Tests Frequency Distributions - Mean Curvature 


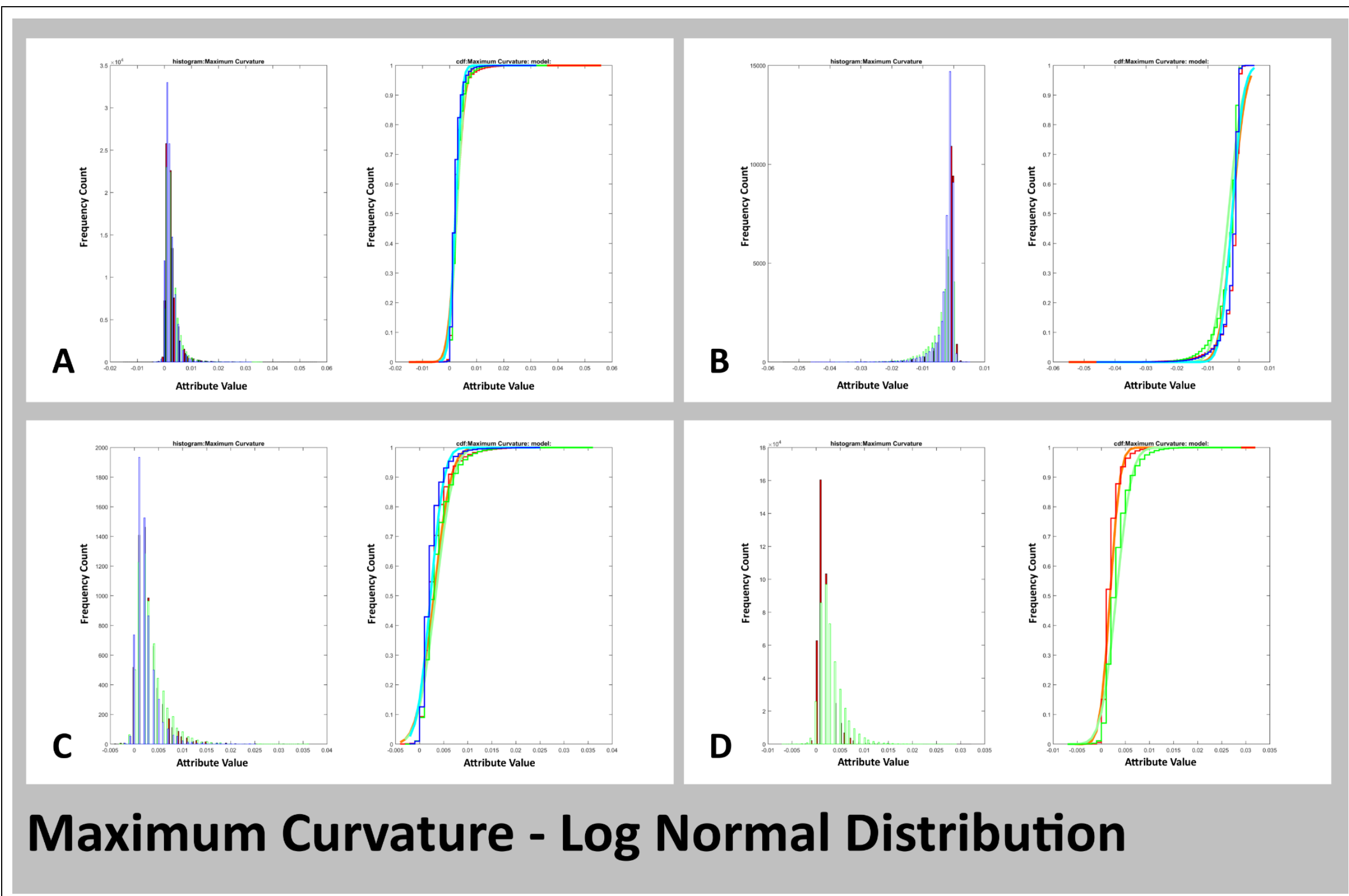

Figure 12.15 RSA Control Tests Frequency Distributions - Maximum Curvature 


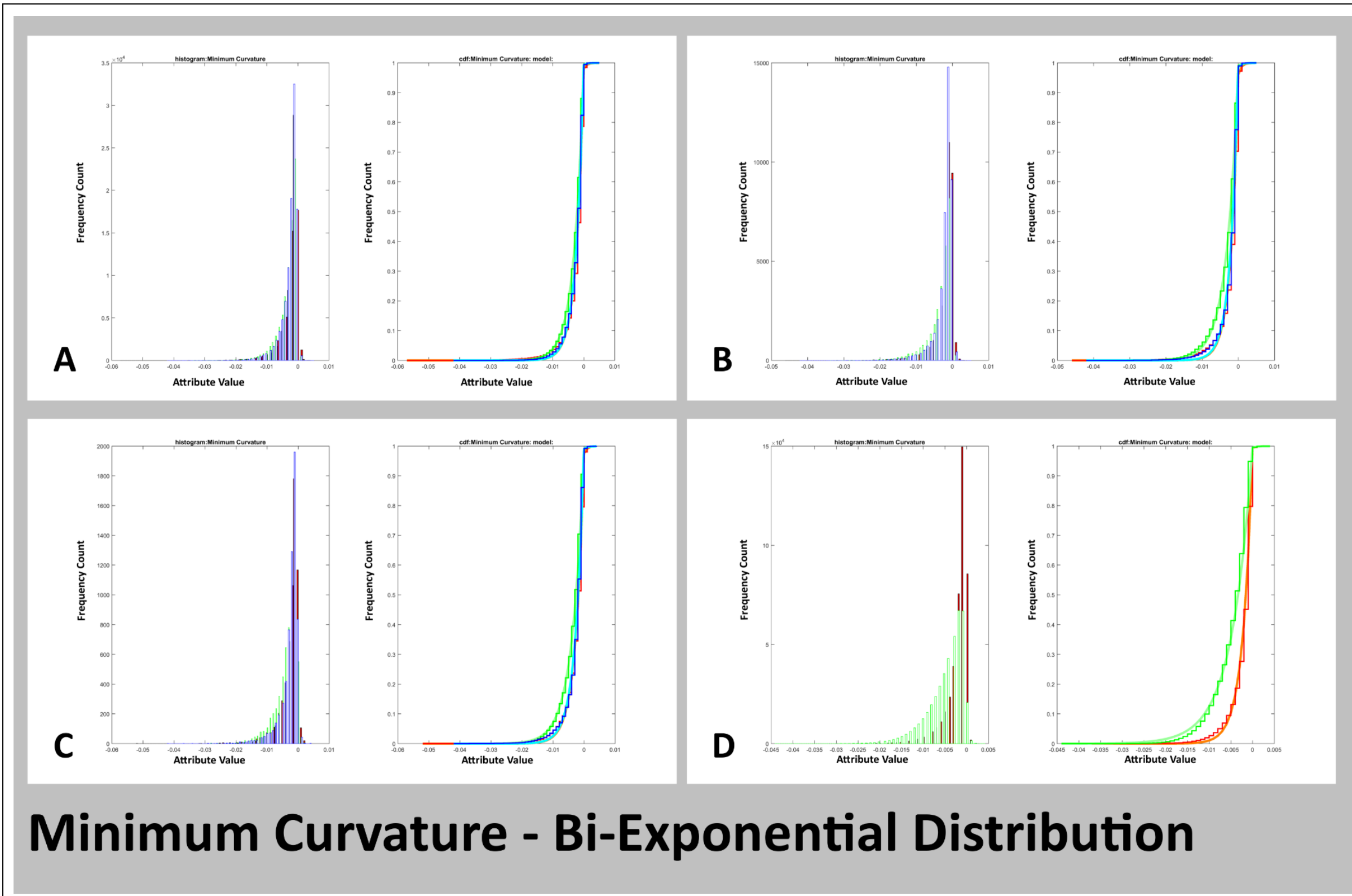

Figure 12.16 RSA Control Tests Frequency Distributions - Minimum Curvature 


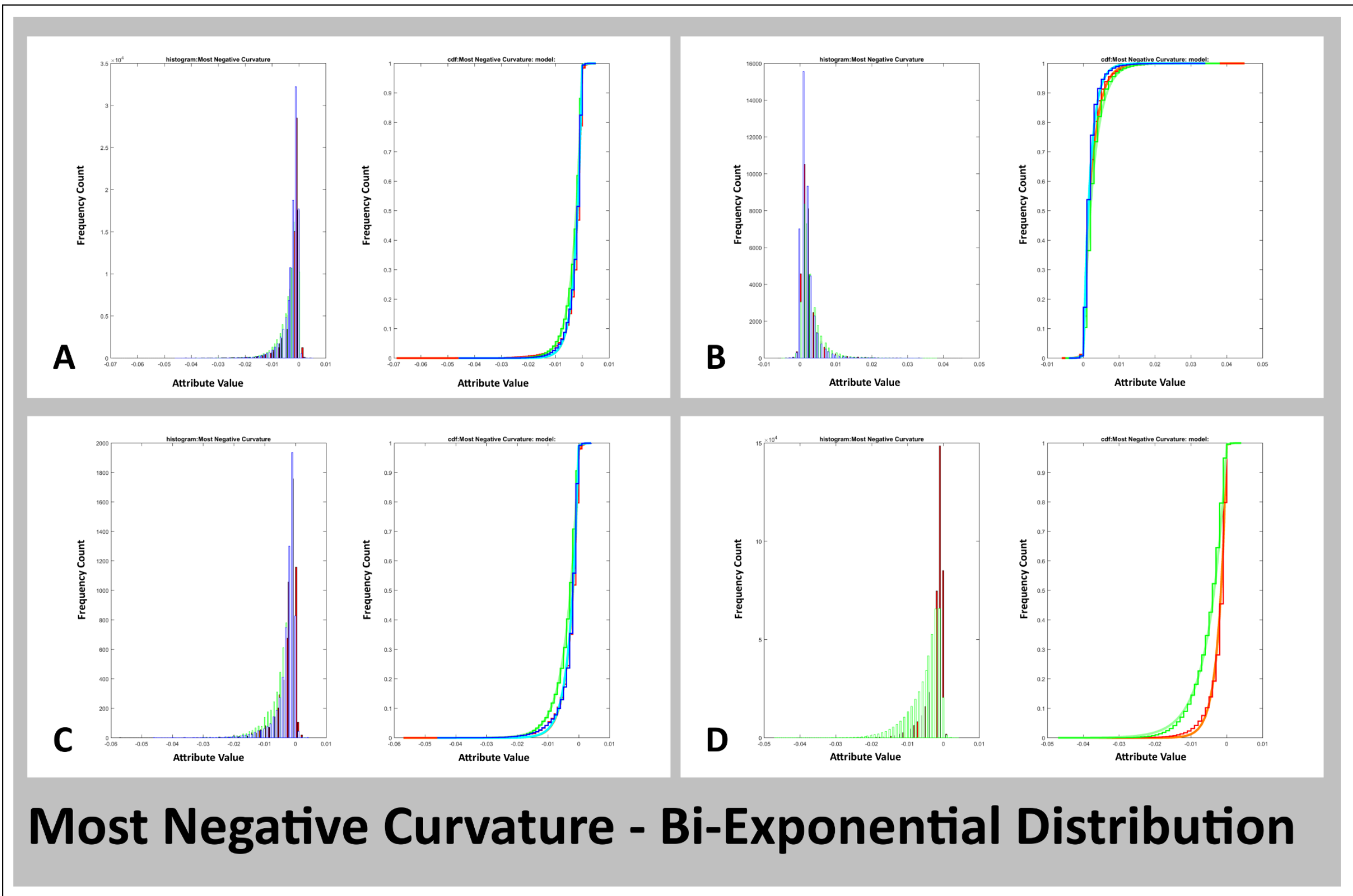

Figure 12.17 RSA Control Tests Frequency Distributions - Most Negative Curvature 


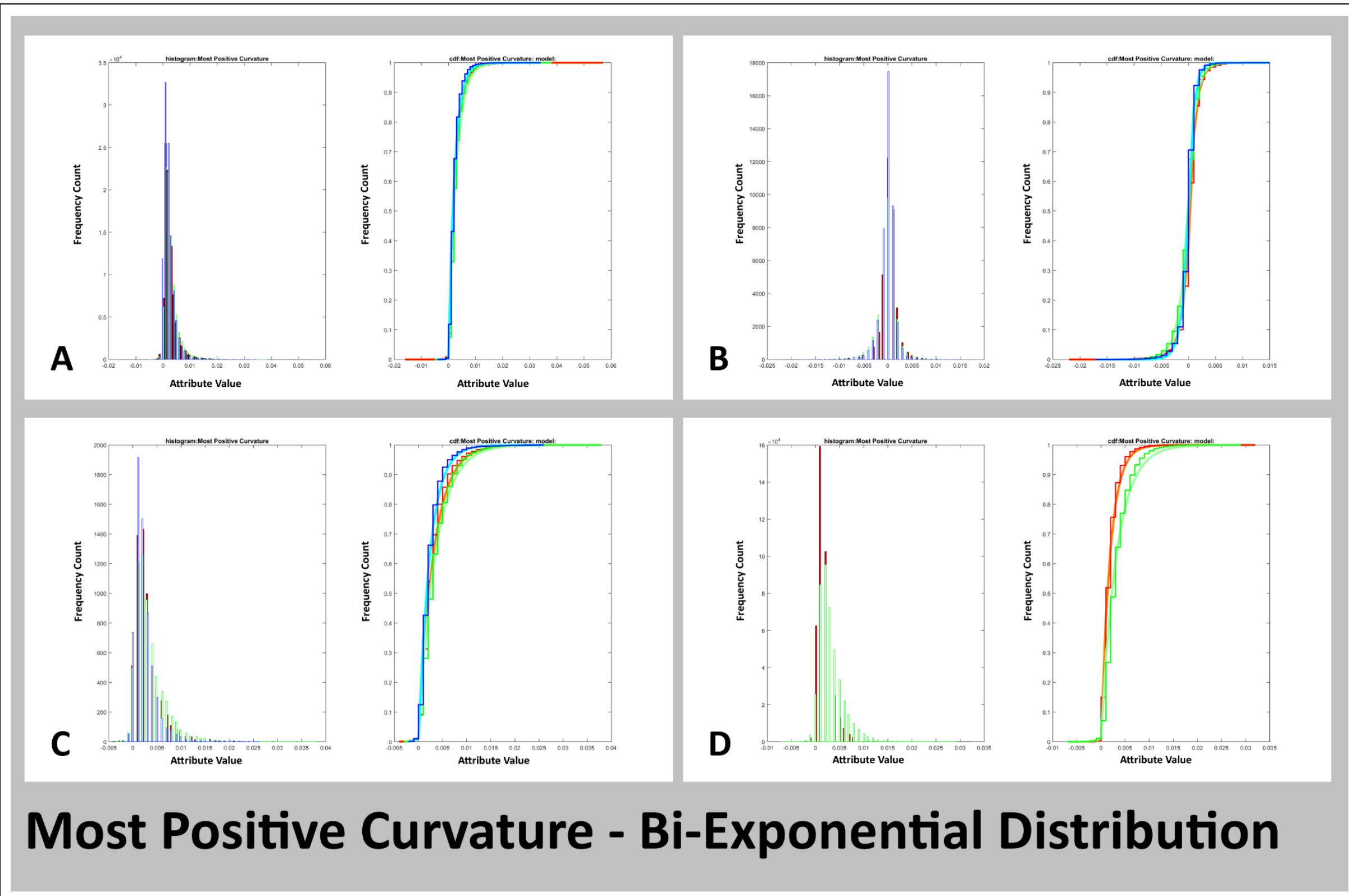

Figure 12.18 RSA Control Tests Frequency Distributions - Most Positive Curvature 


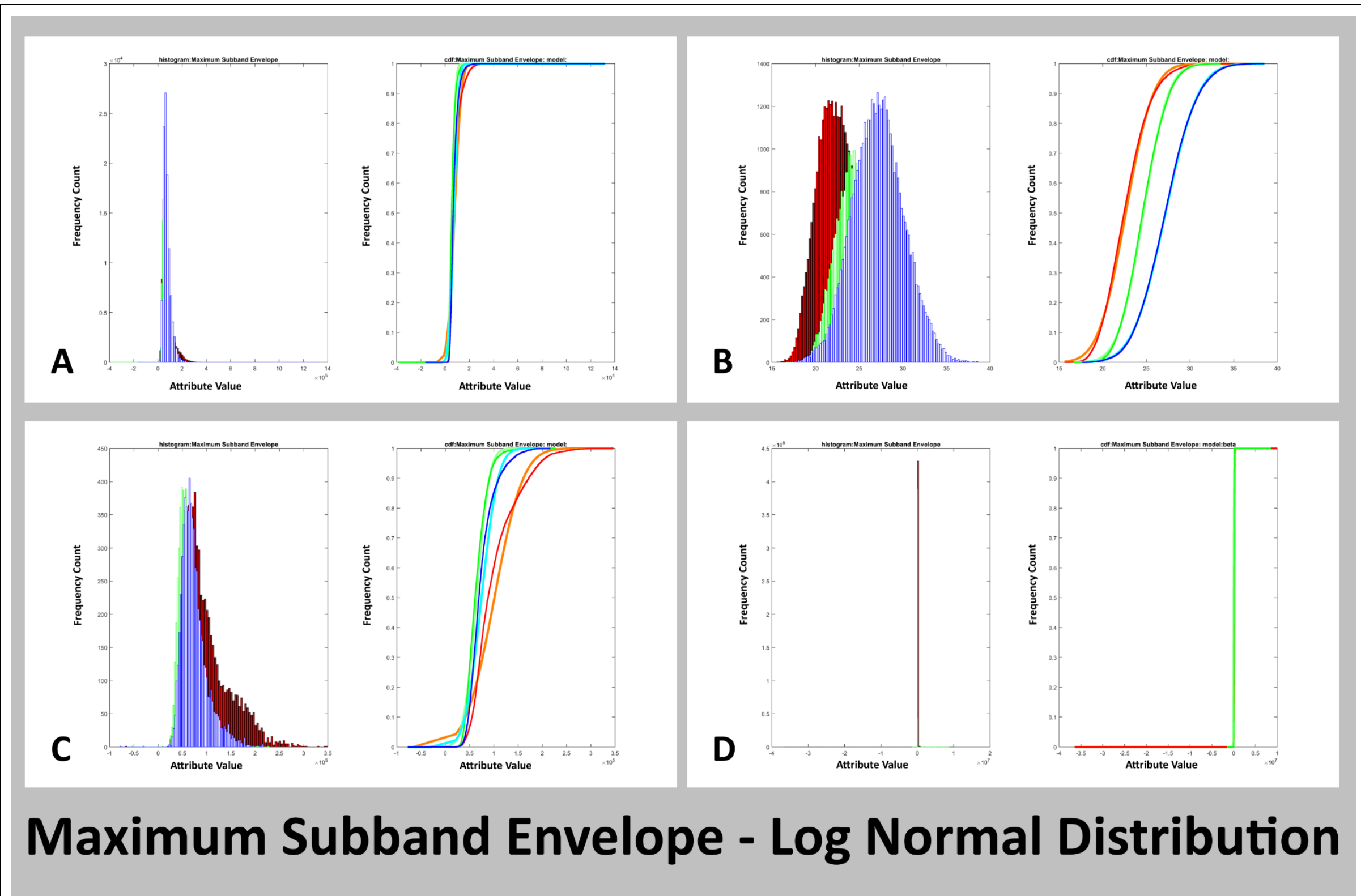

Figure 12.19 RSA Control Tests Frequency Distributions - Maximum Subband of Envelope 
